\title{
Hydraulic Research in the United States
}

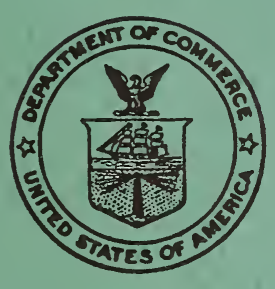

United States Department of Commerce National Bureau of Standards Miscellaneous Publication 205 


\section{RELATED PUBLICATIONS . . . . .}

\section{Capacities of Plumbing Stacks in Buildings}

A study of the maximum load that can be brought from a horizontal branch into a stack down which water is being discharged from fixtures on higher floors. This phase of a projected complete investigation, intended to make drainage design more economical, is concentrated on the drainage stack and the building drain. The report describes tests to determine terminal velocities and terminal lengths in stacks as well as tests on stacks and drains. It analyzes stack conditions in a multistory building and suggests applications of the study's results.

Order NBS Building Materials and Structures Report 132, Capacities of Plumbing Stacks in Buildings, 28 pages. Price: 20 cents.

\section{Self-Siphonage of Fixture Traps}

An explanation of the extent to which trap-seal losses are influenced by such considerations as the diameter of the trap and the depth of trap seal, the diameter and slope of the fixture drain, the type of vent fitting used, and the rate of discharge of the fixture. The report shows the importance of standardizing fixture traps and the hydraulic characteristics of plumbing fixtures, such as lavatories, sinks, and trays; and it makes recommendations for use by code-writing authorities.

Order NBS Building Materials and Structures Report 126, Self-Siphonage of Fixture Traps, 32 pages. Price: 20 cents.

\section{Wet Venting of Plumbing Fixtures}

An account of extensive research and laboratory tests to determine the feasibility of using vented one- and two-story plumbing drainage systems. The conclusions reached regarding satisfactory operation limits for wet-vented fixtures are given in a form suitable for inclusion in plumbing codes. The report describes test procedures and explains results. Diagrams, tables, and graphs are included showing the trap-seal losses that occur under various conditions of wet venting and indicating the maximum permissible unvented lengths of fixture drain.

Order NBS Building Materials and Structures Report 119, Wet Venting of Plumbing Fixtures, 27 pages. Price: 20 cents.

\section{Stack Venting of Plumbing Fixtures}

A report describing tests involving use of pipes, traps, connections, and vents made of transparent plastics which make all flow phenomena visible. Similar tests were made with regular metal fittings to obtain comparative data and to permit correlation of results. The report discusses and interprets results, 


\section{Hydraulic Research in the United States}

Edited by Helen K. Middleton and Sonva W. Matchett

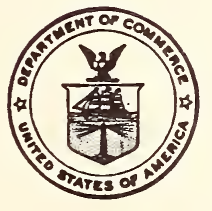

National Bureau of Standards Miscellaneous Publication 205 Issued September 4, 1952 


\section{Foreword}

The information contained in this publication was compiled from reports by the various hydraulic and hydrologic laboratories in the United States and Canada. The cooperation of these agencies is greatly appreciated.

Projects are numbered chronologically, and the number once assigned is repeated for identification purposes until a project is completed. Numbers commencing with 1296 refer to projects which are reported for the first time. All projects are in active state, unless otherwise noted under (f).

It is emphasized that the National Bureau of Standards does not have in its files reports or detailed information regarding the research projects reported by other organizations. Such information may be obtained from the correspondent listed under (c) or immediately following the title of the organization reporting the work. It is of course understood that any laboratory submitting reports on its work will be willing to supply information to properly qualified inquirers.

A similar bulletin, "Hydraulic Research," compiled and published by the International Association for Hydraulic Research, contains information on hydraulic research being conducted in foreign countries. This bulletin is edited by Prof. J. Th. Thijsse, Director of the Hydraulic Laboratory at the Technical University of Delft, Netherlands, and Secretary of the International Association for Hydraulic Research. Copies may be obtained from the Secretary on subscription.

A bulletin entitled "Directory of Hydromechanics Research Projects in the United States Related to Naval Architecture and Marine Engineering" is prepared by the Hydrodynamics Committee of the Society of Naval Architects and Marine Engineers. Copies may be obtained by addressing the Secretary of the Society, Captain W. N. Landers, Society of Naval Architects and Marine Engineers, 29 West Thirty-ninth Street, New York 18, N. Y.

A. V. Astin, Director 
Contents

Page

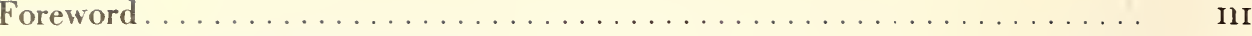

List of contributing laboratories $\ldots \ldots \ldots \ldots \ldots \ldots \ldots \ldots \ldots \ldots \ldots \ldots \ldots$

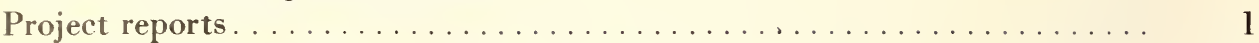

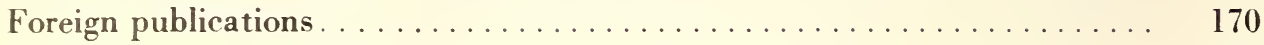

Translations................................ 180

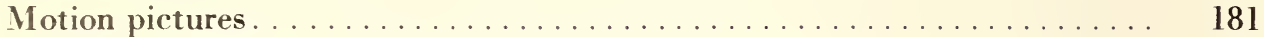

Committees................................... 183

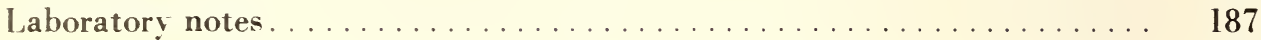

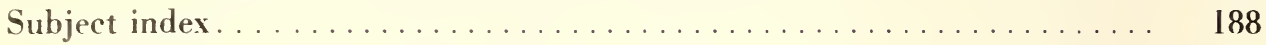

\section{Key to Projects}
(a) Title of project.
(b) Project conducted for.
(e) Description.
(c) Correspondent.
(f) Present status.
(d) Nature of project.
(g) Results.
(h) Publications. 
VIN-LTMA-HAMILTON CORPORATION, THE

Hydraulic Turbine Iaboratory, Philadelphia 42, Pa.

Mr. R. B. Willi, Manager, Hydraulic Turbine Department

Mr. C. H. Diehl, Supervisor of Laboratory

H EROSION BOARD (see U. S. Government)

QVILIE HYDRAULIC LABORATORY (see U. S. Government)

KLYN, POLYTECHNIC INSTITUTE OF

99 Livingston Street, Brooklyn 2, N. Y.

Prof. Chiltion A. Wright, Professor of Hydraulic and Sanitary Engineering $\because$

FORNIA INSTITUTE OF TECHNOLOGY

Hydrodynamics Laboratories, Pasadena 4, Calif.

Dr. Robert T. Knapp, Director

FORNIA, UNIVERSITY OF

College of Agriculture, Davis, Calif.

Prof. E. J. Veihmeyer, Directing Head, Division of Irrigation

FORNIA, LNIVERSITY OF

College of Agriculture, Los Angeles 24, Calif.

Prof. M. R. Huberty, Chairman, Division of Irrigation and Soils

FORNIA, UNIVERSITY OF

College of Engineering, Berkeley 4, Calif.

Prof. J. W. Johnson, Fluid Mechanics Laboratory

FORNIA, UNIVERSITY OF SOUTHERN

Department of General Engineering, Los Angeles 7, Calif.

Prof. K. C. Reynolds, Head

FORNIA, UNIVERSITY OF SOUTHERN

Research Foundation for Cross-Connection Control, Los Angeles 7, Calif.

Dr. Robert E. Vivian, Director

IEGIE INSTITUTE OF TECHNOLOGY

Department of Civil Engineering, Pittsburgh 13, $\mathrm{Pa}$.

Prof. F. T. Mavis, Head

JRADO A AND M COLIEGE

Department of Civil Engineering, Fort Collins, Colo.

Prof. Maurice L. Albertson, Head of Fluid Mechanics Research

JRADO UNIVERSITY

Department of Civil Engineering, Boulder, Colo.

Mr. Warren Raeder, Head.

MBIA UNIVERSITY

Department of Civil Engineering, New York 27, N. Y.

Director, Fluid Mechanics Laboratory

JECTICUT, UNIVERSITY OF

Hydraulic Research Laboratory, Box U-37, Storrs, Conn.

Prof. Victor Scottron, Associate Professor of Civil Engineering

VELL UNIVERSITY

School of Civil Engineering, Ithaca, N. Y.

Dr. N. A. Christensen, Director

Prof. Andre L. Jorissen, Head, Hydraulics Department 
DAVIU TAYIOR MODEL BASIN (see U. S. Government)

GEORGIA INSTITUTE OF TECHNOLOGY

School of Civil Engineering, Atlanta, Ga.

Prof. C. E. Kindsvater

HARVARD UNIVERSITY

Department of Mathematics, Cambridge 38, Mass.

IDAHO, UNIVERSITY OF

Engineering Experiment Station, Moscow, Idaho

Prof. Allen S. Janssen, Dean, College of Engineering

ILIINOIS INSTITUTE OF TECHNOIOGY

Technology Center, Chicago 16, IIl.

Dr. Victor L. Streeter, Director, Fundamental Fluids Research

ILIINOIS STATE WATER SURVEY DIVISION

Engineering Research Subdivision, Box 117, Peoria, IIl.

Dr. Max Suter, Head

Engineering Subdivision, Box 232, Urbana, IIl.

Mr. H. E. Hudson, Jr., Head

ILIINOIS, UNIVERSITY OF

Department of Theoretical and Applied Mechanics, 214 Talbot Laboratory, Urbana, III. Prof. F. B. Seely, Head

ILIINOIS, UNIVERSITY OF

Hydraulic Engineering Laboratory, Urbana, IIl.

Prof. J. J. Doland, Director of Hydraulic Engineering

IO'NA INSTITUTE OF HYDRAULIC RESEARCH

State University of Iowa, Iowa City, Iowa

Dr. Hunter Rouse, Director

IOWA, STATE UNIVERSITY OF (see Iowa Institute of Hydraulic Research)

JOHNS HOPKINS UNIVERSITY, THE

Institute of Cooperative Research, Baltimore 18, Md.

Dr. John C. Geyer

LAFAYETTE COLLEGE

IEFFEL AND COMPANY, THE JAMES

L26 East St., Springfield, Ohio

Mr. J. Robert Groff, President and General Manager

IEHIGH UNIVERSITY

Fritz Engineering Laboratory, Bethlehem, $\mathrm{Pa}$.

Dr. W. J. Eney, Director

IOUISIANA STATE UNIVERSITY AND A ANU M COLLEGE

School of Hydraulic Engineering, Baton Rouge 3, La.

Prof. T. M. Lowe, Director

MARYLAND, UNIVERSITY OF

Glenn L. Martin School of Engineering and Aeronautical Sciences, College Park, Md.

Prof. John B. Cournyn, in charge of Hydraulics Laboratory 
Department of Civil and Sanitary Engineering, Cambridge 39, Mass.

Dr. Arthur T. Ippen, Head, Hydraulics Division

ACHUSETTS INSTITUTE OF TECHNOIOGY

School of Engineering, Amherst, Mass.

Prof. George A. Marston, Dean

IGAN, UNIVERSITY OF

Iake Hydraulics Laboratory, 320 West Engineering Building, Ann Arbor, Mich.

Prof. E. F. Brater

IGAN, UNIVERSITY OF

Experimental Naval Tank, 326 West Engineering Building, Ann Arbor, Mich.

Prof. Louis A. Baier, Director

ESOTA, UNIVERSITY OF (see St. Anthony Falls Hydraulic Laboratory)

ISSIPPI STATE COLIEGE

Engineering and Industrial Research Station, Box 365, State College, Miss.

Dr. Harold Flinsch, Director

OURI SCHOOL OF MINES AND METALLURGY

Department of Civil Engineering, Rolla, Mo.

Prof. Joe B. Butler, Chairman

ONAL HYURAULIC LABORATORY (see U. S. Government)

PORT NEWS SHIPBUILDING AND DRY DOCK COMPANY

Hydraulic Laboratory, Newport News, Va.

Mr. C. H. Hancock, Director

YORK UNIVERSITY

Department of Chemical Engineering, New York 53, N. Y.

Prof. John Happel, Project Director

CH CAROLINA, UNIVERSITY OF

North Carolina State College of Agriculture and Engineering, Raleigh, N. C. Prof. N. W. Connor, Director

CHWESTERN UNIVERSITY

The Technological Institute, Evanston, III.

Dr. Paul E. Klopsteg, Director of Research

RE DAME, UUNIVERSITY OF

College of Engineering

Dr. Karl E. Schoenherr, Dean

J STATE UNIVERSITY

Robinson Hydraulic Laboratory, Columbus 10, Ohio

Prof. S. R. Beitler, Director, Mechanical Engineering Iaboratory

GON STATE COLIEGE

Department of Civil Engineering, Corvallis, Ore.

Dr. C. A. Mockmore, Head

TON WATER WHEEL COMPANY, THE

San Francisco 10, Calif.

Mr. I. M. White, Manager of Engineering

Mr. R. M. Bacchi, Development Engineer 
PENNSYLVANIA STATE COLIEGE, THE

Hydraulic Laboratory, State College, $\mathrm{Pa}$.

Dr. B. A. Whisler, Head, Department of Civil Engineering

Dr. Andre L. Jorissen, in charge of Hydrablics Iaboratory

PENNSYLVANIA STATE COLIEGE, THE

Ordnance Research Laboratory, P. O. Box 30, State College, Pa.

Mr. J. M. Robertson, Assistant Director

PENNSYLVANIA, UNIVERSITY OF

Department of Civil Engineering, Philadelphia 4, Pa.

Mr. E. F. Stover, Director

PENNSYLVANIA WATER AND POWER COMPANY

405 Fulton National Bank Building, Lancaster, Pa.

Dr. S. K. Waldorf, Engineer of Research

\section{PURDUE UNIVERSTTY}

School of Civil Engineering Mechanics, Lafayette, Ind.

Dr. R. B. Wiley, Head

RESEARCH FOUNDATION FOR CROSS-CONNECTION CONTROL (see University of Southern California)

ROCKY MOUNTAIN HYURAULIC IABORATORY

Allenspark, Colo.

Prof. C. J. Posey, Director (address: State University of Iowa, Iowa City, Iowa)

ST. ANTHONY FALIS HYDRAULIC LABORATORY

University of Minnesota, Hennepin Island, Minneapolis 14, Minn.

Dr. Lorenz G. Straub, Director

S. MORGAN SMITH COMPANY

York, $\mathrm{Pa}$.

Mr. Emmert M. Lowry, Jr., Hydraulic Iaboratory Engineer

SOCIETY OF NAVAL ARCHITECTS AND MARINE ENGINEERS

29 West 39th St., New York 18, N. Y.

Capt. W. N. Ianders, Secretary

STANFORD UNIVERSITY

Hydraulic Iaboratory, Stanford, Calif.

Prof. John K. Vennard, Director

STEVENS INSTITUTE OF TECHNOLOGY

Experimental Towing Tank, 711 Huds on St., Hoboken, N. J.

Dr. Kenneth S. M. Davidson, Director

TAYIOR MODEL BASIN (see U.S. Govermment)

TENIESSEE, UNIVERSITY OF

Engineering Experiment Station

Knoxville 16, Tenn.

Dr. G. H. Hickox, Assoc. Director

TEXAS ENGINEERING EXPERIMENT STATION

College Station, Texas

Prof. Arthur W. Mellock, Vice-Director

TEXAS, UNIVERSITY OF

Department of Civil Engineering, Austin 12, Texas

Dr. Walter R. Moore, Directing Head 
STATE AGRICULTURAL COLIEGE

Engineering Experiment Station, Logan, Utah

Dr. J. E. Christiansen, Dean, School of Engineering and Technology

INGTON, STATE COLLEGE OF

Division of Industrial Research, Pullman, Wash.

Prof. C. L. Barker, Hydraulic Engineer

INGTON, UNIVERSITY OF

Department of Civil Engineering, Seattle 5, Wash.

Prof. R. B. Horn, Acting Director

E ONIVERSITX

Department of Civil Engineering, Detroit 1, Mich.

Prof. Dudley Newton, Head

RWYAS EXPERTMENT STATION (see U.S. Govemment)

ONSIN, UNIVERSITY OF

Hydraulic and Sanitary Laboratory, Madison 6, Wisc.

Prof. Amo T. Ienz

ISTER POLYTECHNIC INSTITUTE

Alden Hydraulic Laboratory, Worcester 2, Mass.

Prof. L. J. Hooper, Acting Director

\section{GOVERNMENT AGENCIES}

RTMENT OF AGRICULTURE

FOREST SERVICE

California Forest and Range Experiment Station

P. O. Box 245 , Berkeley 1, Calif.

Mr. Stephen N. Wyckoff, Director

Division of Forest Influences

Washington 25, D. C.

Dr. H. G. Wilm, Division Chief

Intermountain Forest and Range Experiment Station

Ogden, Utah.

Mr. Reed W. Bailey, Director

Northeastern Forest Experiment Station

102 Motors Ave., Upper Darby, Pa.

Dr. Ralph W. Marquis, Director

Northem Rocky Mountain Forest and Range Experiment Station

Missoula, Mont.

Mr. George M. Jemison, Director

Pacific Northwest Forest and Range Experiment Stati on

423 U. S. Court House, Portland 5, Ore.

Mr. R. W. Cowlin, Director

Rocky Mountain Forest and Range Experiment Station

Dr. W. G. McGinnies, Director 
Southeastern Forest Experiment Station

P. 0. Box 252, Asheville, N. C.

Mr. E. L. Dermon, Director

Southwestern Forest and Range Experiment Station

Box 951, Tucson, Ariz.

Mr. Raymond Price, Director

DEPARTMENT OF AGRICULTURE

SOIL CONSERVATION SERVICE

Division of Irrigation and Water Conservation

College Hill, Box 70, Logan, Utah

Mr. George D. Clyde, Chief

North Appalachian Experimental Watershed

Blacklands Experimental Watershed

Central Great Plains Experimental Watershed Division of Drainage and water Control, Soil Conservation Service, Wash. 25, D. C. Mr. Lewis A. Jones, Chief

Research Branch

Division of Drainage and Water Control, Soil Conservation Service, Wash. 25, D. C. Mr. Iewis A. Jones, Chief

St. Anthony Falls Hydraulic Laboratory Hennepin Island, Minneapolis 14, Minn. 104,180 Mr. Fred W. Blaisdell, Project Supervisor

Stillwater Outdoor Hydraulic Iaboratory Stillwater, Okla. Division of Drainage and Water Control, Soil Conservation Service, Wash. 25, D. C. Mr. Iewis A. Jones, Chief

Sub-tropical Experiment Station Route 2, Box 508, Homestead, Fla.

Mr. M. H. Gallatin, Project Supervisor

DEPARTMENT OF AGRICULTURE

U. S. REGIONAL SAIINITY LABORATORY

Riverside, Calif.

Mr. H. E. Hayward, Director

DEPARTMENT OF THE ARNY

\section{CORPS OF ENGINEERS}

Beach Erosion Board

5201 Little Falls Road, N. W.

Washington 16, D. C.

Colonel E. E. Gesler, President

Bonneville Hydraulic Laboratory

628 Pittock Block, Portland, Ore.

The District Engineer 
Little Rock District

300 Broadway, Little Rock, Ark.

The District Engineer

Los Angeles District

P. O. Box 17277 Foy Station

Los Angeles 17, Calif.

The District Engineer

St. Paul District

1217 U. S. Post Office and Custom House,

St. Paul 1, Minn.

The District Engineer

Waterways Experiment Station

P. 0. Box 631, Vicksburg, Miss.

Director

ARTMENT OF COMMERCE

BUREAU OF PUBLIC ROADS

Hydraulics Branch, Washington 25, D. C.

Mr. Carl F. Izzard, Chief

NATIONAL BUREAU OF STANDARDS

National Hydraulic Iaboratory

Washington $25, \mathrm{D}$. C.

Mr. Herbert N. Eaton, Chief

WEATHER BUREAU

Hydrologic Services Division,

Washington $25, \mathrm{D}$. C.

Mr. William E. Hiatt, Chief

ARTMENT OF THE INTERIOR

GEOLOGICAL SURVEY

Washington $25, \mathrm{D} . \mathrm{C}$.

Mr. R. W. Davenport, Acting Chief

BUREAU OR RECLAMATION

Branch of Design and Construction

Denver Federal Center, Denver, Colo.

Mr. I. N. McClellan, Chief Engineer

'ARTMENT OF THE NAVY

DAVID TAYLOR MODEL BASIN

Washington 7, D. C.

The Commanding Officer and Director

NAVAL BOIIER AND TURBTNE LABORATORY

Capt. M. Schreiner, Director

NAVAL ENGINEERING EXPERTIENT STATION

Bureau of Ships, Washington 25, D. C.

The Director

NAVAL ORDNANCE TEST STATION

Pasadena Annex, 3202 E. Foothill Blvd.,

Pasadena 8, Calif.

The Commander 
OFFICE OF NAVAL RESEARCH

Washington 25, D. C.

TENNESSEE VALIEY AUTHORITY

HYDRAULIC DATA BRANCH

Knorville, Tenn.

Mr. Albert S. Fry, Chief

\section{CANADIAN LABORATORIES}

BRITISH COLUNBIA, UNIVERSITY OF

Hydraulic Laboratory, Vancouver, Canada

Prof. H. J. MacIeod, Dean, Faculty of Applied Science

IONTREAL, ECOIE POLYTECHNIQUE DE

Hydraulics Laboratory, 1430 Rue Saint-Denis, Montreal 18, Canada

Prof. Raymond Boucher, Head, Department of Hydraulic Engineering

NATIONAL RESEARCH COUNCIL

Division of Mechanical Engineering

Montreal Road, Ottawa, Canada

Mr. J.H. Parkin, Director

\section{QUEEN'S UNIVERSITY}

Faculty of Applied Science, Kingston, Ontrrio

Prof. D. S. Ellis, Dean, Faculty of Applied Science

TORONTO, UNIVERSITY OF

Toronto 5, Canada

Prof. E. A. Allcut, Professor of Mechanical Engineering 
HYDRAULIC RESEARCH IN THE UNITED STATES

BALDWIN-LIMA-HAMILTON CORPORATION, Hydraulic Turbine Laboratory.

Inquiries concerning Projects Nos. 271, 1054, 1055, 1056, 1296, and 1297 should be addressed to Mr. C. H. Diehl, Hydraulic Turbine Laboratory, Baldwin-Lima-Hamilton Corporation, Philadelphia 42, Pa.

11) ADJUSTABLE AND FIXED BLADE PROPELLER-TYPE HYDRAULIC TURBINE MODELS.

(b) Laboratory project.

(d) Experimental; applied research for design.

(e) To improve performance of present designs, and to extend the range of application of this type of turbine. Propeller runners of various designs in combination with modified turbine settings are being methodically tested in the ll-inch cavitation flume. Efficiency, output, cavitation, runaway speed, hydraulic thrust, and hydraulic blade torque are measured.

(g) Results provide data for improvement of existing design and information for designs which extend the present range of application, particularly with respect to head.

54) INTERMEDIATE HEAD ADJUSTABLE BLADE PROPELLER TYPE TURBINE MODEL FOR IMPERIAL VALLEY IRRIGATION DISTRICT, DROP NO. 2.

(b) Imperial Valley Irrigation District.

(d) Experimental; applied research for design.

(e) A completely homologous model was manufactured, installed and tested to determine its performance.

(f) Completed.

(g) Results indicate that all operating requirements can be readily achieved.

155) HIGH HEAD ADJUSTABLE BLADE PROPELLER TYPE TURBINE MODEL FOR BIG CLIFF PROJECT.

(b) Department of the Army, Corps of Engineers, Portland Oregon District.

(d) Experimental; applied research for design.

(e) The homologous runner was tested in a setting similar, but not identical, to the prototype unit. A completely homologous unit is now manufactured and will be installed and tested in the near future.

(g) Results of the tests in the non-homologous unit indicate that all operating requirements can be readily achieved. Comparisons will be made when tests are completed to ascertain the minor effects on performance of the dissimilarity of the two units.

156) HIGH SPECIFIC-SPEED FRANCIS TYPE HYDRAULIC TURBINE MODELS FOR SHERMAN ISLAND PROJECT.

(b) Eastern New York Power Corporation.

(d) Experimental; applied research for design.

(e) Several runners were designed and tested in a model similar to the existing prototype unit. The purpose was to design a replacement runner that would efficiently develop more output than the present unit.

(f) Completed.

(g) Results indicate that a replacement runner can be installed in the existing units without major changes and obtain approximately a $20 \%$ increase in capacity.

296) HIGH SPECIFIC-SPEED ADJUSTABLE BLADE PROPELLER TYPE HYIDAULIC TURBINE FOR ALBENI FALIS PROJECT.

(b) Department of the Army, Corps of Engineers, Seattle, Washington District.

(d) Experimental; applied research for design. 
(e) The homologous runner was tested in a setting similar, but not identical, to the pr tyoe unit. A completely homologous unit is being manufactured and will be installe and tested in the near future.

(g) Results in the non-homologous unit indicate that all of the operating requirements be readily achieved. Comparisons will be made when all tests are completed to asce: the minor effects upon performance of the dissimilarity of the two units.

(1297) ADJUSTABLE BLADE AXIAL FLOW PUMP FOR MCNARY DAM.

(b) Department of the Army, Corps of Engineers, Walla Walla, Washington District.

(d) Experimental; applied research for design.

(e) A completely homologous model has been installed in the hydraulic laboratory and is process of testing.

POLYTECHNIC INSTITUTE OF BROOKLYN.

Inquiries conceming Projects Nos. 1057 and 1298 should be addressed to Prof. Chilt Wright, Polytechnic Institute of Brooklyn, 99 Livingston St., Brooklyn 2, N. Y.

(1057) INSTALLATION AND INVESTIGATION OF A FOUR-INCH TRANSPARENT CASE WATER TURBINE.

(f) Project completed. Thesis available on loan.

(1298) MODEL WATER SUPPIY SYSTEM.

(b) Student thesis.

(d) A generalized model of a water supply system is being constructed in the hydraulic laboratory out of $1 / 8$ inch brass pipe. It is planned to measure the head losses anc compare them with those obtained by various computation procedures. The flow will k measured by weight.

\section{CALIFORNIA INSTITUTE OF TECHNOLOGY.}

Inquiries concerning Projects Nos. 6, 7, 8, and 805 should be addressed to Dr. Vito Vanoni, and concerning Projects Nos. 15, 804, and 806 to Dr. Robert T. Knapp, Hydrodynamics Laboratories, California Institute of Technology, Pasadena 4, Calif.

(6) MECHANICS OF SUSPENDED LOAD TRANSPORTATION.

(b) Laboratory project.

(d) Experimental; basic research; for thesis (professional degree and doctoral).

(e) To investigate the internal mechanics of transportation of suspended load in flowing water; the effects of the material in suspension upon the velocity distribution of $t$ flow; the distribution of sediment in open channel flow.

(7) TRANSPORTATION OF BED MATERIAL LOAD.

(b) Laboratory project.

(d) Experimental; basic research; for thesis (professional degree and doctoral).

(e) To determine a general relationship between the rate of sediment movement by a streal and the hydraulic factors. The work is being carried out in flumes designed especia: for sediment transportation studies. 
DENSITY CURRENTS.

Laboratory project.

Experimental; basic research; for thesis (professional degree and doctoral). An investigation of density currents resulting from suspensions of fine sediments in reservoirs to establish principles governing their behavior.

STUDIES OF CAVITATION PHENOMENA.

Office of Naval Research, Department of the Navy.

Experimental; basic research.

Photographic studies are being made on bodies of revolution and other shapes while operating under cavitating conditions in the water tunnel in which both the pressure and the velocity are independently controlled. Photographic records are made with high speed motion picture cameras arranged to give precise time histories. The objectives are to delineate the mechanics of cavitation, including the formation and collapse of cavitation bubbles, types of cavitation as they are affected by the shape of the guiding surface and other relevant parameters, and the effect of variation in size for the same geometric shape.

Analysis of one simple type of cavitation in which voids are approximately spherical and travel with the flow indicate that their behavior is closely approximated by the Rayleigh predictions.

"Laboratory investigations of the mechanism of cavitation", by R. T. Knapp and A. Hollander. Trans. ASME July 1948, pp. 419-435.

\section{HYDRODYNAMIC FORCES ON SUBMERGED BODIES.}

Bureau of Ordnance, Department of the Navy.

Mr. John T. McGraw, Hydrodynamics Laboratories, California Institute of Technology, Pasadena 4, Calif.

Experimental; basic research.

Forces on bodies of different shapes and designs are measured in a water tumnel and the important steady state and damping force coefficients are thus obtained. These data are used to predict full-scale behavior.

\section{FLOW IN ROTATING CHANNEIS.}

Office of Naval Research, Department of the Navy. Mr. A. J. Acosta, Hydrodynamics Laboratory, Califormia Institute of Technology, Pasadena 4 ,

) Experimental and theoretical.

To determine the nature of the flow in rotating channels and the mechanism of energy transfer from fluid to rotor or vice versa with a view to the development of design methods for hydraulic machinery. It is possible to study the characteristics of individual elements of hydraulic machines to determine their influence on the whole machine. For axial flow impellers some work has been completed on the comparison of experimental pressure distributions with those expected from the design procedure. Pressure measurements are made using a manometer rotating with the impeller and observed by stroboscopic lighting. Studies are in progress to correlate the design of vanes for two-dimensional impellers with the pressure distributions on the vanes at various flow rates. Another study is in progress on the theoretical and experimental aspects of design of axial-flow impeller vanes.

"Pressure distributions on the vanes of a radial flow impeller", by D. A. Morelli. Heat Transfer and Fluid Mechanics Institute, Stanford University, June 1951. 
(803) DYNAMICS OF CAVITATION BUBBLES.

(b) Office of Naval Research, Department of the Navy.

(c) Prof. Milton S. Plesset, Hydrodynamics Laboratories, California Institute of Techno Pasadena 4, Calif.

(d) Theoretical; basic research.

(e) Analytical study of cavitating flow and boiling of liquids. Dymamic behavior of ca tion bubbles, scaling laws for cavitating flow. Theory of tensile strength of liqu

(h) "A non-steady heat diffusion problem with spherical symmetry", by M. S. Plesset an S. A. Zwick, ONR Report 26-3.

"The dynamics of condensation and vaporization", by F. R. Gilmore, ONR Report 2l-6. "Perturbation effects in bubble dynamics", by M. Rattray, Jr., ONR Report 21-5.

"The collapse and rebound of a gas bubble", by L. Trillin,, ONR Report 26-2.

(804) THE EFFECT OF PHYSICAL CHARACTERISTICS OF LIQUID ON THE INCEPTION OF CAVITATION.

(b) Office of Naval Research, Department of the Navy.

(d) Experimental; basic research.

(e) Experimental study of liquid properties including presence of gas nuclei on the loc: pressure at which cavitation voids will first appear. Cavitation and boiling exper: are being conducted with water containing dissolved gas. Comparison is being made 1 tween properties of untreated liquid and with liquids subjected to high pressure fo: known periods of time.

(g) Boiling point experiments have demonstrated that pressure-treated water has a consil ably higher initial boiling point than the equilibrium flow. Relatively large indi samples (30 cc) have had boiling points of well over $400^{\circ} \mathrm{F}$ at atmospheric pressure. Flow experiments have not, given conclusive results, presumably due to the difficult: obtaining accurately shaped conduits.

(805) DYNAMICS OF PARTICULATE MATT ER IN FLUID SUSPENSIONS.

(b) U. S. Air Forces.

(d) Experimental and theoretical; basic research.

(e) Studies are being made of the transportation of solid particles by turbulent flows. experimental studies are being carried on in an existing water tunnel by means of of servation of tracers whose density can be varied so that it is greater, equal to, or than the water.

(g) Analytical studies are progressing and the new water tunnel is completed.

(h) "Dynamics of particulate matter in fluid suspensions", by Vito A. Vanoni, En-Yun Hsu R. W. Davies, Lab. Report N 7I-I.

(806) HYDRODYNAMICS OF CENTRIFUGAL AND PROPELLER PUMPS, TURBINES, AND ALLIED FLOW PROBLEMS

(b) Laboratory project.

(d) Basic and precise research; thesis for M. E. degree.

(e) The Hydraulic Machinery Laboratory is designed for carrying out basic and precise re studies in the hydrodynamics of centrifugal and propeller pumps, turbines and allied problems. Horizontal dynamometers up to 450 horsepower and a vertical one up to 30 horsepower are avilable with precision speed controls. Accurate instruments for me: ing pressures, flow rates, speeds, and torques are provided. Special equipment for 1 study of cavitation has been developed. Full characteristics of axial and mixed flor deepwell pumps are being determined.

(g) Completed results which will permit visualization of the complete characteristics in function of specific speed will be available soon.

(h) "Complete characteristic circle diagrams for turbomachinery", by W. M. Swanson, paper presented at 1951 Annual Meeting of the ASME, Atlantic City, N. J. Nov. 26-30, 1951. 
EXPERIMENTAI STUDIES FOR HARBOR DEVELOPMENT.

Bureau of Yards and Docks, Department of the Navy.

Mr. John H. Carr, Project Engineer Contract NOy-12561, California Institute of Technology, Pasadena 4, Calif.

Experimental and theoretical applied research.

The penetration of wave energy into harbors, and the distribution of such energy within harbors is being investigated with the aim of developing some general principles of harbor design.

5) Methods have been developed which permit the prediction of wave disturbances at any point in harbors of simple geometric shape taking into account diffraction at the entrance and reflection from the harbor periphery.

1) Interim reports dated June 1950, and Aug.-Oct. 1950, submitted to the Bureau of Yards and Docks.

"Diffraction of water waves by breakwaters" by John H. Carr and M. E. Stelzriede, National Bureau of Standards Symposium on Gravity Waves. June 1951. (To be published.)

\section{9) AIR-TO-WATER ENTRY OF MISSILES.}

(2) Bureau of Ordnance, Department of the Navy.

c) Mr. Joseph Levy, Hydrodynamics Laboratories, California Institute of Technology, Pasadena 4, Calif.

d) Experimental; basic research.

e) Systematic investigations to determine (1) the variables which affect the behavior of missiles during water entry, and (2) the modeling laws by which such behavior may be studied in small scale. Two-inch diameter models are used and test results are compared with full scale data obtained elsewhere. The variables studied include body shape, velocity, trajectory angle, pitch angle, and the pressure of the atmosphere above the water.

\section{0) BASIC WATER ENTRY STUDY.}

b) Office of Naval Research, Department of the Navy.

c) Mr. Joseph Levy, Hydrodynamics Laboratories, Califormia Institute of Technology, Pasadena 4, Calif.

d) Experimental; basic research.

e) An investigation of the phenomena accompanying the entry into water of solids traveling at moderate speeds. The initial study will cover the formation of the cavity, and the measurement of pressure within the cavity formed behind spheres entering the water vertically. A glass-walled tank is bitit, and photographic and pressure measuring equipment is being assembled.

\section{1) HYDRODYNAMICS OF FREE-BOUNDARY FLOWS.}

b) Office of Naval Research and Bureau of Ordnance, Department of the Navy.

c) Mr. J. Pat O'Neill, Hydrodynamics Laboratories, California Institute of Technology, Pasadena 4, Calif.

d) Experimental and analytical; basic and applied research.

a) A free-surface water tunnel with force and pressure measuring apparatus devised to meet the specific needs of the investigation is used in an experimental and analytical study of the dynamics of cavity and jet flows in 2 and 3 dimensions. Effects of and on the solid boundary configurations associated with the cavity and jet flows are determined. The influence of channel boundaries and problems of similitude in cavity-and jet-flow experimentation are being examined.

g) Characteristies of open cavities have been analyzed. The requirements for maintaining air-filled cavities have been determined. Forces on simple boundary shapes have been measured. A cavity around a liquid jet directed upstream in the water tunnel has been studied as a model of an axially symmetrical cavity with re-entrant jet. Further studies on problems of similitude in free-boundary flows are in progress. 
(h) "The dynamics of underwater bodies manning in an open cavity", J. P. O'Neill. Hydrodynamics Laboratories ONR Report No. M-24-I, April 1951.

"The stability of an air-maintained cavity behind a stationary object in flowing wate W. M. Swanson and J. P. O'Neill. Hydrodynamics Laboratories ONR Report No. M-24-3, S 1951.

UNIVERSITY OF CALIFORNIA, College of Agriculture, Division of Irrigation.

(19) THE EFFECT OF THE DEPTH OF WATER TABLE UPON THE ABILITY OF PLANTS TO EXTRACT WATER.

(b) California Agricultural Experiment Station.

(c) Dr. Robert M. Hagan, Division of Irrigation, University of California, Davis, Calif.

(d) Field and laboratory investigations; basic and applied research.

(e) Studies conducted on behavior of plants grown on waterlogged soils and on soils with controlled water tables during crop season to yield information of value in analyzing cropping problems associated with high water tables.

(20) MOVEMENT OF WATER THROUGH SOIIS.

(b) Califormia Agricultural Experiment Station.

(c) Dr.F. J. Veihmeyer, Division of Irrigation, University of California, Davis, Calif.

(d) Field and laboratory investigation; applied research.

(e) The ability of the soil to supply water to plants through capillary movement and the movement of water through soils is being studied under various conditions. Studies a continuing on fundamentals on plant-soil-water relationships.

(h) "Irrigation experiments with apricots", A. H. Hendrickson and F. J. Veihmeyer, Amer. Hort. Sci. Proc. 55:1-10, 1950.

"Responses of fruit trees and vines to soil moisture", F. J. Veihmeyer and A. H. Hendrickson, Amer. Soc. Hort. Sci. Proc. 55:11-15, 1950。

"Growth of walnut trees as affected by irrigation and nitrogen deficiency", A. H. Hendrickson and F. J. Veihmeyer, Plant Physiol. 25(4):567-572, Oct. 1950.

"Soil aeration as a factor in water absorption by the roots of transpiring plants", $R$ Hagan, Plant Physiol. 25(4):748-762, 1950.

"Apricot irrigation", A. H. Hendrickson and F. J. Veihmeyer, California Agriculture 5 13, May, 1951.

(21) STUDY OF HYDRAULICS OF SPRINKLING SYSTEMS.

(b) California Agricultural Experiment Station.

(c) Prof. C. H. Johnston, Division of Irrigation, University of California, Davis, Calif.

(d) Experimental; operation.

(e) Determination of the characteristics of jets and the distribution of water from sprinl Studies of evaporation from sprinkler jets to determine operation losses. Field studj water losses in sprinkler application. High speed photographs of sprinkler jets recol characteristics of these streams.

STUDY OF THERMODYNAMICS OF SOIL MOISTURE.

(b) California Agricultural Experiment Station.

(c) Dr. Robert M. Hagan, Division of Imigation, University of Califomia, Davis, Calif.

(d) Field and laboratory; basic research.

(e) The ability of soil to supply water to plants, and methods of measuring free energy or potential of soil moisture are being studied. The effect of soluble material added to on the potentials of soil moisture is being studied.

(g) Results to date indicate that applications of materials within limits practical under commercial practice do not affect the permanent wilting percentage. The effect of soi additives such as sponge rock, porous glass, etc., respecting water storage in soil, $s$ open to question.

(h) "Effect of salinity on moisture content and freezing point depression of soil at permal wilting of plants", D. W. Henderson, Soil Sci. 72(3):207-217, Sept. 1951. 


\section{HYDROLOGY OF IRRIGATION SUPPLIES IN CALIFORNIA.}

Califormia Agricultural Experiment Station.

Dr. F. J. Veihmeyer, Prof. C. N. Johnston, Division of Irrigation, University of California, Davis, Calif.

Experimental; applied research.

Studies are being continued on the effects of denudation of watersheds upon the water regimen of typical grazing areas. Experimental watersheds and paired plots are located in various counties of California. Soil-moisture histories are obtained from plots from which the brush has been removed by denudation or burning and adjacent plots which are left with original vegetative cover. Laboratory studies of vegetation denudation have been initiated.

Work will be continued for a number of years in connection with the removal of vegetation to permit growth of forage plants and its effect on runoff and erosion. To date, burning of brush has not accelerated erosion or runoff on the areas tested.

"Some effects of fire and ash on the infiltration capacity of soils", R. H. Burgy and V. H. Scott, (in press). Trans. Amer. Geophys. Union.

MEASUREMENT OF IRRIGATION WATER AND IMPROVEMENT IN FARM IRRIGATION STRUCTURES.

Califormia Agricultural Experiment Station.

Prof. C. N. Johnston, Division of Irrigation, Uni versity of California, Davis, Calif. Experimental; design.

Hydraulics of irrigation systems to better the design and efficiency of irrigation structures and equipment are being studied. Investigations conducted on concrete pipe to establish fitting coefficients for flow in concrete pipes with valves attached so that better design of these systems will result. Field studies in progress to investigate drilling technique and casing production in deep wells when water is corrosive. Prefabricated canal linings are being tested in small farm ditches. Calibration of gated concrete turnouts is being made. Studies of gated water distribution pipe and on perforated sprinkler pipe for small application rates have been completed. Further studies on larger capacity perforated pipe are under way.

"Irrigation wells and well drilling", C. N. Johnston, Calif. Agr. Exp. Sta. Cir. 404, 1951.

PHYSICAL AND CHEMICAL FACTORS AFFECTING SOIL INFILTRATION RATES.

California Agricultural Experiment Station.

Dr. L. D. Doneen, Division of Irrigation, University of California, Davis, Calif.

Field and laboratory; basic and applied research.

Soil infiltration rates are being studied by various types of infiltrometers, with particular reference to quality of water applied. Compaction of soils by harvesting and other equipment has introduced new problems over considerable areas of the State and research is started to find solutions if possible.

Gypsum is the most effective agent to improve infiltration where irrigation water contains $50 \%$ or mors sodium.

"Numerical solutions for tile drainage of layered soils", James N. Luthin and R. E. Gaskell, Trans. Amer. Geophys. Union, pages 595-602, 1950.

"Classification of waters", L. D. Doneen, California Agriculture 4(10): 4, 15, Oct. 1950. "Analyses of imrigation water", L. D. Doneen, Califormia Agriculture L(11):6, I4, Nov. 1950. "Proposed method of leaching tile-drained land", James N. Luthin, Soil Sci. Soc. Amer. Proc. (1950) 15:63-68, 1951. 
UNIVERSITY OF CALIFORNIA, College of Agriculture, Division of Irrigation and Soils.

Inquiries concerning Projects Nos. 26, 27, 1058, 1302 and 1.303 should be addressed Prof. M. R. Huberty, Division of Irrigation and Soils, University of California, Lo Angeles 24 , Calif.

(26) DRAINAGE INVESTIGATIONS IN COACHELLA VALLEY, CALIFORNIA.

(b) Cooperative between the Coachella Valley County Water District, Coachella, Calif., U. S. Regional Salinity Laboratory, Riverside, Calif., the U. S. Bureau of Reclamat Boulder City, Nevada, and the California Agricultural Experiment Station, Los Angel Calif.

(d) Field investigations; applied research and design.

(e) The purpose is to develop and improve techniques for observing shallow ground water movement, for reclamation of saline soils, and for installation of drainage devices systems.

(g) Since last report, work has primarily concemed reclamation and a rational approach drainage design. This work not yet summarized.

(27) HYDROLOGY OF IRRIGATION WATER SUPPLIES IN CALIFORNIA.

(b) Laboratory project, coordinated with similar work under Dr. F. J. Veihmejer, Colleg Agriculture, Davis, California. (Project 23, page 7.)

(d) Field experiments; applied research.

(e) Purpose is to evaluate effects of watershed burning on runoff and erosion in southe California.

(g) Data for the past year scant because of light rainfall.

(1058) MOVEMENT OF WATER THROUGH SOIIS. (b) Laboratory project coordinated with similar work under Dr. F. J. Veihmeyer, College
Agriculture, Davis, Calif.

(d) Continuing field and laboratory studies; basic and applied research.

(e) Factors affecting both saturated and non-saturated flow of water into and through s

(f) Most of work suspended during past year.

(1302) OXNARD PLAIN IRRIGATION AND RECLAMATION INVESTIGATIONS.

(b) Califormia Agricultural Experiment Station.

(d) Field investigations; applied research and design.

(e) The work concerms a portion of Ventura County, California, wherein a perched watert. overlies a clay cap creating drainage and salinity problems for the irrigated agric of the area and is divided into two phases: (1) making an inventory of the irrigatj rainfall-surface drainage-subsurface drainage regime for correlation with irrigatior adequacy and salt balance, and (2) investigations leading to development of a ratior approach to drainage design.

(1303) SURGE IN OPEN-TYPE PIPE SYSTEMS.

(b) Laboratory project, cooperative with College of Engineering, Los Angeles.

(e) Model studies of open-type pipe systems to study the mechanism of surge initiation a propagation with air entrainment. (See Project 29, page 9, of National Bureau of Standards Misc. Publ. No. 201, 1951.) 


\section{IRSITY OF CALIFORNIA, College of Engineering, Fluid Mechanics Laboratory.}

Inquiries concerning Projects Nos. 32, 35, 38, 39, 40, 41, 43, 46, 47, 280, 282, 529, 810, 811, 813, 1059 to 1064, incl., and 1304 to 1307, incl., should be addressed to Prof. J. W. Johnson, Department of Engineering, University of California, Berkeley 4, Calif.

ENERGY LOSSES IN INTERSECTING STREAMS IN CLOSED CONDUITS.

Laboratory project.

Experimental; for Master's thesis.

suspended.

\section{OSCILIATORY WAVES.}

Laboratory project.

Experimental.

To obtain experimental information on the details of oscillatory waves in shallow water. Wave velocity, period, length, height, mass transport and orbital velocities through depth and length of channel will be measured and compared with theory. Change in wave characteristics will be studied when the waves pass over various types of bottom discontinuities and through various dampening devices.

Three master of science theses completed.

"Damping of water waves by vertical circular cylinders". R. D. Costello, August 1951. "Model study of amphibious breakwaters." Lt. D. A. Patrick, CEC USN, October 1951.

"Discharge from submerged outfalls." Edward K. Rice, June 1951.

STRUCTURES EXPOSED TO WAVE ACTION.

Laboratory project, Bureau of Yards and Docks and Signal Oil and Gas Co. Experimental, laboratory and field research.

To obtain experimental data for the design and location of such shore protection works as groins, jetties, piers and bulkheads. Present work involves the measurement of forces exerted on both model and field structural elements subjected to wave action.

"Moment distribution exerted by waves on piling." J. R. Morison. (Unpublished report.) "Wave forces on piling (Monterey Field Test)." F. E. Snodgrass, E. K. Rice and M. Hall. (Unpublished report.)

"Final report: Forces on piling." H. W. Iversen and J. R. Morison. (Unpublished report.)

BEHAVIOR OF TWO-PHASE FLUIDS IN POROUS MEDIA.

Laboratory project.

Experimental and theoretical research; Ph.D. and M.S. theses.

Investigation of the behavior of fluids during flow in porous media and an investigation of the capillary properties of porous media. Theoretical and experimental investigation of the micro-behavior of fluid phases moving through inter-connected capillary systems under all possible force fields including interfacial phenomena under dynamic conditions, diffusion, pressure forces, gravity forces, viscous forces and inertia forces. Experimental investigation of the effect of micrompore structure on flow behavior and theoretical and experimental investigation of capillary, electric phenomena on flow of brine and other fluids in porous media. An investigation of equilibrium phase behavior for multi-component two-phase flow will involve flow of refined oil and natural gas through consolidated sand column with liquid saturation changes being determined with Iodine 131 tracer technique. Experiments in progress on capillary-electric studies, and on matrix properties of various types of artificial porous media. Experimental work completed on rates of attainment of pressure equilibrium during pressure transient on crystal oil-methane system in sand packed vessel.

"Steady flow of two-phase, single-component fluids through porous media." F. G. Miller, $\mathrm{Ph} . \mathrm{D}$. thesis, 1950.

"Steady flow of two-phase, single-component fluids through porous media." F. G. Miller, A.I.M.E. Journal of Petroleum Technology, Vol. 192, 1951. 
(40) FLOW CHARACTERISTICS OF SOLIDS-GASEOUS MIXTURES IN A HORIZONTAL AND VERTICAL CONDUIT.

(b) Laboratory project. Supported in part by Research Corporation.

(d) Experimental; basic and applied research, design.

(e) The isothermal flow characteristics of a solids-gaseous mixture $\left(\mathrm{Al}_{2} \mathrm{O}_{3}, \mathrm{SiO}_{3}\right.$ catalyst air) are investigated for various air flow and solids flow rates. Pressure drops acr test sections are measured for air flow rates with solids to air ratio varied from ze: to 11.0 pounds of solids per pound of air. The solids (catalyst) have a size distribi varying from particles less than 10 microns to particles greater than 220 microns. A: velocities in the solids-free approach section vary from 50 fps to 150 fps.

(f) A paper on metering air-solid mixtures is in preparation.

(g) Experimental data being correlated on the metering of mixtures. Design of equipment way for the study of the heat transfer characteristics of mixtures (gaseous-solids).

(h) "Flow characteristics of solids-gas mixtures in a horizontal and vertical conduit." L. Farbar, Industrial and Engineering Chemistry, V. 4l, p. 1184 , June 1949.

(41) PRESSURE DROP ACCOMPANYING TWO-PHASE, TWO-COMPONENT FLOW IN PIPES.

(b) Laboratory project.

(d) Theoretical and experimental investigations; graduate theses.

(f) To determine the transition conditions under which the gas and/or liquid phases are $f$. ing in viscous and/or turbulent motion or in slug flow for isothermal flow in horizont and vertical pipes. Mixtures of air and various liquids are made to flow through vert tubes. Pressure drop and fluid distribution with consideration of flow stability are determined for a range of liquid and gas rates which may be controlled separately.

(g) Some theoretical work is completed. Eight graduate theses completed. Three papers ir preparation. Pressure-drop and velocity distribution data on $1 / 4$ inch diameter columr various wave lengths, frequencies, and amplitudes confirmed that the waves caused axi: shear forces up to 150 times the forces in rigid tubes.

(h) "Stability considerations in vertical annular two-phase fluid flow." A. D. K. Laird, Doctoral thesis, University of California at Berkeley, Sept. 1951 (available on loan).

(43) A PITOT TUBE STANDARD FOR FLOW MEASUREMENT.

(b) In cooperation with Turbine Pump Manufacturers Association.

(d) Experimental; applied research and development.

(e) The project is to design, construct and calibrate a suitable Pitot tube for use with a standard code (to be developed) for application under a variety of field conditions.

(g) Library study and correlation of existing information in progress.

(46) THE MEASUREMENT OF TURBULENT VELOCITY COMPONENTS BY THE METHOD OF ELECTROMAGNETIC INDU

(b) Laboratory project.

(d) Experimental and theoretical investigations; faculty research.

(e) To measure the components of turbulent velocity fluctuations in the axisymmetric flow liquid in a tube as a function of position and flow rate. Velocity fluctuations are measured by determining the potentials induced in water cutting transversely across a steady magnetic field. An electrical probe consisting of two closely spaced fine wire arranged to traverse the pipe cross section in the fluctuating potential gradient. Th electrical impulses of the probe are amplified and measured by means of a thermal mill ammeter.

(g) R.M.S. parallel and transverse components measured, correlation coefficients computed, spectrum measured.

(h) "The statistical theory of turbulence and measurements of turbulent velocity component axisymmetric liquid flow." L. M. Grossman. Ph.D. Thesis, 1948, University of Califor at Berkeley. (Available on loan.)

"Measurements of turbulent velocity components in liquid pipe flow by magnetic inducti A. F. Charwat. M.S. thesis, 1949. University of California. (Available on loan.) "Correlation theory in turbulent pipe flow." W. H. Reid. M.S. Thesis, 1951, Universit California. (Available on loan.)

"Bibliography on the statistical theory of turbulence." W. H. Reid, IER Report Series 46, Issue No. 1, March 19, 1951. 
GRAVITY WAVES AND RELLATED PHENOMENON.

Office of Naval Research and Bureau of Yards and Docks, Department of the Navy. Theoretical and laboratory investigation; basic research. To develop methods of forecasting wind waves and swell, surf conditions and beach changes; measurement of wave characteristics; and make laboratory investigations to provide experimental checks and other information.

"The damping action of under water breakwaters." J. W. Johnson, R. A. Fuchs and J. R. Morison. Trans. Amer. Geophys. Union, October 1951.

"A theory of short crested waves." R. A. Fuchs, Symposium on Gravity Waves, National Bureau of Standards, June 1951.

"Breaker characteristics." H. W. Iversen, Symposium on Gravity Waves, National Bureau of Standards, June 1951.

"The effect of wave steepness on wave velocity." J. R. Morison, Trans. Amer. Geophys. Union, April 1951.

"A note on the tangential transfer of energy between wind and waves." S. A. Schaaf and F. M. Sauer, Trans. Amer. Geophys. Union, December 1950.

\section{SEDIMENT TRANSPORT.}

Laboratory project.

Experimental and theoretical; doctoral thesis.

Determination of the transport characteristics in the transition sizes between bed load and wash load.

"The maximum equilibrium rate of bed-load movement." Ning Chien, Ph.D. Thesis.

\section{EFFECT OF RATE OF FLOW ON RELATIVE PERMEABILITY IN MULTIPHASE FLOW IN POROUS MEDIA.}

Sponsored by American Petroleum Institute.

Theoretical and experimental investigations; graduate thesis.

To investigate the fundamental mechanism of the movement of multiphase fluids in porous media.

Immediate objectives include (1) effect of the rate of flow on the relative conductivity of porous media to each fluid phase, and (2) the behavior of multiphase fluid flow involving phase changes during flow. Using porous matrix of known uniform capillary properties, two immiscible liquids are made to flow under a varying range of potential gradient, thus determining the range of linearity of the fundamental law of flow. Work at immobile brine has been completed. Current work is being carried out at constant total liquid rate for wide range of brine saturation followed by similar experiments covering a wide range of total fluid rate. Work on phase behavior during flow of propane in sand column completed.

"Fluid saturation in porous media by X-Ray technique." A. D. K. Laird and J. A. Putnam, Petroleum Trans., AIME, Vol. 192, 1951. (Technical Paper \#3169).

"Pore size distribution studies of alundum core samples." R. W. Ravenscroft, Report Series No. 38, Issue No. 6, Institute of Engineering Research, Uni versity of California at Berkeley, April 15, 1951.

"Equipment and methods for relative permeability research." R. W. Ravenscroft, Report Series No. 38, Issue No. 7, Institute of Engineering Research, University of Califomia at Berkeley, April 15, 1951.

\section{LITTORAL SEDIMENT FLOW ON A BEACH.}

Beach Erosion Board, Washington, D. C.

On a model beach, the motion of sand is studied under wave action. Determination of the littoral drift as a function of direction, height and period of waves. Development of devices measuring drift of water and sediment. Study of the influence of structures, such as groins. Supplementing the model studies is a field study of littoral transport at Santa Barbara. The procedure is to periodically measure the accumulation of sand in Santa Barbara Harbor and then relate the average transport of sand to measured wave characteristics. 
(h) Unpublished reports submitted to Beach Erosion Board:

"The relationship between sand size and beach face slope." W. N. Bascom. "Initial surveys and instrumentation sand transport study, Santa Barbara, California W. N. Bascom.

"Wave records on the Pacific Coast of the United States." J. W. Johnson. "Sand studies in two dimensional wave motion." E. Shay and J. W. Johnson. "Influence of groins on beach stabilization." E. Shay and J. W. Johnson. "Model studies on the movement of sand transported by wave action along a straight $b$ r E. Shay and J. W. Johnson.

"Investigation of coastal sand movements near Santa Barbara, California." W. N. Bas

(810) VERTICAL SHAFT PUMP SUCTION REQUIREMENTS.

(b) Peerless Pump Division of Food Machinery Corporation.

(d) Experimental; applied research.

(e) Investigation of vortex formation and air entrainment in the suction sumps of typica vertical shaft pump suction sump arrangements. Model and prototype comparisons to d mine the feasibility of model tests. Studies of sump geometries for minimum submerg with no air entrainment and with negligible influence on pump performance.

(g) Model and prototype submergence and air entrainment results agree qualitatively. Op sump geometry for minimum submergence has been determined for rectangular plan form, inflow sumps. Further work to be done to extend the range of investigated condition

(h) "Studies of submergence requirements of high specific speed pumps." H. W. Iversen, Papers presented at Semi-annual Meeting of A.S.M.E., June 1951.

(811) STUDY OF DETACHED SHOCK WAVES.

(f) Completed.

(h) "The development of experimental techniques for the study of compressible flow by th hydraulic analogy." J. V. Flowers, Master of Science Thesis, University of Californ: June 1951.

"A study of transonic gas dynamics by the hydraulic analogy." E. V. Laitone, Univer: of California, Department of Engineering, Report Series No. 3, Issue No. 323, June 1 (Presented at Institute of the Aeronautical Sciences Annual Summer Meeting, June 1951 To be published in the Journal of the Aeronautical Sciences.)

(813) FLUID RESISTANCE IN ACCEUERATED MOTION.

(b) Laboratory project.

(d) Experimental; for graduate thesis.

(e) The fluid resistance of bodies subject to accelerated motion is being studied. Data been obtained for flat circular disks moving through water with the plane of the disl perpendicular to the direction of motion. A drag coefficient has been developed in $t$ of a correlative modulus that includes the acceleration of the system. A continuatic with other bodies is planned.

(h) "Virtual mass of disks." R. Balent, M. S. Thesis, 1949.

"A correlating modulus for fluid resistance in accelerated motion." H. W. Iversen ar R. Balent, Journal of Applied Physics, Vol. 222 No. 3, March, 1951, pp. 324-28.

(1059) HEAT TRANSFER AND PRESSURE DROP IN COOLING TOWERS.

(b) American Society of Heating and Ventilating Engineers; laboratory project.

(d) Experimental and analytical.

(3) To determine the heat transfer from water in contact with air in a mechanical draft, cooling tower as a function of water rate, air rate, water temperature and packing ge To determine the pressure drop as a function of the above-mentioned variables.

(h) "The cooling of a freely falling water drop." N. W. Snyder, Presented at the Heat Tr Discussions in London, England, Sept. 1951. To be published in Proceedings.

"Enthalpy transfer in a cross flow cooling tower." N. W. Snyder and J. E. Mahlmeiste Presented at Eighth Intemational Congress on Refrigeration in London, England, Augus To be published in the Proceedings. 
MASS TRANSFER TO RISING BUBBLES AND ON BUBBLE PLATES.

Laboratory project.

Experimental and analytical.

A study of diffusion to bubbles and mass of bubbles.

STREAMFLOW DISTRIBUTION OF SELECTED PACIFIC COAST BASINS IN CALIFORNIA.

Laboratory project; Geophysics Institute, University of California.

Basic research; analysis of available data.

Development and analysis of flow-duration curves for representative drainage areas in order to relate shapes and slopes of the curves to known physical factors.

Compilation of flow duration curves largely completed; evaluation of statistical parameters in progress.

STUDY OF THE EFFECT OF ACCELERATION ON SHOCK WAVE FORMATION.

Laboratory project.

Experimental.

A wedge is towed through still water at various velocities and accelerations. The resulting shock wave pattern is observed and analyzed.

Completed.

"An experimental investigation of transonic and accelerated supersonic flow by hydraulic analogy." E. V. Laitone, University of California, Department of Engineering, Report Series No. 3, Issue No. 315, July 3, 1950 (paper presented at American Physical Society Annual Meeting, New York, Feb. 1951).

"An experimental investigation of the acceleration effect on bow shock waves by the hydraulic analogy." Arthur C. Ackerman, Master of Science Thesis, University of California, Sept. 1951.

FRICTIONAL EFFECT OF SMALL CROSS SILIS IN SEDIMENT CARRYING CHANNEIS.

U. S. Department of Agriculture, Soil Conservation Service.

Experimental.

The frictional effect of the structures is measured by comparison with the same channel without structures at equal flow and sediment transport conditions.

Completed.

"Linearity of friction in open channel flow." R. B. Banks, Ph.D. Thesis.

"An experimental investigation of stabilizers in a flood channel." H. A. Finstein and

R. B. Banks, Tech. Report Series No. 47, Issue No. 1 of the University of Califormia

to the U. S. Dept. of Agri., Soil Conservation Service.

SINGLE VORTEX IN A REAL FLUID.

Yosemite Chemical Company, San Francisco.

Experimental and analytical.

The effect of friction on 8 single vortices is studied to devise methods of preventing

their development in front of pump intakes.

Completed.

"Single vortex in a real fluid." Huon Li, Master of Science Thesis, June 1951.

VELOCITY DISTRIBUTION IN OPEN CHANNEL BENDS.

Laboratory project.

Theoretical and experimental.

To describe and predict the cross-distribution of velocities in open channel bends. 
(1305) FLOW OF AIR-WATER MIXTURES IN OPEN CHANNEL FLOW.

(b) International Engineering Company.

(d) Experimental and theoretical.

(e) To predict the bulking of water by air in the discharge channels of impulse turbin under load rejection.

(1306) PARTICLE SEGREGATION IN AN AGGRADING STREAM.

(b) U. S. Army, corps of Engineers.

(d) Experimental.

(e) Flume studies.

(1307) DETERMINATION OF PRESSURE FLUCTUATIONS IN TURBULENCE IN LIQUID FLOW.

(b) Laboratory project, Research Corporation Grant.

(d) Experimental.

(e) Development of instruments and methods to measure pressure fluctuations in the fre stream and at the flow boundaries.

UNIVERSITY OF SOUTHERN CALIFORNIA, Hydraulic Laboratory, School of Engineering.

(531) CREATION OF ARTIFICIAL RAIN TO STUDY RUNOFF FROM AIRPORT RUNWAYS.

(b) Laboratory project; cooperative with Los Angeles District, Corps of Engineers.

(c) Dr. K. C. Reynolds, University of Southern California, Los Angeles 7, Calif.

(d) Experimental; basic research, design, and M. S. theses.

(e) The prototype channels are located at the Santa Monica Airport, Santa Monica, Cali The factors which affect the creation of artificial rain and which would influence from airport runways are being investigated by analyzing the runoff hydrograph.

(f) Experiments completed.

(h) "The effect of distribution and size of raindrops of artificially created rain on munoff of airport runways." J. S. Guzman and A. A. Cohan, Master's thesis, Januar. U.S.C. Report on investigations at Santa Monica Airport in preparation by Glenn A. Instructor at U.S.C., in cooperation with Los Angeles District, Corps of Engineers

UNIVERSITY OF SOUTHERN CALIFORNIA, Research Foundation for Cross-Connection Control.

(49) RESEARCH FOUNDATION FOR CROSS-CONNECTION CONTROL.

(b) Laboratory project.

(c) Dr. Robert E. Vivian, Research Foundation for Cross-Connection Control, University Soutnern California, Los Angeles 7, Calif.

(d) Experimental research and field investigations; basic research.

(e) To supplement and evaluate existing information on mechanical backflow prevention $c$ operating under constant line pressure, to perform laboratory acceptance tests on a pressure types of backflow prevention devices.

(f) Temporarily inactive. 
IE INSTITUTE OF TECHNOLOGY, Department of Civil Engineering.

Inquiries concerning Projects Nos. 1308, 1309, and 1310 should be addressed to Prof. F. T. Mavis, and Projects Nos. 1311 and 1312 to Prof. I. M. Laushey, Carnegie Institute of Technology, Pittsburgh 13, $\mathrm{Pa}$.

TRANSPORTATION OF BED LOAD--COMPETENT VELOCITY.

Laboratory project. Experimental; for bachelors' theses.

Competent velocity near the stream bed as a function of grain size, specific gravity of grain materials, velocity profiles, and velocity for a range of sizes of unigranular sand.

MOMENTUM AND KINETIC ENERGY OF TURBULENT FLOW.

Laboratory project.

Experimental; basic research for doctoral thesis.

A theoretical and experimental study of the magnitude of fluid turbulence fluctuations and the role in the conversion of kinetic to potential energy in an expansion. Methods of determining the momentum and kinetic energy of a turbulent stream. Symmetry and isotropy of the three-dimensional fluctuations.

Suspended.

VIRTUAL MASS-ACCELERATION IN FLUIDS.

Laboratory project.

Theoretical and experimental; basic research for doctoral thesis.

Tests will be conducted on accelerated motion in fluids to detemine the physical relationships involved.

FIOW THROUGH VERTICAL SHAFTS.

Laboratory project, sponsored by the Allegheny County Sanitary Authority. Experimental for design.

Uischarge as a function of headwater depth, pipe diameter, and shape and size of inlet tank. Energy dissipation in the shaft under free fall, with and without spiral flow. Quantitative study of air entrainment and design of vents.

\section{TURBULENCE VETOCITY.}

Laboratory project.

Experimental; for bachelor's thesis.

An experimental study of the change in direction and magnitude of the turbulence velocity vector by combining the instantaneous values recorded along three mutually perpendicular axes. 
COLORADO A \& M COLLEGE, Department of Civil Engineering.

Inquiries concerning Projects Nos. 52, 535, 537 to 539, incl., 822, 823, 828, 1072 1075, incl., and 1313 to 1315, incl., should be addressed to Prof. Maurice L. Albe Department of Civil Engineering, Colorado A \& M College, Fort Collins, Colo.

(52) HYDRAULIC SAND SEPARATOR.

(b) Laboratory project.

(d) Experimental; applied research.

(e) The purpose is to obtain data for the design of hydraulic models, and to supply a of separating sand and gravel where a narrow size range is desired.

(g) An apparatus has been designed and built which classifies sand according to fall v by a continuous flotation process. The process is purely dynamic in that sand is duced directly into the flow. A check for duplication of results indicates that $c$ tions within plus or minus one percent are obtained. At present, construction of apparatus is being completed to perform sand separation on a continuous basis of $c$ tion. Preliminary tests indicate satisfactory results.

\section{(53) SAND TRAPS AND SLUICENAYS.}

(b) Soil Conservation Service, Colorado Agricultural Experiment Station.

(c) R. L. Parshall, Soil Conservation Service, Colorado A \& M College, Fort Collins, C

(d) Experimental; applied research.

(e) To develop design data for sand traps using vortex tubes, riffles, and deflectors or in combination, and to perfect the design for sluiceways having a relatively f grade which will effectively transport the bed load material from sand traps to a of disposal. A new type of sand trap of an automatic nature has been designed and under construction for testing in the laboratory.

(g) Investigations, laboratory and field, various designs of sand traps, show that the tube, operated under favorable conditions has been successful. Installations of $t$ riffle deflector-vortex tube sand traps, large size, have been efficient in removi bed load. Based upon previous model studies and field experiences, a riffle defle vortex tube sand trap has been designed for the Kern County Land Company canal car 700 cfs. Final designs have been prepared for the riffle deflector-vortex tube sa for the Belmonte Hydroelectric Project, Bogota, Columbia, S. A.

(h) "Model and prototype studies of sand traps." Ralph L. Parshall, Separate No. 47, ASCE, May 1951.

(55) SNOW COURSE MEASUREMENTS AND FORECAST ANALYSIS.

(b) Soil Conservation Service, Bureau of Reclamation, State Engineer of New Mexico, an Engineer of Wyoming.

(c) H. Stockwell, Soil Conservation Service, Colorado A \& M College, Fort Collins, Col

(d) Field investigation; applied research.

(e) Systematic measurements of depths and water content of snow at high elevations in Colorado mountain areas for the purpose of forecasting the runoff of the principal of the state in the interest of irrigation, power, domestic supplies, and other use

(g) Snow measurement data are correlated with runoff. Once the relationship is establj the snow measurement data are used to predict the runoff for the coming season.

(h) For 1951, Colorado Agricultural Experiment Station, Miscellaneous Series Papers Nos $476,477,484,485,486,487,488,489,491,492$, and 493. These are the monthly s Survey reports for the Rio Grande, Colorado, and Platte-Arkansas Drainage Basin.

(57) PHOTOGRAPHIC METHOD FOR MAKTNG SNOW SURVEYS.

(b) Laboratory project.

(c) Maxwell Parshall, Colorado A \& M College, Fort Collins, Colo. 
Field investigation; applied research.

Photographs of snow cover on a particular area of Cache la Poudre watershed are made. Area of snow cover is correlated with annual runoff.

Fairly good correlation has been obtained.

PERFORMANCE OF WEIL SCREENS.

Colorado Agricultural Experiment Station, Soil Conservation Service, and various well screen manufacturers.

C. H. Rohwer, Soil Conservation Service, Colorado A \& M College, Fort Collins, Colo. Experimental; applied research.

(1) Measurement of loss of head in different types of well screens for discharges suitable for each screen. (2) Determination of the size of opening in well screens, diameter of screen, thickness of gravel envelope, and size and graduation of sand or gravel for most effective control of flow of sands of different finenesses into the well with least loss of head, and to determine the size of openings in well screens and diameter of screen for most efficient operation in natural sands and gravels of a given classification. An additional study is underway on the loss of head at interface of gravels of different sizes.

Using the momentum, energy, and continuity equations, a theoretical analysis has been developed which checked very closely with tests made on simplified well screens. By this means a system has been established for determining a single coefficient which completely describes the hydraulic characteristics of any commercially-manufactured well screen.

"Hydraulic properties of well screens." Gilbert L. Corey, Master's Thesis, Colorado A \& M College, June 1949.

"Effect of well screens on flow into wells." Jack S. Peterson, Master's Thesis, Colorado A \& M College, Aug. 1951.

"Hydraulics of flow through well screens." Peterson, Rohwer, and Albertson. Special report, Colorado A \& M College, Dec. 1951.

FLOW IN CHANNEIS OF DEFINITE ROUGHNESS.

Laboratory project.

Experimental; for design and for masters' theses.

To supply experimental data on the flow of water through a channel of definite roughness. An attempt is being made to use a type of roughness which can be easily reproduced and yet adequately serve as an index of roughness for flow in open channels. Tests are now under way in which natural gravel of various sizes from canals and rivers is used as the roughness. Further investigations include the determination of the sediment carrying capacity of channels with definite roughness.

Tests have been completed using sheet metal baffle plates as a standard. From these data a single function has been established relating the Chezy resistance coefficient with the Reynolds number and the relative roughness.

"Natural roughness in open channels." Arthur W. Van't Hul, Master's Thesis, Colorado A \& M College, Nov. 1951.

VORTEX-TUBE SAND TRAPS.

Laboratory project.

Experimental; for design and for masters' theses.

To obtain generalized data for design of the most efficient vortex tube as a sand trap

in a canal.

A tube placed at a 45-degree angle has been studied, and the relaticnship has been determined between the efficiency of the tube and such factors as the depth of flow, the discharge, the size of the bed material, the concentration of the bed material, and the relative elevation of the downstream lip of the tube. The resulting design curves permit the design of vortex tubes under prototype conditions for maximum efficiency.

"Efficiency of a vortex-tube sand trap." George L. Koonsman, Master's Thesis, Colorado A \& M College, June 1950 .

"Design characteristics of the vortex-tube sand trap." George L. Koonsman and Maurice I. Albertson, Int. Society of Hydraulic Research, 1951. 


\section{(538) HYDRAULICS OF SPILLWAYS.}

(b) Iaboratory project.

(d) Experimental; for design and for masters' theses.

(e) To obtain generalized design information for spillways having the shape of the unde of the nappe from a sharp crested weir. Generalized tests are being made to determ the shape of the nappe with various negative pressures under it. Ultimately, the d charge coefficient and the pressure distribution will be obtained for all practical grees of submergence and ambient pressures. These data will permit the designer to determine in advance the necessary shape of a spillway crest if a certain negative sure is desired for a given head on the crest.

(g) Using data reported by others, and data obtained in this laboratory, dimensionless curves have been developed which permit solving directly for the design head, the d charge, the height of the spillway, or the shape of the spillway crest. Further da have been obtained which show the effect of downstream submergence on the discharge the pressure distribution over the spillway.

(h) "Discharge characteristics of submerged spillways." Herman J. Koloseus, Master's T Colorado A \& M College, Dec. 1951.

"Characteristics of the negative pressure nappe." Fredric C. Repper, Master's Thes Colorado A \& M College, (in preparation).

\section{(539) STILLING WELIS FOR METER GATES.}

(b) Armco Drainage and Metal Products, Inc.

(d) Experimental; applied research for design.

(e) To determine whether it is possible to simplify the design of the stilling wells an retain the accuracy and usefulness of the gate as a device for measuring flow.

(f) Completed.

(g) A satisfactory method was devised by means of constrictions.

(h) "Fluctuation studies in stilling wells for Armco metergate model No. 101." Maurice Albertson, Special Report for Armco Drainage and Metal Products, Inc., Jan. 1951.

(820) THE STUDY OF SEEPAGE LOSSES FROM IRRIGATION CHANNELS.

(b) Soil Conservation Service, Bureau of Reclamation, Colorado Agricultural Experiment s

(c) C. H. Rohwer, Soil Conservation Service,

(d) Experimental and field investigation; applied research.

(e) A study of the factors influencing seepage from channels. It is hoped to perfect $m \in$ for making pre-investigations of seepage for the purpose of determining the seepage existing canals, and predicting the seepage from proposed canals. Methods of measur seepage will be evaluated to determine the limitations and advantages of each.

(h) "Progress report on the study of seepage losses from irrigation channels." Carl Ro April 1950.

"Progress report on the study of seepage losses from irrigation channels." A. R. Ro and Carl Rohwer, April 1951.

\section{(821) GROUND WATER FLUCTUATIONS AND THEIR RELATION TO PUMPING.}

(b) Laboratory project.

(c) W. E. Code, Colorado A \& M College, Fort Collins, Colorado.

(d) Field investigation; applied research.

(e) Measurements of water table elevation in 190 selected wells are made twice annually.

(g) It has been possible to determine from the data whether the ground-water supply in $t$ various pumping areas is adequate for the demand imposed upon them. A definite lowe of the water table is occurring in the Kiowa, Bijou, and Beaver Creek areas where pu is the heaviest.

(h) Sumary is prepared for inclusion in Geological survey Water Supply Paper. 
DIFFUSION OF HEAT, VAPOR, AND MOMENTUM.

Office of Naval Research, Colorado A \& M College.

Experimental; basic research.

A controlled study in a wind tunnel of the fundamental principles describing the process of diffusion of vapor, heat and momentum from various surfaces. Eventually it is intended to use the fundamental information to aid in determining evaporation from free surfaces, land areas with various soil and crop covers, and plant surfaces; and heat and moisture losses from aninals.

"A comparative study of momentum transfer, heat transfer, and vapor transfer."

"Part II, Forced convection, turbulent case." C. S. Yih, ONR Report, June 1951

"Part III, Free convection." C. S. Yih, ONR Report, Feb. 1951.

"Design and operation characteristics of a low-cost, low-velocity, wind tunnel."

Jack E. Cermak and M. L. Albertson, ONR Report, in preparation.

"Atmospheric diffusion from a point source." C. S. Yih, Colorado A \& M College, Report No. 4, Aug. 1951.

"Laminar heat convection in pipes and ducts." C. S. Yih, and Jack E. Cermak, Colorado A \& M College, Report No. 5, Sept. 1951.

"Temperature distribution in a steady laminar, preheated air jet." C. S. Yih, Jour. of Applied Mechanics, Dec. 1950.

"On a differential equation of atmospheric diffusion." C. S. Yih, Colorado A \& M College, Spring, 1951.

"Diffusion from a line source in laminar flow over a wedge and in Blasius flow." C. S. Yih, Colorado A \& M College, Nov. 1950.

"Evaporation from a plane boundary." Maurice L. Albertson, 1951 Heat Transfer and Fluid Mechanics Institute, June 1951.

\section{SCOUR IN A STILLING BASIN.}

Laboratory project.

Experimental; for design and master's thesis.

A laboratory study of the scour in a stilling basin as the energy in a jet of water is being dissipated. It is planned to use jets of various shapes and angles of attack on the stilling basin, and the position of the jet relative to the stilling basin.

A study has been completed of the special problem of comparing the scour from a solid jet with that from a hollow jet valve. The jet was directed vertically downward at various velocities. Variables considered were the depth of the pool, the fall velocity of the erodable material and the size of the jet. Results showed that the depth and rate of scour depended upon the depth of water in the stilling basin and the size of the bed material. As expected, the larger the bed material, the smaller was the degree of scour. As tine depth of the water in the stilling basin increased, the scour likewise increased to a maximum beyond which scour decreased as the depth increased.

INFLUENCE OF SHAPE ON THE FALL VELOCITY OF SAND GRAINS.

Laboratory project.

Experimental; for design and masters' theses.

A study of the fall velocity of sand and gravel particles from various sources such as river beds, sand dunes, glacial moraines, sea deposits, and rock crushers. An attempt is being made to determine a single shape factor which will adequately serve as a third variable in a plot of drag coefficient vs Reynolds number, and also to determine the relationship between the sieve diameter and sedimentation diameter as well as the variation of shape with size of fraction.

A practical shape factor was determined which correlated quite well considering the irregular and random shape of the particles involved.

"Effect of shape on the fall velocity of fine sand particoes." Edmund F. Schulz. Master's Thesis, Colorado A \& $M$ College, in preparation.

"Effect of shape on the fall velocity of gravel particles." Robert Wilde, Master's

Thesis, Colorado A \& $M$ College, in preparation. 
(1072) CALIBRATION OF ARMCO METERGATES.

(f) Completed.

(h) "Calibration of Armco Metergated Model No. 101." Sol D. Resnick, Special report tc Armco Drainage and Metal Products, Inc., Jan. 1951.

(1073) SEDIMENTATION STUDY USING A TURBULENCE TANK.

(b) U. S. Bureau of Reclamation and Colorado A \& M College.

(d) Experimental; basic research.

(e) To determine more completely the effect of relatively uniform turbulence (created b system of lattice structures similar to that used by Rouse), viscosity, fall veloci and gradation of sediment, and percolation upon the concentration gradient and amou of sediment in suspension.

(f) Initial phase completed.

(g) Results explain to a considerable extent the variation of sediment concentration wi temperature, depth, discharge, and bed material which has been noticed in natural $s$

(h) Report in preparation.

(1074) HYDRAULICS OF STILLING BASTNS.

(b) Laboratory project.

(d) Experimental; for design and master's theses.

(e) To obtain generalized design information for stilling basins utilizing the hydrauli jump together with chute blocks, floor blocks, and sills.

(g) Generalized tests have been completed using cubical floor blocks to force the hydra: jump having a length equal to 3 and 5 times the downstream depth when the tailwater elevation is either normal or below normal.

(h) "Direct solution for apron elevation." Maurice L. Albertson, Mineographed Report, Dec. 1950.

(1075) HYDRAULICS OF DROP STRUCTURES.

(b) Laboratory project.

(d) Experimental; for design and masters' theses.

(e) A series of fundamental experiments to obtain generalized design information for dr structures generally associated with irrigation and drainage canals.

(1076) INVESTIGATION OF THE ECONOMICS AND PRACTICABILITY OF SPRINKLER IRRIGATION IN COLORAI

(b) Laboratory project.

(c) W. E. Code, Colorado A \& M College, Fort Collins, Colorado.

(d) Field investigation; applied research.

(e) Collection of data on the performance of sprinklers with respect to use of equipment success as an irrigation method, effect on crops and cost.

(g) It has been found that many systems are poorly designed for a given situation and tr in many cases savings in water are not as large as anticipated. Although many users raised satisfactory crops, others did not because of insufficient water application.

\section{(1313) HYDRAULICS OF ALLUVIAL CHANNELS.}

(b) Laboratory project.

(d) Experimental and theoretical; basic research and design; for master's and doctor's $t$

(e) The long range objectives of the project are to determine the hydraulic characterist (including the sedimentary aspects) of alluvial channels. Consideration will be giv to steady and unsteady flow, uniform and non-uniform flow, transportation of bed loa suspended load, bed material load, and wash load.

(g) Research is now underway investigating the natural shape (cross-section and meander pattern), the boundary resistance, and the sediment transporting characteristics of streams of a given discharge developing in a bed of sand having a given slope, and analysis of bed material.

(h) "The design of stable channels in erodible material." King Yu, Master's Report, Col A \& M College, June 1949. 
MODEU STUDY OF LAKE HEFNER.

Bureau of Ships, Department of the Navy.

Experimental; basic and applied research.

An attempt is being made to reproduce in the models of various sizes the wind structure over Lake Hefner as measured during intensive field investigations. If this first step is successful, an attempt will be made to model the evaporation.

5) WIND CHILL ON A LIFE-SIZED COPPER MAN IN A WIND TUNNEL.

b) Office of the Quartermaster General, Department of the Army.

(d) Experimental; basic and applied research.

e) 1. To determine relationship between the coefficient of heat transfer, the ambient wind velocity, and the difference between skin and air temperature under various conditions of clothing and posture under simulated natural climatic conditions. 2. To develop formulas by which the rate of heat loss from a life-sized man may be predicted under various conditions of climate.

6) MODEL STUDIES FOR RIO GRANDE CANAL COMPANY DIVERSION DAM.

b) Rio Grande Canal Company.

c) Ralph L. Parshall, Soil Conservation Service, Colorado A \& M College, Fort Collins, Colo.

d) Experimental; applied research.

e) Model study was conducted to determine the most desirable spillway and ogee crest design and to provide assurance that prototype will operate as desired.

f) Completed.

.7) PARSHALI DEFLECTIJN METER FOR MEASUREMENT OF DISCHARGE IN CONDUITS.

b) Laboratory project; also sponsored by Alfred J. Ryan, Consulting Engineer, Denver, Colo.

c) Ralph L. Parshall, Soil Conservation Service, Colorado A \& M College, Fort Collins, Colo.

d) Experimental; development.

e) A special shape of vane for a deflection meter has been developed which will have the same deflection for a given discharge in a given channel regardless of the depth and velocity of flow.

8) REYNOLDS NUMBER FOR FLO'N THROUGH SANDS AND GRAVELS.

b) Laboratory project.

c) Prof. D. F. Peterson, Department of Civil Engineering, Colorado A \& M College, Fort Collins, Colo.

d) Experimental; basic research; master's and doctor's theses.

e) The length factor in Reynolds number for flow through sands and gravels is based on the diameter of the particle. This does not take into consideration changes in porosity nor the fact that particle sizes are not uniform. An attempt will be made to find some characteristic length based on the hydraulic properties of the sand or gravel which will result in standard values of Reynolds number.

19) PREVENTION OF ICING ON AIRPLANE WINGS BY LINE-SOURCE OF HEAT.

b) Office of Naval Research, Department of the Navy.

c) Prof. Jack E. Cermak, Colorado A \& M College, Fort Collins, Colo。

(d) Theoretical; basic research.

e) Differential equations are being solved to yield the temperature distribution near the boundary of a cylinder. The cylinder is placed in the air fiow with its longitudinal axis perpendicular to the air stream with a line source of heat at its leading edge.

(g) Two functions in the series of functions describing the temperature field have been solved for the symmetrical case. 
(1320) EVALUATION OF RAINMAKTNG OPERATIONS IN COLORADO.

(b) Laburatory project; also sponsored by the Northern Colorado Natural Resources Associ: tion, Fort Collins, Colo.

(c) Prof. Sol D. Resnick, Colorado A \& M College, Fort Collins, Colo.

(d) Field investigation; applied research.

(e) The study is concerned with analyzing the attempt to increase precipitation and impr precipitation patterns by the artificial nucleation of clouds over North Central

Colorado. The methods of analysis being used are essentially the following (I) stat: tically studying precipitation on the target area and a control area; (2) comparing : pack on the target area and a control area, and (3) studying individual storms passir over the target and control areas.

(g) The results of the analysis indicate that there was no apparent increase in precipit: tion resulting from cloud seeding during the period March 1, 1951 to June 1, 1951 ov North Central Colorado.

(h) "Analysis of climatological data for the spring cloud-seeding period over North Cent Colorado." Colorado A \& M College Experiment Station, Fort Collins, Colo. July, $195:$

UNIVERSITY OF COLORADO, Hydraulics Laboratory, Department of Civil Engineering,

Inquiries concerning Projects Nos. 830, 1077, 1321 and 1322 should be addressed to Prof. Warren DeLapp, University of Colorado, Boulder, Colo.

(830) FLOW IN SHORT TUBES.

(b) Laboratory project.

(d) Experimental; basic research, for master's thesis.

(e) Tests are being made on a 2-inch smooth pipe with a square-edged entrance to study boundary layer development and energy losses. Pipes of other sizes will be used late

(f) Suspended.

(h) "Flow through a smooth short tube with a square-edged entrance." W. W. Carter, Maste Thesis, University of Colorado, June 1951. (Available on loan).

(1077) SPILLWAY CREST SHAPES.

(b) Laboratory project.

(d) Analytical; for design and master's thesis.

(e) Equations have been derived for spillway crest shapes and conduit intakes from experi mertal data.

(f) Completed.

(h) "Equations for concrete outlines of spillway crests and conduit intakes."

E. T. Sche Master's Thesis, University of Colorado, June 1951. (Available on loan).

(1321) ENERGY LOSSES IN OPEN CHANNEL TRANSITIONS.

(b) Laboratory project.

(d) Experimental; for design and master's thesis.

(e) Water surface profiles are being observed to determine the effects of the sidewall $\mathrm{fl}$. on the energy loss in rectangular open channels with subcritical velocities.

(f) Suspended.

(h) "Energy losses in rectangular open channel expansions." D. W. Newton, Master's Thesi University of Colorado, August 1951. (Available on loan.)

(1322) FLOW IN A DIVERGING SFCTION ON A STELP SLOPE.

(b) Laboratory project.

(d) Experimental; for design and master's thesis.

(e) Water surface profiles are being studied for various bottom slopes and various sidewa flares downstream from an ogee spillway. 
BIA UNIVERSITY, Fluid Mechanics Laboratory, Department of Civil Engineering.

Inquiries concerning Projects Nos. 60, 61, 62, 289, 290, 541, 1323, and 1324 should be addressed to The Director, Fluid Mechanics Laboratory, Department of Civil Engineering, Columbia University, New York 27, N. Y.

FLOW OF FLUIDS THROUGH GRANULAR (POROUS) MEDIA.

Office of Naval Research.

Theoretical and experimental; basic research.

To establish rational generalized expressions for permeability of porous beds consisting of grains of uniform or mixed sizes. The present phase is dealing with flow of air through beds of lead shot, sand, and gravel.

Measurements on flow of air through uniform lead shot (spheres) have been completed. Current work is on uniform sand to be followed by mixtures of various sizes.

ELECTROMAGNETIC VELOMETER.

Laboratory project.

Theoretical and experimental; basic research.

To develop instrumentation and technique to record manifestations of turbulence in

liquids and to measure detailed velocity distributions in boundary layers, separation zones, etc. The work concentrated on development of a device for measuring very low spot velocities. The possibility of using electrostatically charged molecules to measure velocities was explored.

Discontinued.

It was found possible to measure mean velocities of water flowing in a l-inch glass tube by both the electromagnetic method and by using electrostatically charged molecules as tracers.

HYDRAULIC STRUCTURES.

Office of Naval Research.

Theoretical and experimental; basic research.

Exploratory experimental work is planned for study of ( 1 ) boundary layer regimen in intake reaches of open channels, (2) flow patterns over beds curved in the vertical plane. Theoretical work on the development of the boundary layer in intake reaches of open channels has been completed.

SEPARATION PATTERNS IN THEIR RELATION TO LOCAL "FORM RESISTANCES".

Laboratory project.

Experimental; masters' theses.

Experimental work has been completed for the case of abrupt expansion of a pipe. A nozzle discharging into a pipe of larger diameter has been used. Pressure distribution downstream from the nozzle is measured. Tests have also been made with a spiral component of velocity artificially introcuced just before the nozzle.

Test work for 3 -masters' theses is complete. A further thesis is planned using a gradually expanding pipe for the test section.

HYDRAULICS OF SHORT OUTLETS IN BODIES OF DAMS.

Office of Naval Research.

Experimental.

The purpose of this study is to investigate the boundary layer regimen in outlet conduits. Pressure distributions along a nozzle and pipe will be measured by open manometers. A pitot tube will be used to determine mean velocity distribution. 
(5L1) PATTERNS OF FLOW OVER WEIRS OF STANDARD OGEE FORMS.

(b) Laboratory project.

(d) Experimental; basic research and design.

(e) To investigate the physical features of the flow phenomena and formulating a compreh sive basis for design, especially in regard to spillways under submerged conditions.

(1323) STUDY OF ENERGY EQUATIONS IN TURBULENT FLOW.

(b) Office of Naval Research.

(d) Theoretical; basic research.

(e) This study reviews various forms of the equations of motion and of energy for the get case of turbulent flow of a real fluid. Reduction of the equations for special case: discussed. Emphasis is on the physical interpretation of the various terms involved their correlation to experinentally measureable quantities.

(1324) LOSSES IN TWO-DIMENSIONAL TEES.

(b) Office of Naval Research.

(d) Theoretical and experimental; basic research.

(e) It is planned to study the flow patterns at junctions in rectangular conduits which c be considered two dimensional flow and the relation of the flow forms to the head los Preliminary tests to be mun with water in a duct 6 inches wide with a slit in the wa] to produce a two dimensional side jet.

UNIVERSITY OF CONNECTICUT, Hydraulic Research Laboratory, Department of Civil Engineoring.

(1078) HYDROLOGIC FACTORS INFLUENCING RAINFALI-RUNOFF RELATIONSHIPS ON SMALL WATERSHEDS IN EASTERN CONNECTICUT.

(b) Iaboratory project.

(c) Prof. K. C. Tippy, Box U-37, University of Connecticut, Storrs, Conn.

(d) Field investigation; applied research.

(e) Rain gages have been obtained and will be installed at various locations on the 4.5 square mile watershed of the Research Laboratory. Infiltrometers and I.ysimeters for isolation and measurement of the factors affecting runoff are being devised. Six add tional sites varying in size from 4 to 400 acres drainage area are being investigated

(1079) STUDY OF WIND EFFECTS ON STRUCTURES.

(b) Laboratory project.

(c) Mr. A. L. Mirsky, Box U-37, University of Connecticut, Storrs, Conn.

(d) Experimental; applied research.

(e) A study of wind action and flow on the roofs of various types of buildings and struct is to be conducted in a small wind tunnel.

(1080) STUDY OF HYDRAULIC DESIGN OF CURB INLETS.

(b) Laboratory project; requested by State Highway Department.

(c) Prof. V. Scottron, Box U-37, University of Connecticut, Storrs, Conn.

(d) Experimental; for design.

(e) Involves the hydraulic and structural design of the curb inlet type of catch basin, w: particular reference to the hydraulic efficiency of the grate now used by the State H: way Department. Half-scale models of highway gratings are under test. 
DESIGN OF A LOW-SPEED TWO-DIMENSIONAL WIND TUNNEL.

Laboratory project.

Mr. A. B. Barton, University of Connecticut, Storrs, Conn.

Experimental; for master's thesis.

A low-speed, two-dimensional. Wind tunnel has been completed for flow and pressure distribution studies.

Completed.

II UNIVERSTTY, School of Civil Engineering.

Inquiries concerning Projects Nos. 1085, 1087, 1088, and 1325 should be addressed to Prof. M. Bogema, and concerning Projects Nos. 1326, 1327, and 1328 to Prof. Andre L. Jorissen, School of Civil Engineering, Cornell University, Ithaca, N. Y.

DIAPHRAGM PUMP OPERATION.

Ace Pump Company, Memphis, Tenn.

Experimental; operation.

Study of corrective measures for reducing impact load on bearings due to water hammer.

WAVE TANK STUDIES OF BEACH STABILITY REIATED TO VARIOUS WAVE CHARACTERISTICS.

Office of Naval Research, Washington, D. C.

Experimental; basic and applied research.

To tie the changes in a beach condition, $i$. e. changes in its texture, its profile, and its firmness, to the characteristics of the waves acting on the beach and eventually to the prevailing weather conditions.

New criteria for the effect of waves on beaches have been established, The importance of wave frequency and previous beach condition has been brought out.

MODEL STUDIES OF THE DEVELOPMENT OF BEACH FORMS.

Office of Naval Research, Washington, D. C.

Experimental; applied research for master's thesis.

To investigate the effect of waves on various types of beaches.

Completed.

Influence of grain size and beach form studied.

Thesis for master's degree, completed.

SUBMERGED ORIFICES.

Laboratory project.

Experimental; master's thesis.

Investigation of discharge coefficients for small ( $\frac{1}{4}-1$ inch) square and circular sharp edged orifices under head differentials of 0.05 to 2.00 feet.

"Investigation of coefficients of discharge versus Reynolds numbers for small submerged orifices at low heads and the rate of diffusion of the jet." James Albert Rout, Master's Thesis, June 1951.

\section{DISCHARGE COEFFICIENTS OF HERSCHEL-TYPE VENTURI TUBES.}

Research Committee on Fluid Meters, American Society of Mechanical Engineers. Analysis.

To correlate avilable information on Venturi tube coefficients in view of obtaining average values suitable for use as standard.

Completed.

"Discharge coefficients of Herschel type Venturi tubes." A. L. Jorissen, Annual Meeting, ASME, Nov. 1951. 
(1327) STUDY OF FLOW METERING DEVICES FOR LOW REYNOLDS NUMBERS.

(b) Builders-Providence, Inc.

(d) Experimental; development; master's thesis.

(e) To develop devices for measuring rate of flow in pipe lines maintaining a constant efficient of discharge at low Reynolds numbers.

(g) Cylindrical nozzles have been found to maintain a constant coefficient of discharge lower Reynolds numbers than standard pressure difference devices. It is now sought decrease the pressure loss by adding a conical diffuser to the nozzles.

(h) "Discharge measurements by means of cylindrical nozzles." A. L. Jorissen and H. T. Newton, ASME annual meeting, Nov. 1951.

(1328) EFFECTS OF ROUGHNESS ON DISCHARGE COEFFICIENT OF FLCW-METERING DEVICES.

(b) Builders-Providence, Inc.

(d) Theoretical and experimental; doctor's thesis.

(e) To investigate the relationship between the conical shape of the velocity-distributi curve in turbulent rough pipe flow and the coefficient of discharge of flow metering devices.

(1329) A PHOTO-ELECTRIC METHOD FOR MEASURING AND RECORDING THE SUSPENDED SEDIMENT LOADS OF STREAMS.

(b) Laboratory project.

(c) Prof. L. Reid, School of Civil Engineering, Cornell University, Ithaca, N. Y.

(d) Experimental; master's thesis.

(e) To determine the effect of suspended sediment size and concentrations on the intensi of a transmitted beam of light, and on the intensity of the scattered light in a dir tion at right angles to the original light beam.

(f) Completed.

(g) Results showed that if average particle size is known the concentration can be deter mined in this manner.

(h) "A photo-electric method for measuring and recording the suspended sediment loads of streams." G. V. Pesce, Master's thesis, Sept. 1951.

(1330) DYNAMIC SIMILARITY OF SEDIMENT MOTION IN FLOWING FLUID.

(b) Laboratory project.

(c) Dr. N. A. Christensen, School of Civil Engineering, Cornell University, Ithaca, N. Y

(d) Experimental; doctor's thesis.

(e) Criterion permitting selection of sediments to be used in a model to predict the beh: of the sediments in the prototype was postulated and tested experimentally.

(f) Completed.

(g) The salient points of the investigation were: the emphasis on the terminal settling velocity of sediment as an index for sediment motion, the establishment of a criteric for dynamic similarity of sediment motion in flowing fluid, the development of the s: larity of flow patterns in the two sand separators.

(h) "Dynamic similarity of sediment motion in flowing fluid." King Yu, Doctor's thesis, Feb. 1952 .

GEORGIA INSTITUTE OF TECHNOLOGY, School of Civil Engineering.

Inquiries concerming Projects Nos. 291, 1331, 1332, 1333, and 1334 should be addresse Prof. C. E. Kindsvater, School of Engineering, Georgia Institute of Technology, Atlar

(291) FLOW OF WATER OVER HIGHWAY EYBANKMENTS.

(b) Laboratory project.

(d) Experimental; basic research. 
Tests on a 1:6_scale model of a typical highway embankment section have been completed. Preliminary tests on a $1: 12$ scale model are underway. Variables include roughness and shape of crown, slope and height of embankment. Data include discharge calibration, water-surface profiles, and tailwater levels corresponding to (1) free flow (2) incipient submergence, (3) lower limit of surface flow, (4) upper limit of plunging flow, and

(5) submerged flow.

Temporarily suspended.

\section{THE DIFFUSION MECHANISM OF FOREIGN PARTICLES IN A FLUID.}

Laboratory project sponsored by the University Center of Georgia.

M. R. Carstens, School of Civil Engineering, Georgia Institute of Technology, Atlanta, Ga. Experimental; basic research.

The diffusion of macroscopic foreign particles is being studied by means of the particle concentration in a vertical diffusion chamber. The spherical particle concentration is to be measured by the dispersion of a parallel light beam on a photo-electric cell. The spherical glass particles will be of sufficient size such that the difference in the diffusion of fluid particles and foreign particles can be studied in detail.

TRANQUIL FLOW THROUGH OPEN-CHANNEL CONSTRICTIONS.

Water Resources Division, Surface Water Branch, U. S. Geological Survey. Experimental; basic research.

Tests are being conducted on various simple forms of width-constrictions in level channels of various cross-sectional shapes. Flows are limited to the tranquil; range of boundary conditions governed by standard practice in bridge-waterway construction. Present investigation is confined to the discharge characteristics of the contracted channel. Future investigation will include an investigation of the total backwater effect.

A satisfactory analysis has been achieved for discharge through a wide variety of vertical-face obstructions.

MODIFICATION OF MARTIN DAM POWERHOUSE DRAFT TUBES.

Alabama Power Company.

Experimental; for design.

Proposed modifications to improve the performance of existing draft tubes will be investigated. Performance will be judged by the hydraulic efficiency of the draft tube as a diffuser, stability of flow pattern, and pressure and velocity distribution. Each model set-up will be tested for various degrees of initial whirl.

\section{DIAMETRIC OBSTRUCTIONS TO FLOW IN CIRCULAR CONDUITS.}

Laboratory project.

Theoretical and experimental; basic research for master's thesis.

A theoretical analysis of the energy loss due to small obstructions (e.g. rods, struts) in circular conduits will be checked in the laboratory. The effect of shape and relative size of the obstruction will be investigated as a function of fluid properties and upstream flow characteristics.

ARD UNIVERSITY, Department of Mathematics.

5) MATHEMATICAL THEORY OF WAVES.

b) Office of Naval Research, Department of the Navy.

c) Dr. Jack Kotik, 21 Vanserg Building, Harvard University, Cambridge 38, Mass.

d) Theoretical. 
(e) Non-periodic wave trains are studied mathematically, using harmonic analysis and st tistical methods. One purpose is to rigorize wave resistance theory. A comparison various methods of computing wave resistance is being initiated.

(h) "Fourier analysis of wave trains." G. Birkhoff and J. Kotik, to appear in Symposiu Gravity Waves, National Bureau of Standards, June 1951.

"Existence and uniqueness theorems for linear water waves." J. Kotik, Ph.D. Thesis Massachusetts Institute of Technology, 1952.

UNIVERSITY OF IDAHO, Engineering Experiment Station.

Inquiries concerning Projects Nos. 547, 548, and 1091 should be addressed to Prof. Warnick, College of Engineering, University of Idaho, Moscow, Idaho.

(547) STUDY OF PRINCIPLES, DEVELOPMENT, AND USE OF HIGH ALTITUDE PRECIPITATION GAGES.

(b) Laboratory project; cooperative with United States Army Engineers, Weather Bureau, Forest Service, and Bureau of Reclamation.

(d) Experimental; design and development.

(e) Tests conducted on movement of air around precipitation gages using sawdust to simu snowstorm conditions. Information is being sought regarding proper design of winds Precipitation gages have been installed at Mullan Pass, Idaho, and at Priest River perimental Forest to check the performance of various shield designs under actual 0 ing conditions against performance observed in the wind tunnel.

(g) Photographs obtained illustrating wind behavior with sawdust blowing around the gag with and without shields. Comparative catch tests made, using sawcust as a simulat snowstorm. Methods have been developed for studying theoretical true catch of sawd in model precipitation gages.

(h) "A wind tunnel for testing precipitation gages." R. L. Gardner, Idaho Engineer, Fe "Laboratory and field experiments with snow gages in Idaho." C. C. Warnick, Proc. Westerm Snow Conference, April, 1951.

(548) METHODS OF EVALUATING SEEPAGE LOSSES IN IRRIGATION CANAIS.

(b) Laboratory project; cooperative with Geological Survey and Bureau of Reclamation.

(d) Field investigation; applied research for development.

(e) Methods of measuring seepage losses are being studied using seepage meters, current meters, and volumetric measurements of loss from pondage sections. Unlined and com earth canals are being studied near Post Falls, Idaho, to provide better means of e ing seepage losses and to give data on the effectiveness of earth-lined canals.

(f) Completed.

(h) "Methods of measuring seepage loss in irrigation canals." C. C. Warnick, Bulletin I Engineering Experiment Station, University of Idaho, Oct. 1951.

(842) THE PROBLEMS AND LIMITATIONS OF SPRINKIING AS A METHOD OF APPLIING IRRIGATION.

(b) Laboratory project; cooperative with Soil Conservation Service and Bureau of Reclame Carried on under Agricultural Engineering Experiment Station.

(c) Prof. M. C. Jensen, Agricultural Engineering Department, University of Idaho, Moscok Idaho.

(d) Experimental and field investigation; design and operation.

(e) To develop a self-cleaning screen for sprinkler systems, and to determine hydraulic formance of current sprinkler system design. A cost study is also being made.

(f) Completed.

(h) "Costs of sprinkler irrigation on Idaho farms." M. C. Jensen and R. C. Bevan, Bulle 287, Agricultural Experiment Station, University of Idaho, Nov. 1951. 
AN ABSOLUTE VISCOMETER FOR NEWTONIAN FLUIDS.

Laboratory project; sponsored in the Mechanical Engineering Department.

Prof. N. F. Hindle, Mechanical Engineering Department, University of Idaho, Moscow,

Idaho.

Theoretical laboratory investigation; design and development for master's thesis.

e) To develop and construct an instrument to measure absolute viscosity.

f) Completed.

h) "An absolute viscometer for Newtonian fluids." R. D. LaRue, Master's Thesis, University of Idaho, May 1951. (Available on loan.)

1) A STUDY OF CANAL LININGS FOR CONTROLIING SEEPAGE LOSSES.

Laboratory project; cooperative with U. S. Bureau of Reclamation.

Field investigation; applied operational research.

e) A study is being made of the effectiveness and permanency of different types of canal linings by installing short test sections of lining in operating canals. Information is being obtained on permeability of soil before construction, and seepage loss before and after lining.

g) Two years of field study have been completed and much data collected on methods of placing linings, seepage losses, and performance of the test sections.

h) "A study of canal linings for controlling seepage losses." C. C. Warmick, Progress Report, Engineering Experiment Station, University of Idaho, Feb. 1951. (Mimeographed copies available on loan.)

"Studies in low-cost canal lining." Glenn Meares. Idaho Engineer, May 1951. "Experiments with prefabricated-asphalt linings for irrigation laterals." C. C. Warnick Western Construction, Nov. 1951.

\section{NOIS INSTITUTE OF TECHNOLOGY, Technology Center.}

1) FRICTIONAL RESISTANCE IN ROUGH PIFES.

b) Office of Naval Research, Department of the Navy.

c) Dr. V. L. Streeter, Illinois Institute of Technology, Technology Center, Chicago I6, III.

d) Experimental; basic research.

e) An investigation of the Darcy friction factor and of the velocity distribution in artificially roughened pipes at Reynolds numbers less than 50,000. Measurements are being made on $4-1 / 2$ inch aluminum pipe with machined square thread type roughnesses using oil as a working fluid. Three different relative roughnesses, each at several longitudinal spacings, are available for testing. Similar measurements for smooth pipe flow are also planned.

g) Measurements on the largest relative roughness, $E / D=0.0203$, have been completed, covering a range of Reynolds number from 1000 to 50,000 .

NOIS STATE WATER SURVEY DIVISION, PeOria.

Inquiries concerming Projects Nos. 556 to 560, incl., 845, and 1335 should be addressed to Dr. Max Suter, Engineering Research Subdivision, Illinois State Water Survey Division, Box 717, Peoria, IIl.

6) PERMEABILITY OF GRADED SAND MIXTURES.

b) Laboratory project.

d) Experimental; basic research. 
(e) The permeabilities of known mixtures of graded sand are measured to determine functic changes.

(f) Permeability tester was installed in Peoria Laboratory.

(557) TURBULENT FIOW THROUG GRANULAR MEDIA.

(b) Laboratory project.

(d) Experimental; basic research.

(e) Critical flow is determined to define conditions under which turbulent flow occurs ou side of well screens.

(f) Permeability tester installed.

(g) In flow through granular media, the Reynolds number cannot be calculated from ordinar formulas. By assuming a critical Reynolds number as existing at the determined criti flow conditiors, the corresponding pore size can be calculated. This has been done $i$ preliminary tests, but further work is needed to get a correlation with screen analys

(558) STUDY OF CAUSES AND PREVENTION OF SAND BOILS.

(b) Laboratory project.

(d) Field investigation; basic research.

(e) Sand boils occurring during floods in levied districts are mapped, classified, and sa pled. Also sampled are river and nearby well waters.

(g) From chemical analyses and temperature measurements it was found that the water flowi in typical sand boils (those free from pipe connections towards the river) is differe from the river water and similar to well water in neighboring wells. Such sand boils can be stopped from flowing by damming them up to a level that is below that of the river stage. They are not caused by leaks through the levee.

(559) ARTIFICIAI RECHARGE OF GROUND WATER.

(b) Laboratory project.

(d) Experimental laboratory and field investigation; basic research.

(e) Experimental pilot plant consists of river intake, control tower with chlorination an measuring devices, gravel pit with bottom 10 feet below river pool stage, sides and bottom covered with sand.

(f) Pit in operation October 4, 1951 and will operate during winter until river water get: warmer than what is desired for the ground water. Shut down during periods of high turbidity.

(g) Present results follow anticipated action. Results will also be checked on a model o: $1 / 8$ of pit.

(560) GROUND WATER INVESTIGATION IN THE PEORIA, ILLINOIS, DISTRICT.

(b) Laboratory project.

(d) Field investigation; basic research.

(e) To determine the ground water resources of the district, inventory of wells was made, including construction and logs of wells. Ground water levels are measured continuous pumpage data collected, river stages and rainfall recorded, chemical analyses for char in composition of ground water are made, areas of infiltration are determined, and al] data are correlated with consideration of local ground conditions.

(g) The existence of a recession was proven to be due to overpumpage and high local concen tration of pumpage. Remedial measures have been recommended.

(845) EXTENSION OF THEIS' NON-EQUIIIBRIUM THEORY FOR VARIABLE FLOW.

(b) Office project.

(d) Theoretical; basic research.

(e) Development of formulas that could be used for conditions of variable flow.

(g) Formulas developed for most important types of variable flow, but the series obtained not been calculated for wide ranges. 
GROUND WATER INVESTIGATION IN THE CHICAGO AREA.

Laboratory project.

d) Field study on variations of natural resources. Investigation of artesian well field with wells 1200 to 2200 feet deep, locally heavily pumped. Study of ground water level recession, interferences, transmissibilities, effect of additional demands.

Б) Results determine recession and give good data for future prediction.

h) "Chicago area water supply." Circular 29, State Water Survey, 1950, Midwest Engineer, February 1950.

\section{NOIS STATE WATER SURVEY DIVISION, Champaign.}

Inquirjes concerning Projects Nos. 551, 555, 561, and 1336 to 1342, incl., should be addressed to Mr. R. E. Roberts, Illinois Water Survey, Box 232, Urbana, IIl.

1) RUNOFF FROM SMALI WATERSHEDS.

b) Laboratory project, cooperative with U. S. Ceological Survey.

d) Field investigation; applied research, design.

e) Measurements are being made of watershed rainfall and stream flow, of stage, discharge over the spillway, and municipal pumpage on five small water supply reservoirs in Illinois.

g) Twenty-two years of continuous measuremerits completed. Data through 1946 published in Survey's Bulletin 38, p. 30 .

2) SEDIMENTATION OF ILIINOIS RESERVOIRS.

b) Laboratory project, cooperative with Soil Conservation Service and Illinois Agricultural Experiment Staticn.

c) Mr. J. B. Stall, Illinois State Water Survey Division, Box 232, Urbana, Ill.

d) Field investigation; applied research.

e) For design of water supply reservoirs, measurements of sediment accumulation have been made on sixteen lakes in Illinois. Sediment samples are being analyzed and complete surveys of watershed soil type, slopes, land use, and conservation practices are being made.

g) Results at Iake Decatur, Decatur, IIl., showed correlation between rate of sedimentation and land use on the watershed.

3) RADAR-RAINFALL PROJECT.

b) Laboratory project, cooperative with the Pfister Hybrid Corn Co., EI Paso, IIl.

c) Mr. G. E. Stout, Illinois State Water Survey Divisicn, Box 232, Urbana, III.

(d) Field investigation; basic research.

e) A radar installation is being used to track rainclouds, showing extent of each rain area and movement. Rainfall data are collected over a concentrated network of 31 rain gages and correlated with the radar for quantitative rainfall measurement. Movies are being made of the PPI scope.

g) Results indicate that radar will give an accurate picture of rainfalj extent. Radar was used for short period rainfall forecasts.

5) EVAPORATION IN ILLINOIS.

b) Laboratory project.

(d) Field investigation; applied research.

e) Measurements are being made of evaporation at three stations in northerm, central, and southern Illinois. Vapor pressure gradients are obtained at Four-Mile Crib in Lake Michigan and at Urbana.

g) One year's record at Four-Mile Crib indicated 41.7 inches evaporation for a period Sept. 1950-Aug. 1951 incl. Equipment at Urbana being rebuilt after laboratory study. 
(561) GROUND WATER INVESTIGATION IN THE EAST ST. LOUIS AREA.

(b) Laboratory project.

(d) Field investigation; basic research.

(e) To determine the ground water resources of the district, inventory of wells was made including construction and logs of wells. Ground water levels are measured continuo pumpage data collected, river stages and rainfall recorded, chemical analyses for ch in composition of ground water are made, areas of infiltration are determined, and a data are correlated with consideration of local ground conditions.

(g) The existence of a recession was proven in locally overpumped areas.

(843) GROUND WATER RESOURCES IN JO DAVIESS, STEPHENSON, AND CARROLL COUNTIES.

(b) Laboratory project.

(c) H. F. Smith, Illinois State Water Survey Division, Box 232, Urbana, Ill.

(d) Field investigation; applied research.

(e) To determine ground water resources of the area, water level contours of the sandstol aquifers, transmissibility and storage coefficients of the aquifers, quantity of wat, available were obtained.

(g) Data indicate that piezometric surface conforms generally with topography, with a 50 foot drop in about 30 miles with no apparent withdrawal. The sandstone aquifers are overlain with 100 to 300 feet and more of impervious limestone.

(844) GROUND WATER RESOURCES IN CHAMPAIGN COUNTY.

(b) Laboratory project.

(c) H. F. Smith, Illinois State Water Survey Division, Box 232, Urbana, IIl.

(d) Field investigation; applied research.

(e) To determine ground water resources of the county, water level contours of two glacie aquifers. Pumping tests to determine transmissibility, rates of flow into heavily pumped areas.

(g) Data show little, if any, communication between two glacial aquifers. Withdrawal in heavily pumped area exceeds recharge by 30 percent.

(1092) HYDROLOGIC CYCLE EVALUATION.

(b) Laboratory project; cooperative with the U. S. Geological Survey.

(c) G. E. Stout, Illinois State Water Survey, Box 232, Urbana, Ill.

(d) Field investigation; applied research.

(e) 55 raingages, 3 stream-gaging stations, 5 groundwater level recorders are being maint Data will be used in analyzing storm rainfall, runoff relationships on small watershe and effect of rainfall on the water table.

(g) Complete analysis of 3 years of storm rainfall data is being analyzed.

(1336) DESIGN OF A 60-FOOT TILTING FLUME.

(b) Laboratory project.

(d) Experimental;

(e) Design of a versatile flume for laboratory projects.

(1337) INSTRUMENTATION DEVELOPMENT FOR WELL TESTING.

(b) Laboratory project.

(d) Experimental.

(e) Development of a pressure recording gage to record well-level recession during a pumpi test. 
(8) DEVELOPMENT OF A RECORDING RAINFALL INTENSITY GAGE.

b) Laboratory project.

d) Experimental.

e) Development of a recording rainfall intensity gage which will use a smaller collector than the gages which have now been developed.

39) FLOW THROUGH POROUS MEDIA.

(b) Laboratory project.

(d) Theoretical.

e) A study of the application of Hatch's equation in the transition region.

10) PHYSICAL PROPERTIES OF FLUIDS.

(b) Laboratory project.

(d) Experimental;

(e) Investigations to determine if any measurable changes in physical properties occur in fluids during flow.

il) CORROSION STUDY.

(b) Laboratory project.

(d) Experimental.

(e) A basic study of corrosion occurring at the steel electrodes under flow through a twenty foot plastic tower.

42) STUDY OF CORROSION AND DEPOSITION RATES WITH DIFFERENT FLOW RATES.

(b) Laboratory project.

(d) Experimental.

(e) One-half inch pipes made of different materials are in service. Changes in flow due to corrosion and at constant head are being measured.

VERSITY OF ILLINOIS, Fluid Mechanics and Hydraulics Laboratory, Department of Theoretical and lied Mechanics.

Inquiries concerning Projects Nos. 562, 1093, and 1343 should be addressed to Prof. F. B. Seely, Department of Theoretical and Applied Mechanics, 214 Talbot Laboratory, University of Illinois, Urbana, Ill.

562) AN EXPERIMENTAL AND ANALYTICAI STUDY OF LAMTNAR FLOW AND THE CRITICAL VELOCI TY IN OPEN CHANNELS.

(b) Laboratory project.

(d) Basic research.

(e) A lucite channel 6 inches in crossssection and fifteen feet long and a glass walled channel 18 inches wide, 26 inches deep, and 30 feet long have been used to study the velocity distribution.

(f) Analysis completed and submitted for publication.

093) AN INVESTIGATION OF A NEW OPEN CHANNEL FORMULA BASED ON DIVENSIONAL ANALYSIS AND CORRELATION OF OPEN CHANNEL DATA WITH THAT OF CLOSED CONDUTTS.

(b) Laboratory project.

(d) Experimental and analytical. 
(e) Data have been collected on the flow of water in a triangular, variable-slope flume. These data have been used to make a dimensionless graph and also a comparison with established pipe flow data. Two roughnesses as well as the smooth channel have been investigated.

(g) Analysis completed and report is in preparation.

(1343) VELOCITY DISTRIBUTION STUDY IN A FLOOD-PLAIN CHANNEL.

(b) Laboratory project.

(d) Basic research.

(e) Data have been collected on quantities of flow varying from 1.59 to $11.5 \mathrm{cfs}$ in a fl, plain channel.

(g) Data being analyzed.

UNIVERSITY OF ILIINOIS, Hydraulic Engineering Laboratory, Department of Civil Engineering.

Inquiries concerning Projects Nos. 564 and 1094 to 1098, incl. should be addressed tc Prof. J. J. Doland, University of Illinois, Urbana, Ill.

(50́4) HYJROLOGY OF URBAN AREAS.

(b) Laboratory project; cooperative with Illinois Water Survey Division and U. S. Geologi Survey.

(d) Experimental and analytical; applied research and design.

(e) Fourteen recording rain gages, one evaporation station including recording dew-point device, one radar station, and two recording stream gaging stations are installed for determination of rainfall and runoff for an area of about eight square miles. Analyt investigation includes frequency analysis of rainfall intensity, area-depth relations for storms, ground-water depletion study, infiltration analysis, and unit-graph analy

(1094) STUDY OF HIGHWAY INLET BOXES AND DISCHARGE PIPE SHAPES.

(b) Laboratory project, cooperative with Illinois Division of Highways and U. S. Bureau 0 Public Roads.

(d) Experimental; basic research.

(e) Full scale inlet boxes of various sizes are being tested with C. I. bell, square, and rounded discharge pipes. Velocity of approach is varied to simulate different approa gutter grades.

(1095) SCALE MODEL STUDIES OF INLET BOXES.

(b) Laboratory project; cooperative with Illinois Division of Highways and U. S. Bureau 0. Public Roads.

(d) Experimental field; applied research, design.

(e) Model tests of inlet boxes with the aim of utilizing kinetic energy of the falling jet to obtain higher velocity discharge in connecting pipes. Temperature studies are beir conducted to determine the desirability of catch basins as heat reservoirs for winter grate operation.

(f) Inactive with the exception of temperature study.

(1096) FULL SCALE GUTTER TESTS.

(b) Laboratory project, cooperative with IIlinois Division of Highways and U. S. Bureau of Public Roads.

(d) Experimental; applied research.

(e) Determination of roughness coefficients for different degrees of surfacing on concrete gutters. 


\section{CORRECTION OF SCOUR BELOW TWO PIER HIGHWAY BRIDGE.}

Laboratory project, cooperative with Illinois Division of Highways.

Experimental, applied research.

A 1:50 scale model of an overflow bridge on flood plain of the Wabash River has been constructed to determine the cause of excessive scour downstream from the bridge. Remedial dikes and topography changes have been tested to determine their suitability.

RESERVOIR MODEL.

Laboratory project.

Experimental, basic research.

Model of triangular longitudinal section reservoir has been constructed for density current studies for various bottom slopes.

INSTITUTE OF HYDRAULIC RESEARCH, State University of Iowa.

Inquiries concerning Projects should be addressed to the following, all at State University of Iowa, Iowa City, Iowa:

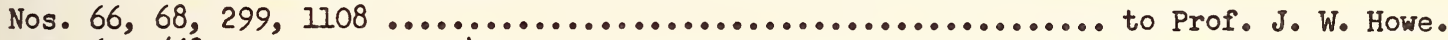
Nos. 69, 568, 1101, 1107, $1347 \ldots \ldots \ldots \ldots \ldots \ldots \ldots \ldots \ldots \ldots$ to Mr. Emmett M. Laursen.

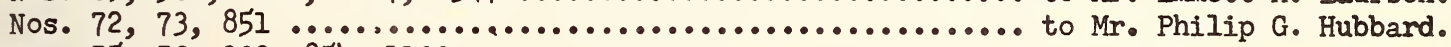

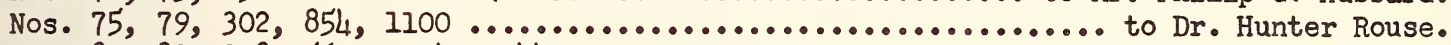
Nos. $81,82,298,567,1104,1344 \ldots \ldots \ldots \ldots \ldots \ldots \ldots \ldots \ldots \ldots$ to Dr. John S. McNown.

\section{HYDROLOGIC STUDIES, RALSTON CREEK WATERSHED.}

Cooperative with Department of Agriculture and Geological Survey.

Field investigation; applied research and masters' theses.

Study being made of relation between rainfall and runoff over a small area. Discharge from a 3-square mile area measured by Geological Survey; rainfall records at five automatic recording stations collected by Soil Conservation Service. Continuous records since 1924 of precipitation, runoff, ground-water levels, and vegetal cover. Yearly records available for examination at Iowa Institute of Hydraulic Research. Annual reports since 1924 available in files at Iowa Institute of Hydraulic Research.

\section{COOPERATIVE SURFACE-WATER INVESTIGATIONS IN IOWA.}

Cooperative with Geological Survey.

V. R. Bennion, Iowa Institute of Hydraulic Research, Iowa City, Iowa.

Field investigation; collection of basic stream-flow data.

Stream-flow and sediment measuring stations maintained throughout the State of Iowa cooperatively on a continuous basis. Records collected by standard methods of Geological Survey.

Records of stream flow and sediment discharge computed yearly.

Records contained in Water-Supply Papers available through offices of the Geological Survey.

\section{HYDROLOGIC STUDIES, RAPID CREEK WATERSHED.}

Cooperative with Department of Agriculture and Geological survey.

Field investigation; applied research and mastens' theses.

Study being made of relation between rainfall and runoff over a small area. Discharge from a 25-square-mile area measured by Geological Survey; rainfall records at four automatic recording stations collected by Weather Bureau. Continuous records since 1941 of precipitation, runoff, and ground-water levels.

2) Rainfall records published in Weather Bureau Climatological Bulletins and surface runoff and ground-water levels published in Geological Survey Water Supply Papers. 


\section{(69) RELATION OF SEDIMENT CHARACTERISTICS TO BED EROSION.}

(b) Cooperative with Office of Naval Research, Department of the Navy.

(d) Experimental; for doctor's thesis.

(e) To evaluate general relations between geometric and kinematic parameters of flow and $n$ size and grading of bed sediments for an arbitrary condition of scour. Selected geome cal proportions kept constant during all runs, the variables being the rate of flow, $t$ mean diameter and standard deviation of the sediment, and time and deptr of scour.

(72) ELECTRICAL ANALOGY OF THREE-DIMENSIONAL FLOW.

(b) Cooperative with Office of Naval Research, Department of the Navy.

(d) Experimental; basic research.

(e) An entire system of elliptical transitions from a reservoir to two-dimensional, axisym ric, and square pipes has been constructed and tested to give the significant boundary pressures.

(g) Transitions based upon ellipses having major to minor axis ratios of $1,1.5$, and 3 hav been constructed and tested for each of the pipes listed in (e) above, for a wide rang effective pipe diameters relative to the ellipse dimensions.

(73) MEASUREMENT OF TURBULENCE IN FLOWING WATER.

(b) Waterways Experiment Station, Corps of Engineers.

(d) Experimental development.

(e) To develop practical instruments for the field measurement of turbulence in flowing wa Instruments are planned to include a rigidly mounted unit for shallow water over a con siderable velocity range, a unit to be suspended on a cable for deep water, and a tape recorder for evaluation of means and root-mean-squares of three velocity components.

\section{(75) DIFFUSION OF SUBMERGED JETS.}

(b) Cooperative with Office of Naval Research, Department of the Navy.

(d) Experimental and theoretical; basic research and graduate theses.

(e) To provide information as to distribution of velocity and turbulence in two- and threedimensional submerged jets. The velocity distribution in an air jet with unlimited bor. ary was originally studied as a function of longitudinal and lateral distribution, velc of efflux and size of outlet, and results were reduced to dimensionless relationships. The distribution of turbulence is being studied in a similar manner with especial refer to the cavitation of submerged jets. The investigation is being extended to the diffus of flow under various related boundary conditions, in particular the hydraulic jump.

\section{CAVITATION.}

(b) Cooperative with Office of Naval Research, Department of the Navy.

(d) Experimental and theoretical; basic research and graduate theses.

(e) Basic information is sought on cavitation for systematically varied boundary conditions Studies are being conducted on high-velocity submerged jets, using underwater noise as criterion, to determine cavitation parameters. Tests are being made to evaluate the re tions between the cavitation index and temperature, relative velocity, and nozzle geome Determination is being made of the effect of relative spacing upon the pressure distrib. around a grid of equidistant cylinders mounted perpendicular to a steady, uniform, twodimensional flow. Previous measurements of the pressure distribution around various rol ellipsodial, and conical head forms are being extended to various angles of yaw.

(81) MATHEMATICAL ANALYSIS OF PRESSURE DISTRIBUTION.

(b) Office of Naval Research, Department of the Navy.

(d) Theoretical; basic research. 
Methods of applying irrotational-flow theory to problems of hydraulic design are being used to obtain information on specific problems. Pressure distributions around faired boundary forms are obtained mathematically, neglecting viscous effects and using both exact and approximate methods. Where possible, results are compared with experimental measurements determined in other studies. The relaxation technique has been applied to such problems as boundary transitions, jet profiles, the form of cavitation pockets, and the shape of spillway sections. Approximate methods of determining the body profile for a given pressure or velocity distribution have been developed.

"Approximation of axisymmetric body forms for specified pressure distributions." John S. McNown and En-Yun Hsu, Journal of Applied Physics, Vol. 22, No. 7, pp. 864-8, July 1951.

\section{HYDRAULICS OF MANIFOLDS.}

Laboratory project; originally sponsored by Committee on Hydraulic Research, Hydraulics

Division, A.S.C.E.

Experimental; for design and masters' theses.

Divided and confluent flow have been studied in a 2-inch smooth brass pipe with a single right-angle lateral to determine effect of discharge and diameter ratios on the changes in pressure at the junction. The effect of spacing in multiple-lateral manifolds and the pattern of flow and pressure variation in the immediate vicinity of the junction were studied. Comparisons have been made with the results of mathematical analyses.

Experimentation completed; preparation of final report in progress.

"Application of conformal mapping to divided flow." John S. McNown and En-Yun Hsu. Proc. of the Midwesterm Conference on Fluid Dynamics, J. S. Edwards, Ann Arbor, Mich., 1951 , pp. 143-155.

\section{FALL VELOCITY OF SEDIMENT.}

Laboratory project.

Experimental; basic research and masters' theses.

The effect of a cylindrical boundary and particle shape on the fall velocity of individual particles, and on concentration on the rate of settlement of sediment samples are being investigated. Velocities of spheres of various sizes, falling along the axes of vertical cylinders of selected diameters and through fluids of different viscosities, have been determined. For larger values of the Reynolds number, the drag force on a sphere fixed in a cylindrical conduit has been determined from measured pressure distributions and computations of the surface drag. The fall velocities for a variety of regular shapes have been determined. Measurements have also been made of the effect on the fall velocity of particle concentration in uniformly dispersed suspensions of sediment, using clouds of uniform sediment, as well as for the effect of a vertical wall or the mutual effect of two identical particles displaced horizontally.

"Particle shape and settling velocity." J. S. McNown, J. Malaika, and H. R. Pramanik. Proc. of Inter. Assoc. for Hydraulic Research, Bombay, Jan. 1951. (Publication pending.) "Drag of spheres within cylindrical boundaries." John S. McNown and John T. Newlin, presented at First American Congress of Applied Mechanics, June 1951.

"Particles in slow motion." John S. McNown, La Houille Blanche. (Publication pending.)

\section{DETERMINATION OF PRESSURE DISTRIBUTION CAUSED BY FLOW OF AIR OVER A SERIES OF THREE-} DIMENSIONAL BUILDING FORMS.

Cooperative with Office of Naval Research, Department of the Navy.

Experimental; applied research and masters' theses.

To determine pressure distributions on simple three-dimensional building forms of various proportions, for winds of different orientations. Extensive investigation of block-type buildings with gabled roofs, hangar-type buildings, and vertical walls completed. Master's thesis on effect of parapets on pressure around flat-roofed buildings completed. Study of effect of eaves now proposed.

Essentially completed. Eaves study suspended. 
(h) "Wind-tunnel studies of pressure distribution on elementary building forms." Chien Feng, Wang, and Siao, Nov. 1951. (Available from Iowa Institute of Hydraulic Resea \$1. 75 per copy.)

"Modification of pressure distribution around buildings due to parapets." Philip S Master's Thesis, State University of Iowa, June 1951. (Available on loan.)

(302) SEDIMENT SIZE ANALISIS BY MEANS OF PRESSURE DIFFERENTIALS IN STRATIFIED SUSPENSION.

(b) Laboratory project.

(d) Experimental; doctoral dissertation.

(e) To develop a technique for rapid size-frequency determination by measurement of pre differentials during relative motion between sediment and suspending liquid. Sampl introduced at top of a water-filled tube containing a pervious piston which can be placed along axis of tube. Piezometers at top of tube and just above piston permit differential pressure, and hence immersed weight of suspended sediment, to be recor during traverse of tube by piston.

(567) A STUDY OF FLOW OVER LATERAL SPILIWAYS.

(b) Laboratory project; originally supported by A.S.C.E. through J. Waldo Smith award.

(d) Experimental; applied research and masters' theses.

(e) Flow over a sharp-crested weir in one side of a rectangular channel is studied as a function of the channel and weir dimensions, the channel depth, and the Froude numbe the channel flow above the weir.

(f) Inactive.

(568) SCOUR AT BRIDGE PIERS AND ABUTMENTS.

(b) Iowa State Highway Commission and U. S. Bureau of Public Roads.

(d) Experimental; applied research.

(e) To investigate the effects of pier and abutment geometry, sediment properties, and s flow characteristics on the rate and pattern of scour, to the end of providing safe design criteria.

(g) Initial phase, the study of pier and abutment geometry, has been extended to various geometrical shapes. The second phase, the study of the effect of stream-flow charac istics, is continuing. The third phase, the study of sediment characteristics, has initiated.

(h) "An investigation of the effect of bridge-pier shape on the relative depth of scour. D. E. Schneible, Master's Thesis, State University of Iowa, June 1951. (Available o Report No. 2, "Scour around bridge piers and abutments, effect of velocity and depth flow." Nov. 1951. (Request should be made of the Iowa State Highway Commission, Am Iowa.)

"Model studies of scour around bridge piers." Jan. 1952. (Request should be made 0 Highway Research Board, 2101 Constitution Ave., Washington, D. C.)

(851) A CONSTANT-TEMPERATURE HOT-WIRE ANEMOMETER FOR THE MEASUREMENT OF TURBULENCE IN AIR.

(b) Office of Naval Research, Department of the Navy.

(d) Experimental; instrument design.

(e) The anemometer was designed to measure funciamental properties of turbulence in a low. velocity air tunnel, with special emphasis on simple operational techniques and high sensitivity at low frequencies. The aims were accomplished by utilizing carefully $d$ electronic control circuits and maintenance of the wire temperature at a constant le above that of the air stream.

(f) Reactivated.

(g) Improvements are contemplated which will lead to greater stability and a more nearly linear response to the magnitude of the velocity. 


\section{BOUNDARY-LAYER DEVELOPMENT ON SMOOTH AND ROUGH SURFACES.}

Office of Naval Research, Department of the Navy.

Experimental and theoretical; basic research and graduate theses.

Preliminary experimental investigation of the drag of smooth and rough surfaces in the low-velocity air tunnel, including boundary-layer development, turbulence, and drag, has been followed by tests on surfaces roughened by abrasive cloth, screen, and arrangements of cubes and of transverse bars. Boundary-layer studies are being supplemented by studies of established flow in a channel over similar surfaces. Investigations of the drag of smooth and rough surfaces has been completed. "An experimental investigation of the boundary-layer development along a rough surface." Walter L. Moore, Doctoral dissertation, State University of Iowa, Aug. 1951. (Available on loan.)

"A literature survey of boundary-layer development on smooth and rough surfaces at zero pressure gradient." W. D. Baines. (Available from Iowa Institute of Hydraulic Research.)

BOUNDARY-LAYER DEVELOPMENT ON STEEP SLOPES.

Waterways Experiment Station, Corps of Engineers. Experimental; basic research, for design and graduate theses. Tests are being conducted in a sloping flume below a spillway crest to determine the velocity distribution and boundary-layer thickness as a function of distance from the crest, discharge rate, angle of slope, and bottom roughness, to develop a means of predicting the location of the zone at which the turbulent boundary layer intersects the water surface and air entrainment begins.

Completed.

"The development of the turbulent boundary layer on steep slopes." William J. Bauer, Doctoral dissertation, State University of Iowa, Aug. 1951. (Available on loan.)

MOVEMENT OF SEDIMENT IN HIGHWAY DRAINAGE SYSTEMS.

U. S. Bureau of Public Roads and Iowa State Highway Commission. Experimental; for basic research and graduate theses.

A study of the movement of sediment in pipes, including the pattern of sand transport and the accompanying hydraulic energy losses; and a study of the effects of the geometry of sand traps on their efficiency in sediment removal.

A study of the transport in pipes flowing full has been completed and is now being extended to pipes flowing partially full. A study of two-dimensional sand traps has been completed and is being extended to three-dimensional traps.

"A study of the transportation of sand in pipes." John P. Craven, Doctoral dissertation, State University of Iowa, Aug. 1951. (Available on loan.)

"The effect of sand-trap proportions on the efficiency of operation." Aly Baligh, Master's Thesis, State University of Iowa, Aug. 1951. (Available on loan.)

HISTORY OF HYDRAULICS.

Laboratory project.

Simon Ince, State University of Iowa, Iowa City, Iowa.

Library research; for doctor's degree.

To trace the historical development of the important theories of hydraulics, covering the fundamental ideas of the science, the critical periods of development, and the contributions of personalities of major importance to this development.

ACCELERATED MOTION OF A SPHERE.

Laboratory project.

Experimental; basic research and doctor's thesis. 
(e) Force components on an accelerated sphere in a fluid were studied experimentally. oscillatory motion, these force components are being separated into the inertial e ive force and dissipative shear force. A study being made of the acceleration of particle falling freely from rest is intended to provide information concerning th diffusion characteristics of suspended sediment. Study is to be extended to inclu other shapes than the sphere and to obtain more detailed information concerning th steady pattern of flow around submerged bodies.

(1107) TRANSPORTATION OF SEIIMENT AS SUSPENDED AND TOTAL LOAD.

(b) Office of Naval Research, Department of the Navy.

(d) Experimental; basic research.

(e) To determine the suspended and total load as a function of hydraulic and sediment eters. Distribution of sediment, and total load will be measured. Effect of sedil transport on velocity distribution, energy loss, and other hydraulic characteristi will also be evaluated.

(1108) RELATION OF WATERSHED CHARACTERISTICS TO THE FORM OF THE UNIT HYDROGRAPH.

(b) Laboratory project.

(d) Analytical investigation; basic research, for master's thesis.

(e) A study was made of the relation of watershed characteristics of stream basins in Illinois and unit hydrographs for those basins, recently developed by the Geologic: Survey in cooperation with the State of Iowa.

(g) The compaction coefficient of the drainage area proved to have a good correlation the time base and the peak percentage of the distribution graph. The land slope is important factor in estimating distribution-graph properties for small watersheds.

(1344) CALCULATION OF FREE-STREAMLINE FLOWS.

(b) Laboratory project; partially sponsored by the Office of Naval Research, Department the Navy.

(d) Theoretical; applied research.

(e) Calculations are being made of various two-dimensional flows using the classical Helmholz-Kirchhoff method. Manifold flow with free and constricted lateral efflux, curved inlets and pier profiles, and the deflection and division of jets by symmetr and unsymmetrically placed vanes are being computed. The intended applications are the design of pipe and lock manifolds, the selection of appropriate profiles for in and the upstream portion of streamlined piers, and the more precise definition of $t$ behavior of Pelton wheel buckets.

(g) Excellent concordance in bulk characteristics has been found between results calcul for two-dimensional flow and those measured in pipe manifolds.

(h) "Application of conformal mapping to divided flow." John S. McNown and En-Yun Hsu. Proc. of the Midwestern Conference on Fluid Dynamics, J. W. Edwards, Ann Arbor, Mic. 1951, pp. 143-155.

\section{(1345) DESIGN OF HIGHWAY FILIS FOR SAFE OVERTOPPING BY FLOOD NATERS.}

(b) Iowa Highway Research Council.

(c) C. J. Posey, Engineering Building, Iowa City, Iowa.

(d) Experimental; applied research for design.

(e) Studies on methods of protecting fine material from erosion are being conducted in: flume in which velocity, depth of flow, and vertical pressure gradients through the can be controlled and measured and which permits close observation of modes of fail When the most economical method that gives promise of being effective has been detes full-scale embankments will be constructed and tested in a large flume.

(g) Tests have been made over a range of thicknesses of uniform-sized riprap, for varion sizes of angular crushed rock particles and of rounded gravel particles. Results $\mathbf{s} \epsilon$ to indicate that economical protection will require two or more layers of riprap of differing size classification.

(h) "Protection of earth embankments by riprap of uniform size." J. O. DeAbreu and W. E Morgan, Master's Thesis, State University of Iowa, Aug. 1951. (Available on loan.) 


\section{RESISTANCE COEFFICIENT OF PLASTIC PIPE.}

Yardley Plastics Company and Carlon Products Corporation. Dr. Walter Rand, State University of Iowa, Iowa City, Iowa. Experimental; applied research. Determination of the resistance coefficient as a function of the Reynolds number for $1 / 2,1,2$, and 4 inch plastic pipe of both rigid and flexible types.

MODEL STUDIES OF SAN JACINTO DAM.

Ambursen Engineering Corporation and City of Houston, Texas. Experimental; for investigation of design. Spillway discharge coefficients for free and submerged flow and efficiency of the stilling basin will be studied in a 1:15 model of one bay. Flow conditions downstream from the dam will be studied in a $1: 150$ model of the flood plain.

OHNS HOPKINS UNIVERSITY, Institute of Cooperative Research.

Inquiries concerning Projects Nos. 855, 856, and 1111 should be addressed to Dr. John C. Geyer, The Johns Hopkins University, Baltimore 18, Md.

\section{HYDRAULIC BEHAVIOR OF STORM SEWER INLETS.}

Baltimore City, Baltimore County, and the Maryland State Roads Commission. Experimental; basic research and design.

Model tests of curb, gutter, and combination inlets of various designs for inflow changes with street dimensions of grade, crown, and roughness. The design of the inlet itself, of the inlet depression, and of deflectors at the inlet are all under study.

To previous results from tests of curb and combination inlets has been added information on the use of deflectors with depressed curb inlets and results on various combinations of grate and curb inlets in which have been varied: (1) pattern of grate, (2) position of grate with respect to curb inlet, (3) length of depression above inlet. Deflectors on curb inlets produced high inlet efficiency which increased with street grade, but their behavior toward debris is still unknown. A feature of the design is that the combination of deflectors and depression produces a plane surface to traffic. Grates with longitudinal bars only are appreciably more efficient than grates with all transverse bars or a combination of the two. With combination grate and curb inlets, extending the depression length upstream from the inlet gives marked increase in inlet efficiency.

"Hydraulic behavior of storm drain inlets, Part I - flow into gutter inlets in a straight gutter without depression." Wen Hsiung Li, John C. Geyer and George S. Benton. Sewage and Industrial Wastes, Vol. 23, No. 1, pp. 34-46, Jan. 1951.

"Hydraulic behavior of storm drain inlets, Part II - flow into curb-opening inlets."

Wen Hsiung Li, Knut K. Sorteberg and John C. Geyer. Sewage and Industrial Wastes, Vol. 23, No. 6, pp. 722-738, June 1951. Reprints available.

\section{HYDROLOGY OF STORM DRATNAGE SYSTEMS IN URBAN AREAS.}

Baltimore City, Baltimore County, and the Maryland State Roads Commission.

Field investigation; basic research and design.

Study of rainfall and runoff relationsiip as affected by types and patterns of ground surface, length and degree of slope, shape of watershed, pattern of drainage ways. Rainfall and munoff records are being obtained from 8 urban areas differing in size and in the other pertinent factors listed above. From 7 of the 8 areas runoff is being gaged by stage measurements only, pending development of a suitable flow meter. 
(1III) DEVELOPMENT OF A FIOW GAGE FOR STORM SEWER DISCHARGES.

(b) Baltimore City, Baltimore County, and the Maryland State Roads Commission.

(d) Experimental; applied research.

(e) The development of gages for measuring both depth and velocity of the debris-laden, shooting flow commonly found in storm sewers. The search is for a method generally adaptable to existing storm sewers that does not require extensive alterations of $t$ sewer channel.

(g) A "Pigmy" type cup (Price) current meter in a special mount to give shielding agair debris has remained satisfactorily free from clogging during a four month trial per in a storm sewer. An electrical system for recording the rate of revolution of the cups is being developed; the depth of flow will be simultaneously recorded on the s chart.

THE JAMES LEFFEL AND COMPANY.

Inquiries concerming Projects Nos. 1348 and 1349 should be addressed to Mr. J. Robe Groff, The James Leffel and Company, 426 East Street, Springfield, Ohio.

(1348) HIGH HEAD FRANCIS TYPE TURBINES.

(b) Laboratory project.

(d) Experimental; applied research,-design, development.

(e) Development and testing of low speed Francis type turbines with special features ir. design for use in high head ranges.

(1349) TURBINE TESTTNG.

(b) Laboratory project.

(d) Experimental; applied research, design, acceptance.

(e) Testing of turbine models for customers and activities relating to improvements in design and operation of certain turbine types, draft tubes, and spiral cases.

\section{LEHIGH UNIVERSITY, Fritz Engineering Laboratory.}

Inquiries concerning Projects Nos. 90, 112, 1113, 1114, 1350, and 1351 should be addressed to Prof. M. B. McPherson, Department of Civil Engineering and Mechanics, Lehigh University, Bethlehem, $\mathrm{Pa}$.

(90) STUDIES OF PRESSURE VARIATIONS CAUSED BY BOUNDARY MISALIGNNENT IN THEIR RELATION TO CAVITATION IN HYDRAULIC STRUCTURES.

(b) A.S.C.E. Subcommittee on Cavitation and the Lehigh Institute of Research.

(d) Experimental; basic research; master's thesis.

(e) Determination of pressure variation as a function of approach velocity and head, an magnitude of misalignment. Study of pressure distribution along one surface of botl rectangular open channel and a closed conduit in which a transverse step of variabl, height has been placed, with the object of defining misalignment tolerances for hyd: structures.

(g) Studies of open and closed conduits have yielded distinct relationships between dif: ence in piezometric head, velocity head and height of misalignment.

(h) Report in preparation. 
MODEL STUDY OF THE HILIS CREEK DAM, PENNSYLVANIA, CHUTE SPILLWAY.

Laboratory project; major portion sponsored by F.H. Dechant, Consulting Engineer. Experimental; applied research; master's thesis. $1: 24$ scale model of a short spillway chute having a $45^{\circ}$ direction change; supercritical flow. Alternate designs investigated.

Completed.

Report and/or thesis available on loan.

A STUDY OF SHARP-CRESTED CIRCULAR WEIRS.

Laboratory project.

Experimental; undergraduate thesis.

Study of the effects of variations in head, approach depths and diameter. Weirs are circular in plan, radial in approach.

Experiments concluded. Report for publication under preparation.

MODEL STUDY OF FALL RIVER DAM, KANSAS, SPILLWAY.

Laboratory project; graduate problem.

Experimental; undergraduate instruction.

1:100 scale including approach area, apron, tailwater area and tainter gates. Experimental proving of Corps of Engineers design.

Completed.

Graduate student report available on loan.

PRESSURE DISTRIBUTION OVER MODEL SPILLWAY OF FALL RIVER DAM, KANSAS.

Undergraduate problem.

Undergraduate instruction.

1:60 scale model of spillway, center to center of piers. Pressure distribution defined for various heads, with and without piers.

Completed.

Undergraduate student report available on loan.

MODEL STUDY OF A DROP INLET SPILLWAY FOR WAYNESBORO, PENNSYLVANIA.

Sponsored by Gannett, Fleming, Corddry and Carpenter, Inc.

Experimental; design.

1:20 scale. Study of tower, elbow and stilling pool characteristics. Pressure distribution throughout conduit being investigated.

IANA STATE UNIVERSITY AND A \& M COLLEGE, School of Hydraulic Engineering.

THE EFFECT OF LENGTH ON PERFORMANCE CHARACTERISTICS OF DIFFUSERS.

Laboratory project.

Prof. T. M. Lowe, School of Hydraulic Engineering, Louisiana State University and A \& M College, Baton Rouge 3, La.

Experimental; basic research for master's thesis.

Tests are being made on two-dimensional rectangular expansions and uniform square expansion of various lengths. This study has resulted as the generalization of "Study of flaring outlet end of culvert to increase rate of discharge."

"The effect of length on performance characteristics of diffusers." Richard A. Smith, Master's Thesis, Louisiana State University and A \& M College, Aug. 1951. (Available on interlibrary loan.) 
(860) THE EFFECT OF THE ADDITION OF SODIJM CHLORIDE UPON THE FLOW OF WATER THROUGH A STAN] OTTAWA SAND.

(b) Cooperative with the U. S. Geological Survey.

(c) Prof. T. M. Lowe, School of Hydraulic Engineering, Louisiana State University and A College, Baton Rouge 3, La.

(d) Experimental; basic research for master's thesis.

(e) Tests are being conducted in a permeameter having a standard Ottawa Sand media. Sa. water of given concentrations is being used. This is a continuation of the study, "The effect of chloride content on flow through sand."

(g) Preliminary studies completed.

(h) "The effect of the addition of sodium chloride upon the flow of water through a stal Ottawa Sand." Hubert J. Tracy, Master's Thesis, Louisiana State University and A \& College, June 1952. (Available on interlibrary loan.)

(863) THE EFFECT OF VISCOSITY ON WEIR DISCHARGE COEFFICIENTS.

(b) Laboratory project in conjunction with engineers of the Waterways Experiment Statio

(c) Prof. Dwight L. Glasscock, School of Hydraulic Engineering, Louisiana State Univers and $\mathrm{A}$ \& $\mathrm{M}$ College, Baton Rouge 3, La.

(d) Experimental; applied research for master's thesis.

(e) Study of the effect of viscosity of model spillway discharge coefficients. Extensi of the study "The effects of surface tension on weir measurement with discussion of other secondary influences."

(g) Laboratory tests substantially completed.

(1352) INVESTIGATION OF FLOW THROUGH VERTICAL RECTANGULAR OPENINGS.

(b) Laboratory project.

(c) Prof. Dwight L. Glasscock, School of Hydraulic Engineering, Louisiana State Univers and A \& M College, Baton Rouge 3, La.

(d) Experimental; basic research.

(e) Investigation of flow through deep notches.

UNIVERSITY OF MARYLAND, Glenn L. Martin College of Engineering and Aeronautical Sciences.

(1353) HYDRAULICS OF MANIFOLDS.

(b) Laboratory project.

(c) Prof. J. B. Cournyn, University of Maryland, College Park, Md.

(d) Experimental; for design and masters' theses.

(e) The equipment is being built for the systematic investigation of several phases of phenomena of divided flow in pipes in view of developing hydraulic laws for divided 
HUSETTS INSTITUTE OF TECHNOLOGY, Department of Civil and Sanitary Engineering, jynamics Laboratory.

Inquiries concerning Projects Nos. 306, 307, 309, 311, 577 to 580, incl., 869, 1354, and 1355 should be addressed to Dr. A. T. Ippen, Hydrodynamics Laboratory, Department of Civil and Sanitary Engineering, Massachusetts Institute of Technology, Cambridge 39, Mass.

SCOUR AROUND BRIDGE PIERS.

Laboratory project.

Experimental; graduate research.

Qualitative study of scour patterns for various geometric arrangements of pile groups. Quantitative comparison of scour for single piles under various conditions of uniform sediment sizes. Plastic sediments in various colors and sizes are used to trace history of scour.

Inactive.

Systematic studies for various pile groups have been completed. A series of scour measurements with different bed materials and flow conditions are available which, however, need further extension with respect to grain size and hydraulic conditions. General conclusions not possible so far.

STABILITY OF FLOW STRATIFIED DUE TO DENSITY DIFFERENCES.

Laboratory project.

Theoretical and experimental; graduate research.

Theoretical analysis of instability at interface of density flow. Laboratory studies of criteria for mixing.

Comprehensive analysis of density flows on basis of gravity and inertia forces was compiled. Experimental study of underflow in reservoirs at equilibrium of gravity and viscous forces was carried out. Velocity distributions in reservoir and density current were determined. Critical state of flow beyond which mixing occurs was determined for a range of characteristic parameters. Shape of initial surge and its celerity were measured. Work to be continued with a wider reservoir to reduce wall effects.

"Steady state characteristics of subsurface flow." Arthur T. Ippen and Donald R. Harleman. Presented at Symposium on Gravity Waves, National Bureau of Standards, June 1951 (to be published).

\section{CHARACTERISTICS OF OSCILLATORY WAVES.}

Laboratory project.

Experimental; basic and graduate research.

Systematic investigation of forms and propagation of oscillatory waves. Development of techniques to record instantaneously wave forms, internal velocities, and pressures during passage of a wave.

\section{HYDRAULIC ANALOGY TO SUPERSONIC FIOW OF GASES.}

\section{U. S. Air Forces.}

Experimental; basic research.

Experiments on airfoils and related shapes in the high velocity water channel are conducted to explore the applicability of the hydraulic analogy in the transonic and supersonic regions. Various electronic and photographic methods of obtaining data are to be investigated.

In addition to the previous experiments with stationary models, present program involves use of towed models in stationary water. Tests on wedges in the transonic region for both steady and accelerated motion are under way. Instruments for recording lift and drag forces in moving models have been devised. The problem of obtaining water depth by stereoscopic means has been studied. 
(h) Part III, "Studies on the validity of the hydraulic analogy to supersonic flow." A. T. Ippen and D. R. F. Harleman, Air Force Technical Report No. 5985, 0ct. 1950. Part IV, (of above report), A. T. Ippen and H. G. Crossley, Jr., Jan. 1952. "Stereoscopic measurement of water surfaces." G. R. Higgins, M. S. Thesis, Aug. Is

(577) CHARACTERISTICS OF SOLITARI WAVES.

(b) Office of Naval Research, Department of the Navy.

(d) Experimental; graduate research.

(e) 1. Experimental investigation of solitary wave characteristics in a horizontal char for comparison with various mathematical theories. Measurements of attenuation dus bottom roughness. 2. Investigation of deformation and resulting characteristics of solitary wave in shoaling water.

(g) Phase 1 of the program is essentially complete. Results are being organized into: final report. Phase 2; Preliminary observations of deformation and breaking have 1 made. Determinations of internal particle motions with changing wave form are alsi under way.

(h) "Properties of solitary waves in channels of varying roughness." S. C. Stephan, J Sc.D. Thesis, Jan. 1952.

(578) TURBULENCE MEASUREMENTS WITH A PITOT TUBE-PRESSURE CELL COMBINATION.

(b) Office of Naval Research, Department of the Navy.

(d) Experimental; development of instrumentation.

(e) Studies of turbulence characteristics in open channel flow.

(g) A thorough analysis of all possible methods to measure and record instantaneous ve. ities and pressures has been completed. A combination of Pitot tube and electric citance pressure cell is presently employed to obtain the distribution of root meal square velocity fluctuations in a turbulent stream and to determine the growth of bulent boundary layers. Electronic circuits are being devised to obtain space and correlation coefficients directly.

(h) "Turbulence studies from recordings of instantaneous pitot-tube pressures." E. M. Jr. M. S. Thesis, June 1951.

(579) INVESTIGATION OF FLUID FRICTION IN UNSTEADY MOTION.

(b) Office of Naval Research, Department of the Navy.

(d) Experimental; basic research.

(e) The influence of unsteady flow on the characteristics of flow in conduits and past merged bodies is to be explored in a specially developed water tunnel.

(g) Experiments to determine the effects of acceleration on wall friction in a smooth $\mathrm{I}$ of uniform diameter are under way.

(h) "The unsteady flow water tunnel at M.I.T." J. W. Daily, K. C. Deemer, A. L. Kelle Hydrodynamics Laboratory Report No. 2, May 1951.

(580) FUNDAMENTAL RESEARCH ON METHODS OF AIR DISPERSION IN THE ACTIVATED SLUDGE PROCESS.

(b) U. S. Public Health Service.

(d) Experimental; basic research.

(e) The experimental apparatus with specially designed diffusers producing a uniform su of small diameter air bubbles has been constructed. An instrument to record contin the oxygen content of the water based on the principle of the mercury electrode met has been developed. Actual tests of oxygen transfer from uniformly distributed bub of constant frequency and diameter are now under way.

(h) "The continuous measurement of oxygen concentration in water during aeration proces A. T. Ippen, R. S. Yoseph, B. N. Posthill. Hydrodymamics Laboratory Report No. 3,

(869) TRANSIENT PERFORMANCE AND OPERATING STABILITY OF HYDROELECTRIC PLANTS.

(b) Laboratory project; previously sponsored by Research Corporation, New York.

(d) Theoretical and experimental. 
To develop methods of analysis for transient problems which are applicable to a wide To develop methods of analysis systems. An electronic analog computer is being used in the
variety of non-linear syalys of transient phenomena.

Current work includes analysis and electronic computation as well as laboratory work and use of field data on the hydraulic and governing stability of hydro units.

"Transient analysis of certain non-linear systems occurring in hydroelectric plants." H. M. Paynter, Sc.D. Thesis, June 1951.

THE MOTION OF DISCRETE PARTICLES ALONG THE BED OF A TURBULENT STREAM.

Laboratory project.

Experimental; graduate research.

To establish a more rational basis for the analysis of some of the complex bed-load phenomena. By use of discrete particles on beds of varying roughness the variables entering the experimental analysis are reduced to distinct sediment and stream characteristics for which analytical concepts can be postulated.

An analytical expression for incipient particle motion has been obtained in terms of the physical characteristics of the sediment, bed and hydrodynamic forces on the particle. Additional experiments to widen the range of the tests are proposed.

"A study of the motion of discrete particles along the bed of a turbulent stream."

R. P. Verma, Sc.D. Thesis, June 1951.

CAVITATION INCEPTION FOR STEADY MOTION.

Office of Naval Research, Department of the Navy.

Experimental; basic research.

Cavitation inception for steady motion is to be studied for systematic variations in

boundary layer development and in the turbulence level for the zone of minimum pressure.

CHUSETTS INSTITUTE OF TECHNOLOGY, Department of Mechanical Engineering.

Inquiries concerning Projects Nos. 881, 882, and 1356 to 1360, incl., should be addressed to Prof. A. H. Shapiro, and Projects Nos. 1363 to 1372, incl., to Mr. J. I. Shearer, Massachusetts Institute of Technology, Cambridge 39, Mass.

EFFECT OF SUDDENLY APPLIED LIQUID PRESSURE ON A METAL SURFACE.

National Advisory Committee for Aeronautics.

Prof. B. G. Rightmire, Massachusetts Institute of Technolgoy, Cambridge 39, Mass.

Experimental; student theses.

Repeated pressure suddenly applied by a liquid to a metal surface is believed to cause damage similar to that produced by cavitation. The effects of amplitude and steepness of the applied pressure wave are to be studied.

Serious deformation and damage to copper specimens are observed after a few thousand applications of stress of 5000 psi amplitude. Cold work extends as much as 0.03 in. beneath the surface. Cavitation may occur in the present apparatus. Precautions are being taken to eliminate it entirely.

"The effect on metal surfaces of steep-fronted pressure waves in liquids." D. D. Streeter. Master's Thesis, Massachusetts Institute of Technology, Sept. 1951.

RECOVERY FACTORS AND HEAT TRANSFER TO AIR FLOWING AT SUPERSONIC VELOCITIES IN A TUBE.

Office of Naval Research, Department of the Navy.

Prof. J. Kaye, Massachusetts Institute of Technology, Cambridge 39, Mass.

Experimental and analytical; basic research for M.S. and D.Sc. theses.

To obtain reliable data for heat transfer from a wall to a fluid moving at supersonic velocities and to determine recovery factors for the same mean stream conditions. The coefficients of friction for supersonic flow in a tube are also measured. 
(h) "Measurement of recovery factors and friction coefficients for supersonic flow of a in a tube." J. Kaye, J. H. Keenan, and R. H. Shoulberg. Presented in General Discussion on Heat Transmission, London, England, Sept. 1951.

"Measurement of recovery factors and friction coefficients for supersonic flow of a in a tube - Part I, apparatus, data, and results based on a simple one-dimensional model." J. Kaye, J. H. Keenan, G. M. Ketchum, K. K. Klingensmith, and T. Y. Toong. "Measurement of recovery factors and friction coefficients for supersonic flow of a in a tube - Part II, results based on a two-dimensional flow model for entrance re J. Kaye, R. H. Shoulberg, and T. Y. Toong. Presented at the A.S.M.E. Annual Meetir Atlantic City, N. J., Nov., 1951.

(881) EFFECT OF REYNOLDS NUMBER ON CALIBRATION OF IMPACT TUBE.

(b) Laboratory project.

(d) Experimental; basic research, for master's thesis.

(e) Measurements have been made to determine the effects of Reynolds number on the pres rise coefficient of an impact tube. A small impact tube was towed at various speec through liquids of different viscosity.

(f) Suspended.

(g) At high Reynolds numbers, the pressure-rise coefficient is unity, according to thec for an inviscid fluid. At low Reynolds numbers, the coefficient rises as the Reync number is decreased. At very low Reynolds numbers, the pressure-rise coefficient $T$ inversely with Reynolds number.

(h) "Experimental investigation of the effect of viscous forces upon pitot tube reading C. W. Hurd and K. P. Chesky, Thesis for degree of Naval Engineer, M.I.T. (1951).

(882) MIXING OF COAXIAL STREAMS.

(b) Bureau of Ordnance, Department of the Navy.

(d) Experimental; basic research for doctor's thesis.

(e) Experiments have been made to investigate the simultaneous transport of momentum, n and temperature between two coaxial moving gas streams.

(f) Completed.

(h) "The turbulent mixing of coaxial gas jets." F. Landis and A. H. Shapiro, Institut Heat Transfer and Fluid Mechanics, 1951.

"Momentum and mass transfer in coaxial gas jets." W. Forstall and A. H. Shapiro, Applied Mechanics, Vol. 17, No. 4, p. 319, 1950.

(III7) SUPERSONIC VORTEX-SOURCE FLOW.

(b) Laboratory project.

(c) Mr. Charles R. Faulders, Massachusetts Institute of Technology, Cambridge 39, Mass.

(d) Theoretical and experimental; applied research for doctoral thesis.

(e) An experimental investigation of the supersonic vortex flow to determine the rate 0 diffusion and the distribution of velocity and stream angle across the vortex. Fri effects, found to be significant, are being given theoretical consideration in orde corroborate the experimental results.

(1II8) RESEARCH ON CASCADES OF AIRFOIIS.

(b) General Electric Company and Westinghouse Electric Corporation.

(c) Prof. E. S. Taylor, Massachusetts Institute of Technology, Cambridge 39, Mass.

(d) Experimental and theoretical, for Sc.D. thesis.

(e) The three-dimensional flow downstream of a cascade of airfoils generated by the bou layer at the end of the aerofoils has been investigated experimentally and theoreti The understanding of this three-dimensional flow will help in the search for the re tion of the secondary losses in turbomachineries.

(g) Preliminary results on the behavior in the boundary layer region of the force coeff of the aerofoils, the effect of the boundary layer on the two-dimensional region of cascade is presented in the Gas Turbine Lab. Progress Report 2006-6. A simplified based on the perturbation method is included. 
USE OF RELAXATION METHOD TO DESIGN CHANNELS HAVING SPECIFIED PRESSURE DISTRIBUTIONS ON THE WALIS.

National Advisory Committee for Aeronautics.

Theoretical and experimental research, for doctor's thesis.

Theoretical methods have been worked out for the design of channel walls having specified pressure distributions. Experiments have confirmed the theory.

Completed.

"Design method for two-dimensional channels." John D. Stanitz, Sc.D. Thesis, 1951.

EFFECT OF COOLING ON THE STABILITY OF LAMINAR BOUNDARY LAYERS IN THE FLOW OF A GAS.

National Advisory Committee for Aeronautics.

Experimental and basic research, for doctor's thesis.

Experiments are being conducted to determine whether the transition to turbulent flow can be substantially delayed by cooling the surface past which the gas flows.

MOTION OF SUSPENDED PARTICLES IN A FLUTD UNDERGOING OSCILIATING MOTION.

Ultrasonic Corporation.

Experimental; basic research for master's thesis.

Small spherical particles are suspended in a liquid. The body of liquid is oscillated in simple harmonic motion and the motion of the spheres relative to the liquid is observed.

Measurements have been made and are being correlated.

EFFECT OF HEAT TRANSFER ON THE STABILITY AND TRANSITION OF LAMINAR BOUNDARY LAYERS IN LIQUID FLOW.

Office of Naval Research, Department of the Navy.

Theoretical and experimental; basic research for doctor's thesis.

A water boundary layer flows past a surface which is heated. The object is to determine whether this heating can substantially delay the transition from a laminar layer to a turbulent layer.

AIR ATOMIZATION OF LIQUIDS AT SUPERSONIC SPEEDS.

Laboratory project.

Experimental; for master's thesis.

Experiments are being conducted to investigate the atomization which occurs when a liquid stream is injected into a supersonic air stream.

\section{SUPERSONIC HEAT TRANSFER TO A FLAT PLATE.}

Office of Air Research.

Prof. John Markham, Massachusetts Institute of Technology, Cambridge 39, Mass. Experimental and analytical; basic research for M.S. and D.Sc. theses.

The objective of this project is to determine experimentally the coefficients of heat transfer to flat surfaces, including the case of wind tunnel walls, for a flow of air at Mach numbers of 1.5 to 3 and higher. The experimental study will cover both the laminar and turbulent boundary layer cases and probably the effect of surface roughness. Analytical work will be done for most of these variables.

FRICTION REDUCTION IN A HYDRAULIC SERVO VALVE.

Laboratory project.

Mr. Gerhard Reethof, Massachusetts Institute of Technology, Cambridge 39, Mass. Experimental; applied research for master's thesis.

The reduction of breakaway friction in hydraulic servo valves by the use of nonferrous metals and sintered tungsten carbide for sleeve materials with a tool steel spool. 
(f) Completed.

(g) Tungsten carbide sleeve with steel spool resulted in reduction of starting frictior. 40 percent as compared with steel sleeve and steel piston. Beryllium copper sleeve resulted in 30 percent reduction.

(h) "Friction reduction in a hydraulic servo valve." Norman M. Edelson, M.S. Thesis, Massachusetts Institute of Technology, May 1951.

(1363) ELECTRONIC ANALOG INVESTIGATION OF HYDRAULIC RELIEF VALVES.

(b) Laboratory project.

(d) Experimental; applied research for master's thesis.

(e) To investigate single stage and two stage relief valve response within conventional hydraulic systems by analytical methods for the simplest cases and by electronic ar. methods for the simple and more complex systems.

(f) Completed.

(g) Good correlation between analytical, analog, and experimental results. Work shows electronic analogy offers promise in study of industrial hydraulic systems.

(h) "The electronic analog investigation of hydraulic relief valves." H. C. C. G. Brie M.S. Thesis, Massachusetts Institute of Technology, 1951.

(1364) INVESTIGATION OF STEADY STATE AXIAL FLOW FORCES ON CONTROL VALVE PISTONS.

(b) Bureau of Ordnance, Department of the Navy.

(d) Theoretical and experimental; basic and applied research.

(e) A theory is given of the origin of the steady-state force exerted upon a piston by flowing past its comer. Brief referencé is made to a considerable body of experin evidence in support of that theory, and there is described a practical constructior. which very nearly eliminates that force. See abstract in Report No. 65 (Meteor).

(f) Completed.

(g) Good agreement of theory and experiments. Practical means was found to greatly rec flow forces.

(h) "Contribution to hydraulic control, Part I, steady state axial forces on control va pistons." S. Y. Lee and J. F. Blackburn, ASME Paper No. 51-A-59.

(1365) INVESTIGATION OF TRANSIENT FLOW FORCES ON CONTROL VALVE PISTONS.

(b) Bureau of Ordnance, Department of the Navy.

(d) Theoretical and experimental; basic and applied research.

(e) An outline is presented of a theory of a transient force which is one likely cause oscillation of control valves, with supporting experimental evidence and methods of eliminating it.

(f) Completed.

(g) Good agreement of theory and experiments.

(h) "Contributions to hydraulic control, Part II, transient flow forces and valve stabi: S. Y. Lee and J. F. Blackburm, ASME Paper No. 51-A-60.

(1366) STUDY OF LATZRAL FORCES ON HYDRAULIC PISTONS CAUSED BY AXIAL LEAKAGE FLOWS.

(b) Bureau of Ordnance, Department of the Navy.

(d) Theoretical and experimental; basic and applied research.

(e) A theoretical study of axial leakage flow phenomena is presented and experimental wc was conducted to substantiate the theory.

(f) Completed.

(g) Good correlation of experiment with theory.

(h) "Lateral forces on hydraulic pistons caused by axial leakage flows." Helmot E. Webt S.M. Thesis, Massachusetts Institute of Technology. 


\section{THE HYDRODYNAMICS OF FLOW REGULATION.}

Laboratory project.

Theoretical and experimental; basic research for Sc.D. Thesis.

General theoretical and experimental investigation of various flow control devices. Completed.

Good correlation of theory and experiment.

"The hydrodynamics of flow regulation." Fredric F. Ehrich, Sc.D. Thesis, Massachusetts Institute of Technology.

DEVEIOPMENT OF A MINIATURE STRAIN-GAGE PRESSURE PICKUP TO MEASURE RAPIDLY CHANGING PRESSURES.

Bureau of Ordnance, Department of the Navy.

Theoretical and experimental; design and development.

To provide a means of measuring dynamic pressures in hydraulic circuits, an extremely small pressure sensitive capsule was wound with Formvar covered cupron resistance wire (.001l in. dia.) and bonded with Formex varnish. The complete pickup with shield attached measures about $1 / 2$ in. dia. $x 1$ in. long. A No. 6-32 male threaded fitting with an "O" ring seal is used to connect into the hydraulic circuit. The windings in the pickup comprise two arms (one active and one dummy) of an electric four arm bridge, and the output of this bridge may be measured directly by a galvanometer or amplified and then displayed on the screen of a cathode ray oscillograph.

Models built for various pressure ranges have given satisfactory service in laboratory work.

Report in preparation.

\section{STUDY OF THE BALANCED FLAPPER VALVE BRIDGE.}

Bureau of Ordnance, Department of the Navy.

Theoretical and experimental; basic research.

A four arm hydraulic bridge operating from a constant pressure supply and consisting of fixed orifices in the upstream arms and balanced flapper type variable orifices in the downstream arms was investigated theoretically. The theoretical investigation included a study of the flow characteristics of the bridge with a general load and the forces required to actuate the flapper orifices. Experimental work was conducted to substantiate theory.

Completed.

Good agreement of experiments with theory.

Report in preparation.

\section{A STUDY OF THE FLAPPER VALVE.}

Laboratory project.

Theoretical and experimental; basic research for master's thesis. A study was made of a single nozzle-flapper type variable orifice. An analysis of the flow pattern was made by classical methods. Experimental apparatus was built to check the theoretical work and various nozzle sizes were used to obtain experimental data. Completed.

Good agreement of experiment with theory for small openings of the valve. "A study of the flapper valve." Fredric F. Ehrich, M.E. Thesis, Massachusetts Institute of Technology, Cambridge, Mass. Sept. 1950.

DEVELOPMENT OF THE FLAPPER VALVE-PRESSURE FOLIOWER HYDRAULIC SERVOMOTOR.

Bureau of Ordnance, Departinent of the Navy.

Theoretical and experimental; for design and development. 
(e) A two stage servomotor has been designed and built employing a small balanced flapk valve bridge as the pilot stage and a set of pressure follower pistons as the power stage to drive a hydraulic ram. The low power level pressure output developed in $t$ pilot stage is transformed into a high power level output by the pressure follower the valve. Ram position is measured by a linear differential transformer and a cor. tional closed loop control system employing electronic feedback is used. A barium titanate bi-morph bender is used to actuate the flapper in this design.

(g) Good correlation of experimental results with original objective. The constructior employed is quite simple to manufacture, service, and repair.

(h) Report in preparation.

(1372) DEVELOPMENT OF A FLAPPER-TYPE HYDRAULIC FLOWMETER.

(b) Bureau of Ordnance, Department of the Navy.

(d) Theoretical and experimental; for design and development.

(e) Previous work with the flapper valve indicated that it could be used as a calibrate orifice to measure the flow of "incompressible" hydraulic fluids. In the design en here, the flapper (a flat plate) is held against the face of a sharp edged nozzle $b$ constant force spring, thereby creating a variable orifice with a pressure drop whi invariant with flow rate. Because of the constant orifice coefficient attainable w this configuration, the flapper position is a very good measure of flow rate for a fluid of constant density. Flapper position is indicated as the electric voltage d veloped by a linear differential transformer.

(g) A working model was built of the design outlined above. The experimental data chec closely with theory and the curve of flow vs flapper position is linear to a flow 0 about $4 \mathrm{gpm}$.

(h) Report in preparation.

(1373) THE DESIGN OF A HYDRAULIC ORIFICE FLOW CONTROLLER.

(b) Laboratory project.

(c) Mr. Robert W. Mann, Massachusetts Institute of Technology, Cambridge 39, Mass.

(d) Theoretical; for design and master's thesis.

(e) The design of a valve-controlled hydraulic position servomechanism with electrical feedback and controls. The system is used in glass pressware production to divide stream of molten glass into discrete gobs of precise weight and shape which are thel molded in a pressing operation. The design features flexibility of control to perm: application to a wide range of gob weight and glass conditions.

(1374) SHEAR FLOW IN BENDS.

(b) Office of Naval Research, Department of the Navy.

(c) Mr. Hans Eichenberger, Massachusetts Institute of Technology, Cambridge 39, Msss.

(d) Theoretical and experimental; for Sc.D. thesis.

(e) Theoretical study of flow through bends with an initial stagnation pressure variatic similarly met in axial flow compressors. Experimentally the flow through a rectangu bent duct has been studied when the approach flow has a stagnation pressure distribu of fully developed turbulent flow. A similar experimental study with air having an stagnation pressure distribution met with in axial flow compressors is in progress.

(g) A theory has been developed which allows calculation of the magnitude of the seconda flow in a bend or in a cascade.

(1375) EFFECT OF INLET PIPE GEOMETRY ON VOLUMETRIC EFFICIENCY OF A FOUR-STROKE TNTERNALCOMBUSTION ENGINE.

(b) The Texas Company.

(c) Prof. C. F. Taylor, Massachusetts Institute of Technology, Cambridge 39, Mass.

(d) Experimental. 
Study of dynamic effects due to fluid inertia and pressure waves in inlet pipe. Flow measurements and pressure-time records in pipe and cylinder. Variables are length and diameter of pipe, speed of engine, valve flow capacity, and valve timing.

Effects are appreciable. Largest factor appears to be the kinetic energy of the inlet air column.

RSITY OF MICHIGAN, Lake Hydraulics Laboratory.

TESTS ON HARBOR MODETS.

Waterways Experiment Station, Corps of Engineers.

Prof. E. F. Brater, 320 West Engineering Building, Ann Arbor, Mich.

Experimental; applied research.

To determine the best harbor arrangement to provide refuge for small draft vessels at Harrisville, Michigan. Tests are being conducted on an undistorted fixed bed model, scale ratio $1: 75$.

Completed.

"Model study for harbor of refuge for light draft vessels at Harrisville, Michigan". Univ. of Michigan Lake Hydraulics Laboratory Technical Report No. 4.

OBSERVATIONS ON THE DIFFRACTION AND REFRACTION OF WAVES.

Research; for doctoral thesis.

Prof. M. S. Priest, 1103 Triphammar, Ithaca, New York.

It is expected that information obtained may find practical application in the design of harbors.

Waves were projected through an opening in an enclosure. The wave characteristics were measured at various locations within the enclosure.

INSTANTANEOUS CREATION OF ARTIFICIAL HARBOR ROADSTEADS ON SANDY COASTAL AREAS.

b) The Horace H. Rackham School of Graduate Studies.

c) Dr. V. Merkys, 322 West Engineering Building, Ann Arbor, Mich.

d) To study methods of temporarily decreasing the height of waves over limited coastal areas. Tests will be conducted on a model.

ERSITY OF MICHIGAN, Experimental Naval Tank.

Inquiries concerning Projects Nos. 585, 1124, 1127 to 1129, incl., and 1378 should be addressed to Prof. L. A. Baier, 326 West Engineering Building, University of Michigan, Ann Arbor, Mich.

\section{RESISTANCE OF BARGE TOWS.}

) Corps of Engineers, Department of the Army.

d) Experimental; design.

e) Tests are made to determine resistance of several formations of certain barge types relative to non-restricted straight channels and to selected channels restricted in width and depth. Each run will consist of movement of one model formation, at one draft and one depth of water for a given channel condition through a range of velocities sufficient to define a curve of functions of resistance versus velocity. 
(1124) BARGE DESIGN AND FLOTILLA ARRANGEMENTS.

(b) St. Louis Shipbuilding and Steel Company.

(d) Experimental; design.

(e) Tests are being conducted for the development of barge forms and arrangements of flc tillas for improvement in river operation.

(1127) TRANSOM IMMERSION ON HIGH-SPEED MOTORBOATS.

(b) Laboratory project.

(d) Research; design.

(e) Tests are being conducted to determine the most efficient transom immersion for varj high speed hull forms.

(1128) COMMERCIAL VESSEIS, 150 to 250 FEET IN LENGTH.

(b) Fairbanks, Morse and Company.

(d) Experimental; design.

(e) A large family of hull forms is being tested in order to provide design data for the future design of commercial vessels, 150 to 200 feet in length.

(1129) BARGE DESIGN AND FLOTILLA ARRANGEMENTS.

(b) Army Transportation Corps.

(d) Experimental; design.

(e) Barge tests are being conducted to determine the most efficient flotilla arrangement for various operating requirements.

(1378) VIBRATION ELIMINATION.

(b) Laboratory project.

(d) Experimental.

(e) Design and testing of fins fitted to single screw hulls in way of propeller aperture order to eliminate fantail vibration.

MISSISSIPPI STATE COLLEGE, Engineering and Industrial Research Station.

Inquiries concerning Projects Nos. 4, 5, and 891 should be addressed to Dr. Harold Flinsch, Box 365, State College, Miss.

(4) DEVELOPMENT OF SURFACE WAVES BY WIND.

(b) Laboratory project.

(d) Theoretical and experimental research.

(e) Research on the theories of surface wave origin and growth, on measurements in the la atory and in nature, and on the comparative results of theory and measurement.

(g) Tests with beaches are in progress.

(5) SHIP STABILITY AND ROLLING PERIOD.

(b) Laboratory project.

(d) Theoretical and experimental research.

(e) Exact and approximate formulas determining certain characteristics of ships, such as rolling period, metacentric height, etc., are compared with the results of experiment on ship models.

(g) Preliminary experiments have been performed on a basic model, and some of the results assembled in a brief report. 


\section{A STUDY OF HEATED FLOW.}

Iaboratory project.

Theoretical and experimental research.

The effect of heating on the flow characteristics of various fluids is to be studied.

JURI SCHOOL OF MINES AND METALLURGY, Department of Civil Engineering.

Inquiries concerning Projects should be addressed to the following, all at the Missouri School of Mines and Metallurgy, Rolla, Mo.

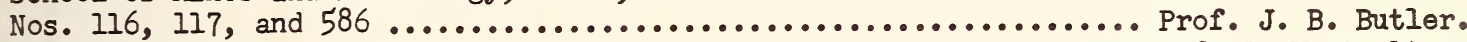

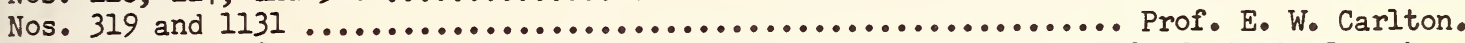

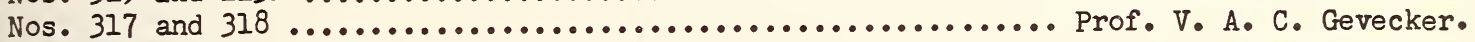

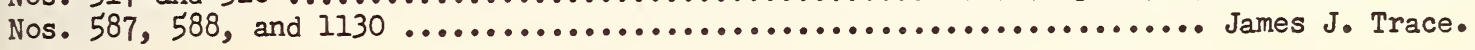

FLOW THROUGH SMALL LOW HEAD SIPHONS.

Laboratory project.

Experimental; for student demonstration.

Tests have been made on siphons of various materials, noting discharge, friction loss, and peak suctions.

Temporarily discontinued.

STUDY OF SUCTION IN TUBES AND SMALL HYDRAULIC APPLIANCES ESPECIALLY AS LIMITED OR AFFECTED BY ADHESION AND COHESION OF WATER.

Laboratory project.

Experimental; for student demonstration.

Tests have been made on several small suction devices noting effect of adhesion and cohesion of water.

Temporarily discontinued.

VELOCITY STUDIES IN A VERTICAL PIPE FLOWING FULL.

Laboratory project.

Experimental; basic research for master's thesis.

Tests were conducted on vertical flow in $1 / 2$ inch hard-drawn copper pipe to investigate flow with pipe flowing full and under positive pressure.

Temporarily suspended.

Further studies using other pipe diameters and pipes of other materials are contemplated.

FLOW THROUGH PIPE TRANSITIONS.

Laboratory project.

Experimental; basic research.

Tests on various shaped transitions were made noting discharge and friction loss.

Temporarily discontinued.

WEIR STUDIES.

Laboratory project.

Experimental; basic research for master's thesis.

Tests on rectangular weirs were made to determine effect of velocity of approach on the relation between crest depth and critical depth of an imaginary open channel having same dimensions as the weir opening.

Suspended. 
(g) Study produced a simple, accurate, and quick solution for plotting of $M$ function. $R$ lationship between the $M$ function and the critical depth is logarithmic. This great simplifies determination of critical flow where the critical depth is known or vice versa. A relationship exists between $M$ function of channels of same shape but diffe dimensions. The velocity of approach does not affect the relationship between physi depth and crest depth.

(h) "Calibration of weirs by means of critical flow and specific energy." R. A. Rapp, Master's Thesis, Missouri School of Mines, 1950. (Available on loan.)

(586) FLUID FION IN PIPES.

(b) Laboratory project.

(d) Library research; basic research for master's thesis.

(e) A study of the various formulas for solution of problems on fluid flow in pipes is being made. A correlation of the categories of roughness recommended by Prof. E. W. Schoder of Cornell. University for use in the "exact type" exponential formula with tl relative roughness curves of Nikuradse used in determining the Reynolds number fricticn factor relationship is being undertaken.

(f) Completed.

(g) A selected bibliography has been assembled. Thesis written.

(587) CROSS-SECTIONAL STREAM VELOCITY IN PIPES.

(b) Laboratory project.

(d) Experimental; basic research.

(e) For studying velocity distribution in pipes, data are obtained by a Pitot tube for a wide range of velocity heads. The equation for the velocity profile is determined $f c$ each overall velocity head and then compared with equations for other velocity heads. The parameters of the equations are also compared.

(f) Discontinued.

(588) SMALL AUGER TYPE TURBINES OPERATING OVER A LARGE RANGE OF HEADS.

(b) Laboratory project.

(d) Experimental; basic research.

(e) Using a 6-inch Auger type runner designed for a 12-foot head and having adjustable bl the efficiency, specific speed, and horsepower output are being studied for each head and setting of the blades. The application of small water turbines in the local stre around Rolla is being studied which necessitates a knowledge of the practicability of using one model of a water turbine for all installations for small output.

(f) Discontinued.

(1130) EFFECT OF FLUID INTRODUCTION ON VENTURI TUBE CHARACTERISTICS.

(b) Laboratory project.

(d) Experimental; basic research.

(e) Study of liquid and gas flow in Venturi tubes with the introduction of fluid at the negative pressure point. Operating characteristics are determined for this condition, using a 2-inch Venturi tube for water with the introduction of water. The characteris of a 6-inch Venturi tube with air as the medium are being obtained.

(f) Discontinued. 
I NEWS SHIPBUILDING AND DRY DOCK COMPANY.

Inquiries concerning Projects Nos. 123, 124, 896, 901, and 1132 to 1137, incl., should be addressed to Mr. C. H. Hancock, Hydraulic Laboratory, Newport News Shipbuilding and Dry Dock Company, Newport News, Va.

HYDRAULIC TURBINE TESTS.

Laboratory project.

Experimental; for design data.

Scale model turbines, using either Francis or propeller type runners, are tested for power and efficiency at various speeds.

METER CALIBRATION TESTS.

Laboratory project.

Experimental; to establish calibration curve for determining correction factors for various rates of flow.

Meters are tested at various heads and rates of flow by the weighing tank method. Time is recorded electrically by chronograph.

VANE MOMENT TESTS ON ADJUSTABLE BLADE RUNNERS.

Laboratory project.

Experimental; for design data.

Tests are to determine vane moment diagrams. The turbine load is applied by an electrical dynamometer and the gate openings are controlled by a governor. The blades adjust automatically and the blade moment is measured by a spring dynamometer.

SHIP MODEL RESISTANCE TESTS.

Laboratory project.

Experimental; for design data.

Scale ship models are towed to determine the effective horsepower, bare hull, required by the ship. Because of their small size, several models may be towed in a short period of time thus allowing much preliminary work to be done on the choice of lines. The final lines are checked by the David Taylor Model Basin. To eliminate a large portion of this preliminary testing, a schedule of systematic models was arranged in which the beam-draft ratio, the displacement-length ratio, and the prismatic coefficient are varied over a wide range. Towing of this set of models is continuing and when completed will provide design data for a standard offset series covering a wide range.

HYDRAULIC PUMP TESTS.

Laboratory project.

Experimental; for design data.

Scale model pumps, centrifugal and propeller types, are tested at constant speeds for head developed, power consumption, and efficiency at various rates of discharge. Cavitation tests are sometimes conducted by lowering the suction head to a point where the developed head and efficiency break down.

CAVITATICN TESTS OF HYDRAULIC TURBINE MODEIS.

Laboratory project.

Experimental; for design data.

Scale model turbines are tested on cavitation stand to determine sigma at which cavitation starts. 
(1134) CAVITATION TESTS ON MODEL SHIP PROPELIERS.

(b) Laboratory project.

(d) Experimental; for design data.

(e) A water tunnel with a 42 -inch test section is under construction. An electric dyna mometer has been built to measure the propeller torque and thrust. Propellers up $t$ 8-inch diameter will be tested and a suction head approaching 33 feet will be avail

(1135) PERFORMANCE TESTS ON WATER CIRCULATING SYSTEMS FOR SHIPS.

(b) Bureau of Ships, Department of the Nary.

(c) Experimental.

(e) A $1 / 6$ scale model of a ship condenser was tested to determine scoop performance and condenser efficiency.

(f) Completed.

(1136) WAVE TESTS ON SHIP MODEIS.

(b) Laboratory project.

(d) Experimental; for design data.

(e) Ship models are tested with scaled waves to determine the speed reduction in waves 1 the pull required for various still water speeds. Pitching periods and angles are determined from light trace photographs.

(1137) IMPACT TEST ON SHIP MODEIS.

(b) Office of Naval Research, Department of the Navy.

(d) Experimental.

(e) Ship models were tested in waves to determine the impact and slamming forces on shir with light draft, encountered in heavy seas.

(f) Test completed, results being analyzed and report being written.

NEW YORK UNIVERSITY, Department of Chemical Engineering.

Inquiries concerning Projects Nos. 590, 1138, and 1379 should be addressed to Prof. Happel, Department of Chemical Engineering, New York University, New York 53, N. Y.

(590) PRESSURE DROP DUE TO FLUID FLOW THROUGH ASSEMBLAGES OF SPHERES.

(b) Laboratory project.

(d) Experimental and theoretical; for two doctoral theses.

(e) Rigid assemblages of uniform spheres of various fractional void volumes in cubical assemblages were constructed, and the effect on pressure drop of passing a viscous liquid through these assemblages was measured. The effect of particle size graduati and roughness on pressure drop is being determined. A theoretical approach to the effect of fractional void volume on pressure drop has also been derived and the vali of the derived expressions are beirg determined.

(h) "Versatile chart aids $\triangle P$ Calculations." John Happel and Norman Epstein, Chemical Engineering, Dec. 1950 .

(1138) EFFECT OF VARIATION OF SOLID TO FLUID DENSITY RATIO ON FLUIDIZATION CHARACTERISTICS.

(b) Laboratory project.

(d) Experimental; for one doctoral and one master's thesis.

(e) Screened particles of very light solid substances will be fluidized in a 2-inch glass tube and the fluidization characteristics observed. The primary objective will be tr. determination of the optimum ratio of solid to gas density for smooth fluidization. 


\section{EFFECT OF SOLID-SOLID FRICTION ON PRESSURE DROP IN FLUTDIZED SYSTEMS.}

Laboratory project.

Experimental; for master's thesis.

Unsupported beds of uniform smooth spheres will be fluidized and the resulting pressure drop measurements will be compared to the pressure drops through rigid assemblages of Project No. 590 in order to discover the effect of solid-solid friction.

ISITY OF NORTH CAROLINA, North Carolina State College of Agriculture and Engineering.

\section{DYNAMIC SIMILARITY OF SMALL HYDRAULIC MODEIS.}

Laboratory project.

Prof. N. W. Conner, Department of Mechanical Engineering, North Carolina State College, Raleigh, N. C.

Theoretical; basic research.

To make a theoretical study of dymamic similarity of small hydraulic models and at large scale ratios.

To be published by Department of Engineering Research, North Carolina State College.

WESTERN UNIVERSITY, The Technological Institute.

Inquiries concerning Projects Nos. 905, 906, and 1141 should be addressed to Prof. D. A. Dahlstrom, Project No. 326 to Prof. W. S. Hamilton, and Projects Nos. 127, 904, and 1140 to Prof. L. H. Kessler, Northwestern Technological Institute, Evanston, IIl.

RELIEF FROM WATER HAMMER BY MECHANICAL-PNEUMATIC SURGE SUPPRESSORS.

Laboratory project.

Experimental; for design.

To determine extent to which surge pressures in pipe lines may be relieved by a preloaded, gas-filled, compression chamber in which the gas is separated from the liquid in the pipes by a stainless steel bellows.

Present work has shown this type of unit to be free from fatigue failure and capable of protecting pipe systems from severe shock. Field tests are now being conducted on pipe lines in oil fields, distilleries, fuel supply lines for railroads, and test stations for jet engines. An improved pressure-time recorder of mechanical rather than electronic type is in use. Design of stainless steel unit preloaded at $125 \mathrm{psig}$, with useful volume of $10,000 \mathrm{cu}$ in. has been completed and unit is under construction.

CAVITATION DAMAGES UNDER CONTROI,LED CONDITIONS.

Laboratory project.

Experimental; basic research, for theses and staff papers.

The pressure in a vertical column of liquid is caused to fluctuate by a motor-operated piston and bellows arrangement, thereby forming and releasing a cavity at the top of the column. The amount of damage to various materials will be related to size of cavity, static load, dissolved air content, and proximity of material to point of cavity collapse. Pits have been caused in brass, lucite, and mortar. An elastic-tube strain gage is being constructed for pressure measurements.

Unpublished progress report dated January 1950 available upon request. 
(904) BULK MODULUS OF PETROLEUM PRODUCTS, INCLUDING CRUDE OIIS AND GASOLINE.

(b) Laboratory project.

(d) Experimental; basic research for design.

(e) Tests have been conducted on three crude oils, one gasoline, and on distilled wate temperatures from $60^{\circ} \mathrm{F}$. to $130^{\circ} \mathrm{F}$. and at pressures ranging from 0 to $1500 \mathrm{psig}$. Further tests will be made on other oils and gasolines, tap water, and a variety 0. chemicals. Specific gravities and viscosities will be determined over the ranges temperature and pressure indicated above.

(g) Tests indicate high modulus with low temperature and rapidly increasing modulus at pressures after which a leveling off takes place with nearly constant modulus abov 1000 psig.

(905) THE LIQUID-SOLID CYCLONE.

(b) Laboratory project.

(d) Experimental and field investigations; basic and applied research, for design and operation.

(e) Application of centrifugal fields as obtained in the liquid-solid cyclone to the $r$ : classification, beneficiation, separation, and desliming of coal and minerals.

(g) Experimental and field investigations on theory and operation of the liquid-solid c have been completed, making it possible to design equipment for any capacity and ef ciency desired. Investigations have indicated that it is easily possible to deslin minerals and coal of minus 200 refuse, and design and operation methods have been $F$ lished. New additions are being made to the cyclone to permit addition of fresh we for maximum separation of fine solids from coarse. Field tests have already been conducted indicating less water is required than in conventional equipment.

(h) "High-speed classifications and desliming with the liquid-solid cyclone." D. A. DahIstrom, Mining Engineering and Mining Trans. ATME.

"Cyclone operating factors and capacities on coal and refuse slurries." D. A. Dahl Mining Engineering and Mining Trans. ATME, 1949.

"High speed classification and desliming with the liquid-solid cyclone." D. A. Dah Mining Engineering and Trans. AIME, 1951.

"Low cost industrial desliming of fine solids." D. A. Dahlstrom, Joint Fuels Confe AIME, ASME, October 10, 11, 1951, Roanoke, Virginia.

(906) SEPARATION OF FINE-SIZED CLOSE GRAVITY SOLIDS BY CENTRIFUGAL FORCE AS OBTAINED IN T LIQUID-SOLID CYCLONE.

(b) Laboratory project.

(d) Theoretical and experimental; basic and applied research for design and operation.

(e) Separation of close gravity solids by liquids and the application of centrifugal fi as obtained in the liquid-solid cyclone is being investigated.

(g) Economical separation and recovery of materials differing by as little as 0.01 in $\mathrm{s}$ ] gravity and as small as 100 mesh in size have been obtained. A small pilot plant h: been constructed, which can be used on any material to obtain necessary design data. Methods for predicting industrial design and operation have been advanced. Two ind installations have been made within the past year based on these results. Actual $r$ conform quite closely with predicted values.

(h) "Fine-size, close-specific-gravity solid separation with the liquid-solid cyclone." J. J. Moder, D. A. Dahlstrom, to be published soon in Chemical Engineering Progress, Journal of the A.S.Ch.E.

(1140) HYDROLOGY OF UNDERGROUND WATER SUPPLIES AND DETERMINATION OF HYDRAULIC CHARACTERISTI SOME SHALIOW AND ARTESIAN WELIS IN NORTHERN COOK COUNTY AND SOUTHERN LAKE COUNTY, II

(b) Laboratory and field project.

(d) Experimental; for design. 
All available information is being obtained from the State Geological Survey and local well drillers. Test wells are being drilled in glacial drift at various locations above the Niagara Cuesta, and one artesian well will be under way soon to determine geologic formations and changes therein, radius of curves of influence, and other hydraulic characteristics of wells in this area. Special attention will be given to sanitary significance of the quality of water obtained from the various aquifers such as hardness, chlorides, iron and sulphur.

Test hole drilling in DesPlaines Complex has been completed without locating satisfactory sands and gravels. One successful well at $90 \mathrm{gpm}$ continuous pumping has been brought in near Gages Lake, Illinois on the side of a pre-glacial valley some two miles from the pre-glacial stream.

\section{HIGH SPEED SEPARATION OF CLOSE SPECIFIC GRAVITY LIQUIDS IN THE CYCLONE.}

Laboratory project.

Theoretical and experimental; basic and applied research for design and operation. Rapid separation of close specific gravity liquids by use of centrifugal fields as obtained in the cyclone is being investigated. Preliminary tests indicate that recovery of either liquid phase will be a function of feed and overflow diameters, cyclone included angle, pressure drop across cyclone, volume split between overflow and underflow, specific gravity difference between liquid phases, feed composition and interfacial tension between liquids. Liquid-liquid separation work will be especially important for liquid-liquid extraction applications.

It has been proven that separation of the two liquid phases can be obtained at a probable cost and simplicity far surpassing that experienced in most liquid-liquid extraction applications to date. Correlations have been obtained for recovery of the various liquid phases as a function of volume split, feed composition and pressure drop across the cyclone.

"A study of separation of two immiscible liquid phases in a cyclone." Frank G. Klein, Master's Thesis, Northwestern University, Sept. 1951.

IRSITY OF NOTRE DAME, Department of Engineering Mechanics.

Inquiries concerning Projects Nos. 907, 909, and 1142 should be addressed to Dr. A. G. Strandhagen, Department of Engineering Mechanics, University of Notre Dame, Notre Dame, Ind.

THREE-DIMENSIONAL INVESTIGATION OF THE STABILITY OF TOWED MARINE SHIPS.

Office of Naval Research, Department of the Navy.

Basic theoretical analysis.

Research to establish conditions necessary for the dynamic stability of a ship towed by a hawser. The effect of the location of the point of attachment of the hawser and of rough water are being considered.

The effects of waves of a simple mathematical type have been introduced into the analysis.

\section{AUTOMATIC REGULATION OF DIVING AND RISTNG OF SUBMARINES.}

\section{Laboratory project.}

Basic theoretical research.

An analysis of the motion caused by the use of various types of automatic controlling devices which actuate the stern elevator and which depend upon the characteristics of the state of the moving submarine. The directional stability of a submarine fitted with various types of controlling devices is also being studied.

Since non-linear differential equations of motion are involved, seven cases have been completed. Calculations have been started for the solutions of other motions resulting from other types of controlling devices.

Report in preparation. 
(1142) THEORY OF WAVE RESISTANCE.

(b) Laboratory project.

(d) Basic theoretical research.

(e) The theory of wave resistance is being studied and extended to provide a better cos lation with experimental results at low and moderate speeds.

(g) A theory has been formulated and calculations have been made which predict the thic boundary layer or viscous wake near the stern. It predicts the extensions to the a outline of the ship. Surface distribution of sources and sinks have been compared the point source and sink distribution.

(h) Report in preparation.

\section{OHIO STATE UNIVERSITY, RObinson Laboratory.}

Inquiries concerning Projects Nos. 598, 910, 1143, 1144, 1380, 1381, and 1382, shou be addressed to Prof. S. R. Beitler, Robinson Laboratory, Ohio State University, Columbus 10, Ohio.

(597) ELIMINATION OF PULSATION ERROR IN FLUID METERS.

(b) American Gas Association and American Society of Mechanical Engineers.

(c) Mr. D. J. Masson, Robinson Laboratory, the Ohio State University, Columbus 10, Ohio

(d) Experimental; applied research.

(e) The flow of air from a two-stage reciprocating compressor, equipped with a pulsatio eliminator, is being measured by two orifices in series. A sonic block is set up b the orifices so that pulsating flow is measured by the first and non-pulsating flow measured by the second orifice. The secondary elements consist of standard flow me The difference in the rate of flow measured by each orifice is a measure of the err due to pulsation. The "pulsameter" is also being used to check its reliability in dicting pulsation errors over one percent.

(f) Inactive.

(g) Results indicate that effective dampeners can be designed to operate over a limited

(598) COEFFICIENTS OF DISCHARGE FOR ECCENTRIC AND SEGMENTAL ORIFICES.

(b) American Society of Mechanical Engineers and American Gas Association.

(d) Experimental; applied research.

(e) Coefficients of discharge are being obtained for eccentric and segmental orifices ir 4-inch, 6-inch, 10-inch, and 14-inch pipe lines. It is desired to publish curves fi which coefficients for commercial use may be chosen for a large range of Reynolds $\mathrm{n}$ diameter ratios, and pipe sizes.

(g) Work has been completed on all but a portion of the 14-inch line orifices and are be analyzed. Tentative results are being disseminated.

(910) CALIBRATION OF ORIFICES, VENTURIS, AND FLOW NOZZLES.

(b) Manufacturers and users of flow meters.

(d) Experimental; calibration for use.

(e) Many primary metering elements for flow measurement are being calibrated individuall for accurate measurements.

(g) Results indicate that published data on orifices and nozzles are satisfactory, but $t$ material for venturi tubes is not complete. 


\section{STUDY OF SUDDEN EXXPANSION IN PIPE IINES.}

Laboratory project.

Experimental; basic research for masters' theses.

A study of pressure and velocity changes with flow through sudden enlargements for both compressible and incompressible fluids.

Theoretical analysis has been completed.

Three theses prepared, available for reproduction.

A STUDY OF FLOW IN BENDS AND ELBOWS IN SMALI PIPE LINE.

Laboratory project.

Experimental; basic research.

A study of the variation of pressure and velocity around bends of different radius smooth tubes of $1-1 / 2$ inch in diameter and less.

Considerable work completed and additional work in progress.

Two masters' theses are available for reproduction.

STUDY OF THE EFFECT OF ROUNDING OF ENTRANCE EDGE ON THE COEFFICIENT OF ORIFICES.

Laboratory project.

Experimental; research for masters' theses.

It is planned to study the effect of different radii of rounding on the coefficient of discharge of orifice plates in a 2-inch pipe line.

STUDY OF THE EFFECT OF CHANGING THE ANGLE OF THE THROAT OF ORIFICE PLATES ON THEIR COEFFICIENTS OF DISCHARGE.

Laboratory project.

Experimental; research for masters' theses.

Orifices for use in 2-inch lines are to be constructed with the bored portion conical rather than cylindrical. The face of the truncated cone is to be upstream. Several orifices are to be used in a 2-inch pipe line. It is hoped to develop a more stable primary measuring device.

STUDY OF THE EFFECT OF INLET VELOCITY PROFILE ON THE FLOW AND DIFFERENTIAL PRESSURE OF PRIMARY METERING ELEMENTS.

Laboratory project.

Experimental; research for masters' theses.

It is planned to set up various disturbances in the inlet section of a metering device, measure the velocity traverse ahead of the primary metering element and the differential across it and attempt to correlate the results to determine the optimum locations for flow straighteners, etc.

N STATE COLLEGE, Department of Civil Engineering.

RELATION BETWEEN RAINFALI AND RUNOFF FROM SMALI WATERSHED IN WESTERN OREGON.

Laboratory project.

Dr. C. A. Mockmore, Oregon State College, Corvallis, Ore.

Experimental; field investigation.

Watershed $10 \mathrm{sq} \mathrm{mi}$, partly wooded, partly farmed; automatic recording raingages and flow recording gages on loan from Weather Bureau or U. S. Geological Survey.

M. S. Thesis available on loan through college library. 
(1383) STUDY OF EFEECT OF ENTRANCE CONDITIONS ON FIOW THROUGH HIGHWAY CULVERTS.

(b) Cooperative with Oregon State Highway Department and Bureau of Public Roads.

(c) Mr. Leslie A. Clayton, Oregon State College, Corvallis, Ore.

(d) Experimental; for design.

(e) Scale model of culvert design by Public Roads Administration practically ready for testing. Emphasis is to be placed on entrance conditions of culvert.

PELTON WATER WHEEL COMPANY.

Inquiries concerning Projects Nos. 1146, 1384, and 1385 should be addressed to Mr. Bacchi, Pelton Water Wheel Company, 2929 19th Street, San Francisco 10, Calif.

(1146) HEAD EFFECT ON IMPULSE TURBINE MODEL TESTING.

(b) Laboratory project; sponsored by Mountain Laboratory Group.

(d) Experimental; applied research.

(e) To establish model law for testing impulse turbines under various operating pressur tests are being made under heads between 100 and $2000 \mathrm{ft}$. The effect of housing si: and shape is under study.

(f) Temporarily suspended for conversion work prior to further testing.

(g) Initial tests have been completed.

(1384) FRANCIS TYPE TURBINE TEST MODEI-EFFICIENCY AND HORSEPOWER TEST.

(b) Department of the Interior, Bureau of Reclamation.

(d) Experimental; applied research.

(e) A complete 13-3/16-inch model turbine with pressure regulator and energy absorber wa tested under a wide speed and head range.

(f) Completed.

(g) Results were used to determine performance and design of prototype units.

(1385) ADJUSTABLE BLADE PROPELLER TYPE TURBINE MODEL. EFFICIENCY AND HORSEPOWER TESTS.

(b) Laboratory project.

(d) Experimental; applied research.

(e) An ll-inch model turbine is being built to study effect of using an existing casing tube combination on a reconstruction project.

PENNSYIVANIA STATE COLLEGE, Hydraulics Laboratory.

(1327) DISCHARGE MEASUREMENTS BY MEANS OF CYLINDRICAL NOZZLES.

(b) Builders-Providence Inc.

(c) Dr. Andre L. Jorissen, Department of Hydraulics and Hydraulic Engineering, Cormell University, Ithaca, N. Y.

(d) Experimental; applied research for master's thesis.

(e) Five cylindrical nozzles of various dimensions have been studied in a 4 -inch smooth pipe to determine the behavicr of the coefficient of discharge at low Reynolds numbe: Nozzle proportions have been varied in order to determine an optimum length to diame ratio for each nozzle. The effect of the addition of a conical diffusor to nozzles optimum proportions will be studied in an effort to design a Venturi tube of simple struction, expected to have a constant coefficient of discharge at low Reynolds numbe and a small permanent head loss. 
The project has recently been transferred from The Pennsylvania State College to Cornell University. See page 26.

Cylindrical nozzles maintain a constant coefficient of discharge at Reynolds numbers lower than standard pressure-difference devices of flow measurement. Tests on nozzles of various opening ratios have indicated the optimum proportions for each ratio which result in a minimum loss of head.

"Discharge Measurements by means of cylindrical nozzles." A. L. Jorissen and H. T. Newton, Annual Meeting, ASME, Nov. 1951.

"Discharge measurements by means of cylindrical nozzles." H. T. Newton, Master's Thesis, The Pennsylvania State College, Feb. 1952.

YLVANIA STATE COLIEGE, Ordnance Research Laboratory.

Inquiries concerning Projects Nos. 328, 1150, 1151, 1152, 1386, and 1389 should be addressed to Dr. J. M. Robertson; Projects Nos. 605, 920, 921 and 1387 to Mr. B. W. McCormick; and Project No. 1388 to Mr. Donald Ross; Ordnance Research Laboratory, P. O. Box 30, State College, Pa.

\section{FLOW PAST SLOTS IN SURFACES.}

Laboratory project.

Experimental; applied research.

Studies were made on the pressure and flow conditions near slots in surfaces, as affected by relative boundary layer thickness and contour of slot corners.

Inactive.

The boundary layer thickness, slot width in the direction of flow, and rounding of downstream edge were found to govern the magnitude of the pressure dip following the slot.

FUNDAMENTALS OF SURFACE CAVITATION.

Cooperative with Department of Mineral Technology.

Experimental; basic research.

A laboratory-size eggbeater apparatus is used in which the noise inception point and noise output is to be correlated with the chemical composition and nature of the liquid and the surface of the propeller.

Suspended.

Effects of air content and electric charge on cavitation inception were investigated for one simple propeller shape.

"Preliminary experiments on cavitation by propellers." E. C. Marboe, W. Capps, W. A. Weyl. Report to Office of Naval Research, Technical Report No. 23, Oct. 1950.

ELECTROMAGNETIC ANALOGY FOR PROPELLERS.

Laboratory project.

Experimental; applied research.

The analogy between the velocity fields of vortices and the magnetic fields of current carrying wires is used to obtain the induced velocities for propellers and to study wide blade effects.

Completed.

Testing program indicated agreement with theoretical calculations within the accuracy of the electrical equipment.

Paper being submitted for publication.

PROPELLERS FOR OPERATION IN SYMMETRIC WAKES.

Bureau of Ordnance, Department of the Navy.

Theoretical and experimental; applied research. 
(e) The problem is the design of optimum-efficiency and cavitation-free propellers for operation behind bodies of revolution. It is being attacked through consideration the physics of propeller action. Design methods resulting from the theory being $t$ by experiment.

(g) Several tests have been made with the first research propeller. Other propellers being fabricated.

(1150) HYDRODYNAMIC PERFORMANCE OF 48-INCH WATER TUNNEL.

(b) Laboratory project.

(d) Experimental; applied research.

(e) Velocity distributions and pressures are being measured in all portions of the 48-: water tunnel at velocities up to $80 \mathrm{fps}$.

(g) The initial testing program indicated the need of a honeycomb and possibly screens straighten the flow. A honeycomb was installed this summer and the testing prograr being repeated.

(1151) DESIGN AND CONSTRUCTION OF 12-INCH WATER TUNNEL.

(b) Laboratory project.

(d) Design.

(e) Tunnel is planned for general supplementary research; interchangeable working secti have been designed. One circular closed jet 12 inch diameter, one circular open je 12 inch diameter, one $4 \frac{1}{2}$ inch by 20 inch rectangular closed; maximum design velocit 70 fps.

(g) "The design of a small water tunnel." Roger L. Steele, Master's Thesis, The Pennsy State College, June 1951. (Available on loan.)

(I152) DESIGN AND CONSTRUCTION OF 48-INCH AIR TUNNEL.

(b) Laboratory project.

(d) Design.

(e) Closed circuit tunnel planned for supplementary research; working section 48-inch 0 16 feet long; maximum design velocity is $200 \mathrm{fps}$. A fifth scale model of the nozzl been constmucted for testing suitability of proposed design.

(f) Construction should start early in 1952 .

\section{(1386) CAVITATION STUDIES.}

(b) Laboratory project.

(d) Experimental; basic research.

(e) Cavitation inception as noted visually and acoustically on bodies is being correlat with the magnitude and location of the minimum pressure coefficient as a function 0 scale, i.e. Reynolds number. The nature and shapes of cavities behind blunt bodies also being studied.

\section{(1387) STUDY OF TIP VORTEX CAVITATION.}

(b) Laboratory project.

(d) Experimental; basic research.

(e) Attempt to correlate such factors as vortex core size, vortex strength, and Reynold: number through studies of an elliptic wing in the 48-inch water tunnel.

\section{(1388) SHEAR STRESS IN TURBULENT BOUNDARY LAYER.}

(b) Laboratory project.

(d) Experimental; basic research.

(e) As a first step to a better understanding of the nature of shear stress in a develor turbulent boundary layer, fluid flow from a rough walled to a smooth walled boundar: be studied in air and water. The spacial variation of the shear stress and turbuler will be determined. 


\section{REDUCTION OF STRUT WAKE.}

Laboratory project.

Theoretical and experimental; applied research.

The model torpedo supporting strut in the 48-inch water tunnel (see Project 921) exerts an asymmetric effect on the velocity distribution at the plane of the propeller. A method of filling in the wake flux deficiency by an extemal pumping apparatus will be tried to alleviate this condition.

SITY OF PENNSYLVANIA, Department of Civil Engineering.

TESTS OF FIRE HYDRANTS FOR FRICTION LOSS.

A. P. Smith Valve Company.

Mr. H. Gaffin, A. P. Smith Valve Company, East Orange, N. J.

Experimental; applied research and design.

Pressure loss measurements were made in detail on various portions of the hydrant such as shoe casting, valve passages, discharge nozzles, and over-all at varying rates of flow.

Completed.

ILVANIA WATER \& POWER COMPANY.

Inquiries concerning Projects Nos. 1154 to 1158, incl., should be addressed to Dr. S. K. Waldorf, 405 Fulton Bank Building, Lancaster, Pa.

MEASUREMENT OF WATER VEI,OCITIES WITH ULTRASONICS.

Laboratory project.

Experimental; applied research.

To develop an improved method of measuring large quantities of water, particularly the discharge of large hydroelectric units having short intake conduits with large rectangular cross-sections. An ultrasonic transducer rod is placed at each of two parellel opposite walls of the rectangular duct in which water velocity is to be measured. The transducers are displaced from each other along the principal axis of flow. The phase angle between the transmitted and received ultrasonic signals is a measure of the water velocity.

Water velocities up to ten feet per second have been measured with an error of one-half percent in a rectangular duct five inches by nine inches.

CORRELATION OF ANNUAL TREE GROWTH WITH PRECIPITATION AND RIVER FLOW.

Laboratory project.

Field investigation; applied research.

Cross-sections of trees from Juniata River drainage area above Huntingdon, $\mathrm{Pa}$. are being measured for correlation with flow records at Huntingdon, and precipitation and temperature records at several other stations.

) INDUCING FRACTURE LINES IN RESERVOIR SHEET ICE WITH AIR BUBBLES.

Laboratory project.

Field investigation; applied research. 
(e) An experimental 2000-foot length of rigid pipe, with holes at intervals for dischar compressed air, is laid on the reservoir bottom, subject to silting. A second 1000 length of flexible tubing, similarly perforated, is installed also. This tubing is anchored to floats several feet above the reservoir bottom to avoid silting difficu It is expected that the warmer water caused to rise with the bubbles will produce a of weakness in the reservoir sheet ice. If successful, a system of such pipes will facilitate breakup of sheet ice and reduce the possibility of ice jams.

(g) Results are encouraging, but not conclusive.

\section{(1157) SEDIMENTATION IN SAFE HARBOR RESERVOIR.}

(b) Laboratory project.

(d) Field investigation; applied research.

(e) With a U. S. D-43 sampler, suspended sediment in the Susquehanna River is measured head of the Safe Harbor Reservoir. The suspended sediment in the discharge of the voir is measured by special means applicable to turbulent water at the station discl and dam overflow. The rate of silting in the reservoir is measured periodically by fathometer soundings.

(1158) FOREWARNING OF FRAZIL ICE FORMATION.

(b) Laboratory project.

(d) Experimental; applied research.

(e) By means of a resistance thermometer and strip chart recorder, the temperature of th Susquehanna River is measured within $0.001^{\circ} \mathrm{C}$ at Safe Harbor and Holtwood.

(g) A cooling rate in excess of $0.01^{\circ} \mathrm{C}$ per hour to the freezing point of the river wate followed by the formation of frazil ice rather than sheet ice.

PURDUE UNIVERSITY, School of Civil Engineering and Engineering Mechanics.

(1391) INVESTIGATION OF THE FUNDAMENTAL THEORIIS OF SEDIMENTATION IN A TANK.

(b) Federal Security Agency, Public Health Service, and National Institutes of Health.

(c) Prof. Don E. Bloodgood, Purdue University, Lafayette, Ind.

(d) Experimental; for design purposes and for masters' theses.

(e) Observing the sedimentation rate of finely divided solids suspended in water moving various velocities. The effect of variation in depth and width and length of channe: eventually will be observed. The sediment used in the first series of tests was fint ground coal. The sediment currently being investigated for a new series of tests is diatomaceous silica.

(h) Findings to date are published in a thesis, "An investigation of the fundamental theories of sedimentation in a tank." H. E. Chapman, Aug. 1951, and in "Sedimentatic studies - progress reports." Mar. 3, 1950 and Feb. 28, 1951 to the sponsoring agency

\section{ROCKY MOUNTAIN HYDRAULIC LABORATORY.}

(332) TESTS OF SCOUR AROUND BRIDGE PIERS.

(b) Cooperative with Bureau of Public Roads.

(c) Prof. C. J. Posey, Engineering Building, State University of Iowa, Iowa City, Iowa.

(d) Experimental; development.

(e) Study of methods of protecting piers from scour.

(f) Active during summers.

(g) Methods so far developed gave model pier complete protection until entire bed had und gone severe degradation.

(h) "Investigation of flexible mats to reduce scour around bridge piers." C. J. Posey, D. W. Appel, and E. Chamness, Jr., Highway Research Board, Research Report No. 13-B, pp. 12-22. April 195'1. 
HONY FALLS HYDRAULIC LABORATORY, University of Minnesota.

Inquiries concerning Projects Nos. 100, 104, 105, 335, 616, 924, 925, 1159 to 1163, incl., 1165, and 1392 to 1397, incl., should be addressed to $\mathrm{Dr}$. Lorenz G. Straub, St. Anthony Falls Hydraulic Laboratory, Hennepin Island, Minneapolis 14, Minn.

Inquiries concerning Projects Nos. 111, 112, 114, 1158 and 1398, which are being conducted in cooperation with the Soil Conservation Service, should be addressed to Mr. Fred W. Blaisdell, U. S. Soil Conservation Service, St. Anthony Falls Hydraulic Laboratory, Hennepin Island, Minneapolis 14, Minn.

Inquiries concerning Projects Nos. 194, 412, 618, 982, 985, and 1206 which are being conducted in cooperation with the Corps of Engineers, should be addressed to the District Engineer, Corps of Engineers, Department of the Army, St. Paul District, St. Paul, Minn. (These projects are listed on pages 115 and 116.

\section{AIR ENTRAINMENT RESEARCH.}

Office of Naval Research, Department of the Navy.

Theoretical and experimental; basic and applied research.

Velocity distributions and air concentration distributions in open-channel, air-entrained

flows are being obtained with specially developed electrical instruments. High speed

still and motion-picture photographic techniques are being utilized to record and study

the irregular flow surfaces and the aeration processes. Installation of additional

supply lines from laboratory pumps is now being computed to augment the natural gravity supply for testing at the highest channel angles. A general analysis of the air-entrained flows is being developed, guided by the experimental results.

\section{FLOW DIVERSION RESEARCH.}

Office of Naval Research, Department of the Navy.

Theoretical and experimental; basic and applied research and design.

Detailed study of flow processes in bends with main emphasis on guide vane bends. Two dimensional and secondary effects are to be separated so that the performance of a given bend geometry can be predicted. Work is now being concentrated on methods of computing losses due to secondary currents in guide vane bends.

The causes of secondary currents and the role they play in flow around bends have already been determined. Some experimental checks of methods of computing losses due to secondary currents developed by others have been obtained.

WATER TUNNEL DESIGN STUDIES.

David Taylor Model Basin, Department of the Navy.

Experimental.

Model studies of a design for a 36 inch open or closed jet variable pressure water tunnel with an air-bubble resorber are being made. Experimental and analytical studies of the test section flow quality, tunnel cavitation characteristics, tunnel energy losses and probable resorption characteristics of the resorber are included.

Tests indicate that the test section velocity profiles were improved by the addition of the resorber and that no detectable pressure or velocity fluctuation from the resorber should be reflected into the test sections. The resorber should permit continuous cavitation testing.

"Design studies for a closed-jet water tunnel." John F. Ripken, St. Anthony Falls Hydraulic Laboratory Technical Paper No. 9, Series B. Aug. 1951.

FLOW IN A TRIANGULAR OPEN CHANNEL WITH VARIES CENTRAL VERTEX ANGLE.

Laboratory project.

Experimental; master's thesis.

To determine the characteristics of bulk flow in a triangular open channel with varied central vertex angle. Water is being used as the testing fluid, and both laminar and turbulent flow are being studied. 
(616) FIOW THROUGH GRANULAR MEDIA.

(b) Laboratory project.

(d) Experimental and theoretical; for master's thesis.

(e) Tests have been made to determine head loss resulting from flow through uniform-si: media of varying shapes. Dimensionless numbers have been developed through considt of the forces and dimensions involved. An attempt is being made to determine the of particle shape and surface area on flow conditions.

(924) FREE-JET WATER TUNNEL STUDIES.

(b) Office of Naval Research, Department of the Navy.

(d) Experimental; applied research and design.

(e) Pilot model studies of a two-inch diameter free-jet water tunnel have been conduct $\epsilon$ develop design criteria for larger systems. Design, construction, and operation of ten-inch diameter free-jet water tunnel for basic research in flows about solid boc under extreme cavitation conditions is in process.

(g) A summary report on model studies indicates that this type of water tunnel can be $\mathrm{F}$ tical and workable tool for hydraulic research.

(h) "Experimental design studies on free-jet water tunnel." Charles D. Christopherson. St. Anthony Falls Hydraulic Laboratory Project Report 25. Sept. 1951.

(925) EXPERIMENTAL STUDY OF A GRAVITY FLOW CYLINDRICAL SEDIMENTATION TANK.

(b) Laboratory project.

(d) Experimental; master's thesis.

(e) To investigate the effects of Reynolds number on sediment retention in the tank. sized spherical glass beads being used as sediment have diameters ranging from $25 \mathrm{~m}$ to 100 microns.

(1159) MISSISSIPPI RIVER REVETMENT STUDIES.

(b) Waterways Experiment Station and Mississippi River Commission.

(d) Experimental; applied research.

(e) Studies on some factors affecting the stability of articulated concrete revetment w made with full-scale revetment blocks. These factors included the pressure pulsatic due to turbulence, steady-state pressures due to slight irregularities in the mattr surface, and sand scour from the interstices between blocks.

(f) Initial phase completed.

(g) Differential pressures across revetment blocks resulting from pressure pulsations al the mattress were directly a function of the amount of sand surrounding the blocks. Revetment settlement occurred as a result of the removal of sand from the openings tween blocks by scour.

(h) "Mississippi river revetment studies." Lorenz G. Straub and Reuben Olson. St. Antr Falls Hydraulic Laboratory Project Report 21, June 1951.

(1160) EFFECT OF TUBE VIBRATIONS ON PRESSURE DROP OF FLOW IN TUBES.

(b) Office of Naval Research, Department of the Navy.

(d) Theoretical and experimental; basic and applied research.

(e) Study of pressure drop in a tube of uniform cross section for steady flow with vario superimposed fluctuations. The first phase of the project involves external vibrati of the tube. The second phase induces pulsation of the flow in the tubes. Iag in transmission of pressure pulses after opening a valve caused by fluctuations are als included in this study. Fluids of large bulk modulus of elasticity are used (hydrau oils and water).

(f) First phase completed. Second phase just begun.

(g) There is no effect due to external vibration of the tube. An incidental result of $t$ first phase investigation is the experimental finding that fully developed laminar $f$ in tubes is stable to all small disturbances up to Reynolds numbers of 15,000 based tube diameter.

(h) "The effect of tube vibrations on flow through tubes." Edward Silberman, St. Anthon: Falls Hydraulic Laboratory Project Report No. 27. Nov. 1951. 
ENTRANCE EFFECTS ON DISCHARGE IN MODEL CULVERT FLOWING PART FULL.

Laboratory project.

Experimental research; master's thesis.

Determination of the stage discharge relationship for the condition when the pipe flows part full and when the outfall is free. Three types of inlets, namely, (I) sharp edged, (2) well rounded, and (3) re-entrant type of inlets are being used. The study is being limited to supercritical flows. Analytical verification of the experimental results is also being made.

STANDING SURFACE WAVES IN AN OPEN CHANNEL WITH A WAVY BOTTOM.

Laboratory project.

Analytical and experimental; for master's thesis.

Tests were made in a six-inch wide glass sided channel. Bottom corrugations were of one-foot length and one-inch height.

Completed.

For waves shorter than five times the depth of water hydrodynamical equations should be used rather than open channel flow analysis. The height of waves in supercritical flow is limited by the breaking condition to a maximum mean value of one tenth wave length. In supercritical flow the boundary layer along the side walls of the channel originates great disturtances. The fronts of these disturbances and the channel walls form an angle. This angle decreases when Froude number increases.

"Surface waves in an open channel with straight parallel side walls and a corrugated bottom." T. Timar, Master's Thesis, University of Minnesota, Dec. 1951.

THE STUDY OF FLOW AT AN INTERFACE.

Laboratory project.

Experimental and theoretical; basic research.

Experiments are to be conducted to study the interfacial instability and to clarify flow conditions before and after mixing and to determine the characteristics of a flow of liquid with the density varying with depth and some facts in connection with bed-load movement, boundary-layer effect, shallow water-wave, etc. Photographic method will be employed to record flow patterns. Analytical and relaxational approaches will be carried in parallel with an attempt to solve some simple cases of incompressible flow with variable density.

RIPPLE FORMATION AND ITS RELATION TO BED-LOAD MOVEMENT.

Laboratory project.

Theoretical and experimental; for doctor's thesis. A basic research to investigate the phenomenon of bed-load movement of an alluvial stream. Analytical study on the items of mechanics characteristics of ripple-formation, its effect on surface wave, frictional resistance of the channel and its relation to bed-load movement. Later on experimental work will be carried out to verify certain analytical results. Experiments on velocity of bed-load material for various size of grain particles and various flow conditions will also be carried out to give additional information on rate of bed-load movement.

GENERAL WAVE STUDIES.

Laboratory project.

Experimental.

Preliminary study and evaluation of wave generators, filters, and related equipment for the creation of waves in both still and moving water. Studies are being conducted in an existing flume with a width of six inches and a depth of fifteen inches; the small cross-sectional area of the flume permits rapid and inexpensive alterations to equipment, Results of the studies will be used in the design of equipment for a large flume, nine feet wide, six feet deep and two hundred fifty feet long, and to develop test procedures, methods, and other background information for future studies. 
(g) Two generators have been developed which can create waves in both still and moving

(1393) METHOD OF CORRELATING FRICTION FACTORS AND RELATIVE ROUGHNESS FOR FULLY DEVELOPED TURBULENT FLOW IN PIPES.

(b) Laboratory project.

(d) Theoretical basic research; for doctor's thesis.

(e) Work was undertaken to explain anomalies in friction factor versus Reynolds number from experimental data on large corrugated and concrete pipes.

(f) Completed.

(g) Fully developed fiow in rough conduits is placed in three classes: (1) isolated rol flow occurring when roughness spacing is great enough for each element to develop separate wake, (2) quasi-smooth flow occurring when roughness spacing is so small there is practically no wake behind each element, and (3) wake-interference flow fi intermediate roughness spacing. Expressions for velocity profile and friction fac the last class and for friction factor in the other two are developed in terms of ness dimensions and spacing, pipe size, Karman's universal turbulence function, an numerical parımeters. Good correlation is obtained with the experimental results ( tained in this laboratory as well as with published results from many other source: this country and abroad. It is shown that roughness spacing rather than height is most important roughness parameter.

(g) "A new concept of flow in rough conduits." H. M. Morris, Doctor's Thesis, Universi Minnesota, Oct. 1950. (Available on loan.)

(1394) MODEL STUDIES OF SEDIMENTATION BASINS.

(b) Laboratory project.

(d) Experimental; for master's thesis.

(e) Tests are being conducted on two similar models of different sizes to determine the degree of similarity attained by the use of the Reynolds law and the Froude law. parisons are made between the flow-through efficiency, as determined by the color n and the sediment retention efficiency.

(f) Experimental work is in progress.

(h) "Model study of a sedimentation basin." C. E. Bowers, Master's Thesis, University Minnesota, June 1949. (Available on loan.)

(1395) VELOCITY DISTRIBUTION AND BOUNDARY SHEAR IN A ROUGHENED RECTANGULAR CHANNEL.

(b) Laboratory project.

(d) Experimental; for master's thesis.

(e) Tests being made in the case where the channel surface acts neither "smooth" nor "r. The surface of the channel will be roughened by attaching sand particles varied as size, uniformity of size, and distribution.

(1396) STUDY OF CRITICAL DEPTH IN VERTICALIY CURVED FLOW.

(b) Laboratory project.

(d) Experimental and analytical; for master's thesis.

(e) Determination of true critical depth in vertical curvilinear flow, with emphasis on abrupt change in grade of open channels. Existing information has been assembled 0 : the free over-fall and related weir studies. Experimental tests are underway on th abrupt change in grade of an open channel; the channel bed downstream of the break be set at $45^{\circ}, 30^{\circ}$, and $15^{\circ}$ with the horizontal. The bed-pressure, surface profile and velocity distribution will be measured for variations in discharge.

(1397) PERFORATED PLATE ENTRANCE TO A FLOW-THROUGH SEDIMENTATION BASIN.

(b) Laboratory project.

(d) Experimental for master's thesis.

(e) To determine the effect of perforated plate entrances upon sedimentation in a flowtype basin. Three such entrances, each with a different size of perforation, will studied over a range of discharges. 
Division of Drainage and Water Control, Soil Conservation Service, in cooperation with the Minnesota Agricultural Experiment Station and the St. Anthony Falls Hydraulic Iaboratory.

Experimental; applied research.

Tests have been made on three different sizes of Lucite pipe set on slopes ranging from 2.5 to 30 percent to verify the similarity relationship. Information on discharges, pressures, and flow conditions has been obtained. Future studies will be on the effect of different types of inlets on the flow conditions.

Pipe drop inlet culverts laid on steep slopes will flow completely full even though the outlet discharges freely. Entrained air did not invalidate the Froude model law.

DROP SPILLWAY WITH BOX INLET.

Division of Drainage and Water Control, Soil Conservation Service, in cooperation with the Minnesota Agricultural Experiment Station and the St. Anthony Falls Hyoraulic Laboratory.

Experimental; for design.

Bxperiments are made on 6-inch wide models to determine the effect of different lengths of box, heights of drop, approach channel widths, dike locations, submergences, etc., on the head-discharge curve.

Completed.

"Capacity of box inlet drop spillways under free and submerged flow conditions." Fred $\mathrm{N}$. Blaisdell and Charles A. Donnelly, St. Anthony Falls Hydraulic Laboratory Technical Paper No. 7, Series B, 36 pp., Jan. 1951. (Copies may be obtained at $\$ .50$ each from Director, St. Anthony Falls Hydraulic Iaboratory, Hennepin Island, Minneapolis 14, Minn.)

"Hydraulic design of the box inlet drop spillway." Fred $N$. Blaisdell and Charles A. Donnelly, St. Anthony Falls Hydraulic Laboratory Technical Paper No. 8, Series B, 63 pp., Jan. 1951. (Copies may be obtained at $\$ .80$ each from Director, St. Anthony Falls Hydraulic Laboratory, Hennepin Island, Minneapolis 14, Minn.)

DIVERGING TRANSITION FOR SUPERCRITICAL VELOCITIES.

Division of Drainage and Water Control, Soil Conservation Service, in cooperation with the Minnesota Agricultural Experiment Station and the St. Anthony Falls Hydraulic Laboratory.

Experimental; for design and master's thesis.

Surface contours are determined for different Froude numbers, shapes of entering stream, sidewall flares, bed slope, bed friction, etc.

Suspended.

A STUDY OF CANTILEVERED OUTLETS.

Division of Drainage and Water Control, Soil Conservation Service, in cooperation with the Minnesota Agricultural Experiment Station and the St. Anthony Falls Hydraulic

Laboratory.

Experimental; applied research.

Pipe outlet conduits for small spillways are frequently cantilevered beyond the toe of the earth dam. Attempts will be made to determine quantitatively the size of the scour hole to be expected under various field conditions.

Suspended.

STRAIGHT DROP SPILLWTY.

Division of Drainage and Water Control, Soil Conservation Service, in ccoperation with the Yinnesota Agricultural Experiment Station and the St. Anthony Falls Hydraulic Laboratory.

Experimental; applied research. Spillway is used as a grade control structure in ditches and streams. Study will result in general design rules for the spillway and outlet. Outlet will have floor blocks, end sill, and possibly longitudinal sills. Moveable sand beds are used to evaluate the outlet performance. 
S. MORGAN SMITH COMPANY.

Inquiries concerning Projects Nos. 1399 to 1403, incl., should be addressed to Mr. Emmert M. Lowry, Jr., S. Morgan Smith Company, York, Pa.

(1399) MODEL TEST - INTERMEDIATE SPEED FRANCIS TYPE TURBINE.

(b) Alabama Power Company.

(d) Experimental; applied research for design.

(e) To develop a new munner with a high HP output for a certain specific speed. A mod turbine complete with wheel case and elbow draft tube was tested for efficiency, c tion, munaway speed, etc. under various design conditions to obtain the proper run design.

(f) Completed.

(g) Results incorporated in the final design of the prototype units.

(1400) ADJUSTABLE BLADE AXIAL FIOW PUIMP.

(b) Laboratory project.

(d) Experimental; applied research for design.

(e) To design a physically small, high capacity, low head, axial flow pump. Space lim: for actual installation limited the actual size. The main hydraulic problem was $t$, minimize the exit losses, which in the case of such a low head pump, would be a col able percentage of the total head. Various designs were proposed and tested.

(f) Completed.

(g) Results provide data for improvement of existing designs with respect to the above ditions, and extend the present range of application.

(1401) LOW SPECIFIC SPEED FRANCIS TYPE TURBINE - MODEL TESTS.

(b) Laboratory project.

(d) Experimental; applied research for design.

(e) To develop a high head, low specific speed runner, a model turbine complete with wh case and elbow draft tube was tested for efficiency, HP, and thrust under various conditions to obtain maximum efficiency and minimum thrust.

(f) Completed.

(g) Results used to provide data for improvements to existing designs and incorporated final design of prototype units.

$\left(\mathrm{J}_{1} \mathrm{O2}\right)$ FIXED BLADE PROPELIER MODEL TURBINE TESTS.

(b) Laboratory project.

(d) Experimental; applied research.

(e) To develop a fixed blade propeller turbine to replace high specific speed Francis $t$ bines, models of various designs were tested for efficiency, HP, cavitation, and m speed over a wide range of conditions. A complete setting was provided, involving complete wheel case and elbow draft tube.

(g) Results will be used for pending prototype designs.

(1403) EFFECT OF MODEL ROUGHNESS ON EFFICIENCY.

(b) Laboratory project.

(d) Experimental; applied research.

(e) To determine effect of actual surface finish of the model on the efficiency, a mode turbine was severely roughened by metal blasting and tested for efficiency. In sev steps the model roughness was reduced to provide various degrees of roughness; for degree of roughness it was tested for efficiency. Roughness was measured with an electronic profilometer.

(f) Completed.

(g) Results indicated that the efficiency of the model depends to some degree on the su finish. 


\section{OF NAVAL ARCHITECTS AND MARINE ENGINEEFS.}

THE COMPILATION OF DATA ON SHIP RESISTANCE.

Office of Naval Research, Department of the Navy.

Capt. W. N. Landers, Secretary, The Society of Naval Architects and Marine Engineers, 29 West 39th Street, New York 18, N. Y.

The compilation of the data on ship resistance presently available at the various model basins and in designing offices, and the presentation of these data in a readily usable form.

A critical study and correlation of existing data on the resistance of ship hull models which have been tested. An analysis of these data to determine systematically the influence of differences of hull form on resistance and to establish the fundamentals of the subject.

A standard form entitled "Model Resistance Data" has been developed to record model data and test results. Another form entitled "Expanded Resistance Data" has been prepared for the expansion of the model test results to ship size. Explanatory notes defining the various dimensions, ratios, and coefficients used on the data sheets have been compiled. Model resistance and expanded resistance data sheets covering $10 n$ models have been completed.

"Model resistance and expanded resistance data sheets with explanatory notes for models 1-40." \$4.00 per set to members of the Society of Naval Architects and Marine Engineers, $\$ 5.00$ per set to non-members.

Same for models $41-60$. $\$ 2.00$ per set to members, $\$ 3.00$ per set to non-members.

Same for models $61-80$. \$2.00 per set to members, $\$ 3.00$ per set to non-members.

\section{RD UNIVERSITY, Hydraulic Laboratory.}

Inquiries concerning Projects Nos. 626, 627, 628, 1171 , and 1172 should be addressed to Prof. John K. Vennard, Stanford University, Stanford, Calif.

EFFECT OF POROSITY ON PERMEABILITY.

"Porosity factor for case of laminar flow through granular media." Joseph B. Franzini, Trans. American Geophysical Union, Vol. 32, No. 3, June 1951.

STUDY OF TURBULENT BOUNDARY LAYERS.

Laboratory project.

Experimental; engineer theses.

Pressure drops and velocity profiles downstream from sharp and bellmouth entrances in smooth pipes of various diameters.

Experimental work completed, theses being written.

EFFECT OF SHAPE OF PARTICLE ON SETTLING VELOCITY.

Laboratory project.

Experimental; basic research.

Measurement of fall velocity of particles of regular geometric shape in the turbulent range. Correlation of results with fall velocities of spheres.

Inactive.

STUDY OF MANIFCLD PORTS.

Laboratory project.

Experimental; engineer thesis.

Measurement and interpretation of pressure varlation near outlet ports in manifold pipes and obtaining hydraulic coefficients for various flow geometries.

Experimental work completed; thesis being written. 
(1172) PERMEAMETER WALI EFFECT.

(b) Laboratory project.

(d) Experimental; basic research.

(e) Permeability tests are to be conducted on Ottawa 20-30 sand using variable head per eters of different sizes.

(f) Inactive.

STEVENS INSTITUTE OF TECHNOLOGY, Experimental Towing Tank.

MISCELLANEOUS PROJECTS.

The Experimental Towing Tank carries out an extensive research program of a classif nature for the Bureau of Ships, Bureau of Ordnance, and the Bureau of Aeronautics, Department of the Navy. A large number of projects involving commercial vessels of many different designs for private clients are also undertaken for the determinatic effective horsepower, the resistance, directional stability of barges, the determin of shaft horsepower for river towboats and comparable vessels, resistances under sa conditions of sailing yachts, and the hydrodynamic characteristics of flying boats seaplane floats.

(340) PLANING SURFACES (Project CC839).

(b) Office of Naval Research, Department of the Navy.

(c) Prof. B. V. Korvin-Kroukovsky, Experimental Towing Tank, Stevens Institute of Techn 711 Hudson St., Hoboken, N. J.

(d) Experimental and basic research.

(e) To investigate the fundamental factors affecting the performance of planing surface for application to seaplanes and planing type surface craft, and to investigate the wave shape formed in the wake of such surfaces.

(g) Investigations will extend from elementary planing surfaces of several deadrises th warped surfaces, surfaces with the steps of Vee plan form, and the combinations of forebody and the afterbody planing in its wake.

(h) "On the virtual mass of water associated with an immersing wedge." John D. Pierson Readers Forrum Section, Jour. of Aeronautical Sciences, June 1951. (Also available ETT Note No. 137.)

Reports in preparation:

"Trim, drag, and wetted area of seaplane in two-step planing." B. V. Korvin-Krouko and Daniel Savitsky.

"Lift, wetted area, and center of pressure of planing surfaces at very low speeds." Daniel Savitsky and Joseph W. Neidinger.

(1173) THE DEVELOPMENT OF A TEST TECHNIQUE FOR THE DETERMINATION OF SHIP MODEL RESISTANCE HEAD SEAS (Project TIl98).

(b) Laboratory project.

(c) Mr. Randolph Ashton, Experimental Towing Tank, Stevens Institute of Technology, 711 Hudson St., Hoboken, N. J.

(d) Experimental and developmental.

(e) Resistance tests in waves of ship models (commercial vessels and fast power boats) that the models are about as free as possible to respond to the oncoming waves - in particular, to heave, pitch and surge fore and aft.

(g) Apparatus has been built to tow a ship model in head seas by means of a constant to force, at the same time permitting freedom in heave, pitch and longitudinal surge. Measurements of average speed of advance are made for the time of several wave impa

(h) Technical memorandum in preparation. 
WAKE FRACTION STUDY (Project TI306).

Laboratory project.

Mr. Edward V. Lewis, Experinental Towing Tank, Stevens Institute of Technology,

711 Hudson St., Hoboken, N. J.

Experimental and developmental.

Self-propelled tests of a twin-screw hopper dredge model to compare the wake fraction and thrust-deduction coefficients with two pairs of propellers - each pair having the same diameter but differing in other respects.

Results being analyzed.

Technical memorandum in preparation.

RUDDER FORCE AND TORQUE MEASUREMENTS DURING TURNING (Project 1345).

Maritime Administration.

Mr. John B. Drisko, Experimental Towing Tank, Stevens Institute of Technology,

711 Hudson St., Hoboken, N. J.

To measure turning diameters, rudder stock torque, and lateral rudder force of a proposed ship design for three alternate rudder designs.

Completed.

Experimental Towing Tank Report No. 409, March 1951.

THE DEVELOPNENT OF A DEVICE AND TEST TECHNIQUE FOR MEASURING MODEL PITCH IN WAVES THROUGH THE USE OF A GENERAL ELECTRIC RECORDER (Project TILO8).

Laboratory project.

Mr. Randolph Ashton, Experimental Towing Tank, Stevens Institute of Technology,

711 Hudson St., Hoboken, N. J.

Experimental and developmental.

Pitching tests in waves of ship models (fast power boats and commercial vessels) to

determine the amplitude of pitch directly, through impulses transmitted to a graphical recorder.

IMPACT LOADS ON THE JR2F-I FOR BOW LANDTNG CONDITIONS (Project DE 1314).

Bureau of Aeronautics, Department of the Navy.

Mr. Wilfred C. Hugli, Jr., Experimental Towing Tank, Stevens Institute of Technology,

711 Hudson St., Hoboken, N. J.

Experimental; applied research for design.

A $1 / 16$ scale dynamic model of the JR2F-1 was catapulted at various bow down attitudes. Two self-contained recording accelerometers measured the impact accelerations. Results of the investigation are to be used in evaluating the validity of present design specifications for loads experienced during bow landings in smooth water.

Report in preparation.

TURBULENCE STIMULATION (Project 1376).

National Advisory Committee for Aeronautics.

Prof. B. V. Korvin-Kroukovsky, Experimental Towing Tank, Stevens Institute of Technology, 711 Hudson St., Hoboken, N. J.

Experimental and basic research.

To investigate the methods of stimulating the boundary layer turbulence, and the methods to indicate the state of turbulence on planing surfaces.

SEAWORTHINESS OF SHIPS (Project 1445).

Society of Naval Architects and Marine Engineers.

Prof. B. V. Korvin-Kroukovsky, Experimental Towing Tank, Stevens Institute of Technology, 711 Hudson St., Hoboken, N. J. Experimental and basic research.

To determine the vertical forces and pitching moments acting on a restrained ship model moving against head seas. This project supplements the project on seaworthiness model tests conducted at David Taylor Model Basin and Massachusetts Institute of Technology. 
(108) HYDRODYNAMIC COEFFICIENTS OF AN AIRSHIP (Project EC-1428).

(b) Bureau of Aeronautics, Department of the Navy.

(c) Mr. John B. Drisko, Experimental Towing Tank, Stevens Institute of Technology, 711 Hudson St., Hoboken, N. J.

(d) Experimental.

(e) Experimental determination, utilizing the rotating arm, of the static and rotary $h$ dynamic coefficients of a conventional airship form. Static (straight-line) value been determined by wind-tunnel tests, and the principal reason for curvilinear tes to determine the rotary (damping) coefficients.

(1409) BENDING MOMENT OF SHIPS IN WAVES (Project 1444).

(b) Society of Naval Architects and Marine Engineers.

(c) Mr. Edward V. Lewis, Experimental Towing Tank, Stevens Institute of Technology, 711 Hudson St., Hoboken, N. J.

(d) Experimental method to check calculations.

(e) Stress measurements of jointed model to determine external bending moment underway waves, for comparison with calculated bending moment in "stationary" wave.

(1410) SELF-PROPELLED MODEL TESTING (Project DF-1321).

(b) Office of Naval Research.

(c) Mr. E. V. Lewis, Experimental Towing Tank, Stevens Institute of Technology, 711 Hu Hoboken, N. J.

(d) Experimental and developmental.

(e) Self-propelled tests with models of 7 to 12 foot length and associated theoretical experimental studies of propulsion scale effect.

(g) A testing procedure has been developed which appreciably reduces scale effects and useful comparative results to be obtained.

(h) "Self-propulsion tests with small models." Allan B. Murray, B. V. Korvin-Kroukovs and E. V. Lewis, Society of Naval Architects and Marine Engineers, Summer Meeting, 1951.

(111) PROPELLER MEASURTNG APPARATUS (Project 1440).

(b) Society of Naval Architects and Marine Engineers.

(c) Mr. Allan B. Murray, Experimental Towing Tank, Stevens Institute of Technology, 711 Hudson St., Hoboken, N. J.

(d) Design and construction.

(e) Equipment will be used for the precise measurement of model propellers.

(1412) DESIGN AND CONSTRUCTION OF PROPELLER BOAT (Project 1440 ).

(b) Society of Naval Architects and Marine Engineers.

(c) Mr. Allan B. Murray, Experimental Towing Tank, Stevens Institute of Technology, 711 Hudson St., Hoboken, N. J.

(d) Design and construction.

(e) Apparatus to enable the carrying out of open water tests of ship propeller models.

(1413) AN INVESTIGATION OF SHIP RESISTANCE USING STATISTICAL METHODS (Project CK 1436).

(b) Office of Naval Research.

(c) Mr. Marvin Zelen, and Mr. Samuel Lum, Experimental Towing Tank, Stevens Institute Technology, 711 Hudson St., Hobo ken, N. J.

(d) Applied research.

(e) Approximately 60 single-screw displacement hulls (reduced to a common $400 \mathrm{ft}$ LBP) 1 been selected to investigate the effects of shape and hull parameters on resistanci statistical techniques will involve the applications of regression analysis and pr. components.

(g) Compilation of data nearly complete. Calculation and analysis work in beginning st 
TY OF TENNESSEE, Engineering Experiment Station.

HYDRAULIC FRICTION.

Laboratory project.

Dr. G. H. Hickox, Engineering Experiment Station, University of Tennessee, Knoxville 16, Tenn.

Experimental; basic research.

A long term investigation to determine the relationship between character of roughness of pipe surface and shape of transition curve for resistance coefficients in the range between smooth and rough turbulent flow. Tests are being made in a four inch lucite pipe which is roughened by the insertion of sleeves.

Experimental work suspended.

Progress report in preparation.

NGINEERING EXPERIMENT STATION, A \& M College of TeXas.

CULVERT MODEI TESTS.

Mr. R. E. Schiller, Jr., Department of Civil Engineering, A \& M College of Texas, College Station, Texas.

Experimental; thesis for professional degree.

Tests are being conducted on a 5 inch lucite pipe, 52 inches long, having flared wing walls, to determine the effect of entrance design on discharge.

Earlier tests on smaller models indicate discharges (under free outfall conditions) may be increased as much as $30 \%$ above conventional design, depending on heads on the culvert.

ITY OF TEXAS, Department of Civil Engineering.

Inquiries concerning Projects Nos. 947 , and 948 should be addressed to Dr. Walter L. Moore, Department of Civil Engineering, University of Texas, Austin, Texas.

FACTORS AFFECTING THE BLOW-OUT HEAD FOR A CUT-OFF WALL IN A PERMEABIE MATERIAL.

Laboratory project.

Experimental.

To make preliminary observations of the blow-out process under a vertical cut-off wall in sand and thus check the contention that factors other than the critical exit gradient are significant.

Inactive.

DIFFUSION OF A TWO-DIMENSIONAL SUBMERGED JET.

Laboratory project.

Experimental; M.S. Thesis.

An experimental study of the diffusion of a water jet to determine the influence of a free surface and solid boundaries.

Detailed measurements have been made of the mean-flow characteristics for a hydraulic jump occurring at an abrupt and a beveled step-down in the channel floor.

"A study of the expansion of a two-dimensional jet in combination with a hydraulic jump." Carl W. Morgan, Master's Thesis, June 1951. 
UTAH STATE AGRICULTURAL COLLEGE, Agricultural Experiment Station.

(151) LINING OF IRRIGATION CANAIS AND DITCHES.

See U. S. Department of Agriculture, Soil Conservation Service, Division of Irrig: and Water Conservation, page 94.

(359) DRAINAGE OF IRRIGATED LANDS (Project 285).

(b) Laboratory project.

(c) Dr. O. W. Israelsen, Irrigation Department, Utah State Agricultural College, Logar

(d) Field studies; applied research and masters' theses.

(e) The major purposes are to find low cost, effective methods of drainage of arid-re waterlogged and alkali lands. Work has been concentrated on four Utah areas and or in Canada in need of drainage; (1) the 10,000-acre area in Cache County, (2) the ] acre area in Salt Lake County, designated respectively the Lewiston and the Drapes and (3) the Delta area in Millard County, and (4) the Logan-Cache County Airport: overlying an artesianaquifer. Basic studies of permeabilities of soils and hydrat of wells are reported.

(g) Use of piezometers for low cost development of ground water flow patterns has beer ful in all areas. Pumping from sand formations having permeabilities as low as 3 feet per second shows a measurable influence in lowering the ground water table.

(h) "Design of shallow wells for drainage by pumping." Gregory L. Pearson, Master's I Utah State Agricultural College, May 1949.

"Drainage by pumping in the Lewiston Area, Utah." Paul J. Pehrson, Master's Thesi Utah State Agricultural College, May 1950.

"Draining Lewiston flats will improve land conditions in Cache County." Orson W. Israelsen and Charles D. Stewart, The Sugar Beet, Amalgamated Sugar Company, Ogden "The seepage problem on the south Okanagan lands project, British Columbia, Canada G. P. Williams, Master's Thesis, Utah State Agricultural College, May 1951.

"Effectiveness of gravity drains and experimental pumping for drainage, Delta Area O. W. Israelsen, D. F. Peterson, Jr., and R. C. Reeve, Utah Agricultural Experimen Station, Bulletin 345, Feb. 1951.

"Measurement of permeability of saturated soils below the water table." Naji A. K Ph.D. Thesis, Utah State Agricultural College, May 1951.

"The hydraulics of wells." D. F. Peterson, Jr., O. W. Israelsen, and V. E. Hansen Utah State Agricultural Experiment Station Bulletin 351, in press (technical). 19 "Drainage of land overlying an artesian aquifer at Logan-Cache Airport." J. P. Ri Irrigation Engineer's Thesis, Utah State Agricultural Coll.ege, May 1952.

"Landslides as influenced by irrigation and drainage on the Uncompahgre project la in Western Colorado and along the West Cache Irrigation Company canal in Idaho." George P. South, Master's Thesis, Utah State Agricultural College, May 1950.

(1189) METHODS OF CONTROL AND DISTRIBUTION OF WATER.

See U. S. Department of Agriculture, Soil Conservation Service, Division of Irriga and Water Conservation, page 97.

(1190) DISTRIBUTION OF WATER FROM PERFORATED PIPE.

See U. S. Department of Agriculture, Soil Conservation Service, Division of Irriga and Water Conservation, page 97.

(1191) DETERMTNATION OF THE DISCHARGE FROM HORIZONTAL PIPE BY THE COORDINATE METHOD.

See Utah State Agricultural College, Engineering Experiment Station, page 82.

(1192) FLOW THROUGH FLEXIBLE NON-EIASTIC PIPE.

(b) Cooperative with Soil Conservation Service, Division of Irrigation and Water Conse and Irrigation Department of the Utah State Agricultural College.

(c) Dr. Vaughn פ. Hansen, Soil Conservation Service, College Hill, Box 70, Logan, Utah 
Experimental and theoretical; applied research, master's thesis.

A light-weight, flexible, non-elastic pipe has recently been developed to convey water. As very little is known regarding the hydraulic properties of this material they are being studied.

PERMEABILITY AND STABILITY OF SOIL AND SOIL MATERIAL.

See U. S. Department of Agriculture, Soil Conservation Service, Division of Irrigation and Water Conservation, page 97.

'ATE AGRICULTURAL COLLEGE, Engineering Experiment Station.

Inquiries concerning Projects Nos. 949, 950, 1178, and 1179 should be addressed to Dean J. E. Christiansen, Engineering Experiment Station, Utah State Agricultural College, Logan, Utah.

\section{DRAINAGE OF IRRIGATED IANDS.}

See Utah State Agricultural College, Agricultural Experiment Station, page 80.

MODIFIED VENTURI SECTION FOR MEASURING FLOW IN OPEN CHANNEIS (Project 14).

Cooperative with Geological Survey, Armco Drainage and Metal Products Company, and Douglas Fir Plywood Association. Field studies conducted at outdoor cooperative (Soil Conservation Service, Utah State Agricultural College) Irrigation Research Laboratory. Experimental and field investigation; applied research and development, masters ' theses. To develop a satisfactory water-measuring device for open channels on very flat gradients. Completed for present.

A practical device for field use has been developed. Test data were not entirely satisfactory for final publication. Additional work needed.

"A modified venturi section for measuring irrigation water in open channels." J. E. Ferguson and J. E. Garton, Agricultural Engineering, Vol. 30, No. 12, pp 584-585, Dec. 1949.

"A field study of a modified venturi section for measuring irrigation water in open channels." J. E. Garton, Master's Thesis, 1950.

"The hydraulic characteristics of a modified venturi section for use as a water measuring device in open channels." Torlief Skjersett, Master's Thesis, 1951.

AN INVESTIGATION OF FRICTION LOSSES IN ALUNINUM TUBING AND COUPLINGS (Projects 18 and 27).

Cooperative with Aluminum Company of America.

Experimental; applied research and master's thesis.

To determine friction loss in aluminum tubing and losses at commercial couplings. Addi-

tional studies being made on aluminum irrigation pipe with deflection angles at couplings.

"The determination of the friction factor for new and used aluminum tubing and head loss

in sprinkler pipe couplers." Howard M. Olson, Master's Thesis, 1950.

"A study of hydraulic losses in sprinkler irrigation couplers." Donald Alan Buhr,

Master's Thesis, 1950.

\section{A STUDY OF THE FACTORS AFFECTING PERMEABILITY OF SOILS TO WATER (Project 23).}

Cooperative with Utah Agricultural Experiment Station.

Experimental and theoretical; basic research, for doctor's thesis.

A careful study of the validity of the equation $k=c^{2} d^{2} / \mu(I+e)$ for the permeability of granular materials. Ottawa sands were prepared by sieving to obtain grains of as nearly uniform size as possible. Tests were conducted with different densities of packing. Completed.

"An anlytical and experimental study of the permeability of sand." Bakir Kashif Alghita, Ph.D. Thesis, 1951. 
(1179) MEASUREMENT OF PERMEABILITY OF SATURATED SOILS BELOW THE WATER TABLE (Project 24 ).

(b) Cooperative with Utah Agricultural Experiment Station.

(d) Experimental and theoretical; applied research for doctor's thesis.

(e) To determine factors affecting the Kirkham method of measuring permeability of sat soils below the water table for various boundary conditions.

(f) Completed.

(h) "Measurement of permeability of saturated soils below the water table." Naji Abdu Ph.D. Thesis, 1951.

(1191) DETERMTNATION OF THE DISCHARGE FROM HORIZONTAL PIPE BY THE COORDINATE METHOD.

(b) Cooperative with Soil Conservation Service, Division of Irrigation and Water Conse and Utah Agricultural Experiment Station.

(c) Mr. Vaughn $\mathrm{E}$. Hansen, Division of Irrigation and Water Conservation, Soil Conserva Service, Logan, Utah.

(d) Experimental and theoretical; applied research, Master's thesis.

(e) To determine the coefficient of discharge for the flow from a horizontal pipe as $d$ mined by the coordinate method. This coefficient has been assumed to be one, whicl definitely not the case in the majority of problems encountered in the field. The are being conducted so that the method may be applied with confidence to the measu of water.

STATE COLLEGE OF WASHINGTON, Division of Industrial Research.

(1180) PRESSURE GENERATION IN PIPES FROM THE RELEASE OF AIR.

(b) Cooperative with Concrete Products Association of Washington.

(c) Mr. J. A. Roberson, Division of Industrial Research, Washington State College, PuI: Wash.

(d) Experimental and field investigation; applied research.

(e) Known volumes of air were released through a constricted vent from an open water $p$ system to produce water hammer. Various vent-main pipe diameter ratios were used. Analytical results compared favorably with experimental results. Current research being done on proper design of irrigation pipe lines to eliminate the water hammer dition.

(g) Results show that water hammer pressures are generated when an entrapped air mass released from a constricted vent or partially opened valve. Water hammer pressure may have appreciable effect on the failure of unreinforced concrete irrigation pip

(h) Progress reports to the Concrete Products Association of Washington, Mar. 1951, Se] 1951. Available upon request.

JNIVGRSITY OF WASHINGTON, Department of Civil Engineering.

Inquiries concerning Projects Nos. 642, 644, 1416 and 1417 should be addressed to H. K. Moritz, Department of Civil Engineering, University of Washington, Seattle 5.

(642) A STUDY OF THE VALIDITY OF THE USE OF THE HYDRAULIC RADIUS AS A MEANS OF CORRELATT RELATIONSHIPS OF FLOW IN CONDUITS OF DIFFERENT SHAPES.

(b) Laboratory project.

(d) Experimental; basic research. 
A series of tests to determine the relationships of the flow functions to the hydraulic radius in channels of different shapes. The project is intended to correlate the work done on closed conduits of various shapes and that done on pipes. It is tributary to Project No. 644 .

Data on closed conduits complete and being analyzed. No data on open conduits.

FLOW IN PIPES AND CHANNEIS.

Laboratory project.

Experimental; basic research.

To establish a means conforming to modern concepts of flow identifying pipe and channel surfaces in relation to their resistance to passage of water, and to introduce a practical formula for applying a specific roughness coefficient, once found, to any size pipe or channel.

Suspended pending completion of several tributary investigations.

Definite concepts of the relations between the types of flow in pipes, and of the relation of the resistance to flow of water in pipes to specific roughness, have been developed.

HYDRAULIC JUMP CHARACTERISTICS IN CIRCULAR CONDUITS.

Laboratory project.

Experimental.

Jump will be provoked in circular conduits by restricting the entrance and gating the exit. Control elements will include slope and quantity variation, and the size of the entrance restriction. Depth and average pressure head readings will be observed by means of piezometers. The experiment is directed toward verification of the mathematical theory of the hydraulic jump based upon the law of conservation of momentum. It will also include a study of the jump characteristics, considering height, length, and factors which affect its stability. Research intended to extend results of Lane and Kindsvater. (Ing. News-Record, Dec. 29, 1928).

STATIC HEAD REQUIRED TO PRODUCE A FULL FLOWING CONDUIT.

Laboratory project.

Theoretical and experimental.

Investigation of the ratio of headwater elevation to pipe diameter needed to develop an absolutely full flowing pipe. Rational analysis of the critical depth caused by an increasing static head loses continuity when the critical depth approaches the limit of the pipe diameter. Complete understanding of the transition from gravity flow to pressure flow is the intended gœl.

PRESSURE IEASUREMENTS FOLIOWING ABRUPT EXPANSION.

Laboratory project.

Mr. J. E. Colcord, Department of Civil Engineering, University of Washington, Seattle 5, Wash.

Experimental and theoretical; basic research.

A study of the magnitude of the pressure rise following an abrupt expansion, comparing theory to the results from two and three-dimensional test expansions. A study will also be made of the eddy patterns in an abrupt expansion with the aid of plastic equipment, polarizing materials, and a bentonite suspension. 
UNIVERSITY OF WISCONSIN, Hydraulic Iaboratory.

Inquiries concerning Projects Nos. 956, 957, 958, and 1181 should be addressed to Dr. J.R. Villemonte, and Projects Nos. 1419, 1420 , and 1421 to Dr. Arno T. Ienz, Hydraulic Laboratory, University of Wisconsin, Madison 6, Wis.

(646) BEHAVIOR OF OIL-IATER SEPARATORS.

(b) American Petroleum Institute.

(c) Dr. G. A. Rohlich, Hydraulic Laboratory, University of Wisconsin, Madison 6, Wis.

(d) Experimental and theoretical; basic research.

(e) Determination of hydraulic characteristics of separating tanks. This is accomplis by dosing the influent with sodium phosphate and making chemical tests at regular vals to indicate the phosphorous concentration in the effluent. Retention studies wax spheres of 200 microns diameter are being used to evaluate performance of infl and effluent baffles.

(g) Vertical slot influent baffle with 3 to 7 percent net area gives best flow charact istics.

(h) "Hydraulic characteristics of gravity-type oil-water separators." Dr. G. A. Rohli Proc. API, 31 M (III), 1951. Univ. of Wisconsin Engineering Experiment Station Re No. 181 .

"The fundamentals and performance of gravity separation." Dr. A. C. Ingersoll, $\operatorname{Pr}$ API, 31 M (III), 1951.

(956) HEAD IOSSES IN FION OF IIQUIDS IN PIPES UNDER HIGH LINE PRESSURES.

(b) Cooperative with Ladish Company, Cudahy, Wis.

(d) Experimental; for master's and doctoral theses.

(e) A circulating system of 2-inch seamless steel pipe with oil flowing will contain a foot section in which energy losses will be measured by latest type strain gages. pressures will be varied from 100 to 2000 psi and show the effect of high line pre on the friction factor for both laminar and turbulent flow.

(957) THE THERMODYNAMICS OF IIQUIUS.

(b) Laboratory project.

(d) Experimental; for doctoral, master's and bachelor theses.

(e) The effects of temperature $\left(35-130^{\circ} \mathrm{F}\right)$ and pressure $(0-2200 \mathrm{psig})$ on the viscosity wide variety of liquids are being observed by use of a new type falling-ball visco

(g) Tests have been completed on one grade of Klondike Medium Oil (Pure Oil Company).

(958) HEAD IOSSES IN FIOW OF IIQUIDS IN WELDING PIPE FITTINGS.

(b) Cooperative with Ladish Company, Cudahy, Wis.

(d) Experimental; for master's and doctoral theses.

(e) Head losses over and above those in straight pipe of same centerline length will b observed for a wide variety of welded pipe fittings, including one and two gore mi

(g) Coefficients $\mathrm{K}$, in equation $\mathrm{H}=\mathrm{Kv}^{2} / 2 \mathrm{~g}$, are as follows for 4 -inch fittings (veloc 1-20 fps):

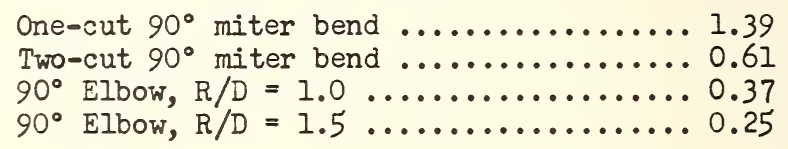

The settling length for all fittings was 40 diameters at a velocity of 20 fps.

(h) "Inergy loss in liquid flow in welding pipe fittings." G. J. Caspary, M. S. Thesi June 1951. (Available on loan.) 


\section{VORTEX FIOW FROM HORIZONTAL THIN-PIATE ORIFICES.}

Cooperative with $\mathbb{P}$. J. C. Stevens, Portland, Ore.

Theoretical and experimental; for doctoral and master's theses.

Existing fundamental considerations are being studied and a new practical approach has been developed. Initial vorticity can be completely controlled, and measurements of head, discharge, and surface profile can be made. Orifice diameters will vary from 3 to 12 inches.

Some tests have been completed on a 4 -inch diameter sharp-edged orifice. The functional relation between head and vorticity and standard orifice discharge coefficient has been determined experimentally and represented as a three-dimensional plot. Vortex flow with free radial approach produced standard discharge coefficients for the orifices tested. "Vortex flow from horizontal thin-plate orifices." R. C. Kolf, M. S. Thesis, June 1951. (Available on loan.)

HEADWALL ANGLE EFFECT ON BOX INLET DISCHARGE.

Laboratory project.

Experimental; applied research for master's thesis.

An 8-inch wide (W) box inlet culvert with lengths $I=1 / 2 \mathrm{~W}, \mathrm{~W}$, and $2 \mathrm{~W}$, and depths $D=$ $\mathrm{W}, I / 2 \mathrm{~W}$, and $I / 4 \mathrm{~W}$ was tested for heads up to $0.7 \mathrm{I}$ with wingwall angles from $45^{\circ}$ to $90^{\circ}$.

For heads less than those required for submergence ( $H / L=0.10 \pm$ ), the $45^{\circ}$ wingwall reduced the coefficient and discharge as much as 20 percent. For greater heads the discharge was dependent upon depth of box but independent of wingwall angle.

"Headwall angle effect on box inlet discharge." G. A. Ekerdt, M. S. Thesis, June 1951. (Available on loan.)

FORECASTING SNOHMELT RUNOFF, BIG EAU PLEINE RIVER, WISCONSIN.

Wisconsin Valley Hydrologic Research Project.

Experimental for Ph.D. thesis.

Using readily available U. S. Geological Survey and Weather Bureau records a method was developed for forecasting the spring runoff volume caused by snowmelt.

By making use of accumulated winter precipitation, length of snowmelt season, antecedent precipitation from Sept. I to beginning of snow accumulation, and depth to groundwater at a key observation well, it was possible to predict runoff in inches which when added to precipitation curing the snowmelt period correlated with measured runoff with a maximum error of 0.68 inches in 12 years studied.

"Forecasting snowmelt runoff, Big Eau Pleine River, Wisconsin." D. K. Fuhriman, Ph.D. Thesis (includes 100-item bibliography), Feb. 1952. (Available on loan.)

CONSUMPTIVE USE OF WATER IN WISCONSIN.

Laboratory project.

Experimental; for B.S. thesis.

Using precipitation and temperature data, consumptive use of agricultural crops was determined by the Blaney-Criddle method for 5 areas in Wisconsin.

Consumptive use of water by potatoes for average rainfall and temperature conditions varies from 17.2 to 18.6 inches in areas where supplemental irrigation is practiced. Irrigation demand averages from 3.8 to 5.8 inches. A probability study indicated that at Antigo 8 inches or more are required for 10 percent of the time.

"Consumptive use of water in Wisconsin." W. G. Ballantine and F. H. Larson, B.S. Thesis, June 1951. (Available on loan.) 
WORCESTER POLYTECHNIC INSTITUTE, Alden Hydraulic Iaboratory.

Inquiries concerning Projects Nos. 961, 1184, and 1422 to 1426 , incl., should be addressed to Prof. I. J. Hooper, Alden Hydraulic Laboratory, Worcester Polytechnic Institute, Worcester 2, Mass.

(961) VALVE TESTS.

(b) Chapman Valve Company.

(d) Experimental; for design.

(e) Head loss measurements for various discharges were made on a 24-inch disc type chec valve. Closure time and pressure changes were determined photographically for vari flows up to $45 \mathrm{cfs}$.

(f) Inactive. Work will be continued.

(1184) C. J. STRIKE POWER DEVELOPMENT.

(b) Ebasco Services, Inc.

(d) Experimental; for design.

(e) A 1:40 model of the proposed spillway and apron were constructed to study the hydra jump formation and to study spillway performance for various gate operations.

(f) Completed; report being written.

(1422) CABINET GORGE POWER DEVELOPMENT.

(b) Ebasco Services, Inc.

(d) Experimental; for design.

(e) A 1:60 model including section of river, arch dam, powerhouse and diversion tunnels constructed to study flow conditions from foot of dam to beyond powerhouse. Flow $c$ ditions for various gate operations were also studied.

(1423) WANETA POWER DEVELOPMENT.

(b) Stone and Webster Engineering Corporation.

(d) Experimental; for design.

(e) A 1:70 model including section of river, gravity dam and powerhouse was constructed study flow conditions on apron of spillway and in vicinity of powerhouse.

(1424) YALE POWER DEVELOPHENT.

(b) Ebasco Services, Inc.

(d) Experimental; for design.

(e) A 1:70 model of the proposed chute spillway and the section of the river into which discharges are being constructed to study flow conditions in the chute and jump con tions at the apron.

(1425) CALIBRATION OF IRRIGATION IETERS.

(b) Hersey Meter Company.

(d) Experimental; for design.

(e) Several 8, 10, and 12 inch meters were tested to determine flow characteristics.

(f) Completed.

(1426) CALIBRATION OF FION NOZZLES.

(b) General Electric Company.

(d) Experimental.

(e) Several flow nozzles for installation in 6, 8, and 10 inch pipe are being calibrate 
JEPARTMENT OF ACRICULTURE, FOREST SERVICE, California Forest and Range Experiment Station.

Inquiries concerning Projects Nos. 261 and 1186 should be addressed to Mr. Stephen N. Wyckoff, California Forest and Range Experiment Station, P. O. Box 245, Berkeley 1, Calif.

WATERSHED MANAGEMENT RESEARCH, CALIFORNIA.

Laboratory project.

Experimental, field investigation; basic and applied research.

Purposes are: (1) to study the disposition of rainfall as influenced by watershed con-

ditions, including vegetation, soils, geology, and topography; and (2) to develop methods of watershed management, including the treatment of areas denuded by fire, to assure naximum yield of usable water, and satisfactory regulation of flood runoff and erosion. Major work center is the San Dimas Experinental Forest. Rainfall, runoff, and erosion are measured on two main drainage areas, on ten large and seven small watersheds within these areas, and on eighteen experimental plots. Twenty-six large lysimeters furnish comparisons of the use of water by various species of plants. Climatic data are obtained from several meteorological stations. Studies of runoff and erosion as influenced by fire and the revegetation of large burns are in progress elsewhere in California. Studies in the improvement of vegetation cover density for increase of soil stability are in progress in the Ios Angeles River watershed and at Pasadena in cooperation with the California Institute of Technology.

A network of rain gages tilted and oriented according to watershed slopes is a better rainfall sampling system than a network of vertical gages for mountainous areas. A field survey of the soil stability on the Los Angeles River watershed was completed and a rough draft report prepared. Fifty-five native plants were excavated by hydraulic means. Chamise (Adenostoma fasciculatum) had the longest roots with a maximum length of 12 to 17 feet and depth of penetration from 4.5 to 11 feet.

"Some aspects of watershed management in southern California." San Dimas Experimental Forest staff, California Forest and Range Experiment Station Misc. Paper No. 1, 1951. "Fire and water in southern California's mountains." E. A. Colman, California Forest and Range Experiment Station Misc. Paper No. 3, 1951.

"Calibration of fiberglas soil-moisture units." T. M. Hendrix and E. A. Colman, Soil Science $71(6): 419-427,1951$.

"Interception of rain and snow by second growth ponderosa pine." P. B. Rowe and T. M. Hendrix, Trans. Amer. Geophys. Union, Dec. 1951.

"San Dimas rainfall and wind velocity recorder." E. L. Hamilton, Bull. Amer. Meteoro. Soc. 32(1): 32-33, 1951 .

FIOOD CONTROL SURVEY RESEARCH, CALIFORNIA AND WESTERN OREGON.

Laboratory project.

Experimental, field investigation; statistical studies in applied research. To furnish a physical base for evaluation of flood control measures as they affect flood and sediment damages. Emphasis is on the determination of the influence of "land use" on frequency of flood peaks, annual and seasonal yields of water, and sediment production from whole watersheds.

Suspended sediment concentration in the streamflow of 14 south coastal watersheds in California was found to be related to the physical characteristics of the soils formed on the various geologic types and to the average brush cover density on the watersheds. For 24 tersheds of the Willamette Basin in Oregon, flood peaks were found to be more closely related to the forest condition on the watershed as expressed by the age and degree of stocking of the forest cover than to the amount of area that had been logged. "Physical characteristics of soils related to erosion." H. W. Anderson, Jour. Soil and water Conserv. 6(3): 129-133, 1951. 
U. S. DEPARTVENT OF AGR ICULTURE, FOREST SERVICE, Division of Forest Influences.

(1427) FUNDAMENTAL PLANT-SOIL-WATER RELATIONS.

(b) Division project.

(c) Dr. H. G. Wilm, Division of Forest Influences, Forest Service, U. S. Department of Agriculture, Washington 25, D. C.

(d) Theoretical (analytical); basic research.

(e) Analysis of basic data concerning plant-soil-water relations and interpretation of effects of these relations upon streamflow under various forest and range conditions and uses.

(f) Completed.

(h) "Some fundamental plant-soil-water relations in watershed management." Leon Lassen, Howard W. Lull, and Bernard Frank. Division of Forest Influences, Forest Service, U. S. Department of Agriculture, Washington 25, D. C. Multilithed - limited edition (available on request and on loan in field research stations and libraries of Forest Service).

(128) SOIL MOISTURE AND INFILTRATION PROJECT.

(b) Cooperative with Waterways Experiment Station, Corps of Engineers, Vicksburg, Miss.

(c) Mr. H. W. Lull, U. S. Forest Service, c/o Waterways Experiment Station, Vicksburg, M

(d) Experimental; basic research.

(e) Development of certain fundamental principles involved in plant, soil and water rela including methods for forecasting rates of soil moisture accretion and depletion for specified vegetation, soil, and climatic conditions.

(h) "A progress report on the development of methods for predicting soil moisture conten E. J. Dortignac and H. W. Lull, Vol. I and II, Nov. 1951.

U. S. DEPARTMENT OF AGR ICULTURE, FOREST SERVICE, Intermountain Forest and Range Experiment Station.

Inquiries concerning Projects Nos. 652 to 655, inclusive, should be addressed to the Director, Intermountain Forest and Range Experiment Station, Ogden, Utah.

(652) SOIL REIATIONS (IN WATERSHED MANAGEMENT AND PROTECTION).

(b) Laboratory project.

(d) Experimental and field investigation; basic and applied research.

(e) Tests on plots and small watersheds of the effects of forest, brush, and herbaceous plant cover in natural, depleted, and restored condition on the infiltration, storag fertility, biology and stability of forest and range land soils; to determine land-ui practices for stabilizing eroding watershed soils and for maintaining soil stability under the impact of grazing, logging, and other wild land uses. Studies are under we. on coarse, granitic soils of southwest Idaho; various soils on steep slopes of Wasat, Mountains in northern Utah; and on heavy.limestane soils in the Wasatch Plateau in central Utah.

(g) On steep granitic soils of southwestern Idaho, overland flow and erosion increased a: ground cover density decreased and as size of bare soil openings in the ground cover increased. In Wasatch Mountains of northern Utah, removal of ground cover converted nonflood source area to an overland flow and sediment producing area. On subalpine range land of Wasatch Plateau in central Utah, reduction in total plant cover by ove grazing resulted in greatly increased erosion during summer storms.

(h) "An approach to watershed protection criteria." Paul E. Packer, Jour. Forestry, 49 (? 639-644. 1951 .

"Status of research on watershed protection requirements for granitic mountain soils southwestern Idaho." Paul E. Packer, Intermountain Forest and Range Experiment Stat: Research Paper No. 27, 20 p. 1951. 
"Summer storm runoff control requirements on aspen sites in northern Utah." Richard B. Marston, accepted by Jour. of Forestry for publication.

"Some methods for relating sediment production to watershed condition." J. M. Rosa and M. H. Tigerman, Intermountain Forest and Range Experiment Station Research Paper No. 26, 18 p. 1951.

WATER REIATIONS (IN NATERSHED MANAGEMENT ANU PROTECTION).

Laboratory project.

Experimental and field investigation; basic and applied research.

Tests on watersheds of the effects of forest, brush, and herbaceous plant cover, and of mechanical soil stabilization structures, on runoff characteristics of mountain watersheds; to determine land use treatments required for flood control and for maximum yields of usable streamflow.

Long-range streamflow studies are under way on experimental watersheds at Great Basin Research Center near Ephraim, Utah, and Wasatch Research Center, Farmington, Utah. "Watershed management with particular reference to forest and range lands." Prepared for the President's Water Resources Policy Commission, Forest Service, U. S. Department of Agriculture, Washington, D. C. Mimeographed, 23 p. with Appendix 20 p. Aug. 1950. "Watershed management: the forester's challenge." George W. Craddock, Ames Forester, $38: 37-44$. 1951.

"Relation of our forests to water supply." A. R. Croft and Marvin D. Hoover, Jour. of Forestry, $49(4): 245-249$. 1951 .

"Watershed management: key to resource conservation." Reed W. Bailey, Proc. 15th North American Wildlife Conference, pp. 68-75, 1950. (Reprinted in Jour. Forestry, 49(9):393-396, Sept. 1950.)

\section{PIANT REIATIONS (IN WATERSHED MANAGEMENT AND P.ZOTECTION).}

Laboratory project.

Experimental and field investigation; basic and applied research.

Tests on plots and watersheds of the effects of forest, brush, and herbaceous cover on interception and evapo-transpiration losses; to determine the kind of plant cover required for producing maximum yields of useful runoff from watersheds. Principal effort now limited to study of evapo-transpiration loss from herbaceous cover on Wasatch Mountains, Northern Utah.

Completed three years of study in aspen-herbaceous cover. Results indicate that removal of the deep-rooted aspen trees from an aspen-herbaceous type increases water available for streamflow. Removal of aspen or any deep-rooted species may be a feasible means of increasing streamflow. Treatment should not be undertaken unless it is absolutely certain that it will not result in overland flow from summer rains.

\section{CLIMATIC REIATIONS (IN WATERSHED MANAGEMENT ANU PROTECTION).}

Laboratory project.

Experimental and field investigation; basic and applied research.

Measurements and studies of climatic factors including precipitation, temperature, wind, etc., that have a bearing on the hydrologic behavior of forest and range watershed lands. Studies are confined to experimental watershed areas at the Boise Research Center near Idaho City, Idaho, Wasatch Research Center, Farmington, Utah, and Great Basin Research Center, near Ephraim, Utah.

Precipitation records at four stations indicate that precipitation increases linearly with elevation as given by the equation $P=0.00494 \mathrm{E}-16.95$. ( $P$ is precipitation in inches, $E$ is elevation in feet.) Yearly pattern of precipitation is that of a sine curve, with a broad crest in late winter and a broad trough in late summer. On steeply sloping lands of south central Idaho, the best opportunity for maximum snow storage and retention in old growth ponderosa pine forest exists on north slopes, where greatest storage and retention effects can be obtained by creating large openings in the forest stand. Numerous small openings and a high percentage of sapling stand area would be almost as effective. Large openings on sunny aspects are least effective.

"Precipitation in relation to altitude in central Utah." Howard W. Lull and Iincoln Ellison, Ecology 31(3):479-484. 1950.

"Snow accumulation and retention on ponderosa pine lands in Idaho." H. F. Haupt, accepted for publication by Jour. Forestry, 1951. 
U. S. DEPARTMENT OF AGRICULTUR פ, FOREST SERVICE, Northeastern Forest Experiment Station.

Inquiries concerning Projects Nos.656, 966, 967, 1187, and 1188 should be addressec Dr. Ralph W. Marquis, Northeastern Forest Experiment Station, 102 Motors Avenue, Up] Darby, $\mathrm{Pa}$.

\section{(656) FOREST INFLUENCES INVESTIGATION (WATLRSHED MANAGEMINT).}

(b) Cooperative with the Pennsylvania Department of Forests and Waters and U. S. Geolog: Survey.

(d) Field investigation; basic and applied research.

(e) Studies have been started on the Delaware-Lehigh Experimental Forest, Monroe County, to determine the water economy for a watershed covered with scrub oak. Afterwards, cover will be converted by planting and fire protiction to a commercially valuable: and the effect on water relations will be measured. Installations have been establ: to evaluate all components of a water balance equation for the watershed.

(h) Progress report covering hydrologic years 1948-49 and 1949-50 being printed.

(966) FOREST INFIUENCES INVISTIGATION (NATERSHED MANAGEMLNT).

(b) Laboratory project.

(d) Field investigation; basic and applied research.

(e) Studies on the Pocono Experimental Forest, Wayne County, Pa., to determine effects forest management practices and logging operations upon the quantity and quality of water yielded by a small watershed.

(967) STUDY OF THE EFFECT OF SOIL AND COVER CONDITIONS ON SOIL MOISTURE REIATIONSHIPS.

(b) Laboratory project.

(d) Field investigation; applied research.

(e) Soil cores were obtzined under different conditions of soil, cover, and use on the Allegheny watershed. Tests were made on about 1,000 cores to determine percolation detention storage capacity, retention storage capacity, volume weight, and organic c tent, for use in flood control surveys to permit more accurate estimates of the incr in infiltration and water storage resulting from a program of land management.

(f) Completed.

(g) Analysis of percolation rates and storage capacities showed that land cover and use primarily affect the upper soil horizons. In the lower horizons the principal factc affecting soil moisture values are texture and drainage. Within the forest, grazing resulted in a greatly reduced rate of water movement and amount of detention storage throughout the A horizon. The effect of cover and use was greatest in the A horizor gradually diminished throughout the $B$ horizon. In the $C$ horizon no significant diff ence between soil moisture values were detected for differing conditions of cover ar use.

(h) "Effect of soil and cover conditions on soil-water relationships." G. R. Trimble, C. E. Hale, and H. S. Potter, Northeastern Forest Experimental Station Paper No. 39, Feb. 1951 .

(1187) FROST STUDIES IN THE NORTHEASTERN UNITED STATES.

(b) Laboratory project.

(d) Field investigation; applied research.

(e) To determine the effect of land use and condition upon type and depth of frost forma Periodic observations of frost type and depth, snow depth, and water content are mac upon a large number of plots in New England, New York, and northern Pennsylvania, s $\epsilon$ to sample a variety of land uses and conditions within certain land use classes. Or vations were made on 186 plots during the winter 1950-51, and will be continued thrc the winter 1951-52. 
Observations during the winter 1950-51 show that concrete-type frost forms earlier and reaches to over 10 inches in depth sooner on open land than on forest land. Hardwood forests have less concrete frost than coniferous forests of the same stand-size class. Concrete frost was gone from hardwood sawtimber stands from four to six weeks before its disappearance in coniferous sawtimber stands. Seedling and sapling stands contained more concrete frost than pole stands, which in turn had more concrete frost than sawtimber stands. Stands in which the forest floor had been destroyed or greatly altered by fire or livestock grazing contained much more concrete frost than less disturbed areas.

\section{FOREST INFLUENCES INVESTICA TION (TATTRSHED MANAGFRENT) .}

Laboratory project.

Field investigation; basic and applied research.

Studies on the Fernow Experimental Forest, Tucker County, W. Va., to determine the effect of different levels of cutting practices and different logging methods upon water quantity and quality. Five watersheds have been equipped with streamgaging stations and raingages. No logging will be done during a calibration period.

DEPARTMENT OF AGRICULTURE, FOREST SERVICE, Northern Rocky Mountain Forest and Range iment Station.

\section{FOREST INELUENCES INVISTIGATIONS.}

Laboratory project.

Ur. George M. Jemison, Northern Rocky Mountain Forest and Range Experiment Station, Missoula, Mont.

Field investigation; applied research.

To develop a detailed hydrological analysis for a small timbered watershed. Also to determine effect of forest cover and other site factors on accumulation of snowfall, rate of snowmelt, and movement of snowmelt water. Work under way at Priest River Experimental Forest, Idaho.

DEPARTMENT OF AGRICULTURE, FOREST SERVICE, Pacific Northwest Forest and Range Experiment on.

EFFECT OF LOGGING AND OTHRR FOREST OPERATIONS ON STREAM FIOW.

Laboratory project.

Mr. R. W. Cowlin, Pacific Northwest Forest and Range Experinent Station, 423 U. S. Courthouse, Portland 5, Ore.

Field investigation; basic research.

(1) Blue River Experimental Forest, in the McKenzie River drainage of west central Oregon; installations still being made; (2) Entiat River study watersheds near Wenatchee, Washington; no work yet begun; (3) Starkey Experimental Range study watersheds near Lacrande, Oregon; no work yet begun; (4) hydrologic analysis of streams in western Oregon and western ilashington; still underway by Division of Flood Control Surveys, with streams in eastern Oregon and eastern Washington now added; (5) soil studies temporarily discontinued; (6) sediment sampling was carried on from October 1950 to May 1951 in several streams of western Oregon and western Washington, and begun again this year in some of the same streams and in several more in eastern Oregon and eastern Washington. A progress report on project 6 is being prepared. One noteworthy observation on project 6 was the 38,400 ppm of sedinent in a sample from the Coquille River at the peak of the flood October 28, 1950. 
(h) "Floods of October 1950 in Southern Oregon." Division of Flood Control Surveys rep Jan. 1951.

"The October floods of Southwestern Oregon - some observations and speculations." $R$ Sartz, Jour. of Forestry, Vol. 49, No. 3, Mar. 1951.

"Wivtershed management and flood control surveys." H. G. Wilm, Jour. of Forestry, V No. 7, July 1951.

"Use of snow surveys in planning regulation of Columbia River floods." H. G. Wilm, Work and M. W. Nelson, Proc. 19th Annual Meeting Western Snow Conference, July 1951 Tech. Bul. No. 683, Oregon Agricultural Experiment Station.

"Further observations on soil freezing in the Pacific Northwest." C. E. Hale, Paci Northwest Forest and Range Experiment Station Research Note No. 74, Oct. 1951.

U. S. DEPARTMENI OF AGR ICULTURE, FOREST SERVICE, Rocky Mountzin Forest and Range Experiment Station.

(376) FOREST INFLUENCES RESEARCH, MANITOU EXPER IMENTA I FOREST.

(b) Laboratory project.

(c) Dr. I. D. Love, Rocky Mountain Forest and Range Experiment Station, Fort Collins, C,

(d) Field investigations, applied research.

(e) Studies of the influence of grazing, timber cutting, and revegetation of depleted we shed lands upon water supplies, and upon erosion and sedimentation, to solve proble in watershed management for the forest and range covered watershed lands of the Rocl Mountain Front lange.

(g) An increase in surface runoff from bunchgrass ranges as grazing pressure was intens: was found from natural precipitation on permanently established plots and from arti. cially applied rainfall on infiltration plots. Erosion on permanent plots continues normal rates under moderate grazing, but doubled when grazing heavy. The remove litter from stands of young ponderosa pine more than doubled runoff and increased si erosion 72 times in the first year of treatment. After 9 seasons of needle fall acr lation the treated plots are again reacting similarly to those untreated. Two smal: watersheds burned to encourage aspen growth and two burned to encourage grass growtl have shown an immediate increase in erosion, while watersheds uncleared remained un. changed in erosion rates.

(h) 1950 Annual Report, Rocky Mountain Forest and Range Experiment Station, Fort Collins Colo. Mar. 1951.

(377) FOREST INELUENCES RESEARCH, FRASER EXPERIMENTAL FOREST.

(b) Laboratory project.

(c) Dr. L. D. Love, Rocky Mountain Forest and Range Experiment Station, Fort Collins, Cc

(d) Field investigation; applied research.

(e) To determine influence of lodgepole pine and spruce fir forests and of cutting on fa associated with yield of water, largely from stored snow. The aim is to solve prob] in watershed management for forested watersheds of the Continental Divide zone of tr. Central lockies.

(f) First phase of experiment in mature lodgepole pine completed in 1944. Studies of th in immature lodgepole pine completed in 1949. Second phase involving the logging of 710 acre experimental watershed has been started with the measurement of the effect logging roads. No logging will be carried out for a period of two or three years tc determine the effect of road construction. The alternate strips to be logged have $t$ located so that pre-treatment studies of snow accumulation and quantity and movement soil moisture to a depth of 5 feet may be made. Stream flow records (not including winters) have been obtained since the fall of 1947 from three high altitude watershe The largest watershed is being commercially logged to evaluate the effect on water $f$ 
Reduction in density of forest canopy through partial clearing has resulted in 15-30 percent increase in precipitation reaching the soil. Increase is largely an addition to ground water, since the combined evaporation and transpiration losses from the soil were not greatly changed. Preliminary results from small forested watersheds show that logging over half of the timbered area has not altered the water quality. Erosion has been negligible and no sediment or bedload has reached the gaging station.

1950 Annual Report, Rocky Mountain Forest and Range Experiment Station, Fort Collins, Colorado, Mar. 1951.

"Progress in snowmelt investigations at the Fraser Experimental Forest." Report No. 2, June 1951.

DEPARTIENT OF AGRICULTURE, FOREST SERVICE, Southeastern Forest Experiment Station.

\section{FOREST INFLUENCES INVESTIGATIONS - WATER RESOURCE AND TATERSHED MANAGEMENT RESEARCH.}

Laboratory project.

Mr. E. L. Demnon, Southeastern Forest Experiment Station, U. S. Forest Service, P. O. Box 252, Asheville, N. C.

Field investigation; basic and applied research.

To determine the effect of vegetation on the phases of the hydrologic cycle, and the effect of land use and land management practices on water yield and water quality. To develop standards and methods of watershed management to derive the greatest benefit from the land and water resources in the southeastern United States. Most of the actual research experiments and hydrologic data collection is carried out on the 5500-acre Coweeta Hydrologic Laboratory in the zone of maximum precipitation in the eastern United States (Nantahala Range, Southern Appalachian Mountains). Within this area are about 35 watersheds whose stream flow is being continuously gaged and which are either being treated experimentally or being used as control checks. There are 11 recording and 70 non-recording (standard) rain gages, 21 recording and 19 non-recording ground water wells, 3 recording hygrothermographs, 2 recording anemometers, and one evaporation pan. Water samples for quality analysis are collected on a weekly and storm period basis from selected experimental watersheds. The Calhoun Experimental Forest near Union, South Carolina, is doing basic research on how piedmont soils influence water resources and plant growth. Studies include measurement of infiltration, daily changes in field moisture, and runoff from several small tersheds. Research projects include determination of effects of (1) permanent complete removal of all major vegetation; (2) temporary complete removal of all major vegetation; (3) removal of riparian vegetation; (4) removal of laurel and rhododendron shrub vegetation; (5) local logging practices; (6) mountain agriculture; (7) woodland grazing; (8) forest fires on water yield and quality; (9) improved techniques for removing wood products and retaining high quality water values on mountain watersheds.

Investigations indicate that in the high rainfall belt of the Southern Appalachian Mountains, the annual water cycle equation tends to balance for an approximate 12 months period between maximum spring storms that being soil moisture up to field capacity. This procedure eliminates the dffficult-to-measure factor of field moisture saturation deficit that exists throughout other times of the year. Iand use studies of mountain farms and woodland grazing have shown the gradual changes in soil structure and porosity that take place and approximate number of years required to affect stream flow. Piedmont studies have shown the relative depth to which field moisture is utilized under bare, grassed, and reforested areas.

"The relations of forest to our water supply." M. D. Hoover and A. R. Croft, Jour. of Forestry, 49(4):245-249, April 1951.

"Stream-flow frequency changes on Coweeta Experimental Watersheds." J.A. Lieberman and M. D. Hoover, Trans. American Geophysical Union, 32(1):73-76, Feb. 1951. "Research in forest-streamflow relations." C. R. Hursh, Unasylva, Vol. V(1):2-9. Jan.-Mar. 1951. 
U. S. DEPARTMENT OF AGRICULTURE, FOREST SERVICE, Southwestern Forest and Range Experiment S1

(657) FOREST INFLUENCIS INVESTIGATIONS AND WATERSHED MANAGEMENT.

(b) Laboratory project.

(c) Mr. Raymond Price, Southwestern Forest and Range Experiment Station, Box 951, Tucsor Ariz.

(d) Experimental; basic and applied research.

(e) To determine the influence of various types and densities of natural vegetation, anc vegetation modified by different methods of land management such as grazing and timk harvesting, on stream flow, water uses, water losses, and erosion and sedinent yielc Work center is at Sierra Ancha Experimental Forest, a 13,255-acre area located in Sa River watershed. Additional plots and watersheds are also located in Salt River wat shed.

(g) In general, watersheds in the Southwest at high elevations are the high water-yieldi areas while the watersheds at low elevations are low ter-yielding but high sedinen yielding. Experimental watersheds sample Salt River watershed. Results point out $t$ varying conditions that are integrated into the larger watersheds of the Southwest. Water yields increase progressively from less than 2 percent of annual precipitation lower elevations to as high as 25 percent at higher elevations. In contrast, sedine yields decrease progressively from as high as 12,000 tons per square mile per year $f$ small watersheds at lower elevations to less than 100 tons per square mile per year watersheds at high elevations.

(h) Annual Reports for 1944-50.

"Consumptive use of water by forest and range vegetation." L. R. Rich, Proc. Americ Society of Civil Engineers, Vol. 77, Sept. 1950.

U. S. DEPARTMENT OF AGR ICULTURE, SOIL CONSERVATION SERVICE, Division of Irrigation and Water Conservation.

(53) SAND TRAPS AND SLUICEWAYS.

See Colorado A \& M College, page 16.

(55) SNOW COURSE MEASUREMENTS AND FORECAST ANALYSIS.

See Colorado A \& M College, page 16.

(151) LINING OF IRRIGATION CANALS AND DITCHES.

(b) Cooperative with Utah State Agricultural College, and Bureau of Reclamation.

(c) Dr. C. 'N. Lauritzen, Soil Conservation Service, Box 179, College Hill, Logan, Utah.

(d) Experimental; basic and applied research.

(e) Linings for irrigation canals and ditches are being tested to develop more effective lower cost methods of reducing conveyance losses in irrigation systems. The investic tion includes: ( 1 ) evaluation of the physical properties of canal lining materials; model testing of linings in an outdoor laboratory; and (3) field testing at selected sites to determine relative durability under varying subgrade and climatic conditions

(g) The tendency for earth linings to become more permeable, judged by the materials stuc will be the rule with few exceptions whether or not the lining is exposed or covered. Asphaltic membrane linings cannot be made water-tight when the asphalt is sprayed on subgrade of texture as coarse as pea gravel with applications as great as 2 gsy. Whe coarse textured subgrades are encountered, the subgrade shouid be dressed up with a $f$ textured material in preparation for applying the asphalt.

(h) "Conveyance loss and canal lining investigations." Progress Report, 1950. (Availab] on loan.) 
PERFORMANCE TESTS OF NELL SCRTENS.

See Colorado A \& $\mathrm{M}$ College, page 17.

DETERMINATION OF THE CHARACTER ISTICS OF THE SUSPENDED SILT IOAD OF TEXAS STREAMS.

Texas Board of Water Engineers.

Dean W. Bloodgood, Soil Conservation Service, 302 West 15th Street, Austin, Texas. Experimental; basic and applied research.

(1) To determine the relationship between the suspended silt load and the discharge of Texas streams; (2) to establish criteria for planning surface reservoir storage based on suspended silt to be handled; (3) to determine the characteristics of silt deposited in reservoirs for use in evaluation of the life of a given reservoir; (4) to secure data necessary to determine the effect of silt load on the cost of preparing water for domestic and industrial use; and (5) to determine the relationship between silt load and the management of the tributary watersheds.

"Pictorial report of cooperative silt, evaporation and irrigation studies at Texas for 1950." Dean W. Bloodgood, Irrigation Division, Department of Agriculture, Soil Conservation Service, Austin, Texas, Feb. 1951.

\section{HYDROIOGY OF SNOW AND STREAM FLOW IN RELATION TO IRRIGATION IN THE NORTHNEST.}

Oregon Agricultural Experiment Station.

Mr. Robert A. Work, Soil Conservation Service, P. O. Box 149, Medford, Ore.

Experimental; applied research.

(1) To develop from snow surveys and related data advance knowledge of the anount and distribution of the water supply available for each stream basin each season for agricultural use; and (2) to determine the factors which influence amount and distribution of water supplied to irrigated areas. Characteristics of stream flow and ground waters in principal stream basins are being studied in relation to occurrence, distribution, utilization, and efficiency of use.

Research projects are being conducted in several states in cooperation with State Agricultural Experiment Stations to determine methods of developing and applying general forecasting principles to local conditions.

EVALUATION OF FACTORS AFFECTING NATER YIELDS FROM HIGH WATERSHEDS IN UTAH.

Utah State Engineer, Utah Agricultural Experiment Station.

Mr. Gregory L. Pearson, Soil Conservation Service, College Hill, Box D, Logan, Utah. Experimental; basic research.

(1) To determine the effect of deviation from normal of late fall and early spring precipitation on the established snow cover-runoff relationship for Utah Streams; (2) to determine the effect of temperature and other climatic factors upon the quantity and distribution of runoff from Utah's snow-fed streams; (3) to determine the effect of various meteorological phenomena on the distribution and extent of the "snow blanket" for particular storms with special reference to established snow courses. At present data are being gathered at two mountain installations.

STORAGE OF WATER UNDERGOUND FOR TRRIGATION IN CALIFORNIA.

Kern County.

Dean C. Muckel, Soil Conservation Service, 222 P. O. Building, Berkeley, Calif. Experimental; applied research.

To determine the factors affecting the percolation rate on water-spreading areas, and to devise ways and means to increase the percolation rate. In some soils the percolation rate cecreases during spreadirg, and the objectives are to determine the cause of the decrease and to find practical methods of maintaining the high initial rates. Field tests are being made on test ponds and strips. 


\section{(390) IMPER IAL VALIEY DRAINAGE INVESTIGA TIONS.}

(b) Imperial Irrigation District.

(c) Mr. George B. Bradshaw, Soil Conservation Service, P. 0. Box 158, Imperial, Calif.

(d) Experimental; applied research.

(e) (1) To continue broadening the drainage criteria on the farm area basis by investiga pumping from deep, pervious strata to determine the effect on lowering the water tab under various stratified conditions, particularly where the aquifer is overlain with heavy soils; (2) to make a study of present drainage problem in relation to irrigati systems and irrigation practices within and adjacent to the area so that when the $\mathrm{Ea}$ Mesa lands are opened up to irrigation some basis for differentiating between local Mesa contributions to the ground water problem may be available; and ( 3 ) to study ir gation methods in relation to leaching to develop irrigation practices that will pro for necessary leaching with minimum contributions to the ground water problem.

(f) Field work completed.

(h) Final report in preparation.

\section{(391) SAN FERNANDO VALIEY DRAINAGE INVESTIGATIONS.}

(b) City of Los Angeles.

(c) Mr. William W. Donnan, Soil Conservation Service, 1059 Post Office and Courthouse, I Angeles, Calif.

(d) Experimental; applied research.

(e) To obtain basic physical data necessary to design an adequate drainage system to con the ground ter in San Fernando Valley Soil Conservation District, and to develop $m$ and techniques that might be applied to the solution of similar problems in other ar

(f) Completed.

(g) Study has materially benefited the Operation Program in San Fernando Valley Soil Cons vation District and helped the City of Los Angeles solve its drainage problem. Defir recommendations of report are now being carried out. The hydrologic water balance ma in the San Fernando Basin, where the basic data such as precipitation, irrigation, $r$ underground water storage capacity, and other factors are measured more accurately $t$ ? probably any other basin in the West, afforded a good chance to check on estimates of consumptive use and deep penetration from irrigation and rainfall.

(h) "Ground water and drainage investigations in San Fernando Valley, Los Angeles, Calif. William W. Donnan, G. Marvin Iitz and V. S. Aronovici, Los Angeles, Calif. Dec. 1950.

(393) IRRIGATION AND SOIL IOSS CHARACTERISTICS OF CONTOUR AND DOWNSIOPE IRR IGATION.

(b) Washington Agricultural Experiment Station.

(c) Stephen J. Mech, Soil Conservation Service, P. 0. Box 590, Prosser, Wash.

(d) Experimental; applied research.

(e) A study of the irrigation and erosion characteristics of different size irrigation streams as they are influenced by furrow grade, crop and crop sequence, tillage, and soil moisture. Application and runoff measured by automatic ter level recorders on type HS flumes. Detailed soil moisture determinations made with soil tube.

(h) "Corn irrigation experiments." 1950 Progress Report, Stephen J. Mech, (mimeographed) available from Prosser, Wash.

(658) INFILTRATION OF WATER INTO AND PERMEABILITY OF SOIIS IN AN IRRIGATED AREA OF THE SOUT WEST.

(b) Arizona Agricultural Experiment Station.

(c) Mr. Karl Harris, Soil Conservation Service, Room 24, Post Office Bldg., Phoenix, Ariz

(d) Experimental; applied research.

(e) To segregate, define, and evaluate the factors which affect water infiltration and permeability of soils; to determine cultural practices for optimum infiltration and percolation; and to develop methods of application of water most effective for given infiltration and permeability characteristics.

(h) "Alfalfa irrigation tests, Mesa Farm, Field B., 1946 to 1951." Progress Report, Harr and Peterson.

"Reclamation and tillage test, covering experiments from 1950 to 1951." Karl Harris. 
THE STUDY OF SEEPAGE LOSSES FROM IRRIGATION CHANNEIS.

See Colorado A \& M College, page 18.

METHODS OF CONTROL AND DISTRIBUTION OF WATER .

Utah Agricultural Experiment Station, BPISAE.

Dr. George D. Clyde, Soil Conservation Service, College Hill, Box D, Logan, Utah. Experimental, field and laboratory; basic and applied research.

Not only existing but proposed and new methods are being tested to determine their feasibility and applicability for the control and distribution of irrigated water. "Irrigation, fertilization, and soil management of crops in rotation." J. I. Haddock, Sterling A. Taylor, and Vaughn E. Hansen, Annual Progress Report, 1950.

DISTRIBUTION OF WATER FROM PERFORATED PIPE.

Utah Agricultural Experiment Station, Bureau of Plant Industry, and $N$. R. Ames Company. Dr. Vaughn E. Hansen, Soil Conservation Service, College Hill, Box 70, Logan, Utah. Experimental; applied research.

The effect of wind on the distribution pattern from perforated pipe is being studied to provide design data and to determine the limitations of this type of distribution for irrigation purposes.

"Water distribution pattern analysis for Perf-0-Rain pipe." Vaughn E. Hansen, Progress Report, 1950.

DETIRMINATION OF THE DISCHARGE FROM HORIZONTAL PIPE BY THE COORDINATE METHOD.

See Utah State Agricultural College, Engineering Experiment Station, page 82.

FIOW THROUGH FLEXIBLE NON-EIASTIC PIPE.

See Utah State Agricultural College, Agricultural Experiment Station, page 80.

PERMEABILITY AND STABILITY OF SOIL AND SOIL MATERIAL.

Soil Conservation Service, Utah State Agricultural College, and Bureau of Reclamation cooperating.

Dr. C. W. Lauritzen, Soil Conservation Service, Box 179, College Hill, Logan, Utah. Experimental; basic and applied research.

Seepage losses from irrigation canals are being studied to determine losses aking place; distribution of seepage losses in canal cross sections; relationship between seepage losses and character of canal bed material; relationship of seepage losses from canals to ground water; reliability of methods employed in estimating seepage losses.

Seepage losses in canals vary widely but on the average accounts for about $1 / 3$ of all the water diverted. Particularly in sandy materials, losses are greater through the sides than the bottom of canals. A satisfactory method of measuring seepage losses in short sections of canals has not been developed. A direct relationship between the permeability of bed material as measured on samples in the laboratory, and seepage losses does not seem likely.

"Conveyance loss and canal lining investigations." Progress Report, 1950.

UTILIZATION OF IIMITED WATER SUPPLIES FOR GRATER ECONOMIC RETURNS.

Arizona Agricultural Experiment Station.

Mr. Karl Harris, Soil Conservation Service, Room 24, Post office Building, Phoenix, Ariz. Experimental; applied research.

To determine the best irrigation practices to follow and amounts of water to use in each irrigation; the frequency of application during the hot and cool seasons; and how best to allocate the available water supply to the different crops during years of critical water shortage in order to secure the greatest economic return. 
(1430) IRRIGATION REQUIREMENTS, EFFICIENCIES, AND METHODS OF WATER APPLICATION IN THE UPPER COIORADO RIVER BASIN.

(b) Colorado Agricultural Experiment Station, USBR, BPISAE.

(c) Mr. Earl Cowley, Soil Conservation Service, P. O. Box 786, Grand Junction, Colo.

(d) Field investigation; applied research.

(e) To evaluate the irrigation efficiencies under present practices and the factors whic fix them; to develop and establish methods of water application which will reduce su and deep percolation losses and erosion and increased irrigation efficiencies, and $a$ the same time apply adequate moisture for plant growth; to determine the effect of $t$ lage practices and crop rotation on infiltration rates and permeability of the soil; and to determine the consumptive water requirements, the total ter requirements, a. the net irrigation requirements for each crop grown in the area.

(131) IRAINAGE OF IRR IGATED IAND IN THE UPPER COLORADO RIVER BASIN.

(b) Colorado Agricultural Experiment Station, USBR, BPISAE.

(c) Nr. Earl W. Cowley, Soil Conservation Service, P. O. Box 786, Grand Junction, Colo.

(d) Field investigation; applied research.

(e) Cooperative research project on irrigation and soil management studies including dra: age, salinity, and fertilization in the Upper Colorado River Basin. To develop and adapt procedures for making drainage investigations involving the source, amount, an distribution of excess ter based upon the amount and distribution of ter to be $r$. moved and the rate of movement of the water through the soil, and to develop effecti methods of drainage by open surface drains, tile drains, or pumping for drainage.

(山32) METHOD OF WATER APPIICATION AND IRRIGATION EFFICIENCIES IN KANSAS.

(b) Kansas Agricultural Experiment Station.

(c) Malter R. Meyer, Branch Experiment Station, Garden City, Kansas.

(d) Field investigation; applied research.

(e) To study methods of wer application and irrigation efficiencies as influenced by sc characteristics, topography, crops, source and quality of ter, and climate; to dete mine the effects of the different methods of applying irrigation water on the physice and chemical properties of the soil, and the resulting effect on plant growth; to sti infiltration rate, permeability, and quality of irrigation water; to compare the effj ciency of sprinkler irrigation to that of surface methods; and to determine under whe conditions sprinklers can be most effectively used.

(h) "Progress report for Garden City Experiment Station, Irrigation Project, 1950." Walt R. Meyer, Ben L. Grover, Carl W. Carlson, Kansas Agricultural Experiment Station, Garden City, Kansas.

(433) METHODS OF WATER APPLICATION ON IRRIGA TED IANDS OF NEBRASKA.

(b) Nebraska Agricultural Experiment Station, Bureau of Reclamation.

(c) Fred B. Hamilton, Department of Agricultural Engineering, University of Nebraska, Lincoln, Neb.

(d) Field investigation; applied research.

(e) To provide factual information for technical recommendations on irrigation practices; to compare methods of application as to irrigation efficiency and operational efficie to study the effects of topography, length of run, amount of ter applied, and other factors on the uniformity with which water is added to the root zone of the crops; ar develop techniques which will be usable by field workers in verifying and localizing irrigation practice recommendations.

(h) "Effect of stream size and length of run in furrow irrigation." Progress Report No. F. B. Hamilton and J. A. Bondurant, Nebraska Agricultural Experiment Station, Univers of Nebraska, Lincoln, Neb. 1950. 


\section{STUDY OF THE EFFECT OF OPEN DRA INS ON GROUND WATER LEVELS IN THE PLATTE VALLEY.}

Nebraska Agricultural Experiment Station.

Nr. Fred B. Hamilton, Department of Agricultural Engineering, University of Nebraska, Iincoln, Neb.

Field investigation; applied research.

To determine the effect of an open drain on adjacent ground ter levels and the effect

of irrigation of adjacent land on ground water and on the flow of the drain.

USE OF WATER BY AGRICULTURAL CROPS AND NATIVE VEGETATION IN NEVADA.

Nevada Agricultural Experiment Station, Nevada State Engineer. Mr. Clyde E. Houston, Agricultural Experiment Station, Reno, Nev.

Field investigation; applied research.

To determine basic consumptive use of the more important agricultural crops in Nevada. To determine the irrigation efficiencies which are practical and feasible under Nevada conditions and the resulting water application and farm delivery requirements, and to determine the use of water by phreatophytes in irrigated and irrigable areas of Nevada.

SURFACE AND INTERNAL IRA INAGE AS AFFECTED BY ARTIFICIAL APPLICATION OF WATER TO SOUTH DAKOTA SOIIS.

South Dakota Agricultural Experiment Station.

Mr. Ieonard J. Erie, Soil Conservation Service, Department of Agricultural Engineering, South Dakota State College, Brookings, S. D.

Field investigation; applied research.

To study surface and sub-surface drainage under conditions of natural rainfall and to determine and evaluate such changes as occur under conditions where irrigation ter is added; to determine source and quantity of ter to be removed from surface and subsurface together with desirable time and rates of removal; to determine infiltration rates and rates of movement of water through the various soil horizons; to investigate the effects of quality of water and methods of application on the accumulation of alkali salts; and to develop methods of prevention of waterlogging and alkali accumulations and relief when such conditions exist.

DEVELOPMENT OF PRACTICAL AND EFFICIENT METHODS OF WATER APPLICATION OF SOUTH DAKOTA IANDS.

South Dakota Agricultural Experiment Station.

Mr. Leonard J. Erie, Soil Conservation Service, Department of Agricultural Engineering, South Dakota State College, Brookings, S. D.

Field investigation; applied research.

To study infiltration and permeability, erosivity, compaction, and volume weights of soil under different cultural practices. To determine irrigation requirements of different crops, and the time, frequency, and amount of each application of ter. To develop methods of applying ter which will provide uniform distribution of moisture with a minimum of water and soil loss taking into consideration the topography, soils, crops, cultural practices, cost, source, and quality of ter; and to adapt the results of research under controlled conditions to typical farms of the area.

INFILTRATION OF WATER INTO AND PERMEABILITY OF SOIIS IN AN IRRICATED AREA.

New Mexico Agricultural Experiment Station.

Mr. Eldon G. Hansen, Soil Conservation Service, Agricultural Engineering Bldg., P. 0. Box 268, State College, N. M.

Field investigation; applied research.

To segregate, define and evaluate the factors which affect water infiltration rates and permeability of soil; to determine cultural practices for optimum infiltration rates; to develop methods of application of water most effective for given infiltration and permeability characteristics. 
(439) DETERMINATION OF OPTIMUM REQUREMENTS AND METHODS OF APPLICATION OF IRRIGATION WATIR TEXAS.

(b) Texas Board of Water Engineers.

(c) Dean W. Bloodgood, Soil Conservation Service, P. 0. Box 2169, Third Floor Post Offic Building, 20\% East 5th, Amarillo, Texas.

(d) Field investigation; applied research.

(e) To determine optimum irrigation requirements for typical crops grown in Texas under varying climatic and soil conditions; to determine the methods of ter application suited to the different crops grown in Texas under given site conditions; to determi effect of the source of supply on the methods of application; and to develop irrigat practices which will increase irrigation efficiencies.

(1440) IRRIGATION WATER APPLICATION EFFICIENCIES IN THE IOWER RIO GRANDE VALIEY OF TEXAS.

(b) Texas Agricultural Experiment Station.

(c) Mr. P. Earl Ross, Soil Conservation Service, P. 0. Box 2169, Third Floor Post Office Building, 207 East 5th, Amarillo, Texas.

(d) Fielo investigation; applied research.

(e) To measure infiltration rates, surface runoff, and deep percolation losses on near 1 and graded runs; to determine the total seasonal use of water by crops; to measure $t$ cost of water application; to determine the water'application efficiency; and to est lish criteria for fixing limits of slope for irrigation.

(h) "Irrigation and variety trials with lettuce in the Lower Rio Grande Valley." Progre Report No. 1258, Texas Agricultural Experiment Station, July 8, 1950.

(1441) METHODS OF WATER APPLICATION ON THE HIGH PIAINS OF TEXAS.

(b) Texas Agricultural Experiment Station.

(c) Mr. Norris P. Swanson, Soil Conservation Service, P. 0. Box 2169, Third Floor Post 0 Building, 207 East 5th, Amarillo, Texas.

(d) Field investigation; applied research.

(e) To measure irrigation efficiencies under present methods of water application on the High Plains of Texas; to develop methods of application best suited to the limited $w$ supply, soil characteristics, cropping systems, and climate of this area; to compare sprinkling vs surface applications; to study time of application, amount and uniform of moisture distribution in the soil with different methods of application; and to s effect of irrigation upon yield and quality.

(1442) IRRIGATION REQUIREMENTS OF CROPS ON THE HIGH PIAINS OF TEXAS.

(b) Texas Agricultural Experiment Station.

(c) Mr. Norris P. Swanson, Soil Conservation Service, P. 0. Box 2169, Third Floor Post 0 Building, 207 East 5th, Amarillo, Texas.

(d) Field investigation; applied research.

(e) To determine the consumptive use, water requirements, and irrigation requirements of agricultural crops on the High Plains of Texas; to measure precipitation and determi: the portion of it that is effective in plant production; to measure evaporation and movement and evaluate their effect on water requirements of crops; to determine irri tion efficiencies for different crops under different methods of hater application.

(443) IRRIGATICN WATER REQUTREMENTS, METHODS OF WATER APPLICATIONS, AND DRA INAGE OF CRASS MEADOWS IN THE MOUNTA IN VALIEYS OF WYOMING.

(b) Wyoming Agricultural Experiment Station, BPISAE.

(c) Mr. Byron R. Tomlinson, Agricultural Building, University of Wyoming, Laramie, Wy.

(d) Field investigation; applied research.

(e) To investigate the current use and application of water on mountain natural grass me: and to establish optimum water management practices relating to reseeded and natural grass meadows in the Green River and Little Laramie Valleys of Wyoming. 
"Water, life for the land." Byron R. Tomlinson and Guy 0. Woodward, Circular 39, Wyoming Agricultural Experiment Station, Nov. 1950.

"A progress report on the cooperative Mountain Meadow project at Pinedale, Wyoming." Byron R. Tomlinson, May 1951.

CONSUMPTIVE WATIR USE AND REQUIIEMENTS IN THE COLORADO RIVIR AREA IN UTAH.

Utah State Engineering; Utah Agricultural Experiment Station.

Mr. Willis C. Barrett, Soil Conservation Service, College Hill, Box D, Logan, Utah. Field investigation; applied research.

To determine the consumptive use of water by agricultural crops and all other water consuming items in two selected hydrological areas in the Colorado River Basin in Utah; to correlate their uses with hydrological and such other data as may be available in this area, and which are generally available in other areas of the Colorado River Basin of Utah; and by this method of correlation to be developed, determine the consumptive use in other irrigated areas of the Colorado River in Utah.

IRR ICA TION PRACTICES, EVAPO-TRANSPIRATION, AND RAINFALL PENETRATION AS THEY AFFECT NATER SUPPLY.

San Bernardino County.

Dean C. Muckel, Soil Conservation Service, P. 0. Box 629, Room 202 Post Office Building, Pomona, Calif.

Field investigation; applied research.

To determine the contribution to the ground water supply by return flow from the irrigated areas and by penetration of rains on the valley floor, and from the foothill areas on the Upper Santa Ana River Basin. The study also includes a determination of farm irrigation use, efficiency of irrigation and water losses by evapo-transpiration. "Rainfall and irrigation water penetration and consumptive use in the Beaumont-Yucaipa area, Santa Ana River Valley, California." Dean C. Muckel, V. S. Aronovici, Irrigation Division, Soil Conservation Service, Pomona, California, March 1950.

WATER REQUIREMENTS IN IRRIGATED AREAS OF THE SOUTHWEST.

State Agricultural Experiment Station and State Engineers of the Southwest. Mr. Harry F. Blaney, Soil Conservation Service, 1509 Post Office and Courthouse, Los Angeles 12, Calif.

Field investigation; applied research.

The objectives are to investigate the quantity of water required by standard cropping systems under conditions prevailing within the principal irrigated locations of the Southwest; to collect, compile, and tabulate the reliable available data whether published or unpublished; relating to irrigation requirements and consumptive use of water as determined by tank, plot, and field experiments; to make estimates of water requirements from climatological and other data in irrigated areas where reliable information on irrigation use is not available; and to prepare reports by states for in-service use of technicians of the Operations Division of the Soil Conservation Service.

"Consumptive water requirements in irrigation areas of the souțwest." Harry F. Blaney, Soil Conservation Service, Logan, Utah, June 1948.

"Consumptive use and irrigation water requirements of crops in Colorado." Harry F. Blaney, Wayne D. Criddle, Soil Conservation Service, Logan, Utah, Aug. 1949.

"Consumptive use and irrigation water requirements of crops in New Mexico." Harry F. Blaney, Eldon G. Hanson, G. Marvin Iitz, Soil Conservation Service, Albuquerque, New Mexico, Dec. 1950.

\section{IRR IGATION AND WATGR CONSERVATION STUDIES IN SOIL CONSERVATION DISTRICTS.}

Soil Conservation Districts in Southern California.

Mr. William W. Donnan, Soil Conservation Service, 1509 Post Office and Courthouse, Los Angeles 12, Calif.

Field investigation; applied research. 
(e) To develop improved irrigation practices for increasing water application efficienc and conserving the available water supply in soil conservation districts.

(h) "Sprinkler irrigation trials, Antelope Valley Soil Conservation District." G. Marv Litz, Charles F. Bons, William W. Donnan, Soil Conservation Service, Los Angeles, Mar. 1951.

\section{(I山18) IRRIGATION PRACTICES AND CONSUMPTIVE USE OF WATER IN CENTRAL CALIFORNIA VALLEYS.}

(b) Cooperative with Director of Wer Resources, Department of Public Works of Califor and Soil Conservation Districts.

(c) Mr. Harry F. Blaney, Soil Conservation Service, 1509 Post Office and Courthouse, Io Angeles 12, Calif.

(d) Field investigation; applied research.

(e) To obtain information on irrigation practices and farm irrigation use, and to deter the consumptive use of water by agricultural crops and native vegetation in specifi areas of Central Valley of California. Of particular interest at this time are are Lake County, Tehachapi area, Livermore area, Auburn-Placerville area, Pajaro Valley areas in Santa Cruz County, Salinas Valley, and the Central Valley of California.

(h) "Progress report on irrigation practices and consumptive use of water in Iake Count California." Harry F. Blaney, Paul A. Ewing, Soil Conservation Service, Los Angele Calif. June 1951.

(1449) SOIL WATER REIATIONSHIPS INFLUENCING THE APPLICATION OF WATER TO AND THE DRA INAGE 0 WATER FROM IRRIGA TED IANDS.

(b) Soil Conservation Districts.

(c) Mr. Vladimir S. Aronovici, Soil Conservation Service, P. 0. Box 629, Room 202 Post Building, Pomona, Calif.

(d) Field investigation; applied research.

(e) To develop techniques for measuring and to evaluate infiltration rates and permeabi characteristics of soils under irrigation agriculture in Southern California; to de mine the effect of soil characteristics upon the amount and uniformity of distribut of waters applied to irrigated lands; and to determine effects of soil characterist upon irrigation practices and of soil permeability upon depth, spacing, and capacit drainage facilities.

(1450) FORMATION OF WATMR BAIANCE SHEETS. (IOS ANGELES WEST COAST BASIN.)

(b) Director of Water Resources, Department of Public Works, State of California.

(c) Mr. Harry F. Blaney, Soil Conservation Service, 1509 Post Office and Courthouse, Io: Angeles 12, Calif.

(d) Field investigation; applied research.

(e) To make a complete inventory of the water supply and utilization within the West Co: Basin, Los Angeles County, California. The specific objective of the Division of Irrigation and Water Conservation in this cooperative study is to establish the mon and average annual quantity of water utilized by native vegetation, irrigated and $n$ irrigated crops, to estimate the rainfall and percolation, and to establish the lim: of a safe water supply in the basin.

(1451) IRRIGATION USE AND WATE SUPPLY OF TEHACHAPI VALIEY, KERN COUNTY, CALIFORNIA.

(b) Water Resources Branch, Department of Public Works, State of California, Tehachapi s Conservation District.

(c) Mr. G. Marvin Litz, Soil Conservation Service, 1509 Post Office and Courthouse, Los Angeles 12, Calif.

(d) Field investigation; applied research.

(e) The objective is to make an inventory of the irrigation water supply for the Tehache Soil Conservation District and to determine the potential net safe yield of undevelc surface and underground water for agricultural use within the District boundaries.

(h) "Third Annual Report for 1950 - Tehachapi Soil Conservation District." Tehachapi Sc Conservation District, Kern County, 1950. 
EFFECT OF METHODS OF IRRIGATION UPON SOIL AND WATER LOSSES AND INEILTRATION.

Oregon Agricultural Experiment Station, U. S. Regional Salinity Laboratory, USBR, BPISAE. Mr. Fred M. Tileston, Soil Canservation Service, The Guss Building, Ontario, Ore.

Field investigation; applied research.

To determine means for increasing infiltration rates and reducing soil and water losses during irrigation of certain Eastern Oregon soils, and to apply the results to the field conditions encountered in the area.

"Irrigation, infiltration, and salinity studies on the Owyhee Project, Oregon." 1951 Progress Report, December 1951.

STREAMFIOW FORECASTING.

Corps of Engineers, Bureau of Reclamation, Bonneville Power Administration.

Mr. Morlan W. Nelson, P. O. Box 835, Boise, Idaho.

Experimental; basic and applied research.

Various factors influencing the rate and volume of runoff fram various mountain watersheds are being measured and their effect analyzed.

Summer runoff of the Columbia River at The Dalles, Oregon, can be predicted on April 1 each year within reasonable accuracy based on historical records. On the same basis, the peak flow which usually occurs in late May or June can be rather accurately predicted.

"Use of snow surveys in planning regulation of Columbia River floods." R. A. Work, H. G. Wilm, and Morlan W. Nelson.

USE OF TRRIGATION WATER IN NORTHWEST AND INTERMOUNTA IN STATES.

Various state experiment stations and state engineers.

Mr. Wayne D. Criddle, Project Supervisor, P. 0. Box 835, Boise, Idaho.

Experimental; basic and applied research.

To determine and publish the water requirements of crops under various cropping systems, climatic conditions, and methods of water application.

A method for estimating use has been developed which has proven to be sufficiently accurate for many purposes.

"Determining water requirements from climatological and irrigation data." Harry F. Blaney and hime D. Criddle, S.C.S. - T.P. -96 .

APPLICATION AND CONTROL OF IRRIGATION WATER APPLIED BY SURFACE METHODS.

U. S. Bureau of Reclamation and Idaho Agricultural Experiment Station.

Mr. Sterling Davis, P. 0. Box 835, Boise, Idaho.

Experimental; basic and applied research.

Information is being gathered on the design, layout, construction, and operation of farm irrigation systems on new and old land.

Annual progress reports have been prepared. Further study is needed on some phases.

PAYETTE VALLEY, IDAHO DRAINAGE INVESTICATIONS.

Idalo Agricultural Experiment Station, Production Marketing Administration, Gem County Commissioners.

Mr. George B. Bradshaw, P. O. Box 835, Boise, Idaho.

Experimental; basic and applied research.

To improve and develop new investigational technique and develop better drainage methods for the valley. 
U. S. DEPARTMENT OF AGR ICULTURE, SOII CONSERVATION SERVICE, North Appalachian Experimental

Watershed; Blacklands Experimental Watershed; and Central Great Plains Experimental Vitersh

(150) HYIROIOGIC EXPERIMENT STATIONS.

(b) Soil Conservation Service, Department of Agriculture, and State Agricultural Experi Stations of Ohio, Texas, and Nebraska.

(c) Mr. Lewis A. Jones, Division of Drainage and Water Control, Soil Conservation Servi Washington $25, \mathrm{D} . \mathrm{C}$.

(d) Experimental; for design and general information in planning farms for soil and wat conservation.

(e) Rainfall and runoff are measured on watersheds ranging from 1 to 5,000 acres. In a tion to rainfall and runoff measurements, studies are made on small Government-oper areas of evapo-transpiration, moisture storage, moisture transmission through the $s$ and percolation of ter to the ground-water table. The purpose is to determine th hydrologic effect of physiography, tillage, and ground surface conditions, vegetal and soils and geology, and the effect of conservation farming on runoff and erosion well as the characteristics of flood runoff from agricultural watersheds.

(h) North Appalachian Experimental Watershed, Coshocton, Ohio.

"Water requirements of crops and available moisture supplies." L. L. Harrold, sub. Dec. 19, 1950, for Ontario Crop Improvement Assoc., Ontario, Canada.

"Infiltration as affected by surface sealing." I. I. Harrold, sub. Feb. 8, 1951, f Intl. Geodesy and Geophysics meeting at Brussels, August 1951.

"Agricultural hydrology as evaluated by monolith lysimeters." L. I. Harrold and F. Dreibelbis, U. S. Dept. of Agriculture Techical Bulletin 1050, 1951.

Central Great Plains Experimental Watershed.

"Results of rainfall and runoff studies." John A. Allis, Agricultural Engineering $518,520,522,524$, illus., 1950.

U. S. DEPARTMENT OF AGRICULTURE, SOIL CONSERVATION SEEVICE, Research Branch.

(394) A STUDY OF THE EFFECTS OF IAND-USE AND FARMING PRACTICES ON RUNOFF FROM SMALI WATER:

(b) Cooperative with Purdue University, Agricultural Experiment Station.

(c) Dr. R. B. Hickok, Agricultural Engineering Building, Purdue University, Lafayette,

(d) Experimental; for design information.

(e) To study the effects of types of land-use and cultural practices as a means of redur rates and amounts of surface rumoff, for soil and moisture conservation and upstrear flood control. Continuous time-rate records of rainfall and runoff are collected $f_{1}$ 20 small watersheds. Twelve tersheds are used in the rotation crop experiments. Determinations are made of the seasonal amounts and periodic high rates of runoff ur a present typical farming system and under a conservation system. The results are : tended to be applicable for soil conditions, the climate, and a type of agriculture generally representative of a large part of the eastern section of the corn belt.

(g) Analysis of runoff rate data for critical storms and seasonal runoff totals for seví years indicate important correlations with the type of soil management (conservatior prevailing practices), crop, and specific soil conditions. More extensive data are needed for quantitative estimating of the expectancies of runoff rates and amounts entirely practical fiducial limits.

U. S. DEPARTMENT OF AGR ICULTURE, SOIL CONSERVATION SERVICE, St. Anthony Falls Hydraulic Laboratory.

Reports on projects conducted by the Soil Conservation Service at the St. Anthony $\mathrm{Fe}$ Hydraulic Laboratory are listed under St. Anthony Falls Hydraulic Laboratory, Univer of Minnesota, Minneapolis, Minn., Projects Nos. 111, 112, 114, 1168, and 1398. Inc ies should be addressed to Mr. Fred W. Blaisdell, U. S. Soil Conservation Service, Anthony Falls Hydraulic Laboratory, Hennepin Island, Minneapolis 14, Minn. 
OEPAR TMENT OF AGR ICULTURE, SOIL CONSERVATION SERVICE, Stillwater Outdoor Hydraulic tory.

\section{3) THE HYDRAULICS AND STABILITY OF CONSERVATION CHANNEIS.}

Soil Conservation Service, Department of Agriculture, and Oklahoma Agricultural Experiment Station.

Ir. Lewis A. Jones, Division of Drainage and Wer Control, Soil Conservation Service, Washington $25, \mathrm{D}$. C.

Experimental; for design.

Measured flows up to 150 cfs are passed through outdoor test channels of various crosssections up to 40 feet in width and slopes up to 10 percent. Measurements of hydraulic elements and scour rates are made for flows of different velocities and for various channel linings. The purpose is to obtain data on (1) effects of linings, vegetal and non-regetal, on the water carrying capacity and other hydraulic characteristics of channels used in soil and water conservation operations; and (2) protective characteristics of various types of linings, vegetal and non-vegetal.

For the vegetal linings and range of velocities utilized in the tests, Manning's $n$ was found to vary as some function of the product of velocity and hydraulic radius.

"Results of tests on a chute with a SAF stilling basin." W. O. Ree, U. S. Department of Agriculture Soil Conservation Service TP-107, 1951.

"Preliminary report of tests on a grass-lined channel with a center concrete gutter section." W. O. Ree, U. S. Department of Agriculture Soil Conservation Service, June 1951. (Processed.)

DEPARTMENT OF AGRICULTURE, SOLL CONSERVATION SERVICE, Sub-Tropical Experiment Station.

Inquiries concerning Projects Nos. 395, 396, and 397 should be addressed to Mr. M. H. Gallatin, Sub-Tropical Experiment Station, Route 2, Box 508, Homestead, Fla.

CONSERVATION OF THE MARL IANDS OF THE HOMESTEAD AREA.

Soil Conservation Service, cooperative with Sub-Tropical Experiment Station, University of Florida, and Dade County Division of Water Control.

Experimental, field investigations; basic research.

Periodic sampling of lands adjoining canals in the Miami and Homestead areas with and without chloride barriers to study the effectiveness of these structures in control of the intrusion of chlorides; effect of pumping from deep rock ditches on the intrusion of chlorides on agricultural lands; effectiveness of diking to protect low-lying lands from tidal inundation. Determination of tolerance of crops to chlorides as they are affected by high concentration and by cultural and tillage methods.

Present study to continue at least one more year for intrusion studies, and several years for pumping, diking, and tolerance studies. Present data indicates that removal of water from areas where ditches penetrate the underlying permeable rock removes the fresh water head and allows the chloride front to move into these areas. Some data available on the tolerance of crops to chlorides.

Monthly reports on existing conditions to sponsors. Annual progress reports to chief of Division of Drainage and Water Control, Soil Conservation Service, Washington 25, D. C. Preliminary paper being prepared on tolerance of crops grown in the area to chloride.

WATER CONTROL ON THE DEEP MARL IANDS IN SOUTH FIORIDA.

Soil Conservation Service, cooperative with Sub-Tropical Experiment Station, University of Florida.

Experimental, field investigation; design and operation. A notch weir was installed on the plot for pumping efficiency tests. Down pipes will be installed for this year's pumping tests. Efficiency tests will be made of the 2000 and 40000 gallon pumps with and without the down pipes to determine the effectiveness at various pump speeds. A study covering the control of weeds in drainage ditches with various chemicals will be covered in and during the coming year. 
(h) Yearly summary report to Chief of Division of Drainage and Water Control, Soil Con: tion Service, Washington 25, D. C.

(397) WATER CONSERVATION AND IRRIGATION STUDIIS ON THE ROCKDALE SOIIS OF THE HOMESTEAD AI

(b) Soil Conservation Service cooperative with Sub-Tropical Experiment Station, Univer: of Florida.

(d) Experimental; field investigation.

(e) To determine cycle, rates of application, and types of irrigation systems best sui to this area. Observations are made of (1) distribution and pattern of various ty] of irrigation systems in use; (2) effect of elevation of water table on irrigation (3) rates of application and their effect on the leaching of plant nutrients; (4) 1 of application, moisture studies on limes and avocados to determine the irrigation (5) the responsiveness of the water table to rainfall; and (6) the water table as ed by ground water conditions as they exist in the Everglades.

(g) Data to date shows definite correlation between water table and irrigation cycle. of application are governed by maturity of grove, amount of organic matter, types material and depth of scarification.

(h) Summary report to Chief of Division of Drainage and Waten Control, Soil Conservatic Service, Washington 25, D. C.

U. S. DEPARTMENT OF AGizICUITURE, U. S. Regional Salinity Laboratory.

(26) DRA INAGE INVESTIGATIONS IN COACHELIA VALLEY, CAITFORNIA.

See University of Califormia, College of Agriculture, Division of Irrigation and Si page 8 .

(1194) PRINCIPLES UNDERLYING THE FIOW INTO AND THROUGH SOIIS.

(b) Laboratory project.

(c) Mr. Ronald C. Reeve, P. 0. Box 672, Riverside, Calif.

(d) Experimental; basic research.

(e) To investigate the factors that influence the flow of water into and through soils.

(1195) CHARACTERISTICS OF FLOW THROUGH WELL CASINGS.

(b) Laboratory project.

(c) Mr. Ronald C. Reeve, P. 0. Box 672, Riverside, Calif.

(d) Experimental; applied research, for design.

(e) To determine the loss of head through various well casings and screens in combinatj with various gravel packs.

(f) Suspended.

U. S. DEPARTMENT OF THE ARMY, CORPS OF ENGINEERS, Beach Erosion Board.

Inquiries concerning Projects Nos. 181, 184, 399, 660, 661, 970, 972 to 977, incl., 1457 to 1461 , incl., should be addressed to the President, Beach Erosion Board, $52 \mathrm{C}$ Little Falls Road, N. W., Washington 16, D. C.

For further information on projects see Quarterly Summary, Waterways Experiment Sta 


\section{EQUILIBRTUM PROFILE OF BEACHES.}

Experinental; basic research.

The purpose is to evaluate the effect of wave form, initial beach slope, and sand grain size in determining the equilibrium profile of beaches. Experiments are conducted in a concrete wave tank, 38 by $\Psi_{4}$ by 4 feet in size. Tests have been made with an original beach slope of $1: 15,1: 30$, and a combination of $1: 10$ and $1: 20$; wave period of 1.3, 1.75, $2.2,2.75$, and 3.3 seconds; wave height of about 0.4 feet; and sand sizes $0.21,0.56$, 0.90 , and $3.44 \mathrm{~mm}$ median diameter. The tests are continued until the rate of change of the shape of the beach is very slight, usually 100 hours.

Completed.

\section{STUDY OF MODEL SCALE EFFECTS.}

Laboratory project.

Experimental; basic research.

The purpose is to determine the laws of model similarity governing the action of waves on moveable sand beaches. The tests are made in a wave tank 42 feet by 1.5 feet by 2 feet. Conditions of wave height, wave period, beach slope and grain size of sand are adjusted to various scales in an attempt to simulate the results of the tests obtained in the large wave tank for Project 181.

Completed.

DEVEIOPMENT AND CONSTRUCTION OF SIX-FOOT WAVE TANK.

Laboratory project.

Experimental; design.

To design and construct a wave tank for the study of the effect of waves 6 feet high and 300 feet long. Various types of wave generating mechanisms, the power required by the generator to form the waves, and the action of the waves on a beach which is placed at an angle to the axis of the tank have been studied in a 1:12 scale model. The large wave tank is completed and is 635 feet long, 15 feet wide, and 20 feet deep. Generation of the waves is to be accomplished by a pusher-type wave generator.

Resumption of activities on this project is awaiting choice of a suitable wave generator design.

\section{OBSTRVED WAVE CHARA CTERISTICS.}

Laboratory project; additional research by New York University.

Field investigation; basic research.

To secure a more thorough knowledge of the characteristics of ocean waves in comparison to the uniform wave train generally studied in the laboratory. Several electrical recording wave gages have been installed in coastal waters and an extensive series of wave records are being analyzed by methods of significant heights and periods. The validity of wave refraction diagrams by present methods as applied to areas with gently shelving bottom topography such as encountered on the Atlantic and Gulf coasts are being studied. Further research for the Board has been undertaken by New York University to develop wave forecasting methods applicable to the Atlantic coast, and to develop electronic means of analyzing the wave records.

A revised report on the application of wave forecasting methods to the North Atlantic was completed by New York University under contract to the Beach Erosion Board.

Beach Erosion Board Technical Memorandurn No. 24.

LITTORAL DR IFT STUDY AT HYPERION, SANTA MONICA BAY, AND SUNSET BEACH, ANAHEIM BAY, CALIFORNIA. (NEN TITLE: REPQRTS ON BEACH PROCESSES BASED ON EXISTING MISSION, ANAHEIM, AND SANTA MONICA BAY FIELD DATA.)

Laboratory project.

Field investigation; basic research. 
(e) A study of the relationship between movement of beach material and natural forces su waves, tides and littoral currents. Fourteen million cubic yards of sand have been on Hyperion Beach, Santa Monica Bay, California and one million cubic yards have bee placed on Sunset Beach, Anaheim Bay, California. The rate of movement of this mater from the placement areas is being studied by frequent hydrographic surveys. The int and direction of the haves are being recorded.

(f) Field work completed. Report in progress.

(970) STUDY OF THE FFFECTS OF JETTY CONSTIUCTION AT MISSION BAY, CALIFCRNIA, ON THE MOVEME LITTORAI IRIFT.

(b) Laboratory project.

(d) Field investigation; basic research.

(e) To observe the effects of construction of the two jetties at Mission Bay, California upon the littoral drift of sand past the inlet with a view of determining the change beach regime associated with jetty construction. Movement of the beach material is correlated with natural forces.

(f) Field work completed. Analysis of data under way.

(972) STRUCTURAL DESIGN OF SHORE STRUCTURES.

(b) Laboratory project.

(d) Experimental; basic research.

(e) To prepare a handbook on the design of shore structures. Field and model tests on $t$ wave pressures caused by breaking wes which act on structures will be made to fill gaps in our present knowledge of these forces not covered by other current investiga

(f) Suspended temporarily.

(g) Laboratory pressure-measuring tests completed, report pending.

(973) CONSTRUCTION OF COAST MODEL BASIN.

(b) Laboratory project.

(d) Experimental; basic research.

(e) The coast model test basin ( 300 by 150 by 3 feet) is under construction. Provisions be made for simulating tides, waves, littoral currents, aand moveable sand beaches. basin will be used to study beach problems involving waves, tides, and littoral drif

(g) The wave tank has been completed and the tide system has been designed and is under struction. The service building was occupied in June, 1951.

（974） SURVEY METHODS-SHALION TATER SOUNDINGS.

(b) Laboratory project.

(d) Experimental; basic research.

(e) To coordinate the development of improvements in shallow ter hydrographic survey $\mathrm{m}$ within the Corps of Engineers. New instruments to aid in survey boat positioning ar being reviewed for possible application to the needs of the Corps of Engineers.

(g) Operational acceptance tests of a new positioning unit for survey boats were observe Final results not yet available.

(975) METHODS OF BY-PASSING SAND PAST INLETS.

(b) Laboratory project.

(d) Field investigation; applied research.

(e) To study methods and requirements for pumping sand past inlets and to determine the applicability of the methods in stabilization of beaches adjacent to inlets. Estima of the cost of pumping sand past selected inlets have been prepared for evaluation of the problem. Field observations of beach changes have been conducted in a step towar. defining the sand by-passing problem. 
STABLISHEINT OF RITERIA FOR CONSTRUCTION OF ARTIFICIAL BEACHES.

aboratory project.

xperimental; basic research.

o evaluate the several factors controlling the ultimate configuration and distribution

f material artificially placed for the purpose of restoring or improving beaches.

ield investigation of artificially-placed fills are being made. In the laboratory, mall scale tank studies of material artificially on beaches will be made.

esults indicate that an unprotected artificial beach is subject to the same degree of rosion as the prior beach unless a change is made in size of the material or protective tructures are provided.

EVEIOPIENT OF WAVE HEIGHT AND WAVE DIRECTION GAGES.

aboratory project.

xperimental; development.

0 develop wave height and wave direction gages for use in securing accurate records of aves. A satisfactory step-resistance wave gage of the surface mounted type and a presure wave gage of the bottom-mounted type for measuring the height and period characterstics of ter surface variations attributable to wave motion was developed and tested $\mathrm{n}$ the laboratory and field. Auxiliary equipment which allows the gages to be operated n a 7-day unattended basis developed; eight of these gages are now in operation. aboratory tests of a vave direction gage which utilizes two wave-height gages operating oncurrently have been made. Results of these trials warrant further tests of such an instrument and plans are underway.

IND SET-UP AND WAVE GENERATION IN INLAND WATERS.

Iffice of the Chief of Ingineers.

nalysis field data; basic research.

nalysis of field data from two hurricanes over Lake Okeechobee, Florida to obtain ormulae for the determination of wind tides, and the revisions necessary to the Sverdruplunk method of forecasting for deep-water waves to be extended to cover wave generation in shallow water.

eulegan's formula for wind set-up appears to check the data extremely well; the we feriods and heights are generally lower than would be expected from the use of the deep vater equation, the degree seeming to depend primarily on the depth-fetch ard depthleight ratios.

leport in progress.

ITUDY OF QUANTITY OF SAND IN SUSPENSION IN COASTAL WATERS.

aboratory project.

ield experiment; basic research.

The amount of sand in suspension is measured at selected locations, and these measurelents are correlated with the we action observed at the time of samp?ing in order to astablish a relationship between wave action and the average amount of beach material raintained in suspension by the wave action. For selected littoral current velocities, - $t$ will then be possible to compute the rate of drift due to sand in suspension.

nalysis indicates the greatest concentration of suspended sand to be in the bottom oneihird of the water depth. The average concentration inside the breaker zone appears to ary directly with wave height.

AVE TANK STUDY OF EFFECT ON BEACH PROFILES OF VARYING WAVE PURIODS. 
(e) It is believed that constant period wave trains as presently used in most small s tanks unduly accentuate profile irregularities peculiar to the ware period used. these tests the wave period will be varied both rapidly and slowly from $10 \%$ to 30 a mean period. Profiles obtained with varying periods will be compared with thos tained with a constant perioc equal to the mean of the varying period in order to mine how much and how frequently the wave period should be varied in wave tank te order to eliminate irregularities due to the use of a fixed period and thereby ar mate more nearly a profile resulting from a "siznificant" wave period with its mu of components.

(1460) MEASUREMENT OF DEEP WATIR OCEAN WAVES WITH AN AIRBORNE WAVE RECORDTR.

(b) Laboratory project.

(d) Experimental; basic research.

(e) Wave records obtained during selected storms from a shallow ter and a floating water recording wave gage, and an airborne wave recorder mounted in a plane flyin and from the storm area will be studied and compared to assess the reliability of ont wave forecasting procedures and formulae for wave transformation in shallow $\mathrm{w}$

(工и́l) IOSS OF WAVE ENERGY BY BOTTOM FíICTION AND PERCOIATION IN A PIRMEABLE BOTTOM.

(b) Laboratory project.

(d) Experimental; basic research.

(e) To test theories developed by J.A. Putman and J.W. Johnson concerning the amoun energy lost due to percolation in a permeable sea bottom and bottom friction by a as it moves from deep water to the beach. On one side of a splitter wall in the flume is a smooth, impermeable beach and sands of various sizes are placed on the side. By running waves of varying periods and heights over the beaches concurren measuring the wave heights on both sides at points along the length of the flume, energy loss can be determined.

U. S. DEPARTMENT OF THE ARMY, CORPS OF ENGINEERS, Bonneville Hydraulic Laboratory.

Inquiries concerning Projects Nos. 189, 408, 409, 410, 667, 979, 1198, 1199, 1202 1462 to 1466 , incl., should be addressed to Mr. R. B. Cochrane, Office of the Dis Engineer, Portland District, 628 Pittock Block, Portland, Ore.

(189) GENEZAL MODEL STUDY OF MCNAY DAM, COLUMBIA RIVR, URATILIA, OREGON.

(b) Department of the Army, Corps of Engineers, Walla Walla District, Walla Walla, Wa

(d) Experimental; for design.

(e) A fixed-bed type, 1:100-scale, undistorted model, reproduces a 3.7 mile reach of Columbia River, at the site of McNary. Dam. After verification of the natural riv features, tests were made to determine the best arrangements of spillway dam, powt fishways, and lock structure in the interest of navigation and power generation, : study certain problems with regard to fishway approaches and cofferdam constructi

(f) Tests completed.

(g) Tests indicated that realignment of the structure, especially that of the powerhol would be necessary. Tests of a revised design showed satisfactory improvements. dam studies indicated satisfactory flow conditions for the various steps or arran during construction of the project structures. Facilities were developed to perm: migration through the structures during all stages of construction. The most ecor alignment of the tailrace was determined.

(h) Prelininary reports have been issued on the various tests.

(408) GENEZAL MODEL STUDY OF CHIEF JOSEPH DAM, COLUMBIA RIVR, TASHINGTON.

(b) Department of the Army, Corps of Engineers, Seattle District, Seattle, Washington

(d) Experimental; for design. 
The 1:80-scale fixed bed model was enlarged to include a 2.5-mile reach of the river upstream from river mile 544.1. Reproduced are the revised 19-bay spillway, 20-unit powersouse, and a powerhouse intake channel. Normal operating head will be 162 feet. Study seing made to determine the most economical and effective arrangements of spillway dam and powerhouse, to determine the forebay and tailbay flow conditions with various operating conditions, and to obtain a satisfactory program of cofferdam construction.

lesting of the powerhouse approach channel, verification of the model river bed, and studies of the first three phases of cofferdam construction and river diversion have been nade.

Preliminary reports have been issued on tests completed to date.

MODEL STUDY OF CHIEF JOSEPH DAM SPILIWAY, COLUMBIA RIVER, WASHINGTON.

Jepartment of the Army, Corps of Engineers, Seattle District, Seattle, Washington. Experimental; for design.

The 1:33 sectional model consists of three 40-foot bays of the tainter gate-controlled -spillway dam. To determine the most effective and economical stilling basin design, to oheck the performance of the spillway abutments, and to obtain crest rating curves and rressures.

Tests completed.

jeveral shapes of spillway piers with trunnion arm supports and training walls downstream, arrangements of stilling basins, and types of baffle piers have been tested. Based on these tests a spillway pier with an elliptical-shaped nose, revised 167-foot long stilling basin, and streamlined baffle piers have been recommended for adoption.

?reliminary reports have been issued on the various tests.

MODEL STUDY OF CHIEF JOSEPH DAM PENSTOCK, COLUMBIA RIVER, WASHINGTON.

Jepartment of the Army, Corps of Engineers, Seattle District, Seattle, Washington. Experimental; for design.

The 1:25 model reproduces a section of the powerhouse forebay, one 20-foot penstock, and the entrances of the adjacent penstocks. Normal head is 162 feet. To study the effects of non-uniform flow conditions at the penstock entrance (as determined from Thief Joseph General Model) on velocity distribution at the entrance to the scroll case. Preliminary results indicate that the direction of flow approaching the penstock intakes has little effect on velocity distribution at the scroll case.

Tne progress report issued.

MODEL STUDY OF MCNARY WASHINGTON SHORE FISHIADDER DIFFUSER, COLUMBIA RIVER, UMATILIA, REGON.

Department of the Army, Corps of Engineers, Walla Walla District, Walla Walla, Wash. Experimental; for design.

The 1:16 model reproduces the complete diffusion chambers and the auxiliary water supply system in the lower end of the fishladder. Pressures were observed in critical sections of the water supply systems to the diffusion chambers to determine the hydraulic grade lines and to locate low pressure areas which might be detrimental to the prototype structure.

Tests completed.

Tests indicate that the valves controlling the flow to the diffusion chambers should be fully open or fully closed for flows throughout the lower range of tailwaters. High negative pressures occurred in the lines downstream from the valves with partial valve openings. The valves were submerged during high tailwater stages and danger from negative pressures was eliminated.

One preliminary report issued. Final report being prepared.

MODEL STUDY OF LUCKY PEAK OUTLET TUNNEL, BOISE RIVER, IDAHO.

Department of the Army, Corps of Engineers, Walla Walla District, Walla Walla, Wash. Experimental; for design. 
(e) The 1:28.75 model includes $575^{\circ}$ feet of 23-foot tunnel, a six-branch manifold out vertical slide valves and flip buckets, the stilling basin, and a 1,600-foot rea river downstream. To determine the hydraulic characteristics of the manifold, $v$ and valve slots, and to develop flip bucket and stilling basin designs which wil ciently dissipate the energy of flow at a head of 230 feet, so as to prevent dam the opposite river bank and areas downstream.

(g) Improved flow characteristics resulted from use of rectangular laterals branchin a tapered rectangular manifold. The flip buckets as originally designed failed duce adequate energy dissipation with any of the basin designs tested to date.

(h) Twelve progress reports issued.

(1198) MODIL STUDY OF FRICTION LOSSES IN CORRUGATED METAL PIPE (CW-828).

(b) Office of the Chief of Engineers, U. S. Army, hashington, D. C.

(d) Experimental; applied research.

(e) Tests are being conducted to determine values of Manning's $n$ for corrugated me of 3-, 5-, and 7-foot diameters with velocities of 1 to $10 \mathrm{fps}$. Additional data sisting of velocity distribution at various sections of the pipe and pressure di tion at various sections of the pipe and pressure distribution along the corruga are being obtained.

(g) Results to date indicate that in a 3-foot corrugated pipe the $n$ value varies $f$ 0.0232 to 0.0242 , for velocities of $I$ to $11 \mathrm{fps}$, and that $\mathrm{n}$ values increase wi Reynolds number to $1 \times 106$ and decrease with higher Reynolds numbers.

(1199) MODEL STUDY OF RUBBER SEAL TESTTR.

(b) Department of the Army, Corps of Engineers, Portland District, Portland, Oregon.

(d) Experimental; for design.

(e) The full-scale apparatus consists of a horizontal fixed plate upon which is moun frame of the seal to be tested and a companion plate which is made to run back a under pressure across the rubber seal frame while under water to simulate protot tion of a rubber seal in service. The speed of the rubbing action can be varied the pressure exerted against the rubber seal can be raised to 250 psi.

(f) Tests discontinued.

(g) Results have been expressed as a family of curves showing friction coefficients J-rubber seals against a steel plate for various periods of operation at pressur from 100 to 250 psi.

(h) Two progress reports issued.

(1202) MODEL STUDY OF COFFERDAM CIOSURE, MCNARY DAM, COLUMBIA RIVER, UMATILIA, OREGON.

(b) Department of the Army, Corps of Engineers, Walla Walla District, Walla Walla, W

(d) Experimental; applied research.

(e) A 1:24 model reproduced natural topography for a 1400-foot reach of the river, $t$ cofferdam, and eleven cells of the main cofferdam adjacent to a river channel wh to be filled before construction of the final cofferdam cells. The fill was to by dropping from an overhead cableway a large number of 8-ton concrete blocks pr tetrahedron form, and 3- to 5-ton boulders. As each of the concrete blocks and was dropped in the river, a similar block or boulder, reduced to model scale, wa dropped at the same relative point in the model. With discharge and water-surfa tions adjusted in the model to coincide with those in the river, it was intended model would show the effectiveness of the various construction steps.

(f) Tests completed.

(g) The model served as a guide for the placement of the prototype fill. Good agree existed between model and prototype results during the initial and final stages fill construction.

(h) One progress and one preliminary report issued. 
GENERAL MODEL STUDY OF THE DALLES DAM, COLUMBIA RIVER, THE DALLES, OREGON.

Department of the Army, Corps of Engineers, Portland District, Portland, Oregon.

Experimental; for design.

A 1:80 undistorted, fixed bed model reproduces 2.7 miles of the Columbia River, a 30 bay spillway, a 22-unit powerhouse, a lock chamber with maximum lift of 90 feet, a rockfill nonoverflow section, and facilities for passing salmon over the dam. The purposes are to study the structures alignment and flow conditions affecting navigation, power generation, cofferdam placement, and fish passage.

Four structures alignments utilizing high rock topography at the site to minimize the necessity of cofferdams and wet excavation have been studied.

Four progress reports issued.

SECTIONAL MODEL STUDY OF ROCK FIIL, THE DALLES DAM, COLUMBIA RIVER, THE DALLES, OREGON.

Department of the Army, Corps of Engineers, Portland District, Portland, Oregon.

Experimental; for design.

A $1: 24$ sectional model constructed reproduced a 120-foot section of the 200-foot high by 600-foot wide rock fill nonoverflow section of The Dalles Dam. The purpose was to obtain prelininary information relative to the rock sizes required to construct the fill with river discharges to $200000 \mathrm{cfs}$ and to withstand overtopping with river flows of 600000 cfs.

Tests completed.

Model results indicated that the fill could be constructed from Elevation 0.0 to Elevation 70 with 3-ton rock, to Elevation 90 with 5-ton rock, and be capped with 12-ton rock. One preliminary report issued.

MODEL STUDY OF ROCK FILL, THE DALLES DAM, COLUMBIA RIVER, THE DALIES, OREGON.

Department of the Army, Corps of Engineers, Portland District, Portland, Oregon. Experimental; for design.

A 1:36 model of the 600-foot wide by 200-foot high rock-fill nonoverflow section of The Dalles Dam including portions of the river channel upstream and downstream therefrom is being constructed to provide information relative to rock sizes and placement necessary to construct the fill during river discharges up to $200000 \mathrm{cfs}$ and withstand overtopping flows of $600000 \mathrm{cfs}$.

MODEL STUDY OF THE DALLES DAM SPILIWAY, COLUMBIA RIVER, THE DALLES, ORECON.

Department of the Army, Corps of Engineers, Portland District, Portland, Oregon. Experimental; for design.

Three bays of the spillway are reproduced to a scale of $1: 36$ to study the hydraulic characteristics of the spillway crest, piers, gates, stilling basin and baffle piers.

MODEL STUDY OF THE DALLES DAM NAVIGATION IOCK, COLUMBIA RIVER, THE DALLES, CREGON.

Department of the Army, Corps of Engineers, Portland District, Portland, Oregon. Experimental; for design.

A $1: 25$-scale model of the lock chamber including its culvert systems and portions of the upstream and downstream approach channels is being constructed. Studies will be made of various types of filling and emptying systems to determine the most advantageous from the standpoints of rate of operations, degree of turbulence, and economy. The several proposed plans include lateral culverts within the lock chamber combined with several locations of intake ports, longitudinal culverts, and outlet works. 
U. S. DEPARTMENT OF THE ARMY, CORPS OF ENGINEERS, Little Rock District.

(669) TEST OF TAINTER GATE FOR CONTROL OF CONDUIT FIOW.

(b) Department of the Army, Office of the Chief of Engineers.

(c) District Engineer, Little Rock District, Corps of Engineers, Little Rock, Ark.

(d) Experimental; design and operation.

(e) A 4-foot wide by 6-foot high tainter gate was constructed and installed at Norfolk the downstream end of an existing conduit. It was operated under a head of about Tests were made to determine down pull, vibration, air-intake volume, and measuren pressures on the face of the gate and in the conduit. Different types of rubber $s$ are being used during the tests.

(f) Tests completed on the gate leaf and on hydraulic and pneumatic rubber seals. An tional eccentric trunnion-type tainter gate with fixed seals is being tested. Adc tests will be made with other types of fixed seals.

(g) The results indicate that both the tainter gate and the eccentric-type tainter gat ated in a satisfactory manner. The hydraulic seals tested are not considered adec However, the pneumatic seals are considered satisfactory.

U. S. DEPARTMENT OF THE ARMY, CORPS OF ENGINEERS, LOS Angeles District.

Inquiries concerning Projects Nos. 980, 1203, and 1204, should be addressed to the District Engineer, Los Angeles District, Corps of Engineers, P. O. Box 17277, Foy Los Angeles 17, Calif.

(980) MODEL STUDY OF WHITTIER NARROWS FIOOD-CONTROL BASIN.

(b) Laboratory project.

(d) Experimental; for design.

(e) Earth dam with gated outlets and spillway. Three models are being used: a 1:24 mo the outlet works for tests on the operation of the four radial sluice gates; a $1: 4$ of a half plan of the spillway for tests on the operation of the nine tainter gate l:60 general model of the flood-control basin for tests on the over-all operation project.

(f) Tests on the 1:42 model are completed. Tests on the 1:60 model are in progress.

(g) A satisfactory plan of operation of a gated spillway at streambed elevation de

(1203) MODEL STUDY OF LOS ANGELES RIVER CHA NNEL TMPROVEMENT, RIO HONDO TO PACIFIC OCEAN.

(b) Laboratory project.

(d) Experimental; for design.

(e) From Rio Hondo to Spring Street the improvement proposed is a paved trapezoidal cha Normal velocity would be supercritical (25 fps) but numerous bridges would produce "B" flow and attendant hydraulic jumps upstream of the bridges. From Spring Stree Pacific Ocean the channel will be trapezoidal, the side slopes will be paved, the : unpaved, and the velocity subcritical (12 fps). The design discharge is $140,000 \mathrm{c}$ : the first reach and $146,000 \mathrm{cfs}$ in the second reach. A 1:50 model will be used to flow conditions at confluences, at bridges, and at the junction of the paved and ur channels. The model tests will be accomplished in stages.

(1204) A IRFIEID SURFACE DRAINAGE INVESTIGATION.

(b) Chief of Engineers, Department of the Army, Washington 25, D. C.

(d) Experimental; applied research.

(e) Paved, turfed, mulched, and bare test sections simulating portions of a landing str parking apron have been constructed to obtain basic data for analysis of rainfall-r relationships for various types of surfaces, cover conditions, and slopes. Natura: simulated rainfall will be studied. Special control devices and recorders are beir to obtain the data.

(f) Tests completed. Preparation of report in progress. 
GPARTMENT OF THE ARMY, CORPS OF ENGINEERS, St. Paul District.

In cooperation with St. Anthony Falls Hydraulic Laboratory.

Inquiries concerning Projects 194, 618, 982, 985, and 1206 should be addressed to the District Engineer, Corps of Engineers, St. Paul District, 1217 U. S. Post Office and Custom House, St. Paul 1, Minn.

\section{A STUDY OF METHODS USED IN THE MEASUREMENT AND ANALYSIS OF SEDIMENT LOADS IN STREAMS.}

Federal Inter-Agency River Basin Committee, Subcomittee on Sedimentation.

Experimental; applied research and development.

Designs for point-integrating and depth-integrating sediment samplers and laboratory apparatus have been developed, and the mechanical features and streamlining of both types of samplers have been improved to provide better operating characteristics and greater stability over a wider range of stream sampling conditions. Sampler designs include a light weight depth sampler (operated by hand), medium weight point and depth samplers, and a heavy point sampler (300 lbs) for use in deep and fast streams. A design for a bed-material sampler is also available.

Samplers already developed are available in quantity to meet the needs of the Federal cooperating agencies. One experimental 300-1b point-integrating sampler was fabricated and subjected to field tests. Six bed-material samplers were produced for two Federal agencies. A visual accumulation tube is being used in the study to develop an improved method of determining particle size gradations of fluvial sediment.

"Field tests on suspended sediment samplers, Colorado River at Bright Angel Creek near Grand Canyon, Arizona." Progress Report, Aug. 1951.

"Operating instructions, suspended sediment hand samplers. US DH-48." Oct. 1951.

ST. ANTHONY FALIS LOCKS.

St. Paul District, Corps of Engineers.

Experimental; for design.

The complete hydraulic systems of the upper lock and the lower lock are being studied in l:22.4 models. The lower lock is to have a single culvert and chamber laterals, and the upper lock a culvert in each all and a system of chamber laterals alternating from the two culverts. The two locks will have a total lift of 75 feet.

\section{ARCTIC AND SUBARCTIC DRAINAGE INVESTIGATIONS.}

Field investigations, library research, translations; for design and operation of airfield drainage facilities.

To determine design, construction, and maintenance procedures suitable for the drainage of airfields located in arctic and subarctic areas and subject to potential military operations. Translation of selected articles from Russian literature is underway. Field work, library research, and four reports completed. One report in press.

"Investigation of airfield drainage in arctic and subarctic regions - Part I field reconnaissance and analysis." Loyal A. Johnson, St. Anthony Falls Hydraulic Laboratory Project Report No. 16, Aug. 1950.

"Investigation of airfield drainage in arctic and subarctic regions - Part II translations of selected topics." Meir Pilch, St. Anthony Falls Hydraulic Laboratory Project Report No. 17, Oct. 1950.

"Investigation of airfield drainage in arctic and subarctic regions - supplement to Part I field reconnaissance and analysis." Loyal A. Johnson, St. Anthony Falls Hydraulic Laboratory Project Report No. 18, Jan. 1950.

"Hydrological analysis and design of surface drainage facilities for airfields in arctic and subarctic regions." Ioyal A. Johnson, St. Anthony Falls Hydraulic Iaboratory Project Report No. 20, Feb. 1951.

"The compressive strength of permafrost and ice in their natural state." Translation by Meir Pilch, St. Anthony Falls Hydraulic Laboratory Project Report No. 26, Nov. 1951. 
(982) SPILIWAY FOR OR'NELL DAM, OTTERTAIL RIVER, MIVNESOTA.

(b) St. Paul District, Corps of Engineers.

(d) Experimental; for design.

(e) A 1:25 model was tested to check the adequacy of the proposed spillway and stillini basin.

(f) Tests completed; final report being prepared.

(g) The spillway and stilling basin designs were found to be adequate, but the upstrear approach to the spillway was redesigned, thereby minimizing turbulence in the apprc area and increasing spillway efficiency.

(985) FILLING AND EMPTYING SYSTEMS FOR HIGH-LIFT IOCKS (CW-820).

(b) Chief of Engineers, Corps of Ingineers, Washington, D. C.

(d) Experimental; applied research.

(e) To develop adequate criteria for the design of filling and emptying systems for hig locks. Tests will be conducted in prototype locks, in model locks for definite prc and in a general lock model simulating a maximum lift of 150 feet.

(g) The general lock model was used to study accentuated momentum and overtravel charac tics and in tests on an adjustable lateral culvert in which the culvert dinensions types of ports were varied.

(1206) CONDUIT GATE STRUCTURES AND TRANSITIONS (CW-805).

(b) Chief of Engineers, Corps of Engineers, Washington, D. C.

(d) Experimental; applied research.

(e) A general model study will be made to establish gate operating procedures for multi gate conduits and design criteria for transition sections between conduit outlets a single and multiple control gates. The model includes a complete outlet conduit wi upper pool reservoir, multiple control gates in conduit intake, and a stilling basi

(f) Suspended.

(g) Tests were made to determine the effect of changes in conduit length on undulations the conduit flow near the discharge portal and on turbulence in the stilling basin.

U. S. DEPARTMENT OF THE ARMY, CORPS OF ENGINEERS, Waterways Experiment Station.

Inquiries concerning Projects Nos. 211, 213, 218, 219, 226, 230, 236, 237, 257, 417 $420,425,426,672$ to 676 incl., $678,679,682,683,986$ to 989 incl., 991 to 1004 1207 to 1212 incl., and 1467 to 1476 , incl., should be addressed to The Director, W ways Experiment Station, Corps of Engineers, P. 0. Box 631, Vicksburg, Miss.

(211) MODEL STUDIES OF OUTLET WORKS, SPILLWAY AND STILLING BASIN, GARRISON DAM, MISSOURI NORTH DAKOTA.

(b) The District Engineer, Garrison District, Corps of Engineers, Bismarck, N. D.

(d) Experimental; for design.

(e) A 1:100 model of the converging-chute spillway and a 1:41.6 model of one spillway b were used to determine the hydraulic performance of the approach channel, crest, ch stilling basin, and pilot channel and to correct unsafe conditions. A $1: 50$ model 0 . 29-foot power conduits, and a 1:25 model of the 22-foot flood-control conduits were to examine the performance of the conduits and stilling basins under diversion and voir operation conditions. Of special interest is the use of a tainter gate to con conduit flow. Incidental models were tested in a vacuum tank to determine the cavi characteristics of the emergency caterpillar gate slots in the flood-control condui and the articulated tunnel joints. Tests were conducted on a 2-foot section of the stock gate seals to determine their operating characteristics under varying heads.

(f) Testing complete; preparation of final report in progress. 
Improvement in the right bank alignment and upstream abutments in the approach channel, thereby assuring an even distribution of flow over the spillway, were developed in spillway and stilling basin model. Tests indicated that the length of basin could be reduced 50 feet and that one row of 8-foot baffle piers would be adequate. Flow conditions in the exit area were found unsatisfactory at the higher discharges with a 400-foot-wide pilot channel. A stilling basin and outlet channel were developed for the flood-control and power conduits that provided satisfactory flow conditions during both diversion and reservoir operation. Refinements in the tainter gate and emergency caterpillar gate designs were developed to reduce downpull forces acting thereon. Air demand requirements for the prototype were determined.

MODEL STUDY OF CONTROI STRUCTURE, MORGANZA FIOODWAY, LOUISIANA.

The District Engineer, New Orleans District, Corps of Engineers, New Orleans, La. Experimental; for design.

The control structure will consist of a broadcrested weir and a stilling basin. Discharge coefficients, head-discharge relationships, stilling-basin design, and effect of crest shape on hydraulic efficiency were determined in a 1:20 model. A 1:30 model was used to test various weir shapes. Flow conditions at the abutments were studied in $21: 16$ model of the right abutment and adjacent five bays of the needle-type control structure. Completed. Results indicated the desirability of using a 5-foot-wide broadcrested weir; flared training walls extending above the maximum expected water surface at the abutments; and a horizontal apron supporting two rows of baffle piers and terminated by a 4-foot high sloping end sill.

"Morganza Floodway Control Structure, Mississippi River; hydraulic model investigation." Waterways Experiment Station Technical Memorandum No.2-326, Aug. 1951. (Available for sale and loan.)

\section{CONDUIT INTAKE MODEL TESTS.}

Office of the Chief of Engineers, Department of the Army, Washington, D. C. Experimental; applied research.

Small-scale models are being used for a general study of the hydraulic characteristics of entrance curves for (1) rectangular conduits in which the entrance is flared in four directions, and (2) a gated tunnel having a rectangular entrance with floor at same elevation as approach channel (entrance flared in three directions).

Tests to date indicate that, for a gradual reduction in the pressure gradient through the conduit entrance and a minimum size entrance, the entrance curve should be shaped to the elliptical curve of $\mathrm{X}^{2} / \mathrm{D}^{2}+\mathrm{Y}^{2} /(\mathrm{D} / \mathrm{L})^{2}=1$, where $\mathrm{D}$ is the dimension of the conduit in the direction concerned. Use of the elliptical curve $\mathrm{X}^{2} / D^{2}+\mathrm{Y}^{2} /(D / 3)^{2}=1$ provided slightly better pressure conditions but also resulted in a slightly larger entrance.

\section{SIIDE GATE MODEL TESTS.}

The Chief of Engineers, Department of the Army, Washington, D. C . Experimental; applied research.

A general study by model and prototype tests to determine (1) the best shape of gate lip to reduce downward hydraulic pull on the gates and any vibration tendencies during opening or closing, and (2) the optimum shape for gate slots to eliminate or reduce cavitation tendencies. A 1:5 model reproducing the gate slots, the slide gate, a portion of the conduit upstream and downstream from the gate section, and the air vent has been tested. Also a 1:10-scale gate with a $45^{\circ}$ lip, designed to fit the 1:6-scale gate slots, is being used to study effect of conduit height on pressure conditions on the gate lip. Some of the tests are being conducted in a vacuum tank to determine the point of incipient cavitation. Tests are in progress on a 1:10 model of the Norfolk Dam slide gate in an attempt to alleviate the cavitation below the gate slots.

Tests conducted with a gate slot 2.5 feet or 1 foot deep and 4,3 , or 2 feet wide and the downstream edge tapered 1 inch in 12 inches revealed very little difference in pressure conditions along the downstream edge. 
(b) The President, Mississippi River Commission, Corps of Engineers, Vicksburg, Miss.

(d) Experimental and field investigations; applied research.

(e) Model studies to provide a means of predicting future changes in meandering of the Mississippi River and the need for bank protection have been completed. Additional $n$ studies involve (1) study of revetment stability, (2) study and development of methoc channel stabilization by means other than revetment, and (3) development and testing comprehensive plans for improving specific troublesome reaches of the Mississippi $\mathrm{Ri}$ Full-scale revetment tests under simulated river turbulence conditions were made at $t$ St. Anthony Falls Hydraulic Laboratory, University of Minnesota. Pressure fluctuatic above and below the revetment and in the underlying sand strata were studied. The ac of the revetment resulting from leaching of the sand from between the revetment inter was also studied. Other field investigations include (l) soil surveys to determine $t$ nature, characteristics, and physical properties of the banks of the Mississippi Rive permit recognition of soil factors affecting bank stability, and (2) hydrographic and hydraulic surveys to provide information in specific revetted reaches to permit recog tion of hydraulic and hydrographic factors affecting revetment stability.

(g) A satisfactory technique was developed in the laboratory to correlate model and proto bed and bank materials in a relatively short and unstable reach of the Mississippi Ri The full-scale revetment tests indicated the leaching of the sand from between the in stices of the revetment is the most important factor influencing revetment behavior.

(230) MODEL STUDY OF FIOOD CONTROL, CUIBERIAND, MARYIAND.

(b) The District Engineer, Washington District, Corps of Engineers, Washington, D. C.

(d) Experimental; for design.

(e) The fixed-bed, 1:60 model of the critical portions of Wills Creek and the North Brancl the Potomac River were used to study and develop proposed plans for the protection of Cumberland from floods. The flow in Wills Creek will be below critical depths. Ther the principal design problems centered around the determination of satisfactory side alignments, satisfactory bridge pier and abutment designs, and a satisfactory junctior sign.

(f) Testing complete; preparation of final report in progress.

(g) A satisfactory channel design was developed to adequately pass the design flow of $50, C$ cfs in Wills Creek and 63,000 cfs in North Branch.

\section{(236) MISSISSIPPI BASIN MODI.}

(b) Office of the Chief of Engineers, Department of the Army, Washington, D. C.

(d) Experimental; for design.

(e) Plans provide for a model of the Mississippi River watershed including the Ohio, Misso White, Arkansas, and Red Rivers and their principal tributaries. Initial construction been limited to the Missouri River from Sioux City to the mouth, the Arkansas River fr Blackburn Dam Site to Pine Bluff, the Upper Mississippi River from Hannibal to Tiptonv and the Ohio River and tributaries from above Pittsburgh to Wheeling. Coordination of releases from reservoirs, effect of reservoir operation on flood stages, routing of pr and other floods, levee grades, stage predictions, and effect of floodways on stage re tion will be studied. Model scales are 1:2000 horizontal and 1:100 vertical. Verific tion of the Missouri, Upper Mississippi, and Arkansas Rivers has been completed, and $t$ are in progress.

(h) "Description of Mississippi Basin Model." Mississippi Basin Model Report No. 1-4, Jul 1951. (Available on loan.)

"Verification of Tulsa-to-Van Buren Reach, Arkansas River and Tributaries, Spring 1941 1943 Floods." Mississippi Basin Model Report No. 14-1, July 1951. (Available on loan "Verification of Hannibal-to-St. Louis Reach, Mississippi River and Tributaries, 1947, 1944, and 1943 Floods." Mississippi Basin Model Report No. 15-1, August 1951. (A vail on loan.) 
The President, Mississippi River Commission, Corps of Engineers, Vicksburg, Miss. Experimental; for design.

The fixed-bed model, with scales of 1:2000 horizontal and 1:100 vertical, reproduces the main channel of the Mississippi River from Helena, Arkansas, to Donaldsonville, Louisiana, the entire Atchafalaya Basin, including Morganza and West Atchafalaya Floodways, to the Gulf of Mexico; and the backwater areas of the Arkansas, Thite, Yazoo, Ouachita, and Red Rivers.

Suspended.

\section{MODEL STUDY OF STABILITY OF RUBBLE-MOUND BREAKWATES.}

The Chief, Bureau of Yards and Docks, Department of the Navy, Washington, D. C. Experimental; for design.

Various types of rubble-mound breakwaters in progressive stages of construction were tested to determine the stability and displacement of material under we action. The linear scale ratio was 1:45. The breakwater material was sized in accordance with specifications established by hypothetical prototype breakwaters.

Testing complete; final report in preparation.

Design wave heights (largest wave which does not damage breakwater) have been determined for rubble breakwaters with slopes from $1: 1$ to $1: 3$ constructed of 2.8-specific gravity cap rock simulating 13-1/2-ton to 27-ton cap rock in prototype. Data obtained were used to determine the coefficient $K^{\prime}$ in Iribarren's formula

$$
W=\left[K^{\prime} y_{w}^{3} y_{r} \mu^{3} H^{3}\right] /\left[\left(y_{r}-y_{w}\right)^{3}(\mu \cos \alpha-\sin \alpha)^{3}\right]
$$

Although the coefficient $\left(K^{1}\right)$ varies considerably with breakwater slope and wave steepness, the equation and coefficients proposed by Iribarren are useful in rubble-mound breakwater design. More data will be necessary, however, before rubble breakwaters can be designed with known safety factors.

MODEL STUDY OF AIGIERS LOCK, INTRACOASTAL WA TERWAY, NEW OR LEANS, LOUISIANA.

The District Engineer, New Orleans District, Corps of Ingineers, New Orleans, Ia. Experimental; for design.

The 760-foot by 75-foot lock is designed to operate under a maximum head of 18.5 feet. The head on the sector lock gates will be reversible. The feasibility of filling the lock through sector gates and gate recesses, thus elimizating a culvert system, was studied in a 1:20 model. Forces developed on the sector gates during operation were also investigated.

Completed.

Tests revealed that it is feasible to fill a lock chamber through sector gates in a reasonable time. A revised design of gate lip was developed to reduce hydraulic forces on the gates.

"Filling characteristics, Algiers Lock, Intracoastal Waterway Gulf Section, Louisiana." Waterways Experiment Station Technical Memorandum No. 2-309, April 1951. (Available for sale or loan.)

SIIDE GATE TESTS, NORFOLK DAM, ARKANSAS.

The District Engineer, Little Rock District, Corps of Ingineers, Little Rock, Ark. Experimental; for design.

The most desirable shape of the bottom of the gate to minimize vibration, negative pressures, and disturbance of flow and the downpuli on the gate leaf and the amount of air dram through air vents, for four types of gates, were determined in a $1: 6$ model. Gates with 60-degree and 45-degree lips were used for further study of the effect of conduit height on pressure conditions on the gate lip.

Testing completed; final report in preparation.

on the four types of gate lip shapes tested, that with the seal connected to the upstream face at angles of 45 degrees and 60 degrees provided best results. The Norfolk type and square-edged lip resulted in low pressures at small gate openings while at large openings flow parted from the lip. The height of the conduit had no apparent effect on pressures on the gate lip. These results were substantiated in field tests made at Norfolk Dam. 
(420) MODEL STUDY OF CONDUITS AND HOWELI-BUNGER VALVES, NARROWS DAM, LITTLE MISSOURI RIVER ARKANSAS.

(b) The District Engineer, Vicksburg District, Corps of Engineers, Vicksburg, Miss.

(d) Experimental; for design.

(e) Tests in a 1:16 model were used to determine discharge coefficients of the Howell-Bu valves, and to study stilling-basin action below the valves with special emphasis on pressures at the end sill.

(f) Completed.

(g) Tests demonstrated the need for some type of hood over the valves to prevent flow fr being projected onto the access road along the right side of the stilling basin. Ho having semicircular tops of 8.75 -foot radius supported by vertical walls from the ba floor gave satisfactory results. It was necessary to replace the sloping end sill o original design by a vertical-faced end sill to maintain a cushion of ter in the $s$ basin. Pressures on the end sill were not of serious proportions. The coefficient charge for the combination of the fully open valves without hoods and the contractio immediately above the valves was found to be about 0.87 .

(h) "Conduits and Howell-Bunger Valves, Narrows Dam, Little Missouri River, Arkansas; Mo Investigation." Waterways Experiment Station Technical Memorandum No. 2-294, July 1 (Avilable for sale or loan.)

(425) COMPREHENSIVE MODEL STUDY, DELAWARE RIVER, PENNSYLVANIA.

(b) The District Engineer, Philadelphia District, Corps of Engineers, Philadelphia, Pa.

(d) Experimental; for design.

(e) To develop and test plans for reduction of shoaling in several ranges of the navigat channel. The entire Delaware River estuary from the Atlantic Ocean to Trenton is re duced in the model which is of the fixed-bed, silt-injection type, with scale ratios 1:1000 horizontally and 1:100 vertically. Tides and tidal currents are reproduced b automatic tide-control machines. Observed prototype salinities are reproduced in th: Delaware Bay portion of the model, and provisions made for the injection of silt, an measuring silt deposits.

(g) Tests were made to determine the effect of increasing the size of certain portions c navigation channel on tidal heights, currents, and salinity. A test to determine tr repository of material evenly distributed in the channel at the beginning of the tes dicated it would move to existing channel shoals and overbank areas of low velocity. water flows necessary to maintain known salinity at Pennsylvania-Delaware state lin determined.

(426) MODEL STUDIES OF EAST BRANCH DAM, CLARION RIVER BASIN, PENNSYLVANIA.

(b) The District Engineer, Pittsburgh District, Corps of Engineers, Pittsburgh, $\mathrm{Pa}$.

(d) Experimental; for design.

(e) Tests were conducted to insure satisfactory hydraulic functioning of the spillway ar outlet works with particular attention to development of a dispersal bucket for the way and to performance of wheel gates, tunnel, and stilling basin of the outlet work Three models were involved: (1) a 1:50 model of the spillway; (2) a 1:25 model of tr let works; and (3) a 1:12 model of one of the control gates for the outlet tunnel.

(f) Completed.

(g) A dispersal bucket which effectively dissipated the energy of flow was developed. spillway coefficient could be increased, without producing dangerous negative pressi by shaping the weir to conform to the nappe of a 12-foot head, although the design 1 produced a 17-foot head. The increase in discharge coefficient permitted a 10-foot duction in spillway crest length. The intake structure and tunnel operated satisfac except with 1 gate open completely and the other open 10 feet. The large air pocket formed in the upper end of the tunnel and traveled into the stilling basin under th: condition were eliminated by addition of a l-foot wide by 2-foot high vane along the line of the transition from the end of the separation pier to the beginning of the The outlet works stilling basin operated satisfactorily and economies in its constri were determined from the model tests. Negative pressures near the bottom of the cor gate were eliminated by adding a small lip along the lower edge of the gate. 
"Spillway and outlet works, East Branch Reservoir, Clarion River, Pennsylvania; model investigation." Waterways Experiment Station Technical Memorandum No. 2-325, July 1951. (Available for sale or loan.)

\section{MODEL STUDIES OF LYNNHA VEN BAY AND INLET, VIRGINIA.}

The District Engineer, Norfolk District, Corps of Engineers, Norfolk, Va. Experimental; for design.

Tests were conducted to develop the most efficient design of inlet and interior channels to provide the desired volume of tidal flow into and out of Lynnhaven Bay and to determine the effectiveness of jetties in preventing shoaling of the inlet channel and the effects of jetties on the beaches adjacent to the inlet. Two models were used: (1) a fixed-bed model, reproducing all Lynnhaven Bay and Inlet and a portion of Cheaspeake Bay to scales of 1:800 horizontally, and 1:80 vertically; and (2) a moveable-bed type, reproducing Lynnhaven Inlet and adjacent beaches, and off-shore areas to about the 25-foot contour of depth on Chesapeake Bay, with scales of 1:400 horizontally, and 1:80 vertically. Testing completed; final report in preparation.

Tests indicated that a single jetty on the east side of Lynnhaven Inlet would be almost as effective as twin jetties in preventing reshoaling of the entrance channel.

\section{GENERAL SPILIWAY MODEL TESTS.}

The Chief of Engineers, Department of the Army, Washington, D. C. Experimental; applied research.

Tests on a 1:40 scale model are used to study hydraulic characteristics of the standard spillway shape with heads up to $11 / 3$ times the design head of the crest, including the effect of crest piers and gates. Tests are also being made to establish general rules for design of roller-type energy dissipators. The drop from spillway crest to bucket will be varied to study the effect of nappe thickness.

Tests to obtain discharge and pressure data for various approach elevation conditions indicated that with height of weir equal to or greater than the head, coefficient and pressure data were in the same range for the same crest shape. The spillway discharge per net foot of width is not materially affected by the use of crest piers or by variation in the shape of these piers.

MODEL STUDIES OF FORT RANDALL DAM, MISSOURI RIVER, SOUTH DAKOTA.

The District Engineer, Omaha District, Corps of Engineers, Omaha, Nebr. Experimental; for design.

A 1:100 comprehensive model was used to determine effects on velocities of depth and curvature of the approach channel; to investigate flow over the chute-type, tainter-gate-controlled spillway, and develop a good stilling basin design; and to study flow conditions in the exit area. A 1:50 outlet stilling basin model was used to develop a satisfactory stilling basin below the eight 22-foot diameter power conduits which will be used for diversion during construction and which will eventually be incorporated in the powerhouse substructure; to verify the design of the stilling basin for the four 22-foot-diameter flood-control conduits to insure satisfactory operation under present and future tailwater conditions; and to determine the limit of required tailrace paving and the necessity for bank protective works by study of currents and wave action. A 1:25 intake and flood-control conduit model was used to determine the character of flow for various reservoir levels; measure loss coefficients of the intake structure; investigate pressures in the transition section; and determine the effects of partial gate operation upon downpull and oscillation of the gates and upon air requirements.

Testing completed; final report in preparation.

An outlet stilling basin was developed that gave the desired flow characteristics for all operating conditions. A further analysis of the design requirements based on model tests and investigations indicated that one spillway gate could be eliminated. Tests on the spillway model developed an approach area, spillway, and exit area that provided the desired flow characteristics for all operating conditions and permitted several economies in construction. Tests on the 1:25 model assisted in the development of a satisfactory intake and transition section for the conduits. 
(675) MODEL STUDY OF FIOOD-CONTROL TUNNEL, BIAKELY MOUNTA IN DAM, OUACHITA RIVER, ARKANSAS.

(b) The District Engineer, Vicksburg District, Corps of Engineers, Vicksburg, Miss.

(d) Experimental; for design.

(e) Tests on a 1:25 model were used to analyze the hydraulic characteristics of all elemen of the 19-foot diameter tunnel and to correct unsatisfactory conditions. Special consideration was given to flow conditions through the 80-foot drop immediately below the tunnel intake and control structure.

(f) Testing completed; final report in preparation.

(g) The hydraulic performance of the structure was studied and a gate operating schedule developed to eliminate an unstable hydraulic jump in the tunnel.

(676) MODEL STUDIES OF JIM WOODRUFF DAM, APALACHICOLA RIVER, FIORIDA.

(b) The District Engineer, Mobile District, Corps of Engineers, Mobile, Ala.

(d) Experimental; for design.

(e) Tests were used to investigate the hydraulic performance of the spillway and lock stru ture as originally designed, and to effect necessary revisions. Particular attention given to currents at the upstream and downstream lock approaches and flow through the span some 0.7 mile below the structure, and the determination of submergence coefficie for the spillways. Four models were involved: (1) a 1:100 comprehensive model; (2) a 1:38.4 section model of one full gate bay plus adjacent half gate bays of the controll portion of the spillway; (3) a 1:30 section model of a 30-foot portion of the uncontro spillway; and (4) a 1:30 section model of a 30-foot portion of the overflow dike.

(f) Testing completed; final report in preparation.

(g) The spillway crest was modified in shape and the stilling basin shortened. The lock n were decreased in length and the depth of approach channel increased. A flip bucket n added to the overflow dike section.

(678) CHARIESTON HARBOR MODEL STUDY.

(b) The District Engineer, Charleston District, Corps of Engineers, Charleston, S. C.

(d) Experimental; for design.

(e) Tests were made to determine whether channel realignment, the provision of channel con works, or other remedial measures will be effective in reducing the present heavy rate shaoling in certain reaches of the harbor navigation channels. The fixed-bed model ha scales of 1:800 horizontally, and 1:80 vertically.

(f) Testing completed; final report in preparation.

(g) Improvement plans tested indicate reductions in six of the eight major shoals. Simult ous shoaling tests of plans at all shoals indicated a reduction of 54 percent in tota] shoaling, while similar tests of improvements at only the three major shoals appeared reduce shoaling 50 percent. Interpretative tests indicate that improvement plans whic do not reduce current velocities in inter-shoal reaches need not be expected to cause shoals to develop. Sedimentation basins in the upper river were tested and found to $k$ unsuccessful in trapping material. Tests showed that spoiling in the water off Daniel Island results in redistribution of the material throughout the lower harbor and that spoiling in the water off Hog Island results in redistribution of the material chiefly shoal 7 .

\section{(679) RAR ITAN RIVER MODEL STUDY.}

(b) The District Ingineer, New York District, Corps of Engineers, New York, N. Y.

(d) Experimental; for design.

(e) Tests were made to determine some means for minimizing the excessive rate of shoaling the 25-foot-deep portion of South Channel. The fixed-bed model had scales of 1:600 hc zontally, and 1:100 vertically.

(f) Tests completed; final report in preparation.

(g) Model tests indicate that realignment of a part of the 25-foot-deep portion of South Channel, together with closure of the main channel by a dike would afford the maximum duction of shoaling in the problem area but would probably increase shoaling in the Ra $\tan$ Arsenal tuming basin. The top of the dike should not be higher than mean high wa in order not to interfere with flood flows in the river. 
HYDRAULIC CAPACITY OF MEANDERING CHANNEIS IN STRAIGHT FIOODWAYS.

Office of the Chief of Engineers, Department of the Army, Washington, D. C. Experimental; applied research.

A general investigation of the hydraulic capacity of meandering channels in straight floodways. Model tests are used to study effects of radius of curvature of bends; sinuosity of channel; depth of overbank flow; overbank roughness; water-surface slope; valley slope; and ratio of overbank area to channel area. Scales are proportionate to average conditions in nature so that the data obtained can be applied to natural problems.

Tests in which changes in one or more of the factors listed in (e) were involved indicated that overbank roughness is an important factor affecting the hydraulic capacity. Preliminary analysis indicated also that discharge is reduced about 35 percent by increasing the sinuousity of a 2-foot (bottom width) channel from straight to semicircular.

\section{MODEL STUDIES OF FIOW CONDITIONS IN PUMPING PIANT SUMP AND SURGES IN SEWERS.}

The District Engineer, Louisville District, Corps of Engineers, Iouisville, Ky. Experimental; for design.

A general study was made of surges in a sewer system due to sudden arrest of flow at the pumping plant and effect of surcharging the sewer upon the concentration time for flow to the pumping plant. Flow conditions in the transition and sump of the pumping plant were also investigated. For study of flow conditions in the pumping plant, a $1: 16$ model was used. For study of surges and concentration time, a l:32 general model was used. Testing completed; final report in preparation.

The surge model verified the initial computations of the surges occurring in the sewer and provided sufficient basic data for the computations of all surges. The pumping plant model demonstrated the original design to be inadequate; a design that had the required discharge capacity was developed.

MODEL TESTS OF CHEATHAM DAM, CUMBERIAND RIVER, TENNESSEE.

The District Engineer, Nashville District, Cors of Engineers, Nashville, Tenn. Experimental; for design.

Tests of 1:12 model were conducted to determine the relative force required to raise a wicket under various operating conditions and to determine the optimum angle for the face of the wicket, the guard sill, and the strut. A 1:36 model was used to determine the most advantageous shape for the submergible tainter gate and the aeration required; the forces acting on the gates; and flow conditions for various tailwater elevations. In addition, the submergible tainter gate developed in the 1:36 model was tested in a 1:10 model to determine its operating characteristics at the larger scale. Tests to determine the location and height of end sill for use with a partially submergible tainter gate are currently underway.

Uplift forces acting on the upstream emergency dam were eliminated by use of a wicket gate with a curved upstream face. A design has been developed for the submergible tainter gate that eliminates the tendency of the gate to oscillate under certain operating conditions. Results obtained on the 1:10-scale model verified those previously obtained on the 1:36scale model.

MODEL STUDY OF CHANNEL IMPROVEMENTS, FARM CREEK, ILIINOIS.

The District Engineer, Chicago District, Corps of Engineers, Chicago, IIl. Experimental; for design.

The proposed plans for control of floods on Farm Creek above, below and within East Peoria have been studied on a $1: 60$, fixed-bed model.

Testing completed; final report in preparation.

The model investigation indicated that: (1) the proposed channel improvements would permit safe passage of the design flood; (2) minor changes in the improvement plans would greatly improve flow conditions; and (3) the capacity of a diversion channel could be increased sufficiently by enlargement of its channel and redesign of its interceptive works to preclude the necessity of improvements in the main channel downstream. 
(988) MODEL STUDY OF SPILIWAY, GENEGANTSLET DAM, NEW YORK.

(b) The District Engineer, Baltimore District, Corps of Engineers, Baltimore, Md.

(d) Experimental; for design.

(e) Model tests were conducted in a 1:36 model to study and, if necessary, provide means improving flow conditions in the curved approach to the spillway, over the spillway cr and in the converging chute.

(f) Testing completed; final report in preparation.

(g) Two designs were developed that gave the desired flow conditions, one design employing two weirs and the other requiring only one weir.

(989) MODEL STUDY OF MISSISSIPPI RIVRR, VICINITY OF GREENVILLE BRIDGE, GREENVILIE, MISSISSIF

(b) The District Engineer, Vicksburg District, Corps of Engineers, Vicksburg, Miss.

(d) Experimental; for design.

(e) The original fixed-bed model was converted to a moveable-bed model using crushed coal bed material. Tests were made to study flow conditions existing in the Mississippi Ri in the vicinity of the Greenville Bridge, Greenville, Miss., and to develop plans for improvement of the reach.

(f) Testing completed; final report in preparation.

(g) Fixed-bed tests indicated that a realignment of the channel probably would improve flo conditions in the vicinity of Greenville Bridge. However, results of moveable-bed tes involving a major realignment of the channel and the installation of dikes along the ? bank in one locality, did not indicate improvement in flow conditions in the vicinity the bridge.

(991) MODEL STUDY OF OUTLET WORKS, TEXARKANA DAM, TEXAS.

(b) The District Engineer, New Orleans District, Corps of Engineers, New Orleans, La.

(d) Experimental; for design.

(e) Tests were conducted on a 1:25 model of the conduits, stilling basin, and portion of $t$ outlet channel to develop an economical and safe stilling basin.

(f) Testing completed; final report in preparation.

(g) A stilling basin incorporating warped inverts at the conduit outlets and a vertical wa midway between the two conduits extending into the stilling basin provided satisfactor energy dissipation.

(992) MODEL STUDIES OF PINE FIAT DAM, KINGS RIVER, CALIFORNIA.

(b) The District Engineer, Sacramento District, Corps of Engineers, Sacramento, Calif.

(d) Experimental; for design.

(e) Special attention was given in the tests to the hydraulic characteristics of the crest flow from the conduits, and to the effectiveness of the flip-bucket in deflecting the water away from the toe of the dam. Pressures on the crest and discharge coefficients were thoroughly investigated because the crest was designed to fit the lower nappe for head only 75 percent as great as the maximum head expected. A deflector block was use in the downstream end of each conduit in the lower tier to spread the discharge onto $t$ surface of the tailwater. Four models were involved in the study: (1) a 1:60 comprehe model; (2) a 1:40 section model of the spillway crest; (3) a $1: 18$ model of the conduit outlet portal; and (4) a 1:18 model of one of the conduits in the upper tier.

(f) Testing completed; final report in preparation.

(g) Negative pressures on the crest were not excessive for any discharge condition. The adequacy of the 50-foot-radius flip bucket to deflect flow was confirmed. Alterations the alignment of the upper tier of sluices and to the outlet portal of the lower tier sluices improved flow conditions.

(993) CAVITATION RESEARCH.

(b) Chief of Engineers, Department of the Army, Washington, D. C.

(d) Experimental; applied research. 
Cavitation characteristics of such structures as baffle piers, steps in stilling basin, spillway gate slots, offset joints, etc., and pressures in horizontal bends are being studied on models installed in a vacuum tank. Models tested to date have been generally of three types; (1) offsets into flow; (2) offsets aw from flow; and (3) gate slots. All shapes have been tested in the floor of a conduit 0.500 foot high by 0.283 foot wide. All test data are compared on the basis of a cavitation index $K$. from the formula $K_{i}=\left(h_{0}-h_{v}\right) /\left(V_{0}^{2} / 2 g\right)$ where $h_{0}$ and $V_{0}$ are pressure and velocity in the vicinity of the area concerned; $h_{\mathrm{v}}$ is the vapor pressure of the water.

EFFECTS OF MODEL DISTORTION.

Chief of Engineers, Department of the Army, Washington, D. C. Experimental; applied research.

A general study is being made to determine the effects of model distortion on velocity distribution, bed movement, and other hydraulic conditions. A series of tests have been completed in a triangular flume having an adjustable central angle and adjustable slope.

\section{SIMUIATION OF AIR ENTRAIMMENT IN MODEIS INVOLVING HIGH VELOCITY FIOW.}

Chief of Engineers, Department of the Army, Washington, D. C. Experimental; applied research.

This investigation comprises a series of studies to determine: (1) the spread of the boundary layer in accelerating flow; (2) the effect of air entrainment on stilling basin performance; and, (3) the relationship between air demand in a model and prototype sluice. The experimental phase of the analysis of boundary layer development in accelerating flow conducted at the University of Iowa has been completed and the report is now being reviewed by the Waterways Experiment Station.

USE OF AIR INSTEAD OF WATER IN MODEL TESTING.

Chief of engineers, Department of the Army, Washington, D. C. Experimental; applied research.

A general study is to be made analytically and by model tests to determine the accuracy of model tests of closed conduits using air instead of water as the model fluid.

Suspended.

\section{SIUICE OUTLET MODEL TESTS.}

Chief of Engineers, Department of the Army, Washington, D. C.

Experimental; applied research.

The study involves model tests of various type sluice outlet portals to determine the relative effectiveness of each type. Tests of sluice outlets with flared side walls and with tetrahedral floor deflector blocks were conducted. A sluice exit portal similar to the Bluestone Dam design was tested to determine its effectiveness for varying conditions of discharge with several slopes on the sluices.

Suspen ded.

Tests to date indicate that the effectiveness of an exit portal of the Bluestone Dam design is not materially affected by the slope of the sluice.

STUDY OF WAVE FORCE ON BREAKWATERS.

Office of the Chief of Engineers, Department of the Army, Nashington, D.C. Experimental; applied research.

A general investigation of wave phenomena and resulting forces is being conducted in a wave tank to develop formulas, supported by experimental data, from which wave pressures on impervious surfaces, vertical and inclined, can be determined.

Accuracy of wave-height measuring equipment has been determined. Preliminary tests are being conducted to determine the reduction in wave height due to viscous friction as a function of distance from the wave machine. 
(999) STABILITY OF RUBBLE-MOUND BREAKWATERS.

(b) Office of the Chief of Engineers, Department of the Army, Washington, D. C.

(d) Experimental; applied research.

(e) Rubble-mound structures are studied in a wave tank to determine size of cap rock and slope of mound necessary to withstand action of waves and to develop formulas, suppor by experimental data, from which the action of waves on rubble structures can be dete mined. Test data will be presented in dimensionless form, therefore no model scale, such, is being utilized. Tests are being conducted to determine the accuracy of wav $\epsilon$ height measuring equipment, and the over-all accuracy of the test results.

(1000) ROUGHNESS STANDARDS FOR HYDRAULIC MODEIS.

(b) Office of the Chief of Bngineers, Department of the Army, Washington, D. C.

(d) Experimental; applied research.

(e) A general study of roughness standards for models is being conducted to evaluate the resistance of definite types of roughness in terms of Manning's $n$ and other parame so that much of the trial-and-error process of adjusting the surface roughness of riv models can be eliminated. Tests were conducted in three rectangular flumes.

(g) Curves prepared from test data were used to determine the channel roughness for the tions of the Mississippi Basin Model now in operation.

(1001) SCALE EFFECTS ON SPILIWAY DISCHARGE COEFFICIENTS.

(b) Office of the Chief of Engineers, Department of the Army, Nashington, D. C.

(d) Experimental; applied research.

(e) Tests are conducted on ogee and sharp-crested weirs to permit comparison of spillway discharge coefficients obtained from models of different scales. Tests to determine effect of variation of viscosity from a high of 220 centipoises to about 3 centipoise are in progress.

(g) Tests to determine effect of surface tension on discharge coefficients of spillways I vealed no appreciable effect in small-scale spillway models. Analysis of viscosity has not progressed sufficiently to permit conclusions.

(1002) SCALE EFFECTS IN HARBOR MODEIS.

(b) Office of the Chief of Angineers, Department of the Army, Washington, D. C.

(d) Experimental; applied research.

(e) Tests will be conducted to determine effect of various model scales and distortion or wave characteristics in a harbor.

(1003) STUDY OF HARBQR DESIGN.

(b) Office of the Chief of Ingineers, Department of the Army, Whington, D. C.

(d) Experimental; applied research.

(e) Tests will be conducted on typical harbors to establish general criteria for designil harbors and harbor works to obtain optinum protection from wave action.

(f) Suspended.

(1004) INSTRUMENTATION.

(b) Office of the Chief of Ingineers, Department of the Army, Washington, D. C.

(d) Experimental; development.

(e) Various types of instruments for use in hydraulic models are being developed to make measurements as those of wave heights, dynamic fluid pressures, gate vibration and d pull, and low velocity flow. Apparztus is under development to analyze the frequenc: spectrum of recorded wave forms. Development of an inproved tidal reproducing appar: is in progress. 
MODEL STUDY OF PENSTOCK INTAKE GATES (FORIERLY MODEL STUDY OF SLUICE COASTER GATE).

Office of the Chief of Engineers, Department of the Army, Nashington, D. C.

Experimental; applied research.

A general study of relative merits of various penstock intake and sluice coaster gate lip shapes, seals and recesses is being conducted. The investigation includes determination of dowmpull effects of changes in gate-lip shape, length and shape of seals, size and shape of the recess in the face of the dam, and need for an air vent in the entrance. The 1:20 model of the sluice coaster gate is presently being tested in combination with a typical sluice which includes a sli.de gate, standard entrance curves conforming to the elliptical equation $\left(x^{2} / D^{2}\right)+\left(y^{2} /(D / 3)^{2}\right)=1$, and a removable constriction at downstream end of sluice.

Tests of the sluice coaster gate with various slide gate openings and sluice exit conditions revealed greatest dompull forves at coaster gate openings of 2 to 4 feet. The slide gate and air vent were then moved upstream 15 feet and tested to determine the effect, if any, of location on the over-3ll performance of the coaster gate. Moving the slide gate 15 feet closer to the intake was found to have little or no effect on the overall performance of the sluice gate.

MODEL STUDY OF PORT WASHINGTON HARBOR, NISCONSIV.

The District Lngineer, Milwaukee District, Corps of Engineers, Milwaukee, Wis. Experimental; for design.

A 1:100 fixed-bed model was used to determine the best plan for providing adequate protection from wave action. Tests included extension of the north breakwater, a companion south detached breakwater, rubble added to lakeside of present caisson breakwaters, and rubble wave absorbers installed at ends of inner harbor basins.

Completed.

A plan involving partial realignment of the north breakwater extension, elimination of the proposed detached breakwater section, and addition of a wave absorber to the harbor side of the north caisson breakwater will provide adequate protection against storms from all critical directions. However, a rubble lakeside slope will be required along the north caisson breakwater to eliminate effects of overtoppizg during storms from the northeast.

"Wave action and breakwater location, Port Washington Harbor, Wisconsin; model investigation." Waterways Experiment Station Technical Memorandum No. 2-334, 1951. (Available for sale and loan.)

MODEL STUDY OF BELTON DAM, LEON BIVER, TEXAS.

The District ingineer, Fort Worth District, Corps of Ingineers, Fort Worth, Texas. Experimental; for design.

Tests were conducted on a 1:100 comprehensive model to determine spill way discharge capacity; the best shape of the spillway excavation; proper alignment of approach walls; height of walls downstream from the control section; and to study orer-all flow in the exit area.

Testing completed; final report in preparation.

Tests indicated that the design flood could be passed over the original spillway by raising the reservoir pool 1 foot and excavating a part of the approach area on a onepercent slope. The right approach wall was realigned to a compound curve and the 9degree bend downstream from the axis of the dan eliminated. Flow conditions in the exit area were satisfactory.

MODEL STUDY OF GRAYS HARBQi, WASHINGTON.

The District Engineer, Seattle District, Corps of Engineers, Seattle, Washington. Experimental; for design. 
(e) The fixed-bed model, with scales of 1:800 horizontally and 1:80 vertically, reproduc the Pacific Ocean area adjacent to the harbor entrance and the tidal portion of the 1 bor and Chehalis River. This model was used to develop a comprehensive plan to prote the existing south jetty from the undermining effects of tidal currents, and to prote Point Chehalis from erosion by current and wave action. Upon completion of this part the investigation a portion of the model was converted to a moveable-bed type to det: mine scour and shoal tendencies of the selected plan. Plans for reduction of shoalir in the 30-foot-deep navigation channel are also being studied.

(g) A plan involving the lowering of the outer 6,000 feet of the south jetty to an eleva of 0.0 foot (MLLW) would reduce the maximum ebb velocity along the jetty by about 20 cent. The construction of groins at Point Chehalis will probably reduce erosion the Model tests indicate that one spoil area retains almost all spoil deposited but that proportion of the spoil placed in all other areas tested returns to the channel.

(1211) MODEL STUDIES OF HOOSIC RIVIR, ADAMS AND NORTH ADAMS, MASSACHUSETTS.

(b) The District Engineer, New York District, Corps of Engineers, New York, N. Y.

(d) Experimental; for design.

(e) Two models are being used to verify the hydraulic design for improvement of the chanr of the North and South Branches of Hoosic liver in North Adams, Mass., and of the maj channel in Adams, Mass., and to determine whether changes should be made for safety, increased efficiency, or economy. The flow in a major portion of these channels will below critical depth. A 1:30 model reproduces the lower sections of the North and Sc Branches and about 1300 feet of the main stream below the confluence of the North anc South Branches. A 1:20 model reproduces a section of the main channel beginning appr mately 8 miles above that reproduced in the 1:30 model. About 1200 feet of Tophet $B r$ which joins the Hoosic River, is also reproduced.

(f) Suspended.

(g) The stilling basin as designed for the North Adams section was found unsatisfactory a a basin was developed that produced the desired flow conditions. The design and loc: tion of the stilling basin in the main channel at Adams were verified. Flow conditic at the junction of Tophet Brook and the culvert flume feeding into the brook were gre improved and the turbulence existing in the Hoosic River below the mouth of Tophet Br was eliminated.

(1212) MODEL STUDY OF OUTLET WORKS, OAHE DAM, MISSOURI RIVRR, SOUTH DAKOTA.

(b) The District Engineer, Omaha District, Corps of Engineers, Omaha, Neb.

(d) Experimental; for design.

(e) A 1:60 model, reproducing the downstream portion of six 18-1/2-foot-diameter outlettunnels, the training piers, stilling basin, and 2300 feet of the discharge and pilot channels is being used to investigate the performance of the outlet works, effect rev sions demonstrated to be desirable, and to observe flow conditions in the discharge a pilot channels. The design of the stilling basin is presently being revised because construction problems.

(f) Suspended.

(g) Tests of the initial design indicated that several economies could be effected in con struction without impairing the hydraulic performance of the stilling basin. These economies consisted primarily of shortening the over-all length of the outlet works $b$ 90 feet; reducing the length of separation piers by 100 feet; raising the floor of th stilling basin 4 feet; and eliminating the slope downstream from the end sill. 
ANALYSIS OF HYDRAULIC EXPER IMENTAL DATA (MODEL AND PROTOTYPE) FORMERLY (221) ANALYSIS OF HYDRAULIC EXPER IMENTAL DATA (MODEL AND PROTOTYPE) AND DEVELOPMENT OF DESIGN CR ITER IA AND (1213) PROTOTYPE ANALYSIS (HYRAULIC).

Office of the Chief of Engineers, Department of the Army, Washington, D. C. Experimental and field investigation; for design.

A general study to develop, analyze, and disseminate to Corps of Engineers establishments design criteria for hydraulic structures to insure adequate hydraulic capacity, economy of construction and safe and satisfactory operation. Criteria are developed from model tests and prototype observations relating to the design of spillways, outlet works, and gates and valves. Program also includes hydraulic design criteria for navigation structures, flood-control channels and natural waterways.

VALDIVIA RIVER MODEL STUDY, CORRAL BAY, CHILE.

Government of Chile, South America.

Experimental; for design.

Model study is to determine whether training works or other remedial measures will make possible the maintenance of a channel at least 6 meters deep over the entrance bar from the Port of Corral to the Valdivia River mouth, and to determine the effect such structures might have on present depths and widths of Corral Harbor. The moveable-bed model, with scale ratios of 1:400 horizontally and 1:80 vertically, reproduces Corral Bay upstream from Point San Carlos and the lower 3 miles of both the Valdivia and Tornagalenes Rivers.

9) MODEL STUDY OF FIOOD-CONIROL PROJECT, ALLENTOWN, PENNSYLVANIA.

b) The District Engineer, Philadelphia District, Corps of Engineers, Philadelphia, $\mathrm{Pa}$.

d) Experimental; for design.

e) The proposed local improvement plan at Allentown is being studied to discover and correct any undesirable features of the plan. The fixed-bed model, scales of 1:150 horizontally and 1:50 vertically, reproduces 3 miles of Lehigh River and 1 mile each of Little Lehigh Creek and Jordan Creek.

0) NIAGARA RIVER AND FALIS MODEL STUDY.

b) The District Engineer, Buffalo District, Corps of Engineers, Buffalo, N. Y.

d) Experimental; for design.

e) Use of the Niagara River for power development and other purposes is controlled by treaty between the United States and Canada which includes a specific allotment of the waters for preservation of the scenic beauty of the Falls. Proposed redevelopment of the Niagara River for power includes large increases in diversion and redistribution of flow in the cascades to preserve the beauty of the Falls. A fixed-bed model is being used to determine the effects of the proposed redevelopment and remedial works required for efficient power diversion and maintenance of adequate river flows. All features of Niagara River from Lake Erie to below the Falls are reproduced to scales of 1:360 horizonally and 1:60 vertically.

(g) Tests indicate that the river flow at Buffalo will increase as much as 5,000 cfs as the result of increased river slopes effected by additional power diversions. Time scale tests indicate that a control structure will be required at the head of the cascades to effect a quick change in the required minimum daytime Falls flow of 100,000 cfs to the required minimum nighttime Falls flow of 50,000 cfs.

71) HYDRAULIC MODEL STUDY OF SAVAGE RIVER DAM SPILIWAY.

(b) The District Engineer, Washington District, Corps of Engineers, Washington, D. C.

(d) Experimental; for design.

(e) Model tests of this side-channel spillway are being conducted on a 1:36 model to determine the discharge rating curve and other hydraulic characteristics of the spillway at heads greater than that for which the spillway was originally designed because the spillway design flood for this dam has been increased. 
(1472) MODEL STUDY OF WAVE ACTION, INDIANA HARBOR, INDIANA.

(b) Youngstown Sheet and Tube Company, and Inland Steel Company, Indiana Harbor Works, F Chicago, Ind.

(d) Experimental; for design.

(e) A 1:150-scale fixed-bed model of Indiana Harbor and sufficient area of Lake Michigan permit reproduction of waves from north-northwest to southeast is being used. Effec of proposed harbor structures on wave action conditions in the entrance channel and the harbor are being studied.

(1473) MODEL STUDIES OF FOISOM DAM, AMERICAN RIVRR, CALIFORNIA.

(b) The District Engineer, Sacramento District, Corps of Engineers, Sacramento, Calif.

(d) Experimental; for design.

(e) To determine the type of stilling basin required for the spillway. In order to expe the tests, two almost identical 1:80 models of the dam and spillway were constructed one to study the action of the spillway with a horizontal stilling basin below five the gates and a high-level flip-bucket below the three gates adjacent to the left ab ment which are to be used less frequently and the other to study the action of the $s$ way with a flip-bucket below all eight gates.

(f) Testing completed; final report in preparation.

(g) The combination of a horizontal stilling basin below five gates and a flip-bucket be three gates was found to be the most desirable plan in order to furnish proper prote tion to the powerhouse. Detailed tests were concerned with a determination of the I and elevation of horizontal apron, height of end sill, slope of ramp leading into th basin, and the treatment of the left abutment where the water from the flip-bucket $w$ impinge upon the natural rock.

\section{(1474) OPERATING FORCES OF MITER-TYPE IOCK GATES,}

(b) The Chief of Engineers, Department of the :rmy, Washington, D. C.

(d) Experimental; applied research.

(e) A general study to collect basic data on operating forces of miter-type lock gates as to determine the effect of various elements upon these forces is being conducted in 1:20 model. A lock chamber 110 feet wide with provisions for varying the length up 600 feet on each side of the gate is reproduced. Forces required for operation of $m$ gates will be measured for variations of the following elements; gate leaves, speeds accelerations of operation, submerged depths, recess shapes, bottom clearances, chaml lengths, and nonsynchronous operation of gate leaves.

(g) Tests indicate that the peak torque occurs as the gates enter or leave the mitered $p$ tion. Nonsynchronous operation of the gates resulted in a slight decrease in torque the leading leaf and a lesser effect on the lagging leaf, as compared with synchronor operation. An increase in the speed of operation or depth of submergence increases peak torque. Bottom clearances had little effect on torque values.

\section{(1475) SIPHON ACTION AT PUMPING PIANTS.}

(b) Office of the Chief of Engineers, Department of the Army, hashington, D. C.

(d) Experimental; applied research.

(e) A general study is being made by model tests of the operating characteristics of sipl operated in connection with purnping plants. The effect of various head-tailwater re: tionships on priming characteristics, the air demand required to break the siphonic action, and the effect of construction or reduction in area of the discharge leg of siphon are to be determined.

(1476) MODEL STUDY OF EAST BEA VER BAY HARBOR, IAKE SUPERIOR, MINNESOTA. (SUPPIEMENTARY INV! GATION.)

(b) Oglebay Norton and Company, Hanna Building, Cleveland, Ohio.

(d) Experimental; for design. 
A 1:150-scale fixed-bed model of the East Beaver Bay harbor site and sufficient area of Lake Superior for reproduction of waves from northeast to southwest was used. The degree of protection provided in the harbor by constructing only two legs of a proposed breakwater system was determined. Also, the adequacy of the complete breakwater system contemplated for construction at a later date was investigated.

Completed.

) Wave action and breakwater location, East Beaver Bay Harbor, Lake Superior, Minnesota; supplementary model investigation." Waterways Experiment Station Technical Memorandum No. 2-295-1, Oct. 1951. (Available on loan.)

DEPARTMENT OF COMMERCE, BUREAU OF PUBLIC ROADS.

TESTS OF SCOUR AROUND BRIDGE PIERS.

Cooperative with Rocky Mountain Hydraulic Iaboratory. See page 68.

SCOUR AT BRIDGE PIERS ANU ABUTMENTS.

Cooperative with Iowa Institute of Hydraulic Research. See page 38.

STUDY OF HIGHWAY INLET BOKES AND DISCHARGE PIPE SHAPES.

Cooperative with University of Illinois. See page 34.

j) SCALE MODEL STUDIIS OF INLET BOXES.

Cooperative with University of Illino . See page 34.

5) FULL SCALE GUTTLR TESTS.

Cooperative with University of Illinois. See page 34.

1) MOVEMENT OF SEDIMENT IN HIGHNAY DRA INAGE SYSTEMS.

Cooperative with University of Illinois. See page 39.

DEPAR TMENT OF COMMERCE, NATIONAL BUREAU OF STANDARDS, National Hydraulic Laboratory.

Inquiries concerning Projects Nos. 159, 160, 166, 432, 433, 1005, 1214, 1216, 1217, and 1477 to 1482, incl., should be addressed to the Chief, National Hydraulic Laboratory, National Bureau of Standards, Washington 25, D. C.

9) MODEL IAWS FOR DENSITY CURIRENTS.

b) Waterways Experiment Station, Corps of Engineers, Department of the Army.

d) Theoretical and experimental; basic and applied research.

e) To determine model laws for models involving the motion of stratified liquids. The two major problems are (1) the motion of a heavy liquid initially confined in a "lock" when released into a long channel containing a stationary lighter liquid, and (2) the motion of a heavy liquid from a "sea" into a long channel with either still or flowing lighter liquid. 
(160) EFFECT OF STORM WINDS ON IAKE LEVEIS.

(b) Laboratory project.

(d) Theoretical and experimental; basic research.

(e) To determine frictional forces of wind on lake surfaces and the resulting set-up.

(h) "Hydrolynamical evaluation of storms on Lake Erie." Conference on Coastal Engineeris Houston, Texas, Nov. 1951.

(166́) NET VENTING, STACK VENTING, AND SEIF-SIPHONAGE OF PLUMBING FIXTURES.

(b) Housing and Home Finance Agency.

(h) National Bureau of Standards Building Materials and Structures Report BMSI26, "Selfsiphonage of fixture traps." John I. French and Herbert N. Eaton, 1951.

(432) FROST CIOSURE OF THE ROOF VENTS OF PLURBING DRA INAGE SYSTEMS.

(b) Laboratory project.

(d) Experimental and theoretical; applied research.

(e) Data have been obtained from the field and from laboratory tests, and theoretical str have been made to provide information for code-writing authorities.

(h) Paper in preparation.

(433) CAPACITIES OF PLURABING STACKS.

(b) Housing and Home Finance Agency.

(d) Experimental and theoretical; applied research.

(e) To determine capacities of plumbing stacks in buildings.

(h) National Bureau of Standards Building Materials and Structures Report, "Capacities of plumbing stacks in buildings." Robert S. Wyly and Herbert N. Eaton. In press.

(685) QR IFICE METERS.

(b) Cooperative with American Gas Association, American Society of Mechanical Engineers, Bureau of Ships, Department of the Navy.

(c) Mr. Howard Bean, National Bureau of Standards, Washington 25, D. C.

(d) Experimental; applied research.

(e) To obtain information on installation requirements of orifices, flow nozzles, and ven tubes with special reference to (1) using shorter meter runs than now recommended, (2 the effects of globe and plug valves preceding an orifice, and (3) possible developme of a field method of evaluating pipe roughness.

(h) Reports available from Naval Boiler and Turbine Laboratory, Philadelphia Naval Base, Philadelphia 12, Pa.

(1005) STANDARDS FOR HOUSE SEWER PIPE.

(b) Housing and Home Finance Agency.

(d) Experimental and theoretical; applied research.

(f) Completed.

(h) Final report, "Performance requirements for domestic house sewer connections and sept tank-to-field connections." Jan. 1952.

(12य) PHYSICS OF FLOW IN PLUMBING SYSTEMS.

(b) Laboratory project.

(d) Theoretical and experimental; applied research.

(e) Preparation of papers giving the results of plumbing research. Papers on the capacit of plumbing stacks and drains are in progress. 
RESEARCH ON FIUIBING SYSTEMS.

The McPherson Foundation for Sanitary Research.

Mr. Ronald G. Mayer, Research Associate, National Bureau of Standards, Washington 25, D. C.

Experimental; applied research.

Study of the proper design of plumbing drainage systems in trailer coaches.

OPEN CHANNELS WITH UNIFORMLY DISTRIBUTED INFLOW.

Laboratory project.

Experimental; basic and applied research.

To determine surface curves, velocity distributions, and friction laws for channels in which the inflow is uniformly distributed along the length of the channel.

"Determination of critical depth in spatially variable flow." Garbis H. Keulegan, Ohio State University, Proc. Hydraulic Conference, March 1952.

TURBULENT EXPANSION OF JETS IN WATER.

Office of Naval Research, Department of the Navy.

Experimental and theoretical; basic research.

To determine experimentally the nature of turbulent expansion of jets in water with relation to Reynolds number, using jets of hot water, salt water, etc.

WIND WAVES.

Office of Naval Research, Department of the Navy.

Experimental and theoretical; basic research.

Includes mathematical and experimental studies of (1) wind tides (set-up), (2) growth of wind waves, and (3) surface traction of wind on wavy surfaces.

ENERGY DISSIPATION IN STANDING WAVIS.

Office of Naval Research, Department of the Navy.

Experimental and theoretical; basic research.

To determine significance of viscous boundary layer effects in wave phenomena.

POSITIVE WAVES IN IRY CHANNELS.

Office of Naval Research, Department of the Navy.

Experimental and theoretical; basic research.

To determine mathematically velocity and form of waves taking friction into account. To analyze the tip of the wave mathematically, and to determine form of wave experimentally as function of time and roughness. Attempt to determine particle trajectories at the tip of the wave experimentally.

CALCUIATION OF NON-LINEAR BREAKING OF WAVES.

Office of Naval Research, Department of the Navy.

Mathematical; basic research.

To obtain significant criteria for breaking of waves by numerical solution with computing machine using the exact non-linear boundary condition satisfied at the displaced surface.

INITIAL VELOCITY DISTRIBUTIONS IN SALT WATER WEDGE.

Laboratory project.

Experimental; basic research.

To determine velocities and particle trajectories during initial motion when a gate separating tivo bodies of liquids of different densities is suddenly opened. 
U. S. DEPARTMENT OF COMRERCE, WEA THER BUREAU.

Inquiries concerning Projects Nos. 1010 to 1015, incl., should be addressed to Mr. William I. Hiatt, Hydrologic Services Division, U. S. Weather Bureau, Washingt D. C.

(1010) ELECTRONIC FIOOD ROUTING ANALOGUE.

(b) Laboratory project.

(d) Experimental; applied research.

(e) A basic circuit for an electronic analogue computer to solve flood wave problems $h$ been developed, and usefulness of the analogue is being studied. Analogues have $b$ installed at the following River Forecast Centers; Cincinnati, Ohio; Knoxville, Te St. Louis, Mo.; Kansas City, Mo.; Tulsa, Okla.; and Portland, Ore.; for use in the solution of local streamflow problems.

(g) Basic analogue circuit generally satisfactory. Experiments continuing to determin possibilities of other circuits.

(h) "Aplication of electronic streamflow routing analogue." Max A. Kohler, Presented 1950 meeting, Jackson, Miss., American Society of Civil Engineers.

(1011) SHORT RANGE SNOW-IELT FORECASTING.

(b) Laboratory project.

(d) Experimental; applied research.

(e) To develop relations between streamflow resulting from melting snow and appropriat meteorological parameters. A statistical approach is being attempted.

(g) A reasonably adequate procedure has been established and is being refined and test,

(1012) AUTOIATIC RADIO REPORTING RAIN GAGE.

(b) Laboratory project.

(d) Field investigation.

(e) A simple telemetering device has been constructed for use with a standard recording gage. Iimited field tests indicate satisfactory performance. Other telemetering for this gage are being considered.

(1013) PRESSURE ACTUATED RIVLR GAGE.

(b) Laboratory project.

(d) Field investigation.

(e) A remote indicating and recording gage has been satisfactorily tested for accuracy laboratory and has been installed under field conditions for service tests.

(1014) UTILIZATION OF SOIL MOISTURE DATA IN FORECASTING STREAMFIOW.

(b) Laboratory project.

(d) Field investigation.

(e) Standard electrical resistance soil moisture and temperature equipment is being ins in selected areas. After sufficient data is obtained, statistical tests will be ut to determine whether such data can be used to improve forecasts of rumoff from rain

(1015) MEASUREMENT OF EVAPQRATION.

(b) Laboratory project.

(d) Theoretical and field investigation; basic and applied research.

(e) Studies are directed toward the derivations of reliable procedures for estimating $\epsilon$ poration from reservoirs (existing and proposed) and land surfaces, utilizing readi available meteorological data and pan evaporation observations.

(g) Reliable relations have been developed (graphical correlation) for estimating pan $\epsilon$ poration from ain temperature, dewpoint, wind, and radiation. A similar relation h been derived for evaporation from Lake Hefner, based on data collected by the Burea Reclamation, Navy, Geological Survey, and Weather Bureau in a cooperative project a Oklahoma City, Oklahoma. Further studies are underway. 
DEPARTMENT OF THE INTER IOR, GEOLOGICA L SURVEY.

UNSATURATED FION OF WATER IN REIATION TO GROUND-WATRR RECHARGE.

Laboratory project.

Mr. W. O. Smith, U. S. Geological Survey, Washington 25, D. C.

Experimental and theoretical; basic research.

Mechanics of nonsaturated flow of water in porous bodies.

Certain definite relations between discharge and time have been found for uniform sand.

The results appear to be independent of the grain radius.

A STUDY OF METHODS USED IN THE MEASUREMTNT AND ANALYSIS OF SEDIMENT IOADS IN STREAMS.

Cooperative. See Project 194, page 115.

STAGE FALI-DISCHARGE REIATIONS FOR STEADY FIOW IN PRISMATIC CHANNELS.

Laboratory project.

Mr. W. D. Mitchell, U. S. Geological Survey, Champaign, Ill.

Experimental; applied research.

An analytic study of methods of determining discharge under variable slope and steady flow, based on laboratory observations reported in Univ. Illinois, Eng. Exp. Station, Bulletin 381.

EFFECT OF REFORESTATION ON STREAM FLOW.

Laboratory project.

Mr. A. W. Harrington, U. S. Geological Survey, Albany, N. Y.

Field investigation; basic research.

To study effect on stream flow of growing trees on abandoned farm land. Observations of stream flow, precipitation, ground-water levels, and evaporation at three small reforested drainage basins and adjacent controls were begun in 1935 .

SMALL RESERVOIRS IN ARID REGIONS.

Laboratory project.

Mr. H. V. Peterson, U. S. Geological Survey, Salt Lake City, Utah.

Field investigation; applied research.

To determine runoff, evaporation, seepage, and sedimentation in arid regions. Readings are being obtained on staff gages installed on a number of representative stock-watering reservoirs in western states.

Progress reports on file.

THERMO-TRANSFER AND ELECTRO-TRANSFER PHENOMENA IN SOIIS AND SEDIMENTS AND THEIR REIATION TO GROUND-WA TER RECHARGE.

Laboratory project.

Mr. W. O. Smith, U. S. Geological Survey, Washington 25, D. C. Experimental and theoretical; basic research.

Relation of the phenomena to flow of liquids in porous bodies.

ELECTROLYTIC POTENTIAL MODEIS FOR SOLUTION OF PROBLEMS IN CROUND-WATER HYDRAULICS.

Laboratory project.

Mr. W. O. Smith, U. S. Geological Survey, Washington 25, D. C.

Experimental and theoretical; applied research.

Development of electrolytic potential techniques for model studies. 
(690) DISCHARGE THIOUGH MULTIPIE OPENINGS.

(b) Laboratory project.

(c) Mr. Tate Dalrymple, U. S. Geological Survey, Washington 25, D. C.

(d) Field investigation; applied research.

(e) Crest-stage gages are installed on upstream and downstream sides of all openings of selected bridge and valley crossings, so that study can be made of the drop through opening and of the transverse water-surface profiles. Current-meter measurements $m$ during the floods will be used to study relationships of discharge through each ope to the total discharge, the drop, and the conveyance.

(691) COMPUTING PEAK DISCHARGES BY INDIRECT METHODS.

(b) Laboratory project.

(c) Mr. Tate DaIrymple, U. S. Geological Survey, Washington 25, D. C.

(d) Field investigation; applied research.

(e) Establishment of maximum stage gages on slope-reaches or suitable contracted openin computing flood discharges and comparing with measured discharge; to test adequacy slope-area method of computing flood discharge.

(1016) INTERPRETATION OF ELECTRIC LOGS.

(b) Cooperative with State of Louisiana.

(c) Mr. Paul H. Jones, U. S. Geological Survey, Baton Rouge, La.

(d) Experimental and theoretical; basic research.

(e) Tests are being made of various combinations of rocks and water, and physical and c ical properties are being correlated similar to the results of electric logs. Theo cal studies are being made to correlate the various factors. It is hoped that defi relationships can be established between results of electric logs, the permeability the rocks, and the quality of the water.

(h) Report in preparation.

(12.29) ELECTR ICAL LOGGING INSTYUMENTS FOR GROUND-WATER WELIS.

(b) Cooperative with State of Tennessee and State of Maryland.

(c) Mr.R.R. Bennett, U.S. Geological Survey, Memphis, Tenn.

(d) Development.

(e) Development, test, and design of instruments for measuring and recording self poten resistivity, and temperature in ground-water wells.

(1220) REIATION OF GROUND WATER TO STREAM FLOW.

(b) Laboratory project.

(c) Mr.S. L. Schoff, U. S. Geological Survey, Washington 25, D. C.

(d) Field investigation.

(e) Network of 23 observation wells in basin of Pond Creek, Okla., begun in March 1948. Water level data are to be correlated with low-water stream flow.

(1221) STEADY STATE ELECTRIC FLOW NET MODELS.

(b) Cooperative with State of Maryland.

(c) Mr. R. R. Bennett, U. S. Geological Survey, Washington 25, D. C.

(d) Experimental.

(e) Preparation of electrical flow net models using coloidal carbon. Boundary conditio simulate those commonly found in nature. Object is to catalogue various types of $n$ for future reference.

(1222) INFILTRATION AND EVAPO-TRANSPIRATION STUDY.

(b) Cooperative with State of Maryland.

(c) Mr. W. C. Rasmussen, U. S. Geological Survey, Washington 25, D. C. 
Field investization.

Weekly measurement of wells, rain gages, soil moisture, runoff and pond storage in two drainage basins near Salisbury, Md., to measure all factors in hydrologic cycle to determine infiltration, evapo-transpiration and specific yield.

EVALUATION OF HYAROLOGIC CICLE.

Cooperative with State of Virginia.

Mr. D. S. Wallace, U. S. Ceological Survey, Charlottesville, Va. Field investigation.

Establishment of gaging station and network of observation wells on headwaters of Hudson Creek, Iouisa Co., Va., for correlation of water levels and stream flow.

INDUCED INFILTAATION OF RIVER NATER.

Laboratory project.

Mr. M. I. Rorabaugh, U. S. Geological Survey, Louisville, Ky.

Applied research.

Analysis of records of Renney collector to determine effects of stage and temperature of river on quantity and temperature of yield.

STORM IATER INFILTZATION IN GROUND-WTARR RECHARGE BASINS.

Cooperative with Nassau County, N. Y.

Wr. A. W. Harrington, U. S. Geological Survey, Mineola, I. I.

Field investigation.

Observations are made of precipitation, evaporation, ground-water levels and storm water inflow into artificial recharge basins, to determine rate of infiltration and amount of storm water available for ground-wer recharge when collected in recharge basins, and to evaluate effectiveness of these basins.

EVAPQRATION FROM IAKES.

Cooperative with Bureau of Reclamation, Navy Electronic Iaboratory, Weather Bureau. Mr. K. W. Davenport, U. S. Geological Survey, Washington 25, D. C.

Field investigation.

Evaporation by mass transfer and energy budget principles to be tested at Lake Hefner, Okla., in relation to evaporation computed from water budget, to develop techniques for determining evaporation from reservoir using meteorologic and limologic data.

STOCK-TATER RESERVOIR STUDIES.

Cooperative with Bureau of Reclamation.

Mr.R. C. Culler, U. S. Geological Survey, Salt Lake City, Utah.

Field investigation.

Development of techniques for determination of effects of stock-water reservoirs on water supply. Detailed surveys made of number, capacity and performance of reservoirs in the Cheyenne River Basin in Wyoming, will be analyzed to determine evaporation, transpiration, and seepage losses and their effect on flow of Cheyenne River.

GIACIR RUNOFF.

Laboratory project.

Ir. C. S. Heidel, U. S. Geological Survey, Helena, Mont.

Field investigation.

Study of recession and accretion of Grinnel Glacier, Mont. Glacier mapped annually for some years, storage rain gage and stream gaging station installed in 1949. 
(1230) EFFECT OF IOGGING ON STR FAM FLOW.

(b) Cities of Tacoma and Seattle.

(c) ir. F. M. Veatch, U. S. Geological Survey, Tacoma, Wash.

(d) Field investigation.

(e) Operation of seven gaging stations on small streams in areas where logging operatiol are scheduled in several years. There are control basins where no timber will be $c$

(1231) CATHODIC PROTECTION OF BUR IED PIPE AGA INST CORROSION.

(b) Cooperative with State of Pennsylvania and State of Louisiana.

(c) Mr. Max Noecker, U. S. Geological Survey, Pittsburgh, Pa., and Mr. R. P. Smith, U. Geological Survey, Jonesboro, La.

(d) Field investigation.

(e) Magnesium anodes are to be installed at several gaging stations where corrosion of wells or intake pipes has required frequent replacement. Anodes and pipes are to b inspected annually to determine rate of loss of magnesium and to observe extent of corrosion.

(1232) VELOCITY VANE.

(b) University of Florida Engineering Experiment Station.

(c) M. D. Bourke, University of Florida, Gainesville, Fla.

(d) Laboratory and field investigation.

(e) Development of a vane to measure direction and rate of water movement in drainage $c_{i}$ in southern Florida. Field model now under test.

(1233) MAGNITUDE AND FREQUENCY OF FLOODS.

(b) Cooperative with several state agencies.

(c) Mr. Tate Dalrymple, U. S. Geological Survey, hashington 25, D. C.

(d) Applied research.

(e) Analyses of flood records to determine magnitude and frequency of flood discharge a. gaging stations, and at supplementary network of crest-stage gages on small streams determine techniques for establishing flood discharges on ungaged streams.

(1235) SEDIMENT CARRIED AS BED IOAD.

(b) Laboratory project.

(c) Mr. P. C. Benedict, U. S. Geological Survey, Lincoln, Neb.

(d) Field investigations; theoretical studies.

(e) Determination of the amount of sediment moving as bed load at three stations, evalu: of the several-bed-load formulas, and basic studies of bed-load movement.

(183) FIOW THROUGH MULTIPLE BRIDGE OPENINGS.

(b) Laboratory project.

(c) Prof. C. E. Kindsvater, U. S. Geological Survey, Atlanta, Ga.

(d) Experimental and theoretical; applied research.

(e) To obtain data on flow through multiple bridge openings in a model study; velocity tribution and division of flow.

(山84) MEASUREMENT OF DEGRADATION AND AGGRADATION IN SAND-BED STREAMS DUR ING FIASH FIOODS.

(b) Laboratory project.

(c) Ir. P. C. Benedict, U. S. Geological Survey, Lincoln, Neb.

(d) Experimental and theoretical; applied research.

(e) Development of practical method of measuring degradation in intermittent sand-bed s. during flash floods. 
BROSION AND DEPOSITION OF SEDIMENT.

Laboratory project.

Mr. P. C. Benedict, Lincoln, Neb.

Field surveys; applied research.

Studies of the effects of climate, soil types, geology, topography, and land use in rates of erosion.

BACKNATER FROM CHANNEL OBSTRUCTIONS.

Laboratory project.

Prof. C. E. Kindsvater, U. S. Geological Survey, Atlanta, Ga.

Experimental; applied research.

Model study on backwater from large constrictions of stream channel, to include a wide range of prototype conditions.

FIOW THROUGH CONTZACTED OPENINGS.

Laboratory project.

Prof. C. E. Kindsvater, U. S. Geological Survey, Atlantz, Ga.

Experimental; applied research.

To obtain data on model and prototype on film through contracted openings.

ROUGHNESS COEFFICIENTS OF SAND BED STREAMS.

Laboratory project.

Mr. C. E. EIlsworth, U. S. Geological Survey, Austin, Texas, and Mr. D. D. Iewis, U. S. Geological Survey, Lincoln, Neb.

Field survey; applied research.

To determine channel coefficients for use in computing peak discharges by indirect

methods in sand bed streams, extent of scour and fill.

MECHANICS OF SALT-WATER INTRUSION:

Laboratory project.

Mr. A. A. Garrett, U. S. Geological Survey, Sacramento, Calif.

Field survey; applied research.

To explore mechanics of salt-water intrusion. The shape of the contact between fresh and salt-ater in the aquifer, the change in shape with change in head of fresh water.

CHEMICAL SEALING AGENTS FOR CONTROI OF CROUND WATER IN GIACIATED MATERIALS.

Cooperative with State of Michigan.

Mr. W. T. Stuart, U. S. Geological Survey, Ishpeming, Mich.

Field survey; applied research.

To test suitability of compound "Kro-plex" for controlling flows of ground ter in the vicinity of operating mines. Small scale experiments indicate impregnations of sand and gravels practicable when more economical methods of injecting into the ground have been found. 
U. S. DEPARTMENT OF THE INTERIOR, BUREAU OF RECLAMATION.

Inquiries concerning Projects Nos. 460, 698, 704, 705, 1023, 1028, 1239, 1243, to 16 incl., 1251 to 1259 incl., 1261 to 1266 incl., and 1491 to 1502 incl., should be addressed to the Chief Ingineer, Bureau of Reclamation, Denver Federal Center, Denve: Colo.

(460) HEART BUTTE DAM SPILLWAY AND OUTLET WORKS.

(b) Laboratory project; field tests on prototype.

(d) Experimental; for design and model-prototype conformance tests.

(e) A 1:21.5 model was used to study the critical features of the uncontrolled morning- $\varepsilon$ spillway combined with outlet gates and tunnel, particularly the prevention of seric vortices and cavitation erosion in the spillway throat and transition.

(f) Model study completed. Field tests continuing.

(g) Field tests show good agreement with model.

(h) ieports being prepared.

(698) SPR ING RREEK DAM OUTLET WORKS.

(f) Completed.

(h) Report No. Hyd-320, "Hydraulic model studies of the outlet tunnel--Spring Creek DamPaonia Project." D. Colgate. (Report available on loan.)

(704) CEDAR BLUFF DAM SPILIWAY.

(h) Report being prepared.

(705) HUNGZY HORSE DAM SPILLNAY.

(b) Laboratory project.

(d) Experimental; for design.

(e) A 1:36 model of a morning-glory type spillway is being tested to develop satisfactor hydraulic characteristics of critical features such as the crest, elbows, tunnels, : stilling basins.

(g) The principal problems have been in connection with the determination of a satisfact crest shape and aeration to prevent cavitation erosion. In connection with design the crest, a basic hydraulic investigation project is set up utilizing a circular, sharp-crested weir to determine the coordinates of the nappe of a morning-glory typk spillway discharge from basic data.

(h) Reports being prepared.

(1023) FALCON DAM SPILLIAY.

(b) International Boundary and Nater Cormission.

(d) Experimental; for design.

(e) A 1:130 model of the Falcon Dam on the iiio Grande was tested to determine the hydra performance of the spillay and the spillway channel leading to the river, together the effect of small and large floods on the river channel below the dam, and the ef of floods on the powerhouses, both on the United States side and the Mexican side.

(f) Completed and report issued. Additional tests were then made because of necessary changes.

(g) Spur-type walls were added below the stilling basin to prevent erosion; the shape 0 pier separating the spillway and intake was changed to reduce draw-down, and the tr: walls were raised to prevent overtopping.

(1028) HYDRAULIC PERFORMANCE TESTS ON IRR IGA TION WATER METERING DEVICES.

(b) Laboratory project.

(d) Experimental; for design and master's thesis. 
Studies of metering devices proposed for use in canal turnouts and in irrigation pipe line distribution systems to determine their hydraulic characteristics for design purposes. Includes four sizes of Armco metergates, two sizes of Denver screw lift gates, four sizes of Fresno venturi meters, and three sizes of a modified venturi-type meter used by the Consolidated Irrigation District of California. Principal points of study are calibration, the coefficients of discharge, pressure losses, adaptability of the devices for a wide range of application in open channel as well as closed conduit distribution systems.

Report No. Hyd-314, "Flow characteristics and limitations of Armco metergates." J.B. Summers. (Report available on loan.)

CIR CUIAR WEIR STUDIES.

Laboratory project.

Experimental; basic research, for design.

A circular, sharp-crested weir is used to determine the under and upper nappe of the jet with varying heads, different velocities of approach, and vary.ing degrees of vacuum under the nappe.

Shapes of upper and under nappe of jet with vacuums from 0 to 40 percent of head and negligible velocity of approach have been determined.

Report being prepared.

\section{RECTANGULAR SEMIBELLMOUTH ENTRANCE STUDIES.}

Laboratory project.

Experimental; for development.

Piezometric pressures on the roof of a rectangular semibellmouth entrance were studied to determine the shape which will best prevent negative pressures.

Completed.

Satisfactory shape was developed.

Report being prepared.

WILIOW CREEK DAM SPILIWAY AND OUTLET WORKS.

Laboratory project.

Experimental; for design.

A 1:16 model of the combined spillway and outlet works was used to determine flow patterns in the conduit, erosion in the riprapped stilling basin and to develop a canal turnout, located in the ski-jump bucket, that will provide a required minimum discharge for all flows through the main conduit.

Completed.

A high-velocity turnout was developed within the ski-jump bucket and satisfactory flow conditions were obtained throughout the structure. Need for modification of control gates was demonstrated.

Report being prepared.

DISCHARGE MEASURING SYSTEM FOR ALVA B. ADAMS TUNNEL.

Laboratory project.

Experimental; for operation and field tests on completed structure.

A $1: 10$ scale hydraulic model of the tunnel near the entrance portal was built for the purpose of developing a satisfactory discharge measuring system.

Field test will continue. Model studies completed. A curved weir was developed and calibrated. It provided an accurate means of measuring the discharge and had a low energy loss at the maximum discharge. Flow conditions immediately downstream of the gates were greatly improved. Field tests showed measuring device to be accurate and satisfactory.

Report being prepared. 


\section{(1246) CACHUMA DAM SPILLNAY.}

(b) Iaboratory project.

(d) Experimentzl; for design.

(e) A 1:60 scale hydraulic model of the spillway was built to study the performance of proposed design.

(f) Completed.

(g) The right approach area was modified to improve the flow distribution. The chute * were moved and a crown incorporated in a section of the chute floor, resulting in a better flow distribution in the stilling basin and a decrease in the amount of conc required for the chute.

(h) Report being prepared.

(1247) RUBBER GATE SEAL DEVEIOPIENT FOR HIGH HEAD STRUCTURAL STEEL GATES.

(b) Laboratory project.

(d) Experinental; for design and master's thesis.

(e) To develop an inproved rubber gate seal for high head gates to replace the unsatisf "music note" shape seal. This was accomplished using a rig capable of testing a li length of full-size seals at heads to 200 feet.

(f) Completed.

(g) A double-stem type of rubber seal is superior to the music note seal.

(h) Report No. Hyd-3ll, "Hydraulic laboratory tests of seals for high-head coaster and wheel structural steel gates." W. C. Case. (Report available on loan.)

(1248) HIGH VELOCITY TURNOUTS.

(b) Laboratory project.

(d) Experimental; for design.

(e) To verify, by laboratory tests, the formulae used in a general design procedure for vertical stilling-wells, both square and circular in section.

(1251) PRESSURE REGULATOR--GRAND COULEE DAM POWER PIANT TRANSFORMER COOLING WATER.

(f) Completed.

(h) Report No. Hyd-308, "Hydraulic studies of a pressure reducing system for the transf cooling wer--Grand Coulee Power Plant--Columbia Basin Project, Vashington." L. V Wilson. (Report available on loan.)

(1252) CAVITATION-IREE OPERATION OF REGULATING GATES.

(b) Laboratory project.

(d) Experimental; for design.

(e) A general study to develop design criteria for cavitation-free operation of regulat gates in closed conduit irrigation distribution systems.

(g) A method of computing the required back pressure to prevent cavitation obtainec use of parameters which were affected by a flow pattern change due to cavitation an which indicated system efficiency.

(h) Report being prepared.

(1253) THENTON DAM SPILIWAY.

(b) Laboratory project.

(d) ixperimental; for design.

( 1 l:54 scale model was used in investigating the over-all hydraulic characteristics the spillway. These characteristics included entrance to overflow section, spillwe chuta, stilling basin, and erosion downstream of the basin.

( Principal development to present is an end pier extension upstream to minimize the blesome flow contraction which causes an unequal flow distribution per foot width $t$ the overflow section. This extension reaches farther upstream at the top than at $t$ bottom, the leading edge being undercut toward the spillway crest.

(i) Report being prepared. 
VIBRATION--KEECHELUS DAM OUTLET WORKS TOWER .

Laboratory project.

Experimental; field operation.

A $1: 15$ scale model was used to investigate a serious vibration of the field structure reported by operating personnel. The results are to be used in rehabilitating the existing tower.

Three possible causes of this vibration have been determined; vibration of the cylinder gates controlling flow from the tower, negative pressures occurring at entrance to the discharge conduit, and extreme turbulence within the outlet works tower. The latter is believed to be the principal cause of the reported vibration and the investigation is proceeding toward reducing this turbulence.

Report being prepared.

\section{PALISADES DAM RECTANGULAR REGUIATING GATIS.}

Laboratory project.

Experimental; for design.

A I:19 model was used to develop a rectangular, downstream seal, regulating slide gate suitable for use at heads up to 240 feet and capable of discharging a smooth, even stream into closed or open conduit or on a spillway. Particular attention was directed to the gate slots using a $1: 2$ scale sectional model. The tests were extended to study the effect of an emergency gate of identical design placed imnediately upstream from the regulating gate.

A practical gate was developed which discharged the desired smooth stream at a discharge coefficient of 0.95 when full open. A slot design was obtained which, when the gate discharges into the atmosphere at a 240 head, produces pressures no lower than minus 1 foot of water. The emergency gate operated satisfactorily when used for the control except at gate settings of 97 to 100 percent open where air must be admitted to relieve low pressures.

Report being prepared.

TRENTON DAM CANAL OUTLET WORKS.

Laboratory project.

Experimental; for design.

A I:12 model was used to determine the feasibility of using the modified high-pressure slide gate for regulating under submerged conditions and to determine the effectiveness of the side entry, vertical stilling-well in dissipating the destructive energy of the released water.

Completed.

The modified slide gate can be safely used submerged at the conditions encountered in the Trenton Canal outlet works and the stilling-well, with a properly designed baffle, dissipates the destructive energy of the water.

Report No. Hyd-300, "Hydraulic model studies of the regulating gate and stilling-well-Trenton Dam canal outlet works--Missouri River Basin Project." W. P. Simmons, Jr. (Report available on loan.)

\section{SURGING-IRRIGATION WATER DISTRIBUTION SYSTEM.}

Laboratory project.

Field investigation; for opmation.

To determine the cause and emedy of water surface surging in open stands--to be specifically applied to the Coachella Distribution System, California.

Air carried into the system where the water falls from a stand baffle into the stream side of a pipe stand is a primary cause of the surging. Airtight lids for the s , vented to limit subatmospheric pressures within the stand, stop or greatly reducr surging. Pipe line vents, regulating gates, and stand inlet riser pipes were mu ass effective than the lids. The height of water fall greatly affects the quantity c entrained. A fall of only 1.5 feet carried air to 7 feet deep into the pool. The ${ }_{3} 001$ depths required to permit air separation were impractical. Numerous baffles, deflectors, and gratings were unsuccessful in attempts to break up the plunging flow so that air would not be carried too deep into the pool. 
(h) Report being prepared.

(1258) PALISADES DAM DIVERSION SCHEME-OUTLET WORKS AND SPILLWAY.

(b) Laboratory project.

(d) Experimental; for design.

(e) To develop a stilling basin suitable for the diversion scheme, a spillway design, a study the over-all flow characteristics of the combined units of powerhouse, outlet works, and spillway.

(g) Testing of diversion scheme and stilling basin completed. Development of spillway: progress. Diversion scheme will use outlet works and power tunnel in free discharge onto a concrete apron which is utilized later for the outlet works. A stilling basi was developed for controlling outlet works discharge.

(h) Report being prepared.

(1259) FIATIZON STILLING BASIN--POWER AND PUMPING PIANT--COLORADO-BIG THOIPSON PROJECT.

(b) Laboratory project.

(d) Experimental; for design.

(e) To develop a stilling basin for the pump turbine bypass valve in the Flatiron Power

(g) Tests have been made on a submerged tube valve and a nonsubmerged hollow-jet valve; former is much preferred.

(h) Report being prepared.

(1261) REPUBLIC DIVERSION DAM, HEADWORKS AND SLUICENAY STRUCTUR US.

(b) Laboratory project.

(d) Experimental; for design.

(e) Tests on a $1: 15$ model of headworks and sluiceway structures were used to improve sei ment-excluding characteristics. This is a continuation of the work begun under Sup Courtland Diversion Dam studies.

(g) Guide walls were found less effective than on previous studies due to lower dischar: and velocities. A headworks incorporating vortex tube desanding apparatus is now bi tested.

(h) Report being prepared.

(1262) SHIEP CREEK DIVERSION SEDIMENTATION BASIN.

(b) Laboratory project.

(d) Experimental; for design.

(e) Tests on a 1:9 model of a sedimentation basin are being conducted to determine the fications required to improve the efficiency of the basin. Tests will also be made prototype structure to determine additional data on model-prototype relationships $f$ movable bed models.

(1263) FORT IARAMIE CANAL SEDIMENTATION BASIN.

(f) Completed.

(h) Report No. Hyd-313, "Hydraulic model studies of Fort Iaramie Canal Desilting BasinNorth Platte Project--Nyoming-Nebraska." E. J. Carlson. (Report available on loan

(1264) VORTEK TUBE.

(b) Laboratory project.

(d) Experimental; for design.

(e) A program of general testing is being made to obtain additional information for des criteria for a vortex tube desanding apparatus. A horizontal vane with a gradually expanding cross section is used to increase the velocity over the vortex tube in or to obtain better action in canals having low water velocities. 


\section{STABLE CHANNEL SHAPES.}

Laboratory project.

Theoretical; for design.

An analytical and theoretical study to obtain data for the design of nonscouring and nonsilting canals in erodible material.

A theoretical study is being made to find a channel shape giving equal force on particles on channel bottom and sides. An analytical study is being made of existing data on critical tractive forces for various materials and velocity distribution in various shaped channels.

Report No. Hyd-307, "Distribution of tractive forces around channel perimeters." A. C. Carter, September 20, 1950.

Memorandum to Head, Research and Geology Division from R. E. Glover, Q. I. Florey, and R. G. Conard dated April 6, 1951, subject "Mathematical computations on the problem of the stable channel."

Memorandum to Head, Canals Division from E. W. Lane dated May 21, 1951, subject "Development of improved earth canal design procedure."

DEVELOPMENT OF THE SALT VELOCITY METHOD OF WATER MEASUR EMENT.

Laboratory project.

Experimental; development.

Proposed developments include an electrically controlled volumetric injaction apparatus for field test use, electrodes that are practical for field tests which will produce results of the desired accuracy, and a correlation between the original electrical conductivity of the ter and the quantity and density of brine needed to produce the required increase in conductivity for detection by a low potential circuit containing a balanced bridge. A study of brine cloud behavior for varying brine density and varying Reynold's number will be made tọ aid in electrode design.

\section{L) POLE HILI SIPHON STUDIES.}

(ग) Laboratory project.

1) Experimental; for design.

e) A siphon was tested in the laboratory to develop an air inlet device which would permit the siphon to operate fully primed at less than full capacity.

3) An air intake device was developed which allowed the siphon to discharge as little as $l \mathrm{cfs}$ and as much as $7 \mathrm{cfs}$ (the maximum discharge) and still remain primed. This was accomplished with relatively small variations in head.

h) Report being prepared.

2) SPILLWAY CREST AND BUCKET STUDIES.

b) Laboratory project.

d) Experimental and analytical.

e) Tests are being made on model spillways of various size to determine the scale effects of negative pressure crests, the effect of more than the design head on a spillway crest, and to establish general design procedures for obtaining a satisfactory roller-type bucket without the need for model tests.

g) Certain limiting bucket dimensions have been definitely established.

HYDRAUIIC JUMP TESTS.

b) Laboratory project.

d) Experimental and analytical.

e) Tests are being made on relatively large jumps, measuring velocities, and pressures in the jump along with profiles and other pertinent data, to determine basic characteristics of a jump, particularly as an energy dissipator. 
(1494) GLENN ANNE SPILLNAY.

(b) Laboratory project.

(d) Experimental; for design.

(e) A 1:16 scale model is being used to determine feasibility of an enclosed hydraulic stilling basin operating under pressure, to provide smooth flow in a steep channel ing a stilling basin, and to prevent erosion below the basin.

(f) Completed.

(g) Enclosed pressurized basin found hydraulically and economically feasible. Oscillogr records of pressures in basin showed unexpectedly high instantaneous impact, making walls necessary. Inergy dissipation found satisfactory.

(h) Report being prepared.

(1495) YELIOWTAIL DAM SPILLWAY AND OUTLET WORKS.

(b) Laboratory project.

(d) Experimental; for design.

(e) A 1:54 scale model of all discharge facilities and surrounding area is being used to determine feasibility of entire lay-out, develop a low-cost tunnel spillway and ener dissipating device, develop an outlet works lay-out, check the proposed powerhouse 1 tion, and determine all inter-related discharge effects in river.

(g) Feasibility has been determined. Tunnel size has been reduced, combination stilling basin and ski-jump bucket has been developed, approach to spillway improved, and out works and powerhouse lay-out improved.

(1496) HYDRAULIC IABORA TORY PROCEDURES.

(b) Laboratory project.

(d) Record of experience, applied research.

(e) A manual for instruction purposes in theory and procedure for hydraulic laboratory personnel.

(h) Bureau monograph being prepared.

(1497) CANAL STRUCTUR IS.

(b) Laboratory project.

(d) Experimental; for design.

(e) Four small table-top models of canal stilling basins were tested to solve problems $r$ ed to canal design.

(f) Completed.

(g) Small models of these relatively small basins proved to be very helpful in solving $\mathrm{p}$ : lems where the usual model tests were believed to be too expensive. The models moun on a piece of plywood were fabricated in the shop and set up at a convenient water $s$ Simple qualitative tests provided most of the answers desired.

(I498) WEIR STANDS--IRRIGATION WATER DISTRIBUTION SYSTEM.

(b) Laboratory project.

(d) Experimental; for design.

(e) 1:2 models and a prototype size weir stand were built to determine the operating cha! istics, weir calibration, and head losses--to be specifically applied to the Exeter : Saucelito Distribution System, California.

(1499) CANAL TURNOUT--ISETER IOCATION.

(b) Laboratory project.

(d) Experimental; for design.

(e) A $1: 2-1 / 2$ model will be used to determine how close an impeller-type irrigation netel can be installed in the turnout downstream from a pipe elbow near the canal for accel able meter accuracy. 


\section{RUBBER-LINED STLEL PIPE.}

Laboratory project.

Experimental; for design.

To determine the number of pipe diameters of rubber-lined steel pipe required to protect

a concrete pipe irrigation line from cavitation pitting downstream from a partially

opened leaf-type valve.

STABLE CHANNEL STUDIES--SCOUR ON CURVES.

Laboratory project.

Experimental; for design.

A program of general testing to obtain information which will correlate extent of scour with degree of curvature in canals.

STABIE CHANNEI STUDIFS--TRACTIVE FORCES REQUTRED TO MOVE MATERIAIS.

Laboratory project.

Experimental; for design.

A program of general testing to determine critical tractive forces required to move given sizes of materials when they are found in normal mixtures. These tests are to be performed in conjunction with tests to determine extent of scour on curves in canals.

\section{DEPARTMENT OF THE NAVY, DAVID TAYIOR MODEL BASIN.}

Inquiries concerning Projects Nos. 467, 468, 470, 709, 710, 711, and 1503 to 1522 incl., should be addressed to The Commanding Officer and Director, Davia Taylor Model Basin, Washington 7, D. C.

\section{TURBULENCE IITASUREMENTS WITH HOT WIRES (HYDRO W. A. 552-8 and 555-3).}

Cooperative with Bureau of Ships.

Basic research.

To develop the hot wire technique for measuring velocities in water in order to correlate turbulence and noise due to turbulence. Includes a review of the theory and application of hot wire anemometry, investigations of the applicability of electrical circuits to the measurement of velocity fluctuations in water and perfect as required to measure the degree of turbulence in water, measuring turbulence parameters under different flow conditions, and the correlation of turbulence parameters with turbulence noise.

A hot vire anemometer has been developed and is being employed successfully for measuring boundary layer thickness and transition to turbulent flow on flat plates and on ship models. An amplifier used to amplify the velocity fluctuations picked up by the hot wire has been redesigned so that its instability and noise level are now within reasonable limits. Studies of the effect of background turbulence are underway. A dynamic method of calibrating the hot wire is being developed, and further studies of background turbulence will be made.

\section{HYDRAULIC ROUGHNESS STUDIES (HYDRO W. A. 555-11).}

Cooperative with Bureau of Ships.

Basic research.

Theoretical and experimental research on nethods for characterizing the hydraulic roughness of surfaces and the frictional resistance of such surfaces leading to a better understanding of the mechanism of frictional resistance arising from surface roughness. Includes the development of instrumentation for measuring and recording surface profiles, the development of methods for their analysis and characterization, and the correlation of surface parameters with drag. Measuring instrumentation completed. 
(470) BLECTROLYTIC TANK (HYDRO W. A. 555-6).

(b) Cooperative with Bureau of Ordnance.

(d) Experimental facility development.

(e) An electrolytical tank for studying potential flow and pressure distributions about $t$ and three dimensional hydrodynanic forms is to be developed.

(g) The basic task and a considerable amount of associated equipment is complete. Veloci distributions about cylinders and bodies of revolution have been measured within two percent. The method is being extended to probe about dimensional bodies with only a single plane of symmetry.

(709) THEORY OF WAVE RESISTANCE (HYDRO W. A. 554-4).

(b) Cooperative with Bureau of Ships.

(d) Basic research.

(e) A mathematical study of the theory of wave resistance for the purpose of establishing methods whereby the theory may be extended to the analysis of ship resistance. Studi will include the general theory of waves in liquids and will encompass reviewing exis ing theory and comparisons with experimental data.

(f) Inactive.

(छ) A synopsis has been written on the application of theory to the calculations of wave resistance. It has been founa that notwithstanding the serious limitations of the th its application to the problem is promising. Calculations are being made to give gen information about the wave resistance of submerged bodies of revolution moving near a free surface. The work is based on the theory developed by T. H. Havelock. The form considered are ellipsoids, Rankine ovals, and a simple family of streamline bodies. calculations are being made at length-diameters ratios of 3, 5, 7, and 9, depth-diame ratio of 1.5 to 3.5 and Froude numbers from 0.20 to 3.5 .

(710) RESEARCH ON CONDENSER SCOOPS AND OVERBOARD DISCHARGES (HYDRO W. A. 552-5, and 555-1).

(b) Cooperative with Bureau of Ships.

(d) Applied research.

(e) Determination of the characteristics of a broad series of scoops and discharges to pr vide design data which will afford a wide scope of information for use in future high speed ship designs.

(g) Tests were conducted on the scoops of a current ship design. Further investigation $i$ planned.

(7II) CAVITA TION RESEARCH (HYDRO W. A. 552-13).

(b) Cooperative with Bureau of Ships.

(d) Basic research.

(e) Conduct research in the mechanism and effects of cavitation phenomena including the physics and analytical description of steady-state cavities in real and ideal fluicis, investigations of the inception of cavitation, the growth and collapse processes of transient cavities, and the effects of cavitation pheonomena of the forces of underwa bodies.

(g) Freliminary work has indicated the direction of investigations to be followed. The w on the (quasi) steady-state cavity was originally started for producing bodies of spe fiea critical cavitation numbers and for checking the limited theoretical work availa This led to questions concerning the processes that are taking place which must be answered to clarify the whole question of the cavitation mechanism. A program of research developed to answer these questions is being progressed slowly.

(h) TMB 647 - "Cavitation methods for the development of forms for specified critical cav tation numbers." P. Eisenberg, Sept. 1947. 
3) BOUNDARY IAYR TRANSITION STUDY (HYDRO W. A. 555-5).

b) Cooperative with Bureau of Ships.

d) Basic research.

e) The position and nature of the transition from laminar turbulent boundary layer on flat plates, with and without artificially induced pressure gradients is to be determined. This study will include investigating the effectiveness of various turbulence stimulators, in inducing transition and turbulent boundary layers, boundary layer surveys on flat plates and ship models to determine transition and velocity profiles, and experiments for various pressure gradients induced on a flat plate.

g) The preliminary theoretical analysis has been completed. Plans are underway for an experimental verification of the theory by tests of a cylindrical element on a flat plate in the miniature circulating water channel.

j4) BOUNDARY IAYERS ON FULI SCALE SHIPS (HYDRO W. A. 555-12).

Cooperative with Bureau of Ships.

Basic research.

Evaluations of existing data and new full scale boundary layer surveys are to be made in order to obtain additional basic knowledge of the boundary layer of ships. Data are available from trials conducted on the USS Hamilton in 1933-35 and an EPC in 1950.

55) EFFECT OF TRANSVERSE CURVATURE ON FRICTIONAL RESISTANCE (HYRRO W. A. 555-4).

(b) Cooperative with Bureau of Ships.

(d) Basic research.

(e) The effect of transverse curvature of a body on its frictional resistance to motion through a fluid is to be determined. This will enable the application of a correction to results of resistance tests on small models having small radii of curvature. The results are also to be extended to include the determination of flat plate frictional resistance whereby surface and edge effects normally present in friction plane results will be eliminated.

(g) A theoretical analysis has been made and significant parameters have been determined. The design and construction of essential models and equipment is underway.

06) STIMUIATION OF TUIRBULENCE ON SHIP MODEIS (HYDRO W. A. 523-20).

(b) Cooperative with Bureau of Ships.

(d) Basic research.

(e) A suitable technique for stimulating a turbulent boundary layer over the entire length of any ship model. Empirical studies will be conducted to evaluate the relative effectiveness of turbulence rods, trip wires, sand roughness and isolated studs. I'he relative effectiveness will be judged by studying the model resistance curve and the character of the boundary layer flow as determined by hot-wire surveys of the bow area.

07) SERIES 57 - RESISTANCE OF VARIOUS REIATED HULL FORMS (HYDRO W.A. 523-10 and 25).

(b) Cooperative with Bureau of Ships and Maritime Commission.

(d) Experimental testing.

(e) The dependence of resistance upon the coefficients of hull forms for a practical range of single screw ship forms is to be determined.

(g) A method for generating a systematic series of forms has been accomplished. Resistance measurements are being obtained for the first of the initial program of 20 models.

08) MODIFICATION OF TAYLOR MODEL (HYDRO N. A. 523-26).

(b) Cooperative with Bureau of Ships.

(d) Experimental testing.

(e) The resistance of models constructed to Admiral Taylor's lines is to be correlated with the test results published by Admiral Taylor, and studies are to be made of the effect of connecting the sterns of these models to single screw sterns of the DTMB Series 57 (See Hycho W. A. 523-10 and 25 above). 
(1509) GBONETRIC SERIZS OF PT MODEIS (HYDRO W. A. 525-3).

(b) Cooperative with Bureau of Ships.

(d) Experimental testing.

(e) Tests of geometrically similar PT models are to be conducted to determine scale effec and to determine the maximum size planing model which can be tested in the DTMB High Speed Basin.

(f) Inactive.

(g) All testing has been completed and some of the data have been analyzed. The final reports to be prepared.

(1510) GENERAL SEAWORTHINESS (HYIRO W. A. 542-17).

(b) Cooperative with Bureau of Ships.

(d) Experimental testing.

(e) To provide information leading to the design of more seakindly ships. The aspects of the seakindliness which this program will investigate are speed in rough ter, and ship motions. Tests will be conducted to determine the optimum shape of hull and erec tions that will permit maximum speed in a seaway. The relationship between ship motic and the ability of the ship to remain operational at the highest attainable sea speed is to be studied also. Studies will also be made of the applicability of model seaworthiness tests to a full-scale ship. The wave damping of basic ship forms, intensiv theoretical studies of the effect of pitching and heaving on ahead motion, the interfe ence effects between ocean waves and the ship's own wave system, and other influences tending to reduce speed will be studied.

(1511) SERIES SEAWORTHINESS.

(b) Cooperative with Office of Naval Research.

(d) Experimental testing.

(e) The effect of various hull form parameters on the reduction in speed, ship motions and dryness of decks in waves is to be determined. A standard series 57 model with block coefficient 0.60 will be the parent for the series. Several hulls and modifications will be used to study the effect of (I) bow sections - U, V, and Bulb, (2) bow flare, (3) freeboard, (4) plumb stern, (5) raked stern, and (6) stern sections - U, V, raised counter.

(1512) MULTIPLICATION OF THE EFFECTIVENISS OF BILGE KEELS (HYDRO W. A . 542-14).

(b) Cooperative with Bureau of Ships.

(d) Experimental testing.

(e) Test data are needed to substantiate design studies in the use of fin stabilizers in connection with research and development on ship stabilization. The amplitudes of rol: versus rolling moment and frequency at or near resonance with and without bilge keels; the increase over calm water resistance of a model subjected to rolling and roll-induci yawing; and the lift, drag and torque developed by the fins will be determined.

(1513) INTERNATIONAL TOWING TANK PROPEIIER COMPARISONS (HYDRO W. A . 526-7).

(b) Cooperative with Bureau of Ships and International Toring Tank Conference.

(d) Experimental testing.

(e) Water tunnel cavitation tests are to be conducted on 4 DTMB designed propellers and 4 AEW designed propellers at a range of cavitation numbers and air contents at water-spe of 18 to 24 feet per second. The tests are to be conducted at various water tunnels throughout the world and then correlated.

(f) Inactive.

(g) Three of the DTMB designs and one of the AEW designs have been tested at the David Tay: Model Basin. Further action is being held in abeyance pending the next ITTC Conferenc 
SINGIE SGEW VESSEL MANEUVRR ING CHARACTERISTICS (HYDRO W. A. 542-24).

Cooperative with Bureau of Ships.

Experimental testing.

It is desired to amplify the explanation of the cause of maneuvering behavior of single screw vessels. A program to conduct various tests of single screw vessels in order to determine maneuvering characteristics including (1) side force exerted on the propeller when operating at various depths, (2) side force exerted by the slip stream on the rudder at various angles, (3) side force on the stern of the model, (4) pressure exerted on the hull on each side at several positions in way of the slip stream with the propeller backing, and (5) wake measurements ahead and astern of the propeller during ahead and backing operations. Principal flow into the propeller to be determined at that time.

j) THEORETICAL SEAWORTHINESS (HYDRO W. A. 513-2).

) Cooperative with Bureau of Ships.

1) Basic research.

e) To provide information leading to more seakindly ships, following theoretical lines, to supplement and extend information secured by experiments with systematically varied models. (Problem Hydro W. A. 542-19). Studies will include investigation of such problems as how far a regular seaway can be substituted for the actual, irregular seaway in determining behavior of ships, and theories of motion, forces, waves, reflection, etc.

5) STUDIES OF RESISTANCE MEASUREMENT AND RESISTANCE PREDICTION METHODS (HYDRO W. A. 555-16).

o) Cooperative with Bureau of Ships.

d) Basic research.

e) The theoretical possibility of separating the viscous and wave drags for surface flows by means of a wake survey method may be demonstrated. The utility of the method depends upon the solution of those problems of practical nature which will arise in the application. The separation of the viscous and wave drags in model tests would permit the possibility of improvement in resistance prediction techniques through the replacement of the Froude method of drag separation and extrapolation by a more rational method. The objective is to develop the wake survey method as a practical technique, and to study improved resistance prediction methods. Theoretical studies of the wake survey method will be followed and supplemented by application to the measurement of drag of surface ships and submerged bodies. The necessary instrumentation including wake survey rakes traversing mechanisms, and manometer systems will be developed and measurement techniques studied. The resistance prediction studies will be theoretical, making use of modern viscous flow theory.

h) TMB Report 772, "The separation of viscous drag and wave drag by means of the wake survey."

7) MINIATURE MODEL BASIN.

b) Cooperative with Bureau of Ships.

d) Facility - theoretical investigations.

e) To obtain correlations of drag, side force, and vortex configurations of vibrating cylinders, including the effect of forced vibrations on the resulting vortex formation. The experiments will be conducted in a special miniature model basin in which continuous force measurements will be recorded of the free and forced oscillations of the cylinders. A miniature model basin with a carriage, and an oscillator for vibrating the cylinder dynamometers for measuring wake has been constructed.

8) HYDROPHONE DEVELOPMENT (HYURO W. A. 562-6).

b) Cooperative with Bureau of Ships.

d) Instrumentation research.

e) Investigations and studies are to be conducted to improve existing hydrophones and hydrophone and associated equipment calibration techniques. 
(1519) NOISE SURVEY OF HYDRODYNAMIC FACILITIES (HYDRO W. A. 562-8).

(b) Cooperative with Bureau of Ships.

(d) Facility improvement.

(e) Background noise and reveberation measurements are to be made of the DTMB test facil: at various conditions: ambient, machinery items on and off, towing carriages operati and inoperative. The data are to be analyzed and combined into a single report.

(1520) HIGH SPEED TOWING CARR IAGE.

(b) Cooperative with Bureau of Ships.

(d) New facility.

(e) A new high speed towing carriage capable of speeds up to 60 knots has been construct:

(1521) 36-INCH VARIABLE PRESSURE WATER TUNNEL (HYDRO W. 4. 518-2).

(b) Cooperative with Bureau of Ships.

(d) Facility development.

(e) A 36-inch variable pressure water tunnel is to be designed.

(1522) WAVEMAKER STUDIES (HYDRO W. A. 517-2).

(b) Cooperative with Bureau of Ships.

(d) Facility development.

(e) Experimental and theoretical studies aimed at the determining of the most desirable configurations for wavemakers are to be made.

(g) An experimental 2-foot wavemaker has been constructed and a program of testing is unc way.

U. S. DEPARTMENT OF THE NAVY, NAVAL BOIIFR AND TURBINE IABORATCRY.

Inquiries concerning Projects Nos. 1523 and 1524 should be addressed to lir. James $W$. Murdock, Instrument Division, U. S. Naval Boiler and Turbine Laboratory, Philadelphia Naval Base, Philadelphia 12, $\mathrm{Pa}$.

(1523) HIGH PRECISION POWER INSTRURENTS (I-II).

(b) Bureau of Ships and Office of Naval Research, Department of the Navy.

(d) Experimental; applied research.

(e) For improvement of fluid flow measurement. (1) Tests under way to determine influenc of approach conditions on orifice meters. Various fittings placed 6 to 60 pipe diame before orifices. (2) Determination of expansion effects of steam, particularly in 10 superheat regions; involves introduction of low superheat steam through proper approa to orifices having beta ratios of 0.30 to 0.87 .

(g) Results indicate (I) length of straight pipe required before orifice meter is reducib to less than $50 \%$ of that presently stipulated without appreciably affecting accuracy measurement; (2) expansion factors for steam are in general agreement with those now specified except at low superheats where empirical equations must be modified.

(h) "Progress on globe valve series."

Test I-II Interim Report No. 1, 22 Jan. 1950.

Test I-II Interim Report No. 2, 9 Mar. 1950.

Test I-1I Interim Report No. 3, 4 May 1950.

Bureau of Ships, Department of the Navy. 
4) DETERMINATION OF HYDRAULIC CHARACTERISTICS OF SHIP PIPING SYSTEM COMPONENTS (I-25).

b) Bureau of Ships, Department of the Navy.

d) Field investigation; design.

e) Study of design arrangement for accurate prediction of pressures in copper-nickel piping systems. (1) Runs conducted to determine friction factors of 2-1/2", 4", 6" IPS CuNi tubing. (2) $\mathrm{K}$ factors for $125 \mathrm{psi}$ Navy and commercial valves, tees, and ells.

g) (1) Friction factors agree with ASME (Moody's factors). (2) K values with special Navy fittings are lower than with standard equipment.

h) "Pressure drop determinations of component parts of piping systems - 6" IPS fittings." Test I-25 Interim Report No. 10, 31 July 1950. (Summary Interim Reports 1-9.) Bureau of Ships, Department of the Navy.

3. DEPARTMENT OF THE NAVY, NAVAL ENGINERR ING EXPERIMENT STATION.

Inquiries concerning Projects Nos. 472 and 1525 to 1529 incl., should be addressed to Chief, Bureau of Ships, Department of the Navy, 'Nashington 25, D. C.

12) ALIOYS FOR CONDENSYR TUBES AND SALT TATER PIPING SYSTEMS - SEA WATER CORROSION AND TROSION.

(b) Bureau of Ships.

(d) Experimental; applied research.

(e) Tests are being made of a dozen or more experimental condensers, Tubes of some 20 alloys are being tested in natural sea water at a water velocity of $20 \mathrm{ft} / \mathrm{sec}$. At the present time much importance is attached to results of tests for 90-10 copper-nickel alloys containing iron as a step toward conserving nickel.

Piping systems containing branches of several copper-nickel alloys together with a number of other materials are under test in sea water at $15 \mathrm{ft} / \mathrm{sec}$. A number of special materials including nylon and titanium are being investigated for valve trim.

(g) Excellent results have been obtained for 90-10 copper-nickel alloys containing about 1.5 percent iron. Successful performance is predicted for the alloy for both condenser tubes and salt water piping systems.

(h) EES Report 4A966845, 4 May 1951. "Comparative tests of condenser tube materials including several varieties of 90-10 copper-nickel alloys--work performed with the cooperation of the International Nickel Company, Inc." EES Report 4B(4)17.K1603, 5 Jan. 1951.

"Investigation of materials and design features for salt water piping systems in connection with development program being conducted by Gibbs and Cox, Inc., New York, N. Y."

25) NOISE ATTENUATION TESTS OF FLEXIBLE PIPE COUPLINGS.

(b) Bureau of Ships.

(d) Investigative.

(e) Investigation of the noise, hydraulic shock, and burst strength characteristics of flexible pipe couplings suitable for isolating naval machinery, particularly submarine auxiliary machinery. Various sizes of pipe couplings are being investigated to determine their suitability for submarine applications. Not only are the couplings subjected to noise tests to determine their noise attenuation but also the noise generated by couplings and coupling configuration under various flow conditions.

(g) Results show noise attenuation characteristics of various couplings at pressures up to $50 \mathrm{psi}$. Burst tests have been conducted showing resistance to couplings to pressures as high as 10,000 psi. A type of coupling employing nonproprietary hose and reusable end fittings has been found which has very high sound attenuation characteristics and is excellent for use in damage control. 
(h) EES test reports submitted to the Bureau of Ships: C-3590-1 "Primary measurements of sound and vibration reducing characteristics of five flexible pipe couplings." C-35s "Noise reducing characteristics of flexible couplings in piping systems." 5D066797 "Standardization of flexible pipe coupling testing facilities." 5A(4)066735 "Noise reducing characteristics of flexible couplings in piping systems." 5A(5)066735 "Nois reducing characteristics of flexible couplings and special damped pipe in piping syst 5A(6)066735 "Noise reducing characteristics of flexible pipe couplings." 5P(5) X1609 "A proposed method of reducing the propagation of noise in piping systems at submarin bulkheads."

(1526) TANK FILIING VALVE.

(b) Bureau of Ships.

(d) Suitability test.

(e) Valve is globe type, diaphragm operated, for use in a pipe line to or from a storage tank. When filling the tank an auxiliary float operated pilot valve permits diversio of a small amount of flow through a small eductor which reduces the pressure on back diaphragm to hold main valve open. When the tank has filled, the float closes the pi shutting off flow through the eductor. The diaphragm valve then closes automatically When drawing liquid from the tank, the diaphragm lifts due to reduction of pressure $a$ and tank head pressure below same. This causes the valve to open. The valve may be controlled manually by small valves in auxiliary piping or may be directly secured by large hand wheel.

(f) Completed.

(g) Valve functioned as intended and will handle liquids of viscosities to 1200 SSU. Aut, matic closure is effected without the development of water hammer.

(h) Report identified by EES Text Serial No. 3Mo66735.

(1527) AUTOHA TIC RECIRCUIATING VALVE FOR BOILER FEED PUIPS.

(b) Bureau of Ships.

(d) Suitability test.

(e) A new device undergoing test is designed to establish recirculation, through boiler fi pumps, only when necessary, at or below predetermined minimum pump capacities, and to shut off recirculation at all higher pump capacities. It comprises a main valve, a p: valve, and a diaphragm controlled recirculating valve. The main valve is installed is the feed pump discharge.

(g) Results are promising but further development work is required to modify operating che acteristics so that within the desired recirculation range the rate of recirculation 1 be inversely proportional to the flow to the boilers. It is expected that test will k completed before the end of the calendar year and that a report will be available abor February 1952. Report identified by EES Test Serial No. 3C-3816.

(1528) HYDRAULIC PUMPS ANU POWER TRANSMISSION.

(b) Bureau of Ships.

(d) Suitability test.

(e) Three hydraulic power transmissions were tested; test of a fourth unit, comprising pur only, is underway. One was a hand operated, fractional horsepower, radial piston. type constant stroke pump with hydraulic motor for the remote operation of valves. One for electric motor drive was of the axial piston, wobble plate type, variable stroke and reversible. A hydraulic motor provided with this unit was similar to the punp in desi but had a fixed stroke. Two other pumps were power driven, radial piston type, one pr vided with hydraulic motor and one consisting of pump only.

(g) The hand operated unit as finally modified, was found satisfactory for use with oil. It lighter in weight and operated at a higher speed than comparable units previous tested. One power driven radial piston pump was considered unsatisfactory because of leakage, slippage, and relatively low efficiency. This unit embodied good design features and it is believed the deficiencies were due to lack of refinement in machine wc finish, and tolerances. It is expected that a new unit will be submitted at a later date. Test of a similar pump, of different manufacture, is currently underway. 
Report of test of hand operated hydraulic transmission is identified by EES Test Serial No. 3L(2)066735; the axial piston, high speed, 80 hp unit by EES Test Serial No. 3 A966889.

EXPANSION JOINTS OF SYNTHETIC RUBBER FOR SALT WATER PIPING AND BLOWER DUCTS.

Bureau of Ships.

Suitability test.

Joints initially were overdesigned as regards bursting strength at a sacrifice of flexibility. Tests include determination of fire resistance, hydrostatic test, resistance of joint to deflection, and deflection-fatigue tests.

All specimens were satisfactory as regards fire resistance. Indications are that new designs will show greater flexibility with adequate resistance to bursting.

Reports will be identified by EES Test Serial Nos. 3ADTL4I and 3ADT442.

DEPARTMENT OF THE NAVY, NAVAL ORDNANCE TEST STATION.

Inquiries concerning Projects Nos. 1270, and 1530 to $1533 \mathrm{incl.,} \mathrm{should} \mathrm{be} \mathrm{addressed} \mathrm{to}$ The Commander, U. S. Naval Ordnance Test Station, Pasadena Annex, 3202 East Foothill Blvd., Pasadena 8, Calif. Attn: Code P8001.

CAVITY SHAPE IN STEADY-STATE FIOW.

Laboratory project.

Theoretical; applied research.

A theoretical investigation of cavity shapes behind arbitrary bodies of revolution in steady and non-steady motion. Development of methods of predicting cavity shapes using potential theory.

DITATISE ON WATER ENTRY RESEARCH.

Laboratory project.

Theoretical; basic research.

To prepare a comprehensive treatise on the theory of water entry impact. This treatise will contain appropriate references to previous work and will present recent work in analytic and pictorial detail so that it can serve as a standard reference textbook on water entry impact.

U. S. Naval Ordnance Test Station, Technical Memoranda:

No. 576 "The vertical water entry of a wedge." W. J. Karzas, 1 0ct. 1951,

No. 581 "The compression shock due to the vertical impact of an axially symmetric body on a plane water surface." R. H. Owens, 26 Nov. 1951.

\section{MECHANISM OF CAVITATION.}

Laboratory project.

Theoretical and experimental; basic and applied research.

Determination of the basic mechanism of cavitation so that the importance of various factors can be applied to the solution of cavitation problems in propulsion systems.

YAWED BODIES OF REVOLUTION.

Laboratory project.

Theoretical; applied research.

Theoretical investigation of the effects of yaw on bodies of revolution. This study concerns the calculation of hydrodynamic coefficients and changes in pressure and velocity distribution due to slight angles of yaw, the effect that yaw has on separation of flow and on the transition from laminar to turbulent flow. 


\section{（1533） PRESSURE-TIME MEASUR IMENTS.}

(b) Laboratory project.

(d) Experimental; basic research.

(e) A measurement of the pressure transient at various points on the surface of various geometric shapes during water entry. A pressure gauge was developed to record extre fast response to transients. It has a rise tine of one to two microseconds in respc to a step-forcing function.

(g) Reliable records for a 12-inch sphere were obtained at the stagnation point for vert entry at $23.5 \mathrm{fps}$.

U. S. DEPARTMENT OF THE NAVY, OFFICE OF NATAL RESEARCH.

For sponsored projects see the following:

Project

(15) Studies of cavitation phenomena

(279) Flow in rotating channels

(803) Dynamics of cavitation bubbles

(804) The effect of physical characteristics of liquid on the inception of cavitation

(1300) Basic water entry study

(1301) Hydrodynamics of free-boundary flows

(47) Gravity waves and related phenomena

(822) Diffusion of heat, vapor, and momentum

(1319) Prevention of icing on airplane wings by line-source of heat

(60) Flow of fluids through granular (porous) media

(62) Hydraulic structures

(290) Hydraulics of short outlets in bodies of dams

(1323) Study of energy equations in turbulent flow

(1324) Losses in two-dimensional tees

(1087) Wave tank studies of beach stability related to various wave characteristics

(1088) Model studies of the development of beach forms

(1335) Mathematical theory of waves

(1) Frictional resistance in rough pipes

(69) Relation of sediment characteristics to bed erosion

(72) Electrical analogy of three-dimensional flow

(75) Diffusion of submerged jets

(79) Cavitation

(81) Mathematical analysis of pressure distribution

(299) Determination of pressure distribution caused by flow of air over a series of three-dimensional building forms

(851) A constant-temperature hot-wire anemometer for the measurement of turbulence in air

(854) Boundary-layer development on smooth and rough surfaces

(I107) Transportation of sediment as suspended and total load

(1344) Calculation of free-streamline flows

(577) Characteristics of solitary waves

(578) Turbulence measurements with a pitot tube - pressure cell combination

(579) Investigation of fluid friction in unsteady motion

(1355) Cavitation inception for steady motion

(880) Recovery factors and heat transfer to air flowing at supersonic velocities in a tube

(1359) Effect of heat transfer on the stability and transition of laminar boundary layers in liquid flow

(1374) Shear flow in bends

(1137) Impact tube on ship models 
7) Three-dimensional investigation of the stability of towed marine ships 61

0) Air entrainment research 69

4) Flow diversion research 69

4) Free-jet water tunnel studies 70

0) Effect of tube vibrations on pressure drop of flow in tubes 70

5) The compilation of data on ship resistance 75

inpo) Planing surfaces 76

0) Self-propelled model testing 78

3) An investigation of ship resistance using statistical methods 78

7) Turbulent expansion of jets in water 133

8) Wind waves 133

9) Energy dissipation in standing waves

0) Positive waves in dry channels

1) Calculation of non-linear breaking of waves 133

1) Series seaworthiness 150

3) High precision power instruments 152

IESSEE VALIEY AUTHORITY, Hydraulic Data Branch.

Inquiries concerning all TVA Projects should be addressed to Mr. Albert S. Fry, Hydraulic Data Branch, Tennessee Valley Authority, Knoxville, Tenn.

Unless otherwise noted work is being done for Tennessee Valley Authority, Hydraulic Laboratory Section.

:3) FONTANA DAM, SPILITAY MOUEL STUUIES.

d) Experimental; for design.

(e) Tests on 1:100 and 1:51 models were made to develop spillway structures that would dissipate the energy of flood overflows without damage to the dam or adjacent structures.

g) A spillway utilizing two diversion tunnels used during construction with buckets to spread the discharge, and a small emergency spillway were also developed.

(h) Final report in preparation.

24) FONTANA DAM, LOW-LEVEL OUTLET, HOWELI-BUNG TR VALVE MODEL STUDIES.

(d) Experimental; for design.

(e) Tests on a 1:42.35 model were made to develop a structure that would safely and efficiently dissipate part of the energy in the Howell-Bunger valve discharge.

(g) Structures were developed which gave satisfactory flow conditions in the 15 -foot diameter tunnel below the valve area. These structures were designed to keep to a minimum the air required when the valve is discharging.

(h) Final report in preparation.

25) FONTANA DAM, IOW LEVEL OUTLET, OUTLET STRUCTURE MODEL STUUIES.

(d) Experimental; for design.

i(e) Tests on a l:100 model were made to develop a structure that would perform satisfactorily under all operating conditions.

(g) A comparatively simple outlet structure was developed.

(h) Final report in preparation.

26) FONTANA DAM, CAVITATION STUDIIS.

(d) Experimental; for design.

(e) To develop specifications for permissible variation in tunnel alignment so as to prevent cavitation damage to the walls of the Fontana spillway tunnels.

(h) Final report in preparation. 
(727) HALES BAR DAM, SPILIWAY MODEL STUDIES.

(d) Experimental; for design.

(e) Tests were made on a 1:34.76 model of the spillway to develop a modification of the existing apron to prevent erosion and assist in reconstruction of the dam.

(h) Final report in preparation.

(728) SOUTH HOISTON AND WATAUGA DAMS, SPILIWAY MODEL STUDIES.

(d) Experimental; for design.

(e) Tests on $1: 100$ and 1:51 models were made to develop a morning-glory spillway to hand: flood overflows.

(g) Proper location of piers on crest were determined, and a deflector in the vertical sl to deflect flow to outside of bend at bottom was developed.

(h) Report in preparation.

(730) SOUTH HOISTON DAM, SPILIWAY OUTLET MODEL STUDIES.

(d) Experimental; for design.

(e) Tests on a 1:51 model were made to develop an outlet structure to dissipate the ener $\varepsilon$ from the morning-glory spillway and the Howell-Bunger valve sluiceway without damage the tunnel or outlet structures.

(h) Report in preparation.

(731) SOUTH HOISTON DAM, SURGE TANK MODEL STUDY.

(d) Experimental; for design.

(e) A 1:50 model of the penstock and surge chamber was used to determine ( 1 ) the orifice size and characteristic shape to produce favorable pressure and water surface elevati changes for the best governor operation; (2) the maximum and minimum water surface el vations to be expected in the surge chamber; and (3) the operational characteristics the selected design.

(g) With the proper orifice between the riser and the surge chamber as satisfactory resul can be obtained as with the differential riser type of surge tank.

(h) Report in preparation.

(732) WATAUGA DAM, BED IOAD STUUY.

(d) Experimental; for design.

(e) A fixed-bed 1:70 model of the river near the powerhouse was tested to determine wheth bed load moved by the spillway discharge would be deposited in the powerhouse tailrac and, if so, how it could be prevented.

(g) A small wall located along the upstream edge of the tailrace channel was found suffic. to keep the bed load from depositing in the draft tubes and the tailrace.

(h) Report in preparation.

(735) TURBINE DISCHARGE RATINGS.

(d) Field tests; applied research.

(e) Measurements of turbine discharges are being made to rectify discrepancies and increa: accuracies in reported discharges. On tributary rivers current meter measurements ar made below the dams. On the main river discharges are determined for individual unit: by making velocity traverses in the turbine intakes.

(g) Equipment for turbine discharge measurements has been tested and method found to be sound.

(736) APA IACHIA DAM, SPILLWAY RATING.

(d) Experimental; operation.

(e) Model tests, checked by field measurements, are to be used in determining the dischar ratings for all anticipatec operating conditions. Discharge tables for operating pur. poses will be prepared.

(f) Model studies completed. 
CHIROKEE DAM, SPILLWAY RATING.

Experimenta 1; operation.

Model tests, checked by field measurements, are to be used in determining the spillway discharge ratings for all anticipated operating conditions. Discharge tables for operating purposes will be prepared.

Model studies completed.

CHEROKEE DAM, SLUICE RATING.

Field investigation; operation.

Measurement of discharges and differential pressures in the sluices, supplemented by model test data, will be used to establish the discharge ratings for the eight sluices. Tables of discharge for any gate opening at any headwater elevation within the operating range are to be prepared.

DOUGIAS DAM, SPILIWAY RATING.

Experimental; operation.

Model tests, checked by field measurements, are to be used in determining the spillway discharge ratings for all anticipated operating conditions. Discharge tables for operating purposes vill be prepared.

Model studies completed.

DOUGIAS DAM, SLUICE RATING.

Field investigation; operation.

Measurement of discharges and differential pressures in the sluices, supplemented by model test data, will be used to establish the discharge ratings for the eight sluices. Tables of discharge for any gate opening at any headwater elevation within the operating range are to be prepared.

FONTANA DAM, LOW-LEVEI OUTLET RATING.

1) Field investigation; operation.

!) Field measurements of discharges and pressures in the Howell-Bunger control valve were used to compile discharge-valve opening data within the expected operating range.

1) Final report in preparation.

FONTANA DAM, LOW-LEVIL OUTLET, AIR DEMAND STUDIES.

Field investigation; operation.

Measurements of air demanded by the 84-inch Howell-Bunger valve were made through its entire range of openings and heads.

5) The results, when plotted as air demand versus water discharge, gave a family of curves varying with head but of unpredictable shape. A constant ratio of air to water exists at each valve opening position.

1) Final report in preparation.

j) FONTANA DAM, SLUICE RATING.

11) Field investigation; operation.

e) Field measurement of discharges and differential pressures in the sluices, supplemented by model test data, will be used to establish the discharge ratings for the six sluices. Tables of discharge for any gate opening at any headwater elevation within the operating range are to be prepared.

6) FORT IOUDOUN DAM, SPILLWAY RATING.

d) Experimental and field investigation; operation. 
(e) Model tests, checked by field measurements, are to be used in determining the dischar ratings for all anticipated operating conditions. Discharge tables for operating pur will be prepared.

(f) Model studies completed.

(753) OCOEE NO. 3 DAM, SPILIWAY RATING.

(d) Experimental and field investigation; operation.

(e) Model tests, checked by field measurements, are to be used in determining the dischar ratings for all anticipated operating conditions. Discharge tables for operating pur will be prepared.

(f) Model studies completed.

(755) WATTS BAR DAM, SPILIWAY RATING.

(d) Experimental; operation.

(e) Model tests, checked by field measurements, are to be used in determining the dischar ratings for all anticipated operating conditions. Discharge tables for operating pur will be prepared.

(f) Model studies completed, discharge tables issued.

(758) CHEROKEE DAM, PROTOTYPE CHECK TESTS.

(d) Field investigation; applied research.

(e) Measurements of pressure in sluices are being obtained to be compared with the pressu measured during the model tests.

(759) DOUGLAS DAM, PROTOTYPE CHECK TESTS.

(d) Field investigation; applied research.

(e) Measurements of pressure in sluices are being obtained to be compared with the pressu measured during the model tests.

(760) FONTANA DAM, PROTOTYPE CHECK TESTS.

(d) Field investigation; applied research.

(e) Plaster surface impressions of carefully located sections are taken after each extend period of tunnel operation to obtain evidence of damage. Entire tumnel is examined $f$, erosion, cavitation damage, or structural failure.

(g) Inspections made in Sept. 1946, Oct. 1949, and May 1950.

(761) KENTUCKY DAM, PROTOTYPE CHECK TESTS.

(d) Field investigation; applied research.

(e) Measurements are made of lateral pressures on the face of the spillway piers and on $t]$ submerged baffle piers on the spillway apron to be compared with the results of the $\mathrm{m}$ tests.

(762) SOUTH HOISTON DAM, PROTOTYPE CHECK TESTS.

(d) Fielc investigation; applied research.

(e) The prototype installation was equipped to allow testing in a manner similar to that 1 in the model studies which established the design. A check on the model accuracy can thus be obtained.

(g) Initial tests made in Feb. 1950.

(763) HIWASSEE DAM, PROTOTYPE CHECK TESTS.

(d) Field investigation; applied research.

(e) Measurements of pressure in sluices are being obtained for comparison with pressures measured in model tests. 
HALES BAR DAM, SPILIWAY APPROACH STUDIES.

Experimental; for design.

Tests are made on a $1: 65$ model to determine effect of the remains of cofferdam structures upstream of the spillway on the spillway discharge and to determine amount of the obstructions which should be removed.

CHANNEL STUDIES BELOW HALES BAR DAM.

Experimental; for design.

) Tests are conducted on a 1:65 model to study effect of channel alignment on spillway discharge and navigation conditions, and effect of lock location and spillway gate operation on navigation conditions.

2) HALFS BAR DAM, POWERHOUSE INTAKTS STUDIES.

d) Experimental; for design.

3) Tests were made on a 1:65 model to determine design for intakes and guide structures to provide good velocity distribution.

g) An upstream guide wall and special pier noses at the intakes were required.

1) Final report in preparation.

3) HALES BAR DAM, MISCELIANEOUS STIRUCTURES STUDIES.

d) Experimental; for design.

e) Tests were made on a 1:65 model to determine location of trash boom and head-water gage intake for a new powerhouse.

h) Report in preparation.

4) BOONE DAM, SPILLWAY MODEL STUUIES.

d) Experimental; for design.

e) Tests are made on a 1:50 model to determine proper dimensions for bucket-type spillway and associated training walls.

g) The tests proved that for certain anticipated operating conditions the bucket-type spillway can be advantageously used.

h) Report in preparation.

7) WATAUCA DAM, PROTOTYPE CHECK TESTS.

d) Field investigation; applied research.

e) Outlet tunnel surfaces are inspected after completion and after extended periods of operation to determine erosion, cavitation damage, or structural failure.

g) Initial inspection in Dec. 1949.

9) WHEELER DAM, PROTOTYPE CHECK TESTS.

d) Field investigation; applied research.

(e) Measurements were made to determine effect of obstructions in the tailrace channel on turbine operation.

f) Tests completed. Memorandum report issued.

32) HOWELI-BUNG KR VALVE DISCHARGE COEFFICIENT.

id) Field investigation; applied research.

(e) Tests made to determine discharge, pressure at base of valve, and dimensions of valves, and all available data analyzed to determine coefficient based on net flow area through body of valve.

(g) Coefficient is about 0.9 at maximum discharge and increases slightly with size. Maximum discharge does not occur at maximurn opening.

(h) Report in preparation. 
Hydro-Meteorological Section, in collaboration with Field Investigations Section.

(764) DETERMINATION OF SEDIMENT CARRIED IN SUSPENSION BY TENNESSEE RIVER AND IRIBUTARIES.

(d) Field investigation; basic research.

(e) To provide data for estimating effective life of storage reservoirs, and loss of soi: from the land. Samples of water were collected periodically at stream gaging statior in the watershed, analyzed to determine the sediment content, and correlated with riv discharge to determine the suspended sediment load at each station.

(h) Report in preparation.

(766) GROUND WATER INVESTICATIONS.

(d) Field investigation; basic research.

(e) Hydrologic study to determine effect of filling of reservoirs upon adjacent water tak Records of ter levels in observation wells are compared with rainfall and river sta for periods before and after reservoir filling.

(f) Observations discontinued.

(g) Preliminary reports prepared for internal use; conditions found to be normal at all sites studied.

(767) RESERVOIR RIM INVESTIGA TIONS.

(d) Field investigation; basic research.

(e) To determine the leakage, through rims of new reservoirs, and to check conditions for other reservoirs. Ground water levels are observed and post-impoundage levels compar with pre-impoundage records; stream flow from rim areas is measured to determine whet any increase has occurred after creation of a reservoir.

(g) Preliminary report prepared for internal use. No serious leakage conditions have bee: found.

(1283) STEAM PIANT AIR POLLUTION STUDIES.

(d) Field investigation; design and operation.

(e) To obtain information for use in studies of air pollution and its control. Measureme: of air temperatures, wind velocities, and atmospheric sulphur dioxide are being obtail in the Johnsonville Steam Plant area. Air temperatures and wind velocities are being taken in the Widows Creek, Shawnee, and Kingston Steam Plant areas.

(1534) FORT PATRICK HENRY DAM, SPILIWAY MODEL STUDIES.

(d) Experimental; for design.

(e) Tests are being conducted on a $1: 50$ scale and a $1: 112.5$ scale model to determine the apron design, training wall dimensions, and other related data.

(g) An apron using a single row of rectangular baffles was developed.

(1535) DEVEIOPMENT OF ERODIBLE BED MATERIAL FOR USE IN MODEL TESTING.

(d) Experimental; developmental.

(e) An erodible material that will start to move at model velocities comparable to the an cipated velocity at which the prototype material will erode is needed when erosion te: are to be made for areas in which steep banks or cliffs exist. Experiments are under to develop such a material.

(g) Limited success has been achieved. Experiments are continuing.

(1536) VHF RADIO GAGES FOR REPORTING RAINFALI AND RIVER STAGES.

(d) Experimental; development.

(e) To change from the present HF to VHF bands new equipment is being developed. When the change-over is complete all stations will be automatically transmitted and received. 
RESER VOIR AND STREAM TEMPERATURES.

Field investigation; basic research.

Study of ter utilization and water movement as concerns industrial plant locations and stream pollution. Variations in temperature from surface to bottom in reservoirs throughout the year are determined by souncings, and by continuous recording gages in natural streams.

\section{INVESTIGATION OF WINDS AND WAVE HEIGHTS.}

Field investigation; basic research.

To obtain data on occurrence of wes of various heights as concerns navigation on TVA lakes and develop relation of wave height to wind for design purposes. Three recording stations were installed.

Observations discontinued.

Records analyzed; special requests answered by reference to available data.

\section{GALLERY DRAINAGE IN IARGE DAMS.}

Field investigation; design.

Weirs are placed in main galleries and drainage measured as check on tightness and stability.

Reports prepared annually for internal use.

WHITE AND RICHIAND CREEKS--DETERMINATION OF ROUGHNESS COEFFICIENT.

Field investigation; basic research.

Determinations being made in several river reaches of known discharge to extend knowledge of relation between roughness coefficient and physical characteristics of rivers.

WATER TRAVEL IN NATURAL STREAMS.

Field investigation; applied research.

Sanitary and chemical changes in water during passage downstream are determined. A given mass of ter is identified by electrical conductivity or chemical titration.

MOVIMENT OF WATER THROUGH IARGE RES IRVOIRS.

Field investigation; applied research.

Because of slow water travel, samples are collected by traverse through lake.

Water entering a reservoir does not intermix with the rest of the reservoir, but remains

as a density current as a result of the difference in temperature between the inflowing

water and that in the reservoir. During certain seasons of the year, in Watts Bar Reservoir the cold ter released from Norris Reservoir passes upstream along the bottom of the Imory hiver arm of the former reservoir.

\section{Field Investigations Section.}

2) FIOOD INVESTIGA TIONS, TENNESSEE RIVER AND TRIBUTARIES.

d) Field investigations; basic research.

(a) Survey to obtain data for hydraulic studies and for planning flood-control projects. High-water marks are set and observations made as floods occur; field search is made for high-water marks of past floods. Data are collected on rainfall, runoff, and damages incurred by floods.

3) INVESTICATIONS OF SPRINGS AND RUNS BELOW DAMS.

d) Field investigation; design and operation. 
(e) Hydrologic investigation related to construction activities. Flows from springs and small streams below dam sites are measured before and after construction of dams to determine leakage. Observation weirs are observed regularly and the records are anal to account for current rainfall.

(g) Records have shown no appreciable leakage through any dam which has been constructed date.

(775) BACKWATIR EFFECT OF RESERVOIRS ON SMALI TRIBUTARIIS.

(d) Field investigation; operation.

(e) On small tributaries automatic crest markers were located to record crest elevations reached by tributary floods. Profiles obtained before filling a reservoir are compar with those for similar discharges after filling to obtain backwater effect.

Hydraulic Investigations Section.

(733) HENDERSON COUNTY WEIR CALIBRATION.

(d) Experimental; design.

(e) Studies were made on a 1:5 model of a modified Columbus deep-notch weir with upstream silting basin.

(g) iatings for various amounts of silting were determined and a modified silting basin developed.

(h) Final report completed.

(734) WHITS CREEK SUSP INUED SEDIMTNT SAMPLIR.

(d) Experimental; for design.

(e) Full-scale studies were made to develop a continuous sampler which would collect $1 / 10$ of any discharge between 0.7 and $24 \psi_{4}$ cfs.

(g) Sampler developed retains 1/105,000 part of total stream discharge.

(h) Final report completed.

(765) EVAPORATION IN THE TENNESSEE BASIN.

(d) Field investigation; applied research.

(e) To provide data for estimating reservoir losses and derive a general rule, applicable to the Basin, permitting computation of evaporation from pans at six locations in Bas: together with standard meteorological readings.

(h) Complete sumnary of evaporation data appears in 1950 annual issue of "Precipitation il Tennessee River Basin", and also in Report No. 0-5164, "Ivaporation in Tennessee Rives Basin."

(768) PRECIPITATION IN TENNESSET RIVIR BASIN.

(d) Field investigation; basic research.

(e) A cormprehensive study of rainfall and other weather phenomena for purposes of water d: patching and improvements in water control; storm studies as related to maximum preci] tation, rainfall-runoff, spillway design and operation, etc.

(h) Monthly bulletin, "Precipitation in Tennessee River Basin." Also annual sumnary.

(777) RUNOFF-SILT INVESTIGATIONS ON SMALI NATERSHEDS.

(d) Field investigation; basic and applied research.

(e) To evaluate hydrologically existing or changed land-use practices or management. Dat: are obtained on rainfall, runoff, and soil loss, and in some instances include ground. water levels and soil moisture.

(h) Progress report for Henderson County runoff-erosion project in preparation. Report $N_{1}$ 0-5163, "Effect of 15 years of forest cover improvement upon hydrologic characteristic of White Hollow Watershed." June 1951. 
EFFECT OF ALTITUDE UPON RA INFALL.

Field investigation; basic research.

At four locations, rainfall data have been or are being collected. The stations are arranged in series at varying elevations, up one side of a ridge and down the other, so that exposure as well as altitude will be reflected in the result.

MAXIMUM POSSIBLE PRECIPITA TION IN TENNESSEE VALLEY.

Cooperative with U. S. Weather Bureau.

Theoretical; applied research.

Hydrometeorological analysis of large storms with upward adjustments of controlling

factors to maximum limits as applied to the Tennessee Valley and subdivisions.

Results to be published as one of current series of hydrometeorological reports by the

U. S. Weather Bureau and cooperating agencies.

MONTHLY EVALUATION OF GROUIND-TIATER STORAGE.

Theoretical; operation.

By analysis of current records of stream discharge, the volumes of runoff in ground-water and channel storage are determined for use in operation of multi-purpose reservoirs. Results reported monthly within the organization.

SNOWFALI IN GREAT SMOKY MOUNTAINS.

Cooperative with U.S. Weather Bureau and National Parks Service.

Field investigation; basic research.

Daily observations of snowfall, its water equivalent, temperature, and relative humidity at altitudes from 1400 to 6300 feet.

Discontinued May 11, 1951.

Processed data available through cooperating agencies.

WIND VEIOCITIDS AND DIRECTIONS--WHITETOP MOUNTAIN.

Cooperative with U. S. Weather Bureau and Radio Station WOPI, Bristol, Tenn.

Field investigation; basic research.

In connection with possible wind-power installations, a wind travel and direction recorder has been installed on a radio tower 150 feet above ground and 40 feet above the treetops at the mountain summit, elevation 5600.

) Discontinued June 2, 1951.

Complete sumnary of data from Sept. 1949 to Dec. 1950 appears in 1950 annual issue of "Precipitation in Tennessee River Basin."

RESHRVIR SLDIMENT DENSITY SAMPLER.

Cooperative with Federal Inter-Agency River Basin Committee, Subcommittee on Sedimentation.

Experimental; applied research, design, operation, development.

A device is being developed for making in-place density measurements of deposited reservoir sediment. Principle is that shielding of a radioisotope varies with mass between source and metering point.

Special Investigations Unit.

SEDTMENTATION OF EXISTING RESERVOIRS.

Field investigation; basic research.

Selected ranges in reservoirs are probed and sounded, volumetric samples are collected and analyzed, quantity and distribution of sediment are computed to determine deposition by stream, probable life of reservoir, effect of sediment storage on navigation channels and sedinentation of downstream reservoirs, and probable sedimentation in future reservoirs. 
UNIVERSITY OF BRITISH COLUMBIA, Hydraulics Laboratory.

(1044) FRASER RIVER MODEL.

(b) Cooperative with Department of Public Works of Canada, National Research Council of Canada, and University of British Columbia.

(c) Mr. J.H. Parkin, National Research Council, Ottawa, Canada.

(d) Experimental; to assist in problems of river regulation and control.

(e) An erodible-bed tidal model to study methods of maintaining stable navigational chas with a minimum of dredging and river regulation. Horizontal scale, 1:600; vertical scale, 1:70. Flume studies on bed-load movement are being carried out concurrently the Hydraulics Laboratory.

(h) Progress and technical reports submitted periodically to the National Research Coum of Canada.

ÉCOLE POLYTECHNIQUE DE MONTREAL, Hydraulics Laboratory.

(266) HYDRAULIC MODEL STUDIES OF DIFFERENT SPILIWAY PROFILES.

(b) Laboratory project.

(c) Prof. Raymond Boucher, École Polytechnique de Montreal, Montreal 18, Canada.

(d) Experimental; applied research.

(e) To establish a comparison between the discharge capacities of different spillway des Studies are made on concrete models of existing and recommended spillway profiles. Pressure distribution on spillway faces and coefficients of discharge are determines various heads up to the designed head. The effect of gate piers of various design $j$ also investigated. Seven different profiles have been studied, including two modif: tions of the Creager-Justin profile upstream of crest line.

(268) CALIBRATION TESTS OF A SHARP-CRESTED PARABOLIC WEIR.

(b) Laboratory project.

(c) Prof. Raymond Boucher, École Polytechnique de Montreal, Montreal 18, Canada.

(d) Experimental; applied research.

(e) To obtain the head-discharge curves and head-discharge coefficient curves for a shar crested parabolic weir (2l-inch maximum width by 18-inch maximum height) having a ca city of $3 \mathrm{cfs}$. The influence of viscosity is also being investigated. This weir is be used in a new flume for model testing and open channel studies.

(791) NEW METHOD OF UTILIZING THE WATER HAMMER FOR THE DETECTION OF LFAKS IN PIPES.

(b) Laboratory project.

(c) Prof. Andre Leclerc, École Polytechnique de Montreal, Montreal 18, Canada.

(d) Experimental; applied research.

(e) To develop a very sensitive recorder for pressure waves in pipes to be used for the tion of leaks in distribution systems. The sensing element is made of a cylinder ta to the pipe. The wire wound around the cylinder acts as a strain gage in the measur of the pressure variation produced in the pipe by ter hammer. A cathode-ray oscil graph is now being developed to register the deformation of that cylindrical strain 
ANAL RESEARCH COUNCIL, Division of Mechanical Engineering.

Inquiries concerning Projects Nos. 1286 to 1288, incl., should be addressed to the Director, Division of Mechanical Engineering, National Research Council, Ottawa, Canada.

1) FRASER RIVER MODEL.

1) See page 166 .

1) A brief description appeared in the Quarterly Bulletin of the Division of Mechanical Engineering, No. 1951-2.

j) MODEL STUDIBS OF A DAM ON THE TOBIQUE RIVER.

ग) New Brunswick Resources Development Board.

1) Experimental; for design.

2) A 1:50 scale model of a proposed dam, spillway, and power plant together with a portion of the river channel was constructed to determine flow conditions at the entrance of a fishway. The probable effect of different operating procedures on scour below the dam was studied.

:) Completed.

3) Report being prepared.

7) MODEL STUDIIS OF SPILIWAY FOR DAM ON THE MAYO RIVER.

D) Department of Resources and Development.

1) Experimental; for design.

a) 1:50 models of two alternative designs of spillway and channel were studied to determine the capacity, turbulence, and height of side walls for maximum flow.

f) Completed.

g) Report being prepared.

3) MODEL STUDIUS OF TYPICAL SMA LL FISHING CRAFT.

ग) Laboratory project.

d) Experimental; development.

a) A series of models of fishing craft, typical of those used on the west cos it, is being studied to obtain design data and to improve the form of the hulls.

f) Suspended.

N'S UNIVERSITY, Hydraulics Laboratory.

8) TIDAL MODEL OF STRAIT OF CANSO.

b) Department of Transport, Dominion Government, Ottawa.

c) Prof. D. S. Ellis, Queen's University, Kingston, Ontario, Canada.

d) Applied research.

e) Experimental study of effect of dam in the Strait.

if) Completed.

9) WATIR HAMMER.

b) Queen's University Science Research Committee.

c) Prof. F. M. Wood, Queen's University, Kingston, Ontario, Canada.

d) Experimental; applied research.

e) Study of effects of pipe friction on water hammer wave. Pipe 2-inch diameter, 100 feet long. Using electronic recording of waves.

f) Suspended. 
(1537) PITOT TUBE.

(b) Queen's University Science Research Committee.

(c) Prof.R.J. Kennedy, Queen's University, Kingston, Ontario, Canada.

(d) Experimental.

(e) Study of the efficacy of a cubic tipped pitot tube for measurement of flows in pipes

UNIVERSITY OF TORONTO, Department of Mechanical Engineering.

Inquiries concerning Projects Nos. 1538 to 1543, incl., should be addressed to Prof. G. Ross Lord, University of Toronto, Toronto 5, Canada.

(1289) DISCHARGE CHARACTERISTICS OF WEIR TYPE SPILLWAYS.

(b) Laboratory project.

(c) Prof. L. E. Jones, University of Toronto, Toronto 5, Canada.

(d) Experimental; applied research for master's thesis.

(e) A continuing research carried on with a view to systematizing discharge characteristj for spillways having various pier spacings and proportions.

(1538) MODEL STUDY OF SUMMT CONTROL DAM.

(b) Canadian Brazilian Services, Limited.

(d) Experimental; design.

(e) A scale model of the existing Summit Control Dam was tested to overcome scour below $t$ spillway.

(f) Completed.

(g) Reported to sponsor.

(1539) MODEL STUDY OF A PULPWOOD HOIDING BOOM.

(b) Quebec North Shore Paper Company.

(d) Experimental; design.

(e) A section of the Manicouagan River, Province of Quebec, was built in a model to a sca of 1:400 horizontal and 1:100 vertical. The purpose of the tests was to determine th. best location of a holding boom and jack-ladder site. Measurements of velocity were tained with a miniature current meter and pulp-wood movement was studied by the use $c$ half matches to represent model logs.

(f) Completed.

(g) Reported to sponsor.

(15L0) MODEL TEST OF ISIAND FALIS DAM, ABITIBI RIVER.

(b) Abitibi Power and Paper Company, Limited.

(d) Experimental; design.

(e) To design an energy dissipator for an existing dam.

(1541) CAVITATION IN BUTTERFIY VALVES.

(b) Laboratory project.

(d) Experimental; applied research and for master's thesis.

(e) Brass sections of butterfly valves were placed in a venturi-type cavitation channel.

(f) Completed. 
2) AN EXPER IMENTAL INVESTICATION OF THE CONTROL OF SIPHONIC FLOW IN WATER MAINS BY THE USE OF AIR AT ATMOSPHYR IC PRESSURE.

D) Laboratory project.

i) Experimental; applied research for master's thesis.

e) Tests are being conducted to determine the effect of air in solution and supplied air on the operation of a siphon.

3) INVESTICA TION OF IOSSES IN BUTTERFIY VALVES.

ग) Laboratory project.

d) Experimental; applied research for master's thesis.

e) A wooden model of a butterfly valve disc was placed in plastic piping and tested under various conditions of setting, the flow medium being air.

f) Completed.

g) Valves were tested with the disc thickened and faired at the outer diameters near the shaft, with streamlined tail-pieces and with pipe constrictions upstream and downstream from the valve. The effect of an elbow just below a valve was also studied. 
The foreign publications which have been received by the agencies below are available loan, unless otherwise indicated.

U. S. DEPARTMENT OF THE ARMY, CORPS OF INGINEERS, Waterways Experiment Station.

Direct inquiries to The Director, Waterways Experiment Station, Corps of Engineers, P. 0. Box 631, Vicksburg, Miss.

\section{ARGENTINA}

San Juan, Argentina. Instituto de Hidraulica. Facultad de Ingenieria.

\section{AUSTRALIA}

Baird, J. M. and McIllwraith, J. F.

AUSTR IA

Grzywienski, Anton

\section{BEIGIUI}

International Congress of Navigation. 17th Lisbon, 1949.

International Congress on Harbor Engineering, Ist. Antwerp, 1949.

Lamoen, J. and Robberecht, 0 .

Lamoen, J.
"Chimeneas de equilibrio." (Surge tanks.) A Bibliography San Juan, no date. (In various languages.)

"Spillway provision in dams controlled by Metropolitan Wat Sewerage and Drainage Board, Sydney, N.S.W." Paris, no da (Fourth International Congress on Iarge Dams, New Delhi, I! R.1. Question No. 12.) (In English.)
"Anti-vacuum profiles for spillways of large dams." Paris no date. (Fourth International Congress on Large Dams, $\mathrm{Ne}$ Delhi, 1951. R.19. Question No. 12.) (In English.)

Annales des Travaux Publics de Belgique, Vol. 103, Oct. 19!

"Account of the XVIIth Congress." Brussels, General Secre of the Association, 1949. (In English.)

"Haventechniek." (Harbor engineering.) Antwerp, 1949. (: Dutch, Flemish, and French.)

"Appareil electronique pour l'enregistrement de niveaux d'، dans un modele a echelle reduite de cours d'eau." (Electr, water-level recorder for reduced-scale models.) Bruxelles 1951. Reprinted from Annales des Travaux Publics de Belgii April 1951. (In French, with English translation.)

"Ia collaboration du laboratoire de recherches hydraulique: l'activite de l'ingenieur civil des constructions." (The contribution of hydraulic research laboratories to the act: ties of civil engineers in construction.) no date. Taken from Bulletin de Centre d'Etudes, de Recherches et d'Essai: Scientifiques des Constructions du Cenie Civil et d'Hydrau: que Fluviale, Vol. 4, 1949. (In French.)

BRAZIL

Andreoni, Aldo

"O Rio Tocantins sua navegacao e seus barcos." (The Tocan River, its navigation and ships.) Sao Paulo, Brazil, Inst to de Pesquisas Tecnologicas, 1950. Reprinted from Revist Engenharia, Nov., Dec., 1950. (In Portuguese.) 
$\therefore \mathrm{DA}$

Blench, T.

Canada Dominion Water and Power Bureau

Canada Dominion Water and Power Bureau

Montague, J.R.
"Hydraulics of sediment-bearing canals and rivers." Vancouver, B.C., Evans Industries Itd., 1951. (In English.)

"Surface water supply of Canada, Pacific drainage, British Columbia and Tukon Territory, 1944-46." Water resources paper No. 102, 1950. (In English.)

"Surface water supply of Canada, Atlantic drainage (South of St. Iawrence River), New Brunswick, Nova Scotia, and Prince Edward Island, 1946-48." Water resources paper No. 104, 1951. (In English.)

Canadian Journal of Research, Section F, Vol. 28, No. 10, October $1950+$.

"Engineering aspects of the Ottawa River power developments." 1950. From Engineering Journal, Vol. 33, No. 10, p. 850-863, October 1950. (In English.)

Revue trimestrielle Canadienne, Vol. 36, No. 143, Fall 1950 +. (In French and English.)

"Sbornik." (Bulletin.) 1947. Praha, 1948. (In Czech; Summaries in English and French.)

"Meddelelser." (Reports.) Kobenhavn, Kommission; H. Hagerups Boghandel. (In Danish.)

No. 7 Bdcher, S. B. "Vandkraftens Udnyttelse." (Utilization of hydraulic power.) 1942.

No. 8 Bdcher, S. B. "Vandmoller og andre vandkraftudnyttelser i Ribe Amt." (Water mills and other utilization of hydraulic power in Ribe County.) 1944.

No. 9 Schou, Axel. "Det marine forland." (The marine foreland.) 1950.

AND

Barber, N. F.

Bowden, K. F. and

Proudman, J.

Brunn, Per
"The behavior of wes on tidal streams." 1949. From Royal Society, Proc., Vol. 198, No. 1052, Series A, p. 81-93, July 2, 1949. (In English.)

"Observations on the turbulent fluctuations of a tidal current." 1949. From Royal Society. Proc., Vol. 199, No. 1058, Series A, p. 31l-327, Nov. 7, 1949. (In English.)

"The Danish Westcoast; littoral drift problems and measures against coast erosion." 1950. From the Dock and Harbor Authority, Vol. 31, No. 359, p. 163-167, Sept. 1950. (In English.)

Civil Engineering and Public Works Review, Vol. 45, No. 532, October $1950+$. 
Croker, G. N.

Fox, C. S.

Lowe1l, S. C.

Minikin, R. C. R.

Proudman, J.

Williamson, J.

\section{FINIAND}

Renquist, $H$.

Saarivirta, N.

\section{FRANCE}

Biesel, F.
Civil Engineer's Review, October $1950+$.

"Records of flows in the River Wye System, as determined current meter measurements, with a note on flood wing arrangements." Journal of the Institution of Water Engin Vol. 5, No. I, p. 39-97, February 1951. (In English.)

Dock and Harbour Authority, Vol. 31, No. 360, October 195( Engineer, Vol. 190, No. 4941, October 1950 +.

Engineering, Vol. 170, October $1950+$.

"The transportation and depositing of soil materials by $f$ : ing and evaporating water." Paris, no date. (Fourth Int national Congress on Large Dams, New Delhi, 1951, R.18. Question No. I4.) (In Inglish.)

Geotechnique, Vol. 2, No. 2, December 1950 +. (In Englis!

Institution of Civil Engineers, Journal, Vol. 35, No. I, November $1950+$.

Journal of the Junior Institution of Engineers, Vol. 61, I October $1950+$

"Gravity waves of finite amplitude." London, Office of $\mathrm{N}$ : Research, 1950. (In English.)

"Floating and foundationless breakters." 1948. From $E_{y}$ eering, p. 577-579, Dec. 17, 1948; p. 604-605, Dec. 24, Is (In English.)

"On the turbulence of a tidal current." 1940. From Roya: Society, Proc., Vol. 176, No. 967, p. 449-468, Oct. 27, I! (In English.)

"Round-crest, syphon and trumpet shaft spillways." Paris no date. (Fourth International Congress on Iarge Dams, $N$ Delhi, 1951. R.38. Question No. 12.) (In English.)

"Suomen sisavedet." (Inland waters of Finland.) Helsink: 1951. (In Finnish.)

"The arrangement and selection of spillway openings and $t$ porary outlets in Oulujoki River." Paris, no date. (Fou International Congress on Iarge Dams, New Delhi, 1951. R Question No. 12.) (In English.)

Annales des Ponts et Chaussees, No. 5, Sept.-Oct. $1950+$.

"Calcul de l'amortissement d'une houle dans un liquide vi: de profondeur finie." (Calculation of wave damping in a cous liquid of known depth.) 1949. Reprinted from Ia Hor Blanche, No. 5, Sept.-Oct. 1949. (In French.) 
$1, F$

, C. and

S, E.

de, I.

onn, G.

sen, A.

e, G. and

n, $\mathrm{X}$.

$\mathrm{y}, \mathrm{A}$.

t, F.

$t, F$
"Etude theorique de la houle en eau courante." (Theoretical study of wave in running ter.) 1950. Reprinted from Ia Houille Blanche, numero special A, May 1950. (In French.)

"Calcul pratique de l'amplitude de la houle diffractee derriere une jettee semi-indefinie." (Diffraction of water waves on the lee side of a jetty.) 1951. Reprinted from Ia Houille Blanche, No. 1, Jan.-Feb. 1951. (In French.)

"Barrages-deversoirs a seuil Creager deprime." (Diversiondams with depressed "Creager" crest.) 1951. From Ie Genie Civil, Vol, 128, No. 4, p. 69-72, Feb. 1951; Vol. 128, No. 5, p. 86-89, March 1951. (In French.)

Ie Genie Civil, Vol. 127, No. 19, October $1950+$.

"Etude della mise en regine des ecoulements sur les ouvrages a forte pente. Application au probleme de l'entrainement d'air." (Study relative to the determination of flow regimes for installations with steep slope." Application to the problem of air entrainment.) Grenoble, 1951. (In French.)

Ia Houille Blanche, Vol. 5, No. 5, Sept.-Oct. $1950+$.

"Contribution a l'etude des pertes de charge continues dans les conduites circulaires." (Contribution to the study of continuous losses of head in circular conduits.) no date. (In French.)

"Etude sur modele reduit della modification du cours du Rhin au droit de Strasbourg." (Model study of channel improvement of the Rhine at Strasbourg.) Strasbourg, Ia Navigation du Rhin, 1950. (In French.)

"Note sur l'entrainement des materiaux par charriage." (Note on bed load movement.) 1949. Reprinted from Ia Houille Blanche, numero special A/1949. (In French.)

"Pulsometre hydrodynamique." (Hydrodynamic pulsimeter.) 1950. Reprinted from Ia Houille Blanche, No. 6, Nov.-Dec. 1950. (In French.)

Revue generale de l'hydraulique, No. 59, Sept.-0ct. $1950+$.

"Etude experimentale du deferlement de la houle." (Experimental study on the break of waves.) 1950. Reprinted from Ia Houille Blanche, No. 3, May-June 1950. (In French.)

"Houle en profondeur variable relation entre l'amplitude et la vitesse de groupe." (The wave in varying depth; the relationship between the amplitude and the group velocity.) 1949. Reprinted from Ia Houille Blanche, No. 6, Nov.-Dec. 1949. (In French.)

"Trajectoires internes dans un clapotis partiel." (Trajectories of particles with a partial clapotis.) 1950. Reprinted from Ia Houille Blanche, No. 4, July-Aug. 1950. (In French.)

Travaux, Vol. 34, No. 192, October $1950+$. 
Valembois, J.

Van Wetter, I.

Wyart, P.

\section{GERIANY}

Press, H.

\section{HUNGARY}

Bogardi, J.

\section{INDIA}

Ahmad, M.

Indian Institute of Science, Bangalore, India. Dept. of Power Engineering, Hydraulics and Civil Engineering Section.

Central Board of Irrigation.

Central Board of Irrigation.

Central Board of Irrigation.

Central Board of Irrigation.
"Un manometre enregistreur de pressions sousmarines pour determination des caracteristiques de la houle par la me des variations de pression en profondeur." (The determi of wave characteristics by measurements of deep pressure tions.) 1949. Reprinted from Ia Houille Blanche, numer special B, 1949. (In French.)

"Evacuateur de crues." (A flood outlet.) Paris, no dat (Fourth International Congress on Large Dams, New Delhi, R.10. Question No. 12.) (In French, with English summa

"Monographie hydrologique du Guil affluent de la durance (The monography of the Guil River.) 1950. Reprinted fr La Houille Blanche, special No. A, 1950, (In French.)

Die Bautechnik, Vol. 27, No. 10, Oct. $1950+$.

"Mitteilungen aus dem Institut fur Wasserbau (Wasserbaul torium) der Technischen Universitat Berlin-Charlottenbur (Comnunications from the Institute for Hydraulics (Labor for Hydraulic Research) of the University of Technology, Berlin-Charlottenburg.) 1950. (Berlin. Technischen Ho Institut fur Wasserbau. Mitteilung $\mathrm{nr}$. 37.) (In German

"Lebegtetett Hordalekmozgas a Tisza Zahony-Razompusztai Szakaszan." (Suspended silt transportation by the Tisza on the Zahony-iazompuszta Section.) Budapest, 1950. (I Hungarian, with English summary.)

Vizugyi Kozlemenyek (Hydraulic Proceedings). No. 1-2/19 3-4/1950. (In Hungarian; summaries in various languages

"Some aspects of the design of weirs or canal falls in $r$ to scour." Iahore, 1951. Reprinted from Punjab Enginee Congress, Lahore, 1951. Proc., p. 33-45. Paper No. 289 (In English.)

"Research publication." (In English.)

No. I, Annual Report, 1950.

Abstracts, No. 126, October $1950+$.

"Engineering organizations and societies in India." Pop series, leaflet No. 6, 1950. (In English.)

"Irrigation in India through ages." Popular series, lea No. 7, no date. (In English.)

Journal, Volurne 7, No. 6, November $1950+$. 
entral Board

if Irrigation.

entral Waterpower

rrigation and

avigation Research

tation, Poona.

irrigation Research

tation, United

rovinces of Agra

nd Oudh.

unjab. Irrigation esearch Institute.

est Bengal. River esearch Institute.

lilan. Regio 'olitechnico. stituto di draulica e ostruzioni drauliche.
"International engineering conferences, Journal, special issue, New Delhi, January 1951." 1951. (In English.)

Research publication. (In English.)

No. 14 Annual report (technical), 1948, 1949.

"Annual report on research progress during the year 1949." Uttar Pradesh, India. 1950. (Technical Memorandum No.20.) (In English.)

"Report for the year ending 1949." Lahore, 1950. (In English.)

"Annual report." Alipore, West Bengal Government Press. (In English.)

On 1949 report: Publication No. 5.

on 1950 report: Publication No. 6.

Memorie e studi. (In Italian.)

No. 83, Marchetti, Mario. "Tubazioni per liquidi." (Piping for liquids.) 1950.

No. 84, Marchi, Guilio de. "Carateristiche idrologiche e idrauliche dei Grandi Laghi Subalpini." (Hydrological and hydraulical characteristics in the Large Sub-Alpine Lakes.) 1950.

No. 85, Gentilini, Bruno. "Ricerche sui canali degli impianti del medio adige." (Research on the channels of the hydraulic power plant installations in the Middle Adige (River). 1950.

No. 86, Marchi, Guilio de. Mipercussioni della regolazione del Lago Magiore sulle Piene del Lago e Su Quelle del Ticino a Sesto Calende." (Repercussions of the regulation of the Maggiore Lake on the high water of the lake and upon its Ticino source at Sesto Calende.) 1950.

RIANDS

ndel, T. H. van.

ssociation Interlationale pour :echerches Hydrauliques.

ichunfeld, J. C.
"Provenance, transport and deposition of Rhine sediments; a heavy mineral study on river sands from the drainage area of the Rhine." Wageningen, Netherlands, H. Veenman and Zonen, no date. (In English.)

"Recherches Hydrauliques 1949." (Hydraulic Research 1949.) Vol. 5, August 1950. (In French and English.)

De Ingenieur, 62nd year, No. 40, October 1950 +. (In Dutch.)

"Propagation of tides and similar waves." Gravenhage, Staatsdrukkerij - en Uitgeverijbedrijf, 1951. (In English.) 


\section{NEW ZEAIAND}

Benham, A. D.

Furkert, F. W.

POR TUGA L

Abecasis, C. K.

SWEDEN

Hellstrom, B.

Stockholm. Tekniska Hogskolan, Vattenbyggnadsinstitutionen.

\section{SWITZERLAND}

Meyer-Peter, E. and Mbller, R.

Meyer-Peter, E. and Mller, R.

Meyer-Peter, E. and Muller, $\mathrm{R}$.

\section{YUGOSIAVIA}

Joksimovic, M. T.
"The estimation of extreme flood discharges by statistica methods." Wellington, Ferguson and Osborn, Ltd., 1950. lished in New Zealand Institution of Engineers, Proc., Vc p. 119-187, 1950. Reprinted for the Soil Conservation ar Rivers Control Council, Wellington, C. I. (In English.)

"Tidal compartments, their influence on dimensions of har entrance channels." 1947. From New Zealand Institution Engineers, Proc., Vol. 33, p. 195-211, 1947. (In Englist.

"Protective works adopted to limit erosion along the open coast; how they work." Iisbon, 1949. (17th Internationa Congress of Navigation. Paper. Section II - Ocean Navig Communication I. Lisbon, 1949.) (In English.)

"The Israelites' crossing of the Red Sea." Stockholm, Ro Institute of Technology. Institution of Hydraulics, 1950 (In English.)

Bulletin. (In English.)

No. $25 \mathrm{Hellstrom,} \mathrm{B.} \mathrm{"Model} \mathrm{tests} \mathrm{for} \mathrm{Port} \mathrm{of} \mathrm{Malmo} \mathrm{impro}$ ments." 1950.

"Affouillements en aval des barrages." (Erosion downstre of dams.) 1948. From International Association for Hydr Structures Research. Report on the second meeting, Stock 1948. No. 29 (prelim.) (In French.)

"Eine formel zur berechnung des geschiebetriebs." (Formu for the computation of bed load movement.) Zurich, Ieema 1949. (Zurich. Eidgenossische Technische Hochschule. Versuchsanstalt fur Wasserbau und Erdbau. Mitteilungen n Reprinted from Schweiz. Bauzeitung, Vol. 67, No. 3, 1949 (In German.)

"Formulas for bed-load transport." 1948. From Internati Association for Hydraulic Structures Research. Report on Second Meeting, Stockholm, 1948. Appendix 2. (In Englis

"Flood peaks determination and choice of spillway capacit dams in Yugoslavia." Paris, no date. (Fourth Internatio Congress on Iarge Dams, New Delhi, 1951. R.17. Question 12.) (In English.) 
DEPARTMENT OF THE INTERIOR, BUREAU OF RECIAMATION.

Direct inquiries to the Chief Engineer, Bureau of Reclamation, Denver Federal Center, Denver, Colorado.

IA

Terres et Eaux. (Bimonthly.)

ALIA

Commonwealth Engineer. (Monthly.)

Soil Conservation Service of New South Wales. (Quarterly Journal.)

IA

Oesterreichische Wasserwirtschaft. (Monthly.)

UM

Bulletin du Centre Belge d'itude et de Documentation des Eaux. (Quarterly.)

IN

Institution of Civil Engineers. (Journal.)

Water and Water Engineering.

Water Power.

Revista Chilena de Ingeniera. (Bimonthly.)

La Houille Blanche. (Bimonthly.)

L'Eau. (Monthly.)

Le Genie Civil.

Memoires et Travaux de la Societe Hydrotechnique de France Paris.

Revue Generale de I'Hydraulique.

Parde, M.

L'abundance fluviale dans le bassin du Mississippi (The abundance of the stream flow in the Mississippi River basin), and Ies variations fluviales saisonnieres dans le bassin du Mississippi (Seasonal stream flow variations in the Mississippi River basin). Undated. (Approx. 1950.)

Parde, M.

Nouveatues sur le Hoang-Ho. (Recent notes on the Hoang-Ho.) 1951.

Parde, M.

Sur le mecanisme des transports solides effectues par les rivieres et sur les alterations correlatives des lit fluviqux. (The action of the transported solids in rivers and the changes in the stream beds.) 1951.

Parde, M.

Sur les regimes de quelques gros fleuves. (On the regimen of a few large rivers.) 1949. 
Societe Hydrotechnique de France. Stations hydrometriqu Francaises; nomenclature et caracteristiques, Region du Central. (French hydrometric stations in lassif-Central nomenclature and characteristics.) 1951.

GERMANY

Wasser und Boden. (Monthly.) Hamburg - British Zone.

HUNGARY

Vizugyi Kozlemenyek. (Monthly.)

INDIA

Journal of the Central Board of Irrigation. (Quarterly.

\section{ITALY}

De Marchi, Guilio

De Marchi, Guilio

Gentilini, Bruno

De Marchi, Guilio
Giornale del Genio Civile. (Monthly.)

L'Energia Ellettrica. (Monthly.)

Giornale del Genio Civile. (Monthly.)

Caratteristiche idrologiche e idrauliche dei grandi legh subalpini. (Hydrologic and hydraulic characteristics of great subalpine region.) Rome, 1950.

Ripersuccioni della regolazione del Lago Maggiore sulle del lago e su guelle del Ticino a sesto calende (The eff of the control of Lake Maggiore on its and Lake Ticino's une capacity). Milan, 1950.

Ricerche sui canali degli impianti del Medio Adige. (St) of the canal system of the Medio Adige.) Instituto di Idraulica e Costruzioni Idrauliche, Milan. 1950.

Canali con portata progressivamente crescente. (Channel: gradually increasing discharge.) Milan, 1941.

La Terre Marocaine. (Monthly.)

NORWAY

Association Internationale d'Hydrologie Scientifique. Ci rendus des seances et rapports; Assemblee generale d'Osl, Norway. 3 volumes. 1948.

SPAIN

Revista de Obras Publicas. (Monthly.)

Caminos Revista Tecnica. (Monthly.)

U. S. DEPARTMENT OF THE NAVY, OFFICE OF NAVAL RESEARCH.

A catalog of all foreign publications received is available in the Technical Informat Division, Naval Research Iaboratory, washington 25, D. C. 
NAL RESEARCH COUNCIL, Division of Mechanical Engineering, Ottawa, Canada.

TE

Annales des Ponts et Chaussees, Paris.

Ia Genie Civil, Paris.

Ia Houille Blanche, Grenoble.

Sonolet, Raymond

Recherches sur la genése de la turbulence dans les conduites en charge. Ministere de l'Air. Publications Scientifiques et Techniques, No. 246, 1950. (In French.)

${ }_{4} \mathrm{NY}$

Die Bautechnik, Berlin.

Hansa, Hamburg.

Planen und Bauen, Berlin.

Schiff und Hafen, Hamburg.

Annual report of the River Research Institute, West Bengal, 1949. Government of West Bengal, Directorate of Irrigation and Waterways, Publication No. 5, 1950.

IRLANDS

De Ingenieur. The Hague.

Schip en Werf. Wageningen.

Ingenieria Naval. Madrid.

Publications issued by the Statens Skeppsprovningsanstalt. The Swedish State Shipbuilding Experimental Tank, Gyteborg.)

Nordstorm, H. F. and Edstrand, Hans.

Nordstr $8 \mathrm{~m}, \mathrm{H} . \mathrm{F}$. and Edstrand, Hans

Nordstr\&m, H. F.
Propulsion problems connected with ferries. Med. No. 17. 1951. (In English.)

Model tests with turbulence producing devices. Med. No. 18, 1951. (In English.)

Some tests with models of small vessels. Med. No. 19, 1951. (In English.) 
Translations of foreign articles have been prepared at the laboratories listed belor are available on loan. Requests should be directed to the agency indicated.

ST. ANTHONY FALIS HYDRAUIIC LABORATORY, University of Minnesota.

Direct inquiries to $\nu_{r}$. Lorenz G. Straub, Director, St. Anthony Falls Hydraulic Labo Hennepin Island, Minneapolis 14, Minn.

Valembois, J.

"Etude d'un appareil permettant la reproduction de l'onde maree da modele d'estuaire." (Investigation of a device designed to simula tidal wes in a model estuary.) International Association for $\mathrm{Hy}$ lic Structures Research, Third Meeting, Grenoble, Sept. 1949. By Meir Pilch.

Miscellane ous

Investigation of airfield drainage, arctic and subarctic regions, II, Translation of selected topics, by Meir Pilch. (Sponsored by St. Paul District, Corps of Engineers, Department of the Army.) Is (Minor revisions suggested by the Office of the Chief of Engineers Corps of Engineers, Washington, D. C., are included in the final pi ing, 1950.) 140 pages, 96 illustrations.

Khomechivskaya, L. S. "O vremennom soprotivlenii szhatiyu vechnomerzlykh gruntov I I'da estestvennoi struktury." (The compressive strength of permafrost : ice in their natural states.) Project Report No. 26, St. Anthony I Hydraulic Laboratory, University of Minnesota, 54 pp., by Meir Pilc Nov. 1951.

U. S. DEPARTMENT OF THE ARMY, CORPS OF ENGINEERS, Waterways Experiment Station.

Direct inquiries to The Director, Waterways Experiment Station, Corps of Engineers, P. 0. Box 631, Vicksburg, Miss.

Blanchet, $\mathrm{Ch}$.

"Formation et destruction par un courant d'eau de massifs en pierre (Formation and destruction of stone masses by a water current.) Fr La Houille Blanche New Series, No. 2, March 1946. By William W. Ge Jr. Translation No. 50-5.

Iribarren, C. R. and Nogales y Olano, C.

Suquet, $F$.
"Generalizacion de la formula para el calculo do los diques de esco y comprovacion de sus coeficientes." (Generalization of the formuli calculation of rock-fill dikes and verification of its coefficients From Revista de Obras Publicas, Madrid. May 1950. By Arthur Harit Translation No. 51-4.

"Houle en profondeur variable, relation entre l'amplitude et la vit de groupe." (Waves in variable depth, relationship between the amp: tude and the group velocity.) From Ia Houille Blanche, Vol. 4, p. ? 843, 1949. By William W. Geddings, Jr. Translation No. 50-6.

\section{U. S. DEPARTMENT OF THE INTERIOR, BUREAU OF RECLAMATION.}

Direct inquiries to the Chief Engineer, Bureau of Reclamation, Denver Federal Center, Denver, Colo.

"Norske kraftverk i fjell." (Norwegian underground power plants.) Teknisk Ukeblad, Norway. No. 13, pp. 235-245, March 29, 1951. Trar lated by T. Rusletvedt, 1951. (Rough draft.) 
"Normy dopuskaemykh nerazmyvaiushchikh skorostei." (The maximum permissible average velocity in open channels.) Gidrotekhnicheskoe stroitelstvo, Moscow, U.S. S. R., No. 5, pp. 5-7, 1936. Translated by I. Mitten, April 1951. (Rough draft.)

DEPARTMENT OF THE NAVY, OFFICE OF NAVAL RESEARCH.

A catalog of translations made by this office is available in the Technical Information Division, Naval Rr.search Laboratory, Washington 25, D. C.

\section{ON PICTURES.}

A list of films illustrating various phases of fluic flow has been brought up to date by the Fluid Dynamics Committee of the American Society of Civil Engineers, and is available in mimeographed form. The list includes the title, source, availability, type, and a very brief description of each film. Copies of the list can be obtained by writing to Professor Walter I. Moore, Department of Civil Engineering, 173 Engineering Building, The University of Texas, Austin 12, Texas, or to the American Society of Civil Engineers at 33 West 39 th Street, New York 18, N. Y. 
ADVISORY COMMITTEE ON BASIC RESEARCH IN UNDERWATER BALLISTICS, Office of Naval Research, Department of the Navy.

Chairman, Eugene C. Cooper, U. S. Navy Radiological Laboratory, Hunters Point, San Francis Calif.

Purpose: (a) To plan an effective hydrodynamics research program; (b) to aid the coordir tion of research and development; (c) to arrange meetings of larger groups in order to discuss recent developments; (d) to edit and arrange for publication of reports; (e) to encourage publication of papers; (f) to encourage visits to laboratories and research facilities; and $(\mathrm{g})$ to keep the program alive and thereby attract qualified experts to $t$ field.

BUREAU OF ORDNANCE HYDROBALLISTIC ADVISORY COMMITTEE, Bureau of Ordnance, Department of the 1 Chairman, J. M. Robertson, Ordnance Research Laboratory, P. O. Box 30, State College, Pa.

Purpose: This committee is organized to advise the Bureau of Ordnance on basic and found tional research in hydroballistics.

COMMITTEE ON LETTER SYMBOIS FOR HYDRAULICS, American Standards Association, Y10.2. Chairman, J. M. Robertson, Ordnance Research Laboratory, P. O. Box 30, State College, Pa. Purpose: This committee is reviewing the 1942 Standard to determine what changes are required.

COMMITTEE ON TIDAL HYDRAULICS, Department of the Army; Corps of Engineers.

Chairman, Clarence F. Wicker, Distric' Engineer's Office, Philadelphia, Pa.

Purpose: (a) To evaluate the present state of knowledge of tidal phenomena of interest tc the Corps of Engineers; (b) to recommend program of study, investigation and research designed to provide the knowledge necessary to arrive at adequate solutions for the enginee ing problems associated with such tidal phenomena; and (c) to exercise technical supervis of the prosecution of the recommended programs.

COMMITTEE ON SURFACE DRAINAGE, Highway Research Board, National Research Council.

Chairman, Carl F. Izzard, Bureau of Public Roads, Washington 25, D. C.

Purpose: To coordinate research in hydraulics and hydrology as applicable to highway engineering.

RESEARCH COMMIT'TEES OF THE SECTION OF HYDROIOGY, American Geophysical Union. CHEMISTRY OF NATURAL WATERS.

Chairman, W. W. Hastings, Geological Survey, Washington 25, D. C. 


\section{NAMICS OF STREAMS.}

Chairman, J. W. Johnson, 244 Hesse Hall, University of California, Berkeley 4, Calif. TAPORATION AND TRANSPIRATION.

Chairman, A. Russell Croft, 2525 Madis on Ave., Ogden, Utah.

LACIERS.

Chairman, William 0. Field, Jr., American Geographical Society, Broadway at I5th Street, New York, N. Y.

ROUND WATER.

Chairman, Joseph F. Poland, Geological Survey, 2520 Marconi Ave., Sacramento 15, Calif. NFILTRATION.

Chairman, Lloyd L. Harrold, 1527 Denman Ave., Coshocton, Ohio.

AKES.

Chairman, Jack L. Hough, Department of Geology, University of Illinois, Urbana, Ill. AND EROSION.

Chairman, Harold V. Peterson, 502 Federal Building, Salt Iake City 1, Utah. HYSICS OF SOIL MOISTURE.

Chairman, Geoffrey B. Bodman, Division of Soils, University of California, Berkeley 4 , Calif.

'RECIPITATION.

Chairman, William C. Ackerman, Tennessee Valley Authority, Knoxville, Tenn. LUNOFF.

Chairman, Carl F. Izzard, Bureau of Public Roads, Washington 25, D. C. iNOW.

Chaiman, Forrest L. Rhodes, P. 0. Box 385, Lafayette, Calif.

IL ANU WATER DIVISION, American Society of Agricultural Engineers .

Chairman of Division, R. R. Poynor, Consumer Relations Department, International Harvester Jompany, 180 North Michigan Avenue, Chicago 1, Ill.

STEERING COMMITTEE.

Chairman, R. B. Hickok.

DOMMITTEE ON RURAL WATER SUPPLIES.

Chairman, E. I. Arnold.

Subcomittee on Water Conditioning, H. H. Beaty, Chairman. 
COMMITTES ON EROSION CONTROL.

Chairman, D. D. Smith.

COMMITTEE ON MECHANICAL APPLICATIONS OF SOIL CONSERVATION PRACTICES.

Chairman, A. J. Wojta.

COMMITTEE ON DRA INAGE.

General Chairman, J. G. Sutton.

Subcommittee on Depth and Spacing of Tile Drains, R. K. Frevert, Chairman.

Subcomnittee on State Drainage Laws, I. D. Mayer, Chaiman.

Subcommittee on Drainage of Irrigated Lands, M. R. Iewis, Chairman.

Subcommittee on Drainage Equipment, I. I. Saveson, Chairman.

Subcommittee on Specifications for Design and Construction of Tile Drainage, K. H. Beauchamp, Chairman.

COMMITTEE ON IRRIGATION.

General Chairman, M. R. Lewis.

Subcommittee on Sprinkler Irrigation, Aldert Molenaar, Chairman.

Subcommittee on Sprinkler Irrigation Research, E. H. Kidder, Chairman.

COMMITTEE ON PONDS AND RESERVOIRS.

Chairman, M. W. Clark.

HYDRAULICS DIVISION, American Society of Civil Engineers.

Purpose: The advancement and dissemination of knowledge relating to the occurrence of water in nature and its behavior in structures, water courses, and underground. In particular tr field of the Hydraulics Division shall embrace meteorology and hydrology as they affect the engineer, fluid mechanics in engineering usage, and applied hydraulics as a branch of engir: eering science which furnishes the basis for hydraulic design and for the practical use of water in the different specialized branches of hydraulic engineering.

EXECUTIVE COMMITTEE.

Chairman, Morrough P. O'Brien. Secretary, Albert S. Fry, Tennessee Valley Authority, Knoxville, Tenn.

CONMITTEE ON RESEARCH.

Chairman, Robert Y. Hudson.

Purpose: To initiate, organize, sponsor, and coordinate research in the hydraulic fi and to further the advancement of hydraulics through coordination of endeavor with related fields of fluid mechanics.

Subcomittee on Cavitation in Hydraulic Structures, Robert T. Knapp, Chairman. 
[TTEE ON HYDROIOGY.

iirman, Albert L. Cochran.

Purpose: (a) To stimulate in civil engineering practice the adoption of precepts, theories, and design methods progressively developed in the field of applied hydrology; (b) to sponsor activities designed to increase knowledge of that phase of the hydrologic rycle beginning with the causes of rainfall and ending with the accumulation of runoff into channel flow and percolation to the ground water table; (c) to maintain cooperation with the Section of Hydrology of the American Geophysical Union, and other groups representing hydrology and related fields of science; and (d) to encourage cooperation between federal, state, and private interests in establishing and maintaining facilities for obtaining hydrometeorological data.

ITTEE ON DESIGN.

airman, W. M. Lansford.

Purpose: To stimulate the accumulation and dissemination of hydraulic design methods, and of comparisons of predicted and measured flow characteristics, and to foster the reduction of research results to reliable design methods.

ITTEE ON PUBLICATIONS.

lairman, George H. Hickok.

Purpose: To review critically and edit papers submitted for publication in the Society publications, this to be done in accordance with the policies of the Society Committee on Publications, and to encourage and stimulate the preparation of papers for publication and presentation at sessions of the Division.

IT COMMITTEE ON FIOODS.

zairman, George R. Schneider.

Purpose: To promote the collection and compilation of data pertaining to floods in the United States, giving particular attention to the following: the interpretation of flood data; methods of flood control; hydraulic factors underlying the design of flood control works; problems arising from the operation of flood control works. Consideration is to be given to prevention of flood damage by methods othe $r$ than flood control.

NT COMMITTEE ON GROUND WATER.

hairman, Maurice L. Albertson.

Purpose: To study the physical laws governing the occurrence and movements of ground water and the engineering, economic, and legal aspects of its development, uses, and conservation.

NT COMMITTEE ON SEDIMENTATION.

hairman, Carl B. Brown.

Purpose: To study and report on problems connected with the erosion, transportation, and deposition of sediment in rivers, canals, reservoirs, and harbors; including methods of sediment control.

NT COIMITTEE ON SNOW, ICE, AND PERMAFROST.

hairman, A. F. Ghiglione.

Purpose: To advance basic research in, and to promote dissemination of knowledge of snow, land ice, sea ice, and permafrost. 
TECHNICAL AND RESEARCH COMMTTTEES, Society of Naval Architects and Marine Engineers.

\section{STEERIVG COMMITTEE.}

Chairman, Edward L. Cochrane, The Society of Naval Architects and Marine Engineers, 29 West 39th Street, New York 18, N. Y.

HYDRODYNAMICS COMIITTEE.

Chairman, Hollinshead de Iuce.

This committee issues annually a bulletin listing research projects in progress in $t$ United States related to naval architecture and marine engineering. Copies may be 0 tained by addressing the Secretary of the Society, Captain W. N. Ianders, USN (Retir The Society of Naval Architects and Marine Engineers, 29 West 39th Street, New York N. Y.

Subcomittee on Hydromechanics:

Analytical Ship Wave Panel, D. S. M. Davidson, Chairman. Seaworthiness Panel, B. V. Korvin-Kroukovsky, Chairman.

HULL STRUCTURE COMMITTEE

Chairman, Edward A. Wright.

SHIP'S MACHINERY COMMTTTEE.

Chairman, Douglas C. Macliillan.

COMMITTEE ON SEAWORTHINESS, American Towing Tank Conference.

Chairman, B. V. Korvin-Kroukovsky.

INTERNATIONAL ASSOCIATION FOR HYDRAULIC RESEARCH.

President, Iorenz G. Straub, Director, St. Anthony Falls Hydraulic Laboratory, Hennepin Island, Minneapolis 14, Minn.

The Association issues annually a bulletin listing hydraulic research in progress throu the world (excepting United States and Canada, and the Soviet countries). Copies may b. tained on subscription by addressing the Secretary, Professor J. Th. Thijsse, Raam 6I, Delft, Netherlands. 


\section{UNIVERSIIIY.}

During the past year the renovation of the hydraulic laboratory has been continued. Dr. Andre L. Jorissen has been appointed Head of the Department of Hydraulics and Hydraulic Engineering.

IVSTITUIE OF HYDRAULIC RESEARCH.

The Fifth Hydraulics Conference is scheduled for June 9-11, 1952. The general subject is The Sediment Problem, which is discussed under the topics of (1) entrainment and suspension, (2) measurement and analysis, (3) movement of bed load, and (4) scour and deposition. Guided tours of the Institute laboratories are scheduled. As in the case of previous conferences, a volume of Proceedings containing all papers plus a resune of discussions will be published.

\section{ETTE COLLEEE.}

The hydraulic laboratory, under the direction of Prof. William S. Lohr, is devoted solely to undergraduate instruction. A new laboratory will be provided in the engineering building now under construction.

\section{JRGAN SMITH CO.}

Mr. Emmett M. Lowry, Jr. is Hydraulic Laboratory Engineer of the Company. New testing equipment is being installed to facilitate the testing of pump-turbine models. This equipment will permit greater accuracy over a wider range of operating conditions.

\section{ANTHONY FALIS HYDRAULIC IABORATORY.}

Concurrently with a meeting of the Hydraulics Division, American Society of Civil Engineers, the International Association of Hydraulic Research will hold its next triennial meeting in Minneapolis, August 31 to September 4, 1953. The four topics selected for discussion are (1) density currents; (2) air entrainment by flowing water; (3) waves, beach erosion, and the hydromechanics of shore structures, and (4) fundamental principles of sediment movement in flowing water.

The Permanent Committee of the Association includes Lorenz G. Straub, President, United States; Wolmar Fellenius, Past President, Sweden; A. N. Khosla, Vice President, India; Pierre Danel, Vice President, France; J. Th. Thijsse, Secretary, Netherlands; M. Bayer, Czechoslovakia; B. O. Helstrßm, Sweden; C. C. Inglis, England; G. de Marchi, Italy; and E. Meyer-Peter, Switzerland.

\section{ERSITY OF WASHIINGTON.}

The hydraulic laboratory has been named the Charles W. Harris Hydraulics Laboratory in honor of Professor Harris who has retired.

\section{:RWAYS EXPERIMENT STATION.}

Much of the past year's work has been of a general nature to provide basic data for the development of design criteria. Particular emphasis has been placed on procurement of fie..d data, and an active program of collection of field data is in progress.

\section{JE LNIVERSITY.}

The new engineering building, which will contain the hydraulic laboratory, is still under construction. It should be completed within the year.

IERSITY OF INISCONSIN.

The Hydraulic and Sanitary Laboratory has undergone major reconstruction which makes better use of space. Two offices, an instrument room, a stock room, a conference room, a sanitary bacteriological laboratory, and new facilities for graduate students have been added. 
Accelerated motion

disks $(813) \ldots \ldots \ldots \ldots \ldots \ldots \ldots \ldots . \ldots 12$

spheres $(1104) \ldots \ldots \ldots \ldots \ldots \ldots \ldots \ldots . . . . .639$

virtual mass $(1310) \ldots \ldots \ldots \ldots \ldots \ldots . . \ldots 15$

Air entrainment

flunes $(100) \ldots \ldots \ldots \ldots \ldots \ldots . \ldots . \ldots 69$

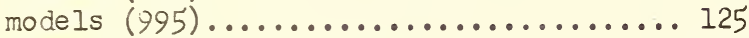

pipes $(1303) \ldots \ldots \ldots \ldots \ldots \ldots \ldots . . . . .68$

" (1311)......................... 15

turbines $(1305) \ldots \ldots \ldots \ldots \ldots \ldots \ldots . . \ldots \ldots 1_{4}$

Air pollution $(1283) \ldots \ldots \ldots \ldots \ldots \ldots . \ldots 162$

Airfield drainage

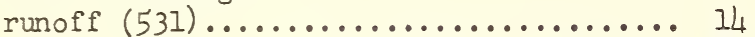

(1204)....................... 114

Airfoils, cascades (1ll8).............. 48

Airship, hydrodynamic coefficient $(1,08) \ldots 78$ Apparatus

channels rotating $(279) \ldots \ldots \ldots \ldots \ldots \ldots 3^{3}$

coast model basin (973)............... 108

cyclone, liquid-liquid (1141).........6 61

liquid-solid $(905)(906) \ldots \ldots .60$

flood forecasting (1010)............... 134

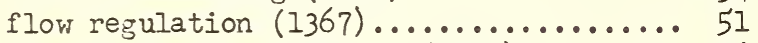

permeameter, wall effect (1172)........ 76

photo electric, sediment (1329)........ 26

" " " (1331)........ 27

pitch measurement, ship $\left(\mathrm{I}_{4} 04\right) \ldots \ldots \ldots . .77$

precipitation gage $(547) \ldots \ldots \ldots \ldots \ldots 28$

" ", radio (1012)......... 134

pressure recorder $(791) \ldots \ldots \ldots \ldots \ldots \ldots . \ldots 166$

propeller measuring (1411) ........... 78

rubber seal tester (1199) .............. 112

sand separator $(52) \ldots \ldots \ldots \ldots \ldots \ldots \ldots . \ldots 15$

" " (1330)................ 26

sediment sampler $(194) \ldots \ldots \ldots \ldots \ldots \ldots . \ldots 115$

" " (734)................. 164

sedimentation tank $(925) \ldots \ldots \ldots \ldots \ldots . .70$

stream gage (1013).................. 134

tank, electrolytic (470).............148

tilting design (1336).............. 32

towing carriage $(1520) \ldots \ldots \ldots \ldots \ldots \ldots . \ldots 152$

viscometer $(1090) \ldots . . . \ldots \ldots \ldots . . . . .29$

water tunnel $(79) \ldots \ldots \ldots \ldots \ldots \ldots \ldots . . . . .6$

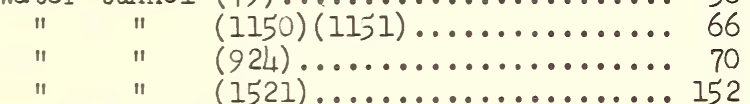

wave gages $(977) \ldots . . . \ldots \ldots . . . . . .109$ wave generator $(973) \ldots \ldots \ldots \ldots \ldots . \ldots 108$

$(1522) \ldots \ldots \ldots \ldots \ldots \ldots \ldots \ldots \ldots \ldots \ldots \ldots 152$

wave recorder, airborme $(1460) \ldots . . . . .110$

wave tank (399) ................... 107

wind tunnel (1081)................. 25

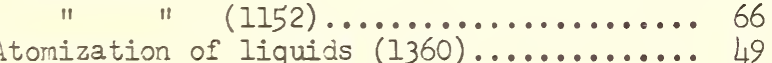

Backwater

constricted channels (1332)........... 27 " " (1486)(1487)....... 139

reservoirs $\left(775^{\circ}\right) \ldots \ldots \ldots \ldots \ldots \ldots \ldots . \ldots 164$

uniform channels (437)............... 135

Baffle piers, cavitation $(993) \ldots . . . . . .124$

\section{Barges}

design (1124) (1129)

resistance (585)

\section{Beaches}

artificial (976)

by-passing sand, inlets (975)

effect, jetties (970)

equilibrium profile (181)

model laws (184).

sand in suspension (1458)

shallow soundings (974).

structures, design (972)

wave action (47) (529).

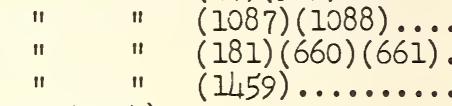

Benas (1304).

shear flow (1374).

Bibliography, ships (895)

Blow-out head (947).

Bodies of revolution (1532)

Boundary flow (1301)

Boundary layer

conduits (290)

laminar (1350) (1359)

open channels $(62)$.

" " (1100)

ships (1504).

slots (328).

surfaces $(854)$

turbulent

(627)

$"$

Breakwaters

(1388)

(1503).

pervious and impervious (998).

rubble-mound (257).

wave diffraction (47)

Bridge piers

back water (1332)

scour (1097)

" $(568)$
$"(306)$

the ory

$(1344)$

Bubbles

diffusion (1060)

ice sheets (1156)

oxygen transfer (580)

resorption (803)

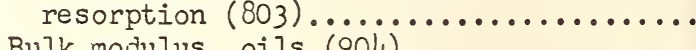
Canals

density currents (1482)

irrigation

linings (151)

seepage (820)

"

(1091) 
Is

our on curves (1501) ................. 47 illing basin (1497) ............... 146 llary flow

inds (1318)

'eway

fect on tides (1048).................. 167

tation

iffle piers (993).................. 124

sic research

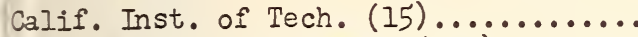
David Taylor Model Basin (711)........ 148

Iowa State Univ. $(79)(81) \ldots . . . . . . .36$

Mass. Inst. of Tech. (312) .......... 47

" $"$ " $"(579) \ldots \ldots \ldots \ldots \ldots . . .46$

Northwestem Univ. (326) ............ 59

Penna. State College (1386).......... 66 Waterways Experiment Station (993)..... 124 undary misalignment $(90) \ldots . . . \ldots . . .42$ bbles

air nuclei (804)...................

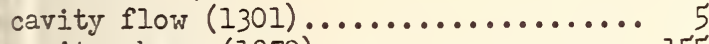

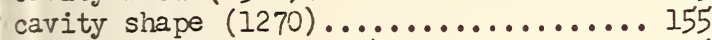
nduit contractions $(72) \ldots \ldots \ldots . . . . . .36$ namics of $(803) \ldots \ldots \ldots \ldots . . . \ldots \ldots$ te slots $(993) \ldots . . . \ldots \ldots . . . . . . . . .124$ iception $(1355) \ldots \ldots \ldots \ldots \ldots \ldots \ldots . . \ldots \ldots$

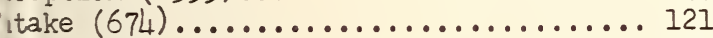

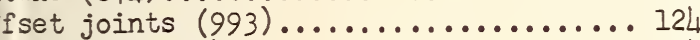

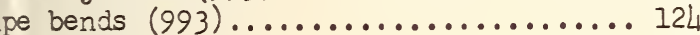

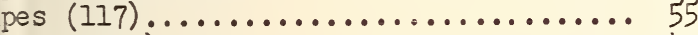

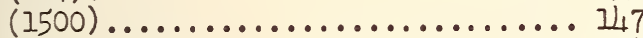

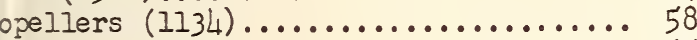
" $(605) \ldots \ldots \ldots \ldots \ldots \ldots \ldots . \ldots \ldots$

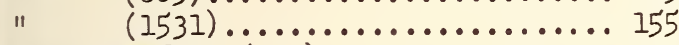
tating channels (279)................ 3 Luice gates $(79) \ldots . . . . . . . . . . . .36$ " $"$ (219).................. 117 jilling basin steps (993)............ 124

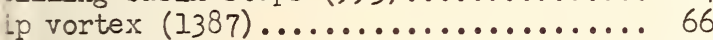

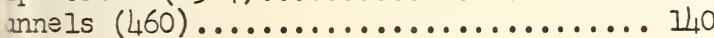
" (726)..................... 157

urbines

Francis (1056)

models (1133).

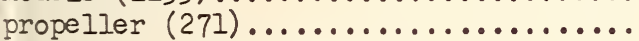
$(1054)(1055)$

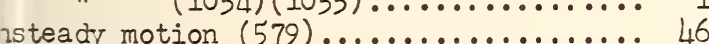

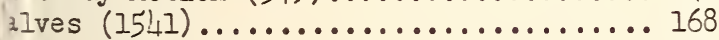

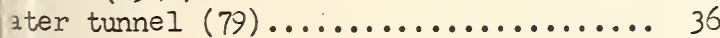
ities

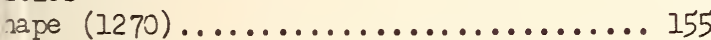

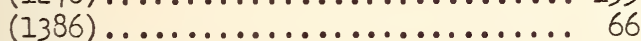

inel improvement

lood control

Allentom, Pa. (11469)............... 129

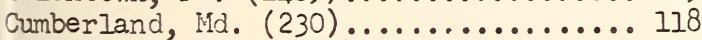

Farm Creek, Ill. (987) .............. 123

Hoosic River, Mass. (1211)........... 128

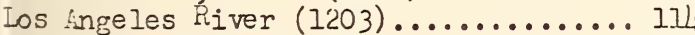

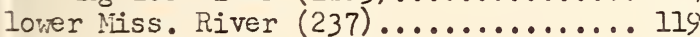

midcle Miss. River $(236) \ldots \ldots \ldots \ldots \ldots . . .118$
Channel improvement

navigation

Charlestom Harbor, Ia. (678) ........ 122

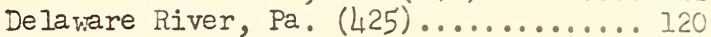

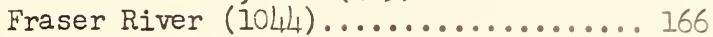

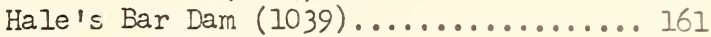
Iynnhaven Bay, Va. (672) ............ 12]. Miss. River, Kiss. (989) ............. 124 Raritan River, N. J. (679) .......... 122 Valdivia River, Chile (1468)......... 120 power development $(1470) \ldots . . . . . . . .129$ Channels (see Open channels)

alluvial (13].3).................... 20

backwater $(437) \ldots \ldots \ldots \ldots \ldots \ldots \ldots . . \ldots \ldots$ conservation linings (152) (153)........ 105

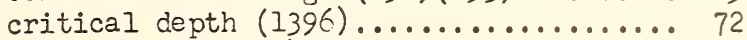

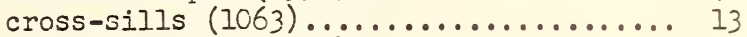
hydraulic jump (1493) ................ 145 meanders $(226) \ldots \ldots \ldots \ldots \ldots \ldots \ldots \ldots . \ldots \ldots$

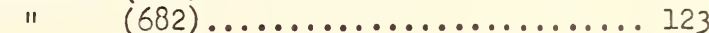

" (1313)..................... 20

pressure distribution ( 2356$) \ldots \ldots \ldots . . .49$

rotating flow $(279) \ldots \ldots \ldots \ldots . . . \ldots \ldots$

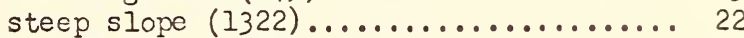
transitions $(1321) \ldots \ldots \ldots \ldots . \ldots \ldots . . \ldots 22$

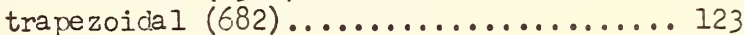

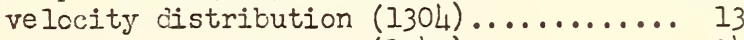

\section{Cofferdams}

(1343) ........... 34

Chief Joseph Dam; Wash. (408) .......... 110

Dalies Dam, Ore. $(1462) \ldots \ldots \ldots \ldots \ldots \ldots \ldots . \ldots \ldots$

McNary Dam, Ore. (189) ................ 110

Conduits

boundary layer (290) ................ 23

energy losses $(32) \ldots \ldots . . . \ldots . . . . . .99$

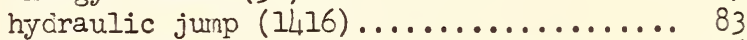

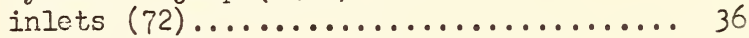

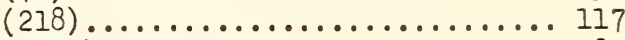

$(1417) \ldots \ldots \ldots \ldots \ldots \ldots \ldots \ldots \ldots \ldots . \ldots \ldots$

Narrows Dam, Ark. (420) .............. 120

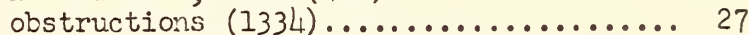

separation at expansions (289)......... 23

Corrosion

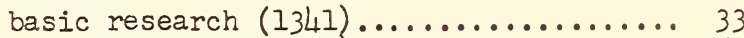

concienser tubes $(472) \ldots \ldots \ldots \ldots \ldots \ldots \ldots . \ldots 153$

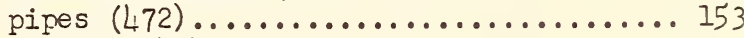

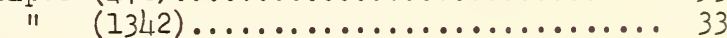

plumbing $(49) \ldots \ldots \ldots \ldots \ldots \ldots \ldots \ldots$

Culverts

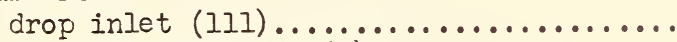

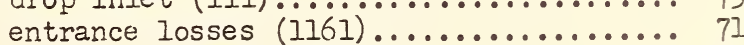

" $"$ (1383)............... 64

general research, inlets (1419) ........ 85

inlets, flaring ends $(1414) \ldots . . . . . . .79$

outlets, flaring ends (859)............ 43

Cylinders

vibrations (1517)........................

Dams

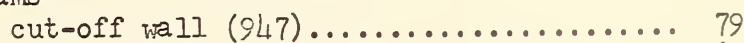

gallery drainage $(771) \ldots \ldots \ldots \ldots \ldots \ldots . \ldots 163$

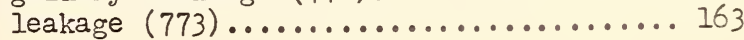


Density currents

basic research (8)................. 3

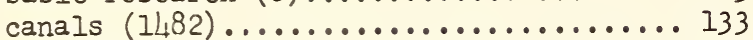

interface $(1163) \ldots \ldots \ldots \ldots \ldots \ldots \ldots . . . \ldots 71$

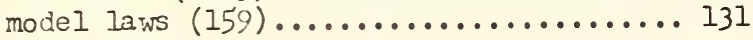

reservoir

model tests $(1098) \ldots \ldots \ldots \ldots \ldots \ldots . . . .635$

sedimentation $(307) \ldots \ldots \ldots \ldots \ldots . . . . .45$

suspended sediment $(8) \ldots \ldots \ldots \ldots \ldots . .3$

salt water intrusion

Delatare River $(425) \ldots . \ldots \ldots \ldots \ldots . . .120$

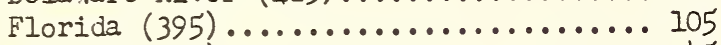

stability $(307) \ldots \ldots \ldots \ldots \ldots \ldots \ldots . . . \ldots 45$

Diffusion, heat $(822) \ldots \ldots \ldots \ldots \ldots . . .19$

particles in fluid (1331)............ 27

Disks, accelerated motion (813)........ 12

Draft tubes

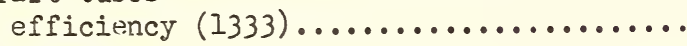

Drainage

Coachella Valley, Calif. (26).......... 8

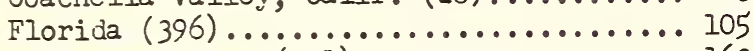
galleries, dams $(771) \ldots \ldots \ldots \ldots \ldots \ldots 163$

Imperial Valley, Calif. (390)........... 96

irrigated lands (1302)............... 8

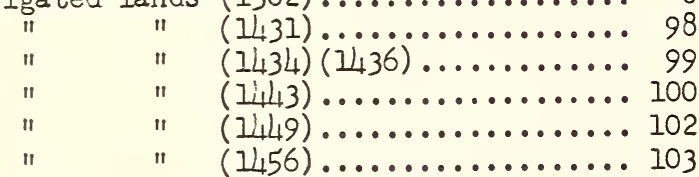

manual, irrigated lands (390)........... 96

San Fernando Valley, Calif. (391)....... 96

Drop structures $(1075) \ldots \ldots \ldots \ldots . . \ldots 20$

Electric analogi

surge tanks $(869) \ldots \ldots \ldots \ldots \ldots \ldots \ldots . . \ldots 46$

three-dimensional (72) ............... 36

valves $(1363) \ldots \ldots \ldots \ldots \ldots \ldots \ldots \ldots \ldots \ldots . \ldots \ldots$

Embankments (291).................... 26

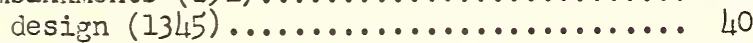

Entry, water

airplanes $(1405) \ldots . . \ldots \ldots \ldots . . \ldots \ldots 77$

reference book $(1530) \ldots \ldots \ldots \ldots \ldots \ldots . \ldots 155$

Erosion control

contour irrigation (393)............. 96

streams, meandering $(226) \ldots \ldots \ldots \ldots \ldots 118$

Tennessee Basin (777)................ 164

Erosion research

canal, ditch linings (151)........... 94

conservation farming ( 150$) \ldots . . \ldots \ldots . . .104$

effect sediment characteristics (69).... 36

effect vegetation (261)............. 87

" " (376)............... 92

forest influences $(380) \ldots \ldots \ldots \ldots \ldots . .93$

" $\quad$ " (657) .................... 94

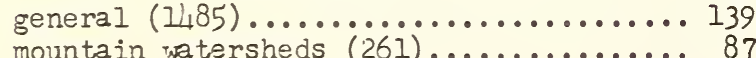

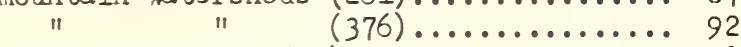

range management $(27) \ldots \ldots \ldots \ldots \ldots \ldots . .6$

semi-desert vegetation (657).......... 94

stream-bed $(69) \ldots \ldots \ldots \ldots \ldots \ldots \ldots . . . \ldots 36$

$(1484) \ldots \ldots \ldots \ldots \ldots \ldots \ldots \ldots \ldots \ldots \ldots \ldots \ldots$
Evaporation

arid regions $(445) \ldots \ldots \ldots \ldots \ldots \ldots . . . . .$.

effect of reforestation (439)

evapo-transpiration (1222)...

heat diffusion (822)

Illinois (555) ...........

irrigated lands $(14,45)$

lake models (1314)...

lakes (1226) .........

measurement (1015)

reservoirs $(765)$
Salton Sea $(390)$

semi-desert vegetation (657)

urban areas (564).

watersheds

Tennessee Basin (765)

Expansions (1309).

Fish ladders

dams

Dalles Dam, Ore. (1462)

McNary Dam, Ore. (189).

Tobique River (1286).

diffusers

McNary Dam, Ore. (667)

Flood control

basin, Whittier Narrows (980)

crop rotation (394)

research (1186)

rivers

Cumberland, Md. (230)

Farm Creek, IIl. (987)

Mississippi basin (236)

Ouachita River, Ark. (675)

Tennessee River basin (772)

Flood discharge

frequency-magnitude (1233)

measurement (691).

Fluidization (1138)

Fluids

physical properties (1340)

Flumes

air entrainment (100)

tilting design (1336)

Frost in ground (1187)

Gas

jets $(882) \ldots \ldots \ldots \ldots \ldots \ldots \ldots \ldots \ldots \ldots$ supersonic flon (3II).

Gates

caritation (993).

lock $(1474) \ldots$ meter (539)

" (1072)

" (1028)

operation (1206)

$$
\text { " (1252). }
$$

rubber seal tester (1199)

slide (2l9)

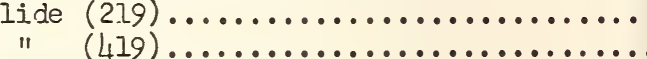

" $(1255)(1256)$ 
es

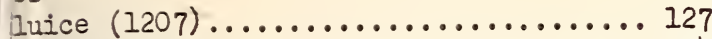

'ainter (669) (980) .................. 114

licket $(986) \ldots \ldots \ldots \ldots \ldots \ldots \ldots \ldots . \ldots . \ldots . \ldots 123$

und water

rtificial recharge (559)............ 30

arroll County, Ill. (843).......... 32

hampaign County, Ill. (844) ......... 32

'hicago area $(1335) \ldots \ldots \ldots \ldots \ldots \ldots . . .631$

achella Valley, Calif. (26).......... 8

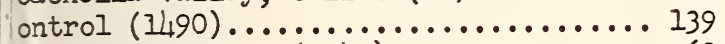

sook County, Ill. (IJi 0$) \ldots \ldots \ldots \ldots \ldots 60$

last St. Iouis area $(561) \ldots \ldots \ldots \ldots . . . .32$

ffect forests $(656) \ldots \ldots \ldots \ldots \ldots . . . .90$

lectric flow net (1221)............ 136

lectric log $(1016) \ldots \ldots \ldots \ldots \ldots \ldots \ldots . \ldots \ldots$

lectrolytic potential $(450) \ldots \ldots \ldots \ldots . .135$

lectro-transfer $(47) \ldots \ldots \ldots \ldots \ldots \ldots . \ldots \ldots$

luctuations (821)................. 18

lydrologic cycle (1092).............. 32

rrigation (389)................... 95

(1434)................... 99

io Daviess County, IIl. (843)........ 32

ake County, Ill. $(11140) \ldots \ldots \ldots \ldots \ldots . .60$

seoria area, Ill. (560)............. 30

Ralston Creek, Iowa.(66)............ 35

lapid Creek, Iowa (68).............. 35

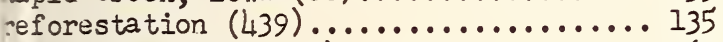

reservoirs $(766)(767) \ldots \ldots \ldots \ldots \ldots \ldots 162$

Stephanson County, IIl. (843)........ 32

stream flow $(1220) \ldots \ldots \ldots \ldots \ldots \ldots \ldots \ldots$

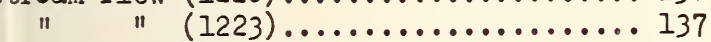

rennessee valley $(777) \ldots \ldots \ldots \ldots \ldots \ldots . . . . .164$

" $"$ (780)............... 165

thermal-transfer $\left(4 l_{1} 7\right) \ldots \ldots \ldots \ldots \ldots \ldots 135$

unsaturated flow (169)................. 135

variable flow $(845) \ldots \ldots \ldots \ldots \ldots \ldots . . . . .630$

ide vanes $(104) \ldots \ldots \ldots \ldots \ldots \ldots \ldots . . . .69$

tters, highways (1096).............. 34

rbor design (1003)................. 126

" " (1377)................. 53

rbor improvement

Charleston, S. C. (678)............. 122

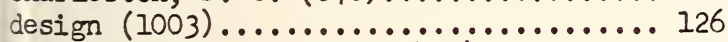
East Beaver Bay, Minn. (1476) ......... 130 Grays Harbor, Wash. (1210) ........... 127 Harrisville, Mich. (1123)............ 53 Indiana Harbor, Ind. (1472)......... 130 penetration, wave energy $(808) \ldots \ldots \ldots .5$ 'Port Washington, Wisc. (1208)......... 127 rbor models, scale effects (1002)....... 126 at, effect on flow (891)............ 55 at transfer

cooling towers (1059).

general research (808)

(822) $\cdots \cdots \cdots \cdots \cdots \cdots \cdots$

supersonic flow (880)

(1361).............. 49

-ghway drainage

culverts $(859)$

(1161)
Highway drainage

culverts (111).................... 73

" , inlets $\left(\mu_{4} \Psi_{4}\right) \ldots \ldots \ldots \ldots \ldots . \ldots 79$

embankments (291).................. 26

flow gage, sewers (lill)............. 42

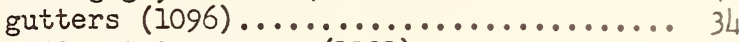

sediment in sewers $(1101) \ldots \ldots \ldots \ldots \ldots 39$

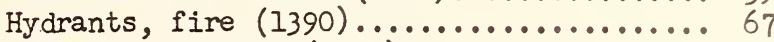

Hydraulic history (1102) .............. 39

Ice, frazil (1158)................ 68

Ice sheets, fracture (1156)........... 67

Infiltration

contour irrigation (393).............. 96

effect vegetation $(376) \ldots \ldots \ldots \ldots \ldots \ldots 9 . \ldots 9$

" " (658)............... 96

irrigated lands $(1438) \ldots \ldots \ldots \ldots . . . . .99$

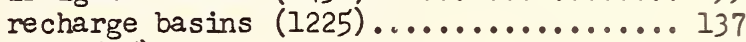

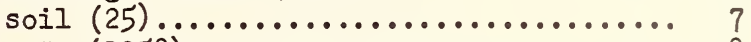

" (1058)..................... 8

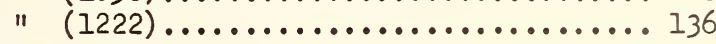

Inlets

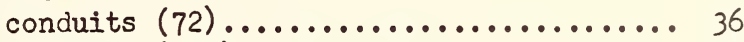

culverts (111) .................... 73

" (1419)...................... 85

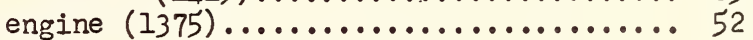

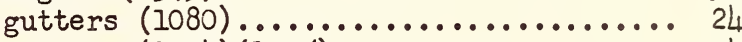

" $(1094)(1095) \ldots \ldots \ldots \ldots \ldots \ldots . . . . . .34$

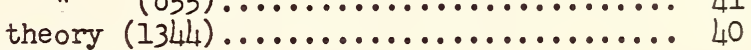

\section{Instruments}

current meters

turbine ratings $(735) \ldots \ldots \ldots \ldots . . . .158$

electric logs, groundwater (1016)....... 136

flow gage, storm sewers (1111)........ 42

hot-wire, anemometer (851)............ 38

" " meter (467) ................. 近7

hydrophone $(1518) \ldots \ldots \ldots \ldots \ldots \ldots \ldots \ldots . \ldots \ldots 15$

irrigation $(1028) \ldots \ldots \ldots \ldots \ldots \ldots \ldots \ldots \ldots$

$(1125) \ldots \ldots \ldots \ldots \ldots \ldots \ldots \ldots, 86$

pitot tubes $(1537) \ldots \ldots \ldots \ldots \ldots \ldots \ldots \ldots . \ldots \ldots$

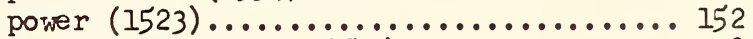

precipitation gage (547)............. 28

$(1338) \ldots \ldots \ldots \ldots \ldots \ldots, 33$

pressure cells $(1004) \ldots \ldots \ldots \ldots \ldots \ldots \ldots 126$ pressure fluctuation (1307)............ 14

" " (1533)............ 156

pressure vane $(1372) \ldots \ldots \ldots \ldots \ldots \ldots \ldots, 52$

radio rain gage $(1012) \ldots \ldots \ldots \ldots \ldots \ldots 134$

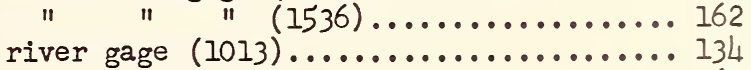

" $"(1536) \ldots \ldots \ldots \ldots \ldots \ldots \ldots \ldots \ldots . \ldots \ldots 2$

shallow water sounding $(974) \ldots \ldots \ldots \ldots 108$

velocity $(1317) \ldots \ldots \ldots \ldots \ldots \ldots \ldots . . . .21$

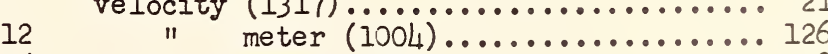

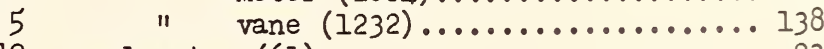

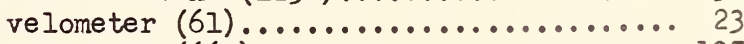

have gage $(660) \ldots \ldots \ldots \ldots \ldots \ldots \ldots \ldots \ldots . . \ldots 107$

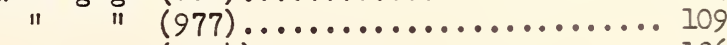

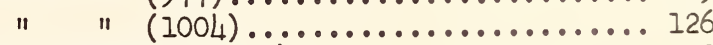

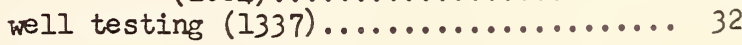


Intakes

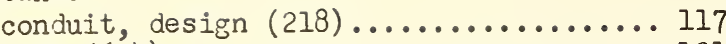

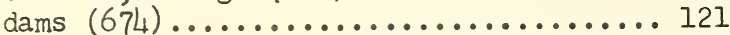

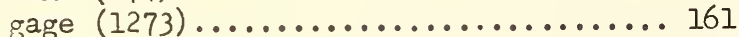

pressures $(1243) \ldots . . . . . . . . . .141$

Irrigation

canals

linings $(151) \ldots \ldots \ldots . . \ldots \ldots . . \ldots 94$

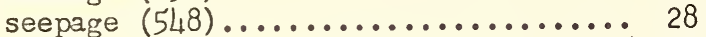

$(820) \ldots \ldots \ldots \ldots \ldots \ldots \ldots \ldots \ldots$

$(1415) \ldots \ldots \ldots \ldots \ldots \ldots \ldots \ldots \ldots$

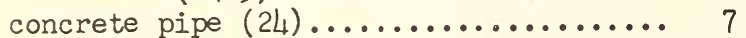

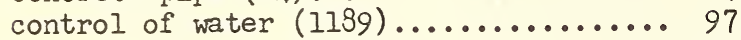

" $"$ " $\left(1455^{\prime}\right) \ldots . . . \ldots \ldots . . . .103$

drainage studies $(390)(391) \ldots . . . \ldots . . . . .96$

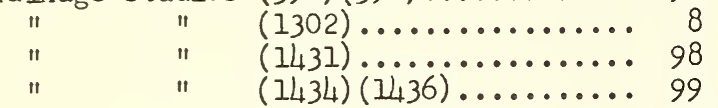

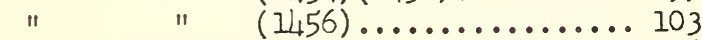

erosion, contour irrigation (393)..... 96

farm structures $(24) \ldots \ldots \ldots . . \ldots \ldots . . . .7$

Imperial Valley, Calif. (390)......... 96

infiltration (1438) ................. 99

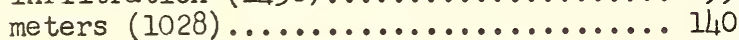

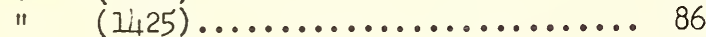

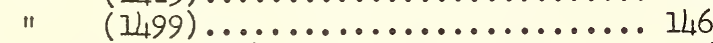

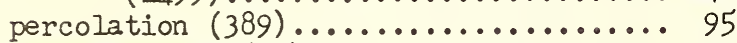

pipe friction (24) ................. 7

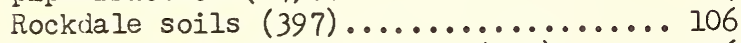

San Fernando Valley, Calif. (391)...... 96

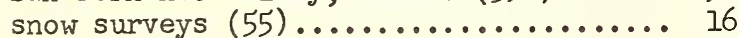

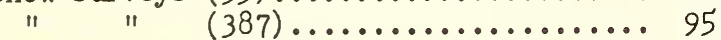

soil moisture $(20)(22) \ldots \ldots \ldots \ldots \ldots . \ldots . \ldots . \ldots$

$" \quad " \quad(26) \ldots \ldots \ldots \ldots \ldots \ldots \ldots \ldots . \ldots . \ldots . \ldots . \ldots . \ldots$

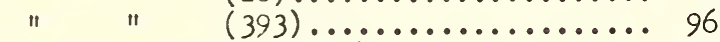

soil permeability $(658) \ldots \ldots \ldots \ldots . . \ldots 96$

sprinkler, perforated pipe (1190) ...... 97

sprinkling systems $(21) \ldots \ldots \ldots \ldots \ldots \ldots$

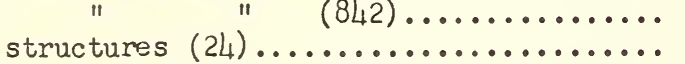

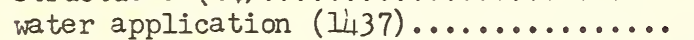

$(1439)(1440)(1441) \ldots 100$

$" \quad " \quad \quad(1442)(1443) \ldots \ldots \ldots . . .100$

water measurement $(24) \ldots \ldots \ldots \ldots \ldots . . . .7$

water supply $(23) \ldots \ldots \ldots \ldots \ldots \ldots \ldots \ldots$

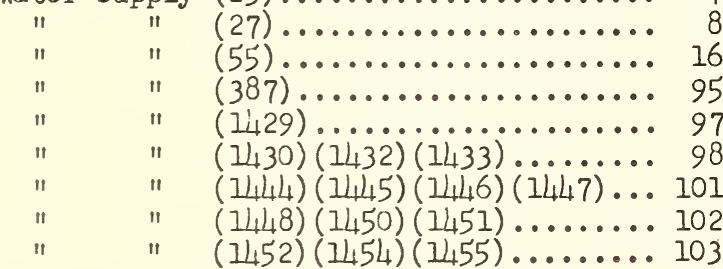

weir stands $(1498) \ldots \ldots \ldots \ldots \ldots . . . \ldots \ldots$

well drilling $(24) \ldots \ldots \ldots \ldots \ldots \ldots . . \ldots \ldots$

Jets

boundary effects (1301).

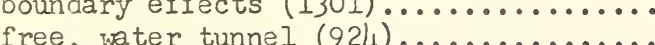

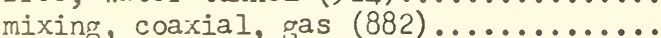

pressure distribution $(72) \ldots \ldots \ldots \ldots \ldots$
Jets

submerged, diffusion (75)

$"$ " $"$ " $(1325)$

turbulent expansion (1477)

Jetties

design, location (38)

effect littoral drift (970)

effect wave action (529).

Lynnhaven Inlet, Va. (672)

Iaboratory

procedure (1496).

noise survey (1519)

lake levels, storm winds (160)

" " " (770).

Leakage

dams (773)

pipes (791)

reservoirs (767)

Liquids, thermodynamics (957)

Locks

approaches

Intracoastal Naterway, Ia. (417)...... I

filling, emptying systems

Dalles Dam, Ore. (1466)............. I

Intracoastal Waterway, La. (417)...... I

Jim Woodruff Dam, Fla. (676)......... I

McNary Dam, Ore. (189) ............... 1

Miss. River, Keokuk, Iowa (985)....... I

" " St. Anthony Falls (985)... I

New Cumberland, Ohio River (985) ....... I

St. Anthony Falls, Minn. (412) ........ I

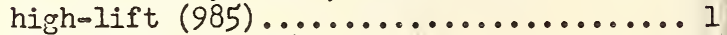

miter gates $(1474) \ldots \ldots \ldots \ldots \ldots \ldots \ldots$

Log boom (1539) ...................... 1

Manifolds (82)

$$
" \quad(1171)
$$

pipes (1353)

theory (1344).

Meanders $(226) \ldots \ldots \ldots \ldots \ldots \ldots \ldots . \ldots \ldots$

" (682).

(1313)

Meters (see Nozzles, Orifice meters, Venturis,

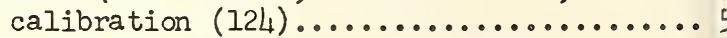
turbine ratings $(735) \ldots \ldots . . .1$

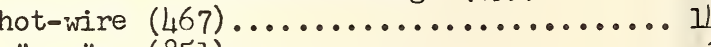

" " (851)

irrigation (24).

$$
\text { " }(1425)
$$

permeameter (1172) precipitation gages $(547) \ldots \ldots \ldots \ldots \ldots . . . .$. pulsation eliminators (597)

turbulence (578)

velocity, electro-magnetic $(46)$

viscometer, absolute (1090).

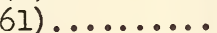

Model distortion (994).................. 12

Model laws

air entrainment $(995) \ldots . . . \ldots \ldots . . . . .12$

air instead of water $(996) \ldots \ldots \ldots \ldots . . . . . . . . .12$ 
1 laws

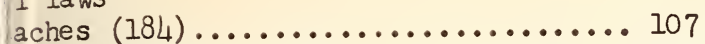

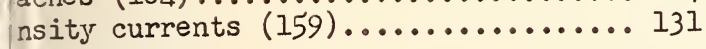
ale effects

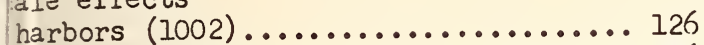

spillways (1001) .................. 126

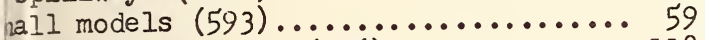

reams, meandering $(226) \ldots \ldots \ldots \ldots \ldots 118$

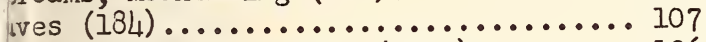

.I roughness standards $(1000) \ldots \ldots \ldots . . \ldots 126$

II verification

:essure measurement

penstocks, South Holston dam (762) .... 160

sluices, Cherokee Dam (75') .......... 160

" Douglas Dam (759).......... 160

" Hiwassee Dam (763) ......... 160

spillway piers and baffles

Kentucky dam (761) ............... 160

rototype confirmation (1467) ......... 129

Chief Joseph Dam, Wash. (408) ....... 110 els

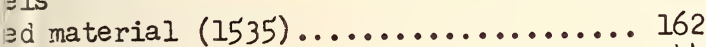

ches $(1352) \ldots \ldots \ldots \ldots \ldots \ldots \ldots . \ldots \ldots . . \ldots \ldots$

zles

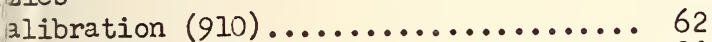

$(1426) \ldots \ldots \ldots \ldots \ldots . \ldots \ldots 68 \ldots \ldots$

trance effects $(1382) \ldots \ldots \ldots \ldots \ldots 6 . \ldots \ldots$

low measurement $(1327) \ldots \ldots \ldots . . . \ldots 64$

nstallation effects $(685) \ldots \ldots \ldots . \ldots 132$

ow Reynolds number (1327) ............ 26

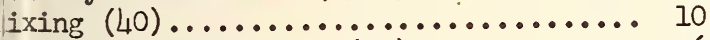

ressure distribution $(72) \ldots \ldots \ldots . \ldots . \ldots 36$

oughness $(1328) \ldots \ldots \ldots \ldots \ldots . \ldots \ldots$

in channels (see Channels)

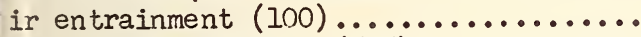

rtificial roughness $(535) \ldots \ldots \ldots \ldots \ldots$

"

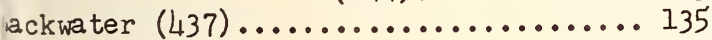

(1332).................... 27

"

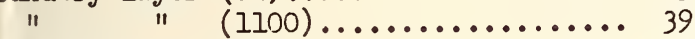

ritical depth $(1396) \ldots \ldots \ldots \ldots \ldots \ldots \ldots$

low past slots $(328) \ldots \ldots \ldots \ldots \ldots \ldots . \ldots \ldots$

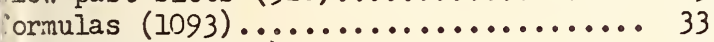

aminar flow $(562) \ldots \ldots \ldots \ldots \ldots . \ldots \ldots . . \ldots \ldots$

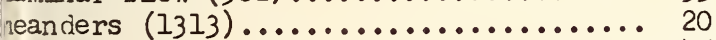

stable shapes $(1265) \ldots \ldots \ldots \ldots \ldots \ldots . \ldots \ldots$

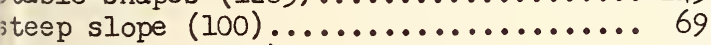

" " $(1322) \ldots \ldots \ldots \ldots \ldots . \ldots \ldots 22$

supercritical flow

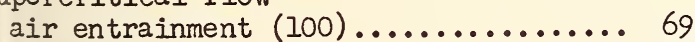

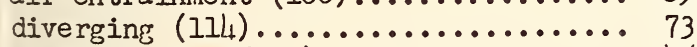

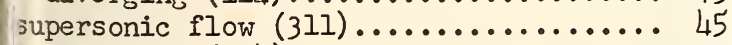

transitions $\left(1 \mathrm{li}_{4}\right) \ldots \ldots \ldots \ldots \ldots \ldots \ldots . \ldots \ldots$

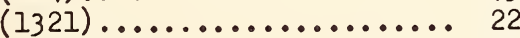

uniform inflow $(1217) \ldots \ldots \ldots \ldots \ldots \ldots \ldots \ldots$

relocity distribution $(1304) \ldots \ldots . . . . . .13$

" $"$ " $(1343) \ldots \ldots \ldots \ldots . \ldots 34$

$" \quad$ " 1395$) \ldots \ldots \ldots \ldots . . . . .72$

ifice meters

calibration (910).

62
Orifice meters

eccentric and segmental (598).........66 62

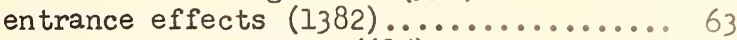

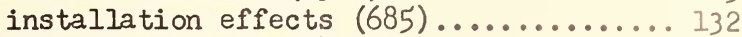

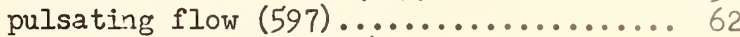

rounded entrance $(1380) \ldots \ldots \ldots \ldots . \ldots 63$

throat angle $(1381) \ldots \ldots \ldots \ldots \ldots . \ldots . \ldots 63$

Orifices

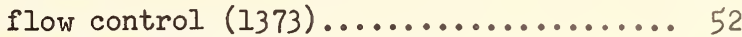

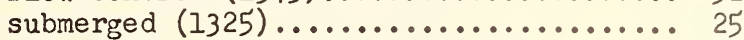

vortex flo: $(1181) \ldots \ldots \ldots \ldots \ldots \ldots . . \ldots \ldots$

oscillating motion (1358).............. 49

outlets

drop spillway (112) ................ 73

flaring ends $(859) \ldots \ldots \ldots \ldots \ldots \ldots . . . \ldots 43$

pipe, cantilevered (1168)............ 73

short, in dams (290)................. 23

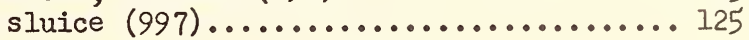

Outlet works

dams

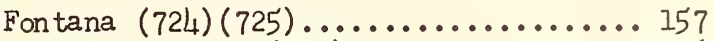

Garrison, N. D. (2l1) .............. 116

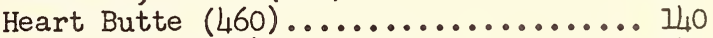

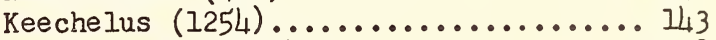

Oahe, S. D. (1212) ................. 128

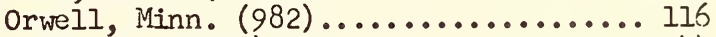

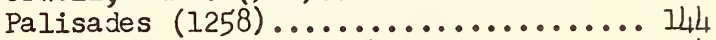

Rio Hondo, Calif. (980) ...............114

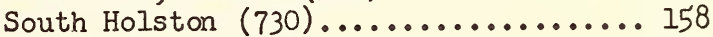

Spring Creek (698)................ 140

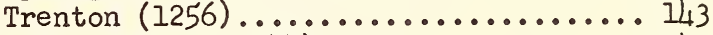

Willow Creek $(1244) \ldots . . . . . . . . .141$

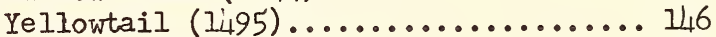

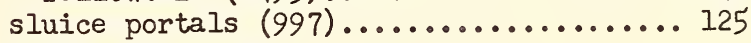

spillway tunnels

South Holston Dam (730)............ 158 valv'e operation

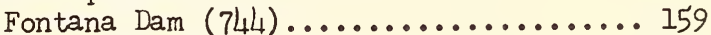

vibration $(1254) \ldots \ldots . . . . . . . . . . .143$

Penstocks

Chief Joseph Dam, Wash. (410,......... 111

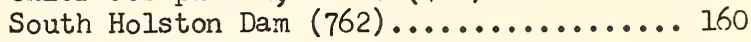

Percolation studies

San Joaquin Valley, Calif. (389)....... 95

Pipe fittings

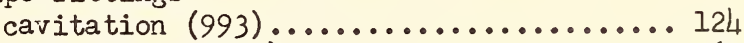

guide vanes $(104) \ldots . . . . . . . . . . . . .696$

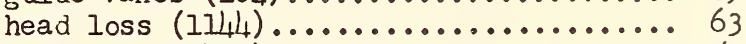

salt water $(472) \ldots \ldots \ldots \ldots . . \ldots \ldots . . . \ldots 153$

ships $(1524) \ldots \ldots \ldots \ldots \ldots . . \ldots \ldots . . . \ldots 153$

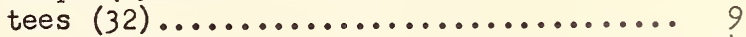

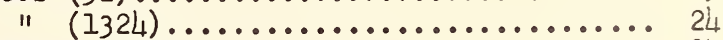

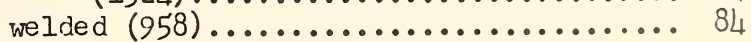

Pipes

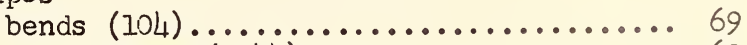

" elbows $(1144) \ldots \ldots \ldots . . . . . . . .63$

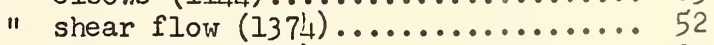

" separation (289) ................ 23

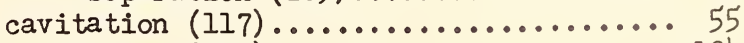

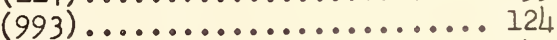

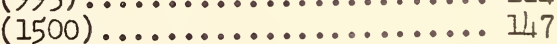




\section{Pipes}

conduits

obstructions (1334).............. 27

corrosion (1231)................. 138

(472)...................... 153

(1342).................. 33

discharge measurement (1191).......... 97

effect, shape $(642) \ldots \ldots \ldots \ldots \ldots \ldots . . . .62$

entrance sections (290).............. 23

" " (627).............. 75

expansion joints $(1529) \ldots \ldots \ldots \ldots \ldots \ldots 155$

expansions $(1143) \ldots \ldots \ldots \ldots \ldots \ldots \ldots 6 . \ldots \ldots$

fittings, tees $(1324) \ldots \ldots \ldots \ldots \ldots . . . .24$

flexible (1192).................. 97

flow formulas $(586) \ldots \ldots \ldots \ldots \ldots \ldots \ldots$

" " (64 $\ldots \ldots \ldots \ldots \ldots \ldots \ldots . . . . .63$

flow of mixtures

solid-gas $(40) \ldots \ldots \ldots \ldots \ldots \ldots . . . . .10$

two-phase, two-component (4l)........ 10

friction

aluminum $(950) \ldots \ldots \ldots \ldots \ldots . . \ldots . . .61$

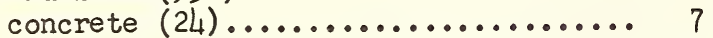

corrugated (1198)................ 112

high pressure $(956) \ldots \ldots \ldots \ldots \ldots . . . . .64$

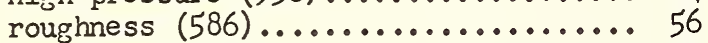

(1393)................. 72

(944)................... 79

, artificial (1).......... 29

$(644) \ldots \ldots \ldots .63$

salt water $(472) \ldots \ldots \ldots \ldots \ldots \ldots . \ldots 153$

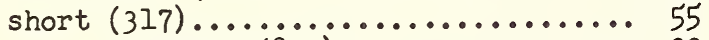

", intakes $(830) \ldots \ldots \ldots \ldots \ldots \ldots . . .22$

heat transfer $(40) \ldots \ldots \ldots \ldots \ldots \ldots \ldots . . .10$

" " (880)................. 47

hydraulic radius $(642) \ldots \ldots \ldots \ldots \ldots \ldots . . .62$

leakage $(791) \ldots \ldots \ldots \ldots \ldots \ldots \ldots \ldots \ldots \ldots$

manifold ports $(82) \ldots \ldots \ldots \ldots \ldots \ldots \ldots . . \ldots 37$

" " (1171)............... 75

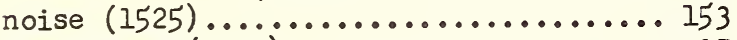

perforated $(1190) \ldots \ldots \ldots \ldots \ldots \ldots \ldots . \ldots . \ldots 9 . \ldots \ldots$

plastic, resistance $(1346) \ldots . . . \ldots \ldots . . .41$

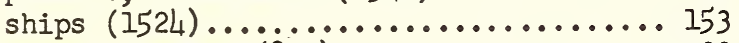

short, intakes $(830) \ldots \ldots \ldots \ldots \ldots \ldots . \ldots 22$

small siphons (115) ................ 55

standards, house sewer $(1005) \ldots \ldots \ldots . .132$

suction $(117) \ldots \ldots \ldots \ldots \ldots \ldots \ldots . . . \ldots 5$

supply system, model (1298).......... 2

surge suppressors $(127) \ldots \ldots \ldots \ldots \ldots \ldots . . \ldots 9$

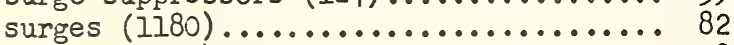

" (1303).................... 8

transitions $(318) \ldots \ldots \ldots \ldots \ldots \ldots \ldots \ldots \ldots 5$

turbulence $(467) \ldots \ldots \ldots \ldots \ldots \ldots \ldots . \ldots \ldots 147$

velocity distribution (587) .......... 56

" fluctuations $(46) \ldots \ldots \ldots \ldots \ldots .10$

vertical $(317) \ldots \ldots \ldots \ldots \ldots \ldots \ldots \ldots \ldots \ldots \ldots \ldots \ldots \ldots \ldots \ldots \ldots \ldots$

(1311).................... 15

vibrations (1150) .................. 70

welded junctions $(32) \ldots \ldots \ldots \ldots . . . .69$

Pitot tubes

development (43)................. 10

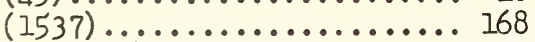

Reynolds number $(881) \ldots \ldots \ldots \ldots \ldots . . . .48$
Plates

rough (854)

Plumbing

backflow prevention (49)

contamination (1216)

corrosion (49) ............

cross-connections (49)

fixtures (49)

flow in systems (12ii)

frost closure (432)...

stacks, capacities (433)

trailer coaches (1216)

vents, stack (166)

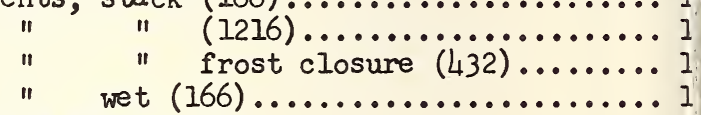

Porous media, flow

basic research (60)

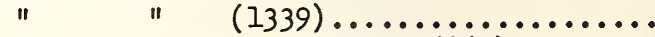
effect of chloride content (860)......... electro-transfer effects $(447) \ldots . . . \ldots$... I fluidized, systems (1379)

multi-phase (282)

sand (1318).

spheres (590)

" (626)

thermal-transfer effects $(447)$

turbulence (557)...

two-phase media (39).

unsaturated flow (169)

Pressure distribution

basic research (79) (81)

" " (1356)...

building forms (299)

by electric analogy (72)

" " $"$ "

deformation of metals $(312) \ldots \ldots \ldots \ldots \ldots . .4$

entrances (1243)..................... 14

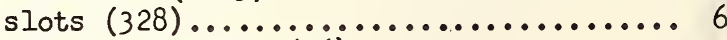

submerged bodies (16)

Pressure measurement

electric analogy $(72) \ldots \ldots \ldots \ldots \ldots \ldots \ldots \ldots \ldots$

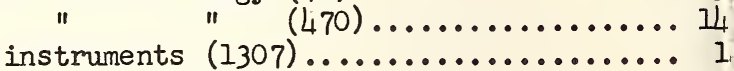

" (1368)..................... 5

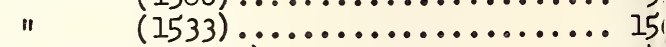

pressure vanes $(312) \ldots \ldots \ldots \ldots \ldots \ldots \ldots 4$

sluices

Cherokee Dam (758).................16

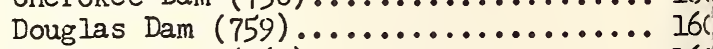

Hiwassee Dam $(763) \ldots \ldots \ldots \ldots \ldots \ldots \ldots . . \ldots 16$

wave action $(38) \ldots \ldots \ldots \ldots \ldots \ldots \ldots \ldots \ldots \ldots \ldots$.

Pressure regulator $(1251) \ldots \ldots \ldots \ldots \ldots \ldots .14$
Propellers

cavitation (1531).................... 15

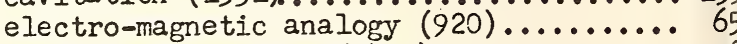

measuring apparatus (1l11) ............ 7ह

symmetric wakes $(921) \ldots \ldots \ldots \ldots \ldots \ldots \ldots$ 6,

Prototype check tests

penstocks (762). 
totype check tests

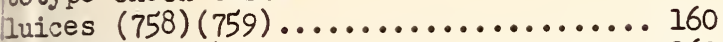

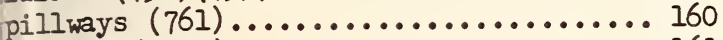

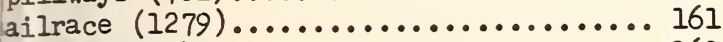

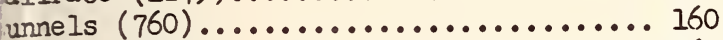

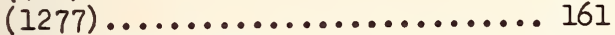

ıping plant, sewers $(683) \ldots \ldots \ldots \ldots \ldots . . . . . .123$ ips

djustable blade (1297)............... 2

" ower transmission $(1528) \ldots \ldots \ldots \ldots . \ldots . \ldots . \ldots . \ldots . \ldots \ldots$

esearch $(806) \ldots \ldots \ldots \ldots \ldots \ldots . . \ldots \ldots$

suction, air $(810) \ldots \ldots \ldots \ldots \ldots \ldots . \ldots \ldots \ldots$

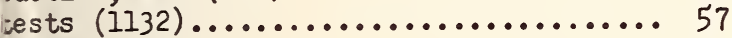

infa 11

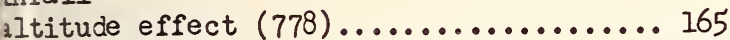

artificial, airport runways (531)....... I4

iffect of altitude (778)............. 165

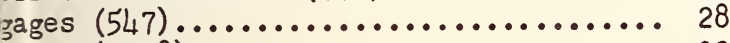

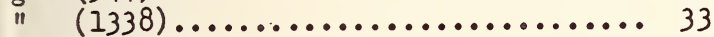

hydrologic cycle (1092).............. 32

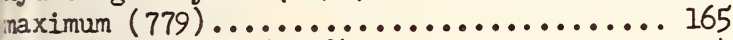

rainfall-run off $(1078) \ldots \ldots \ldots \ldots \ldots . \ldots . \ldots . \ldots$

$" \| \quad(564) \ldots \ldots \ldots \ldots \ldots \ldots \ldots . \ldots \ldots$

(68) .................... 35

(856) .................. 41

(918) .................6 63

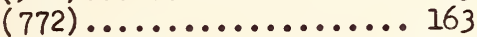

$(768)(777) \ldots \ldots \ldots \ldots \ldots 164$

rainmaking $(1320) \ldots \ldots \ldots \ldots \ldots . . \ldots \ldots . . \ldots 22$ research, Southern California (261)..... 87 Tennessee River Basin (768) ............. 164 " $(778)(779) \ldots \ldots . . . .165$

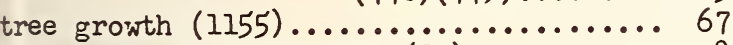
nge management practices (27) .......... 8 servoirs

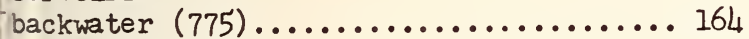

density currents

model tests $(1098) \ldots \ldots \ldots \ldots \ldots . \ldots . \ldots 35$

suspended sediment $(8) \ldots \ldots \ldots \ldots \ldots \ldots \ldots$

design, Clarion River, $\mathrm{Pa}$ (426) .......... 120

evaporation $(765) \ldots \ldots \ldots \ldots \ldots . . . \ldots 164$

" , arid regions $(445) \ldots \ldots \ldots 135$

ground water $(766) \ldots \ldots \ldots \ldots \ldots \ldots . . \ldots \ldots 2$

leakage $(767) \ldots \ldots \ldots \ldots \ldots . \ldots \ldots . . \ldots \ldots$

sedimentation $(307) \ldots \ldots \ldots \ldots \ldots \ldots . \ldots \ldots$

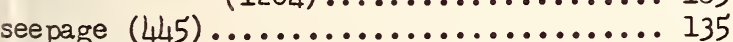

silting $(8) \ldots \ldots \ldots \ldots \ldots \ldots \ldots \ldots$

arid regions $(445) \ldots \ldots \ldots \ldots . \ldots . \ldots . \ldots . \ldots 135$

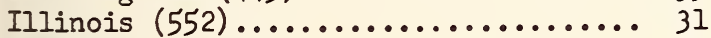

Safe Harbor $(1157) \ldots \ldots . . . \ldots . . . . . .68$

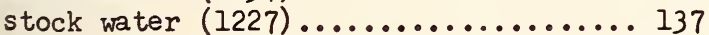

temperature gaging $(769) \ldots \ldots \ldots . . \ldots 160$

Tennessee River $(764) \ldots . . \ldots \ldots . . . \ldots 162$

water supply, Illinois (551)........ 31

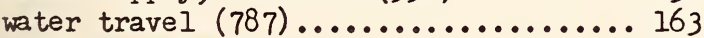

wind, wave heights $(770) \ldots \ldots \ldots \ldots \ldots 163$
Revetments

Miss. River (1159) .................. 70

stream control, meandering (226)....... 118

Rockfill

model tests $(1463)(1464) \ldots \ldots \ldots \ldots . . . . .113$

Roughness

artificial

open channels $(644) \ldots \ldots \ldots . . . . . . .83$

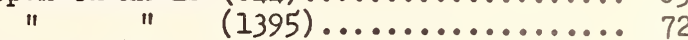

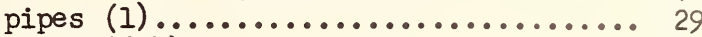

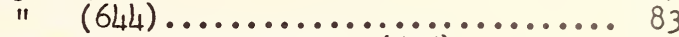

sediment transportation (535)......... 17

standards, models (1000)............. 126

surfaces, drag (854)............... 39

\section{Runoff}

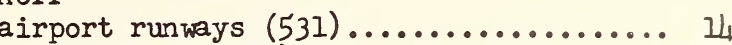

arid regions $(445) \ldots \ldots \ldots \ldots \ldots . . \ldots \ldots$

denudation effects $(23) \ldots \ldots \ldots \ldots \ldots \ldots . . \ldots$

effect of forest $(656) \ldots \ldots \ldots \ldots \ldots \ldots \ldots$

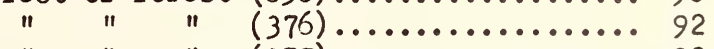

forecasting

snow surveys $(387)(388) \ldots \ldots \ldots \ldots \ldots$

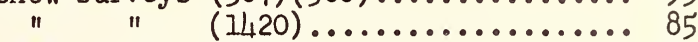

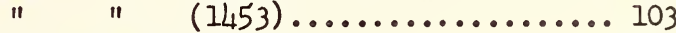

soil moisture $(1014) \ldots \ldots \ldots \ldots \ldots \ldots . \ldots 134$

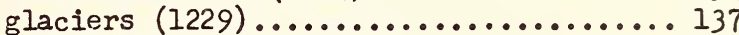

hydrologic cycle (1092) .............. 32

rainfall-munoff $(564) \ldots \ldots \ldots \ldots . \ldots . \ldots . \ldots . . . \ldots$

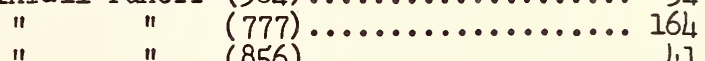

$n \quad(856) \ldots \ldots \ldots \ldots \ldots \ldots \ldots \ldots \ldots$

" $\quad(918) \ldots \ldots \ldots \ldots \ldots \ldots \ldots \ldots \ldots \ldots$

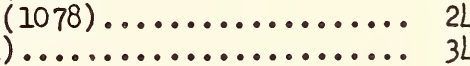

$" 1 "$ (856).................. 41

watersheds

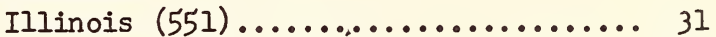

Lafayetee, Ind. (394)............. 104

Ohio and Great Plains (150).......... 104

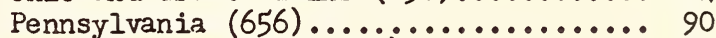

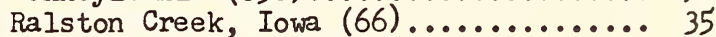

Rapid Creek, Iow (68) ............. 35

Tennessee River Valley (777)......... 164

" " " (780)......... 165

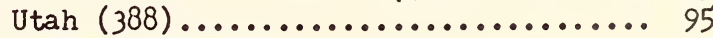

Salt water intrusion

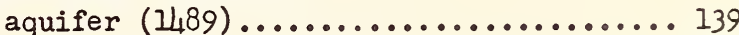

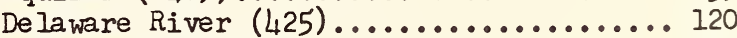

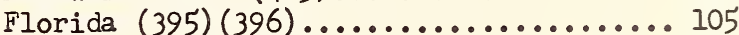

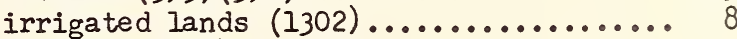

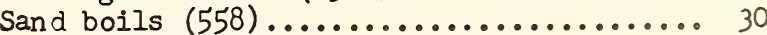

Sand classification methods (52) .......... 16

Sand mixtures, permeability $(556) \ldots \ldots . . .29$

Sand traps, design $(53) \ldots \ldots \ldots \ldots \ldots . . \ldots \ldots$

Sand traps, vortex tube (537)........... 17

Scour

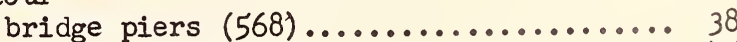

" $"$ (306)..................... 45

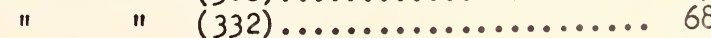

canal curves $(1501) \ldots \ldots \ldots \ldots \ldots \ldots \ldots \ldots \ldots$ 
Scour

dams

Ft. Randall, S. D. (674)............ 121 stilling basins (823)............. 19

\section{Sediment}

analysis methods $(322) \ldots \ldots \ldots \ldots \ldots . \ldots 38$

bed erosion (69) .................. 36

exclusion (1261) (1264)..............144

measurement $(1329) \ldots \ldots \ldots \ldots \ldots \ldots . \ldots 26$

reservoir sampler $(1284) \ldots \ldots \ldots \ldots \ldots . . \ldots 165$

similiarity $(1330) \ldots \ldots \ldots \ldots \ldots \ldots . . .26$

suspended, measurement (734) ......... 164

Sediment transportation

artificial roughness $(535) \ldots . . \ldots \ldots \ldots$

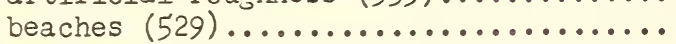

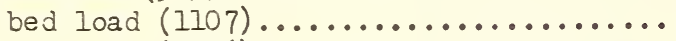

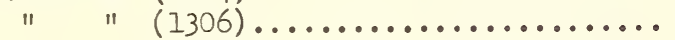

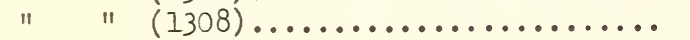

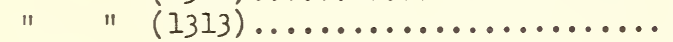

" $\quad(1354) \ldots \ldots \ldots \ldots \ldots \ldots \ldots . \ldots 47$

Delaware River $(425) \ldots \ldots \ldots \ldots \ldots . . .120$

internal mechanics (7)............ 2

Niobrara River (1235)............. 138

channels with sills (1063)........... 13

critical tractive force $(1502) \ldots \ldots . .147$

density currents (8).............. 3

" " (307).............. 45

forces on particles (280)............ 11

measurement (194) ................. 115

(734) .................. 164

reservoirs $(386) \ldots \ldots \ldots \ldots \ldots \ldots \ldots . \ldots 96$

ripple formation $(1165) \ldots \ldots \ldots \ldots \ldots . . \ldots 7$

suspended load (1107)............... 40

" " (1313)............... 20

density currents $(805) \ldots \ldots \ldots \ldots . . .4$

intermal mechanics (6)............ 2

measurement $(386) \ldots \ldots \ldots \ldots \ldots \ldots . \ldots 95$

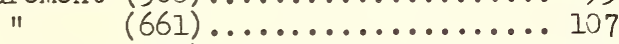

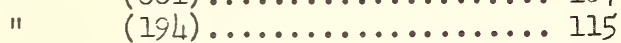

$(194) \ldots \ldots \cdots \cdots \cdots \cdots \cdots \cdots \cdots \cdots \cdots \cdots \cdots \cdots \cdots \cdots \cdots$

Tennessee River $(764) \ldots \ldots \ldots \ldots \ldots . . \ldots 162$

Texas streams $(386) \ldots \ldots \ldots \ldots \ldots . . .69$

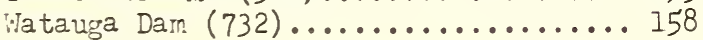

Sedimentation

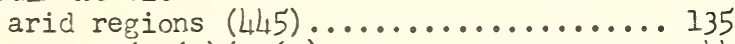

basins $(1262)(1263) \ldots \ldots \ldots \ldots \ldots \ldots 144$

$(1394)(1397) \ldots \ldots \ldots \ldots \ldots \ldots \ldots . \ldots \ldots$

general research $(1073) \ldots \ldots \ldots \ldots . . .20$

reservoirs $(552) \ldots \ldots \ldots \ldots \ldots \ldots \ldots . . . . .631$

(1157).................6 68

$(785) \ldots \ldots \ldots \ldots \ldots \ldots \ldots \ldots \ldots$

$\operatorname{tank}(1391) \ldots \ldots \ldots \ldots \ldots \ldots \ldots \ldots . \ldots 6$

Seepage

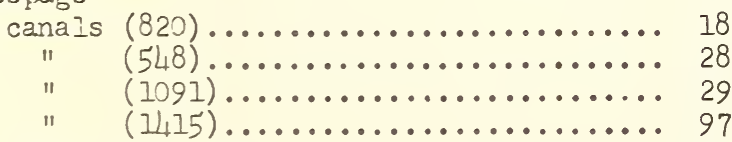

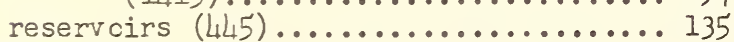

Separators

liquid-liquic cyclone $(1141) \ldots . . . .661$

$"$ solic" $"(905)(906) \ldots . . .660$

oil-water $(646) \ldots \ldots \ldots \ldots \ldots \ldots . . . . . .64$
Settling, fall velocity

effect boundaries (298)

$$
\begin{array}{ccc}
" & \text { shape }(828) \ldots \ldots \ldots \\
" & " & (298) \ldots \ldots \ldots \\
" & " \quad(628) \ldots \ldots \ldots \\
" \quad \text { suspensions }(1073)
\end{array}
$$

velocity (1330)

Sewage

activated sludge process (580)

pumping plant (683)

Sewers

pipes, standaris (1005)

surges (683)...

Ships

bending moment (1409)

bilge, keels (1512).

boundary layers ( 1504$)$.

commercial, design (1128)

design

injection scoops (710)

fishing vessels (1288).

maneuvering ( 1514 )

models, turbulence stimulation (1506)

Taylor (1508).

motor-boats, transom imersion (1127).

pitch, measurement $(14.04)$

planing surfaces (340)

propellers

cavitation (1134)

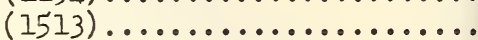

electro-magnetic analogy (920).

symmetric wakes (921).

PT, geometric series (1509)

resistance

compilation data (395)

frictional (468)

" (1413)

hull forms (1507)

measurement (1516)

models (901)

prediction (15.16)

theory (709)

wave $(1142)$.

rudder force (1175)

vibration (1378)

seaworthiness

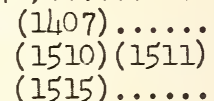

self-propelled models (iilio) (ilii2)

Shore protection, structures (38).
$"$
(972)

Silting

basins, Henderson County (733)...

reservoirs

arid regions (445).

Illinois (552)

Lake Mead (445).

Tennessee Valley (785)

small watersheds (777) 
ing

reams, Texas $(386) \ldots \ldots . . . \ldots . . . . .95$

ons

inlet $(1491) \ldots . . . . . . . . . . . .145$

igation $(24) \ldots \ldots \ldots \ldots \ldots \ldots \ldots \ldots \ldots \ldots$

nping plants (1475)................ 130

111 pipes $(115) \ldots \ldots \ldots \ldots \ldots \ldots . . \ldots \ldots$

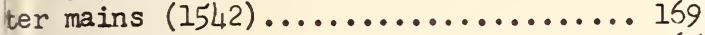

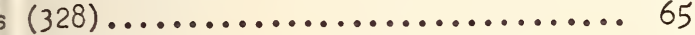

ze gates

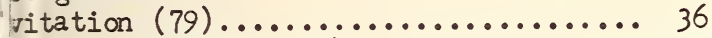
design $(219) \ldots \ldots \ldots \ldots \ldots . \ldots 17$

zeways

Thief Joseph, Wash. (409) ............ 111

discharge ratings

Cherokee Dam (739).............. 159

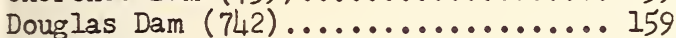

Fontana Dam $(743)(745) \ldots . . . . . .159$

pressure measurement

Cherokee Dam (758) ............... 150

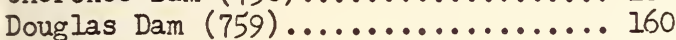

Hiwassee $\operatorname{Dam}(763) \ldots . . . . . . . . . .160$

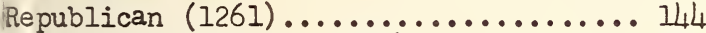

Superior Courtland $(1256) \ldots \ldots \ldots \ldots . \ldots 14$

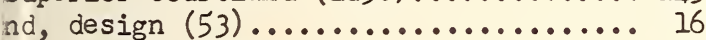

forecast, melting (1011).......... 134

surveys

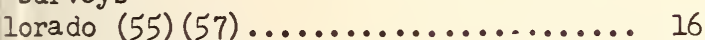

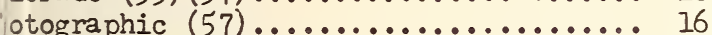

noff forecasting $(55) \ldots \ldots \ldots \ldots \ldots \ldots$

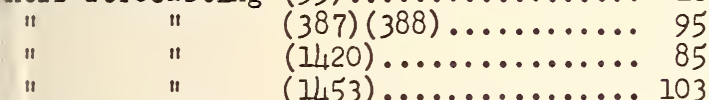

moisture

ntour irrigation (393)............. 96

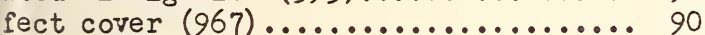

denudation (23) ................. 7

timber cutting $(377) \ldots \ldots \ldots . . . . .92$

recasting stream flow $(1014) \ldots . . . . .134$

rest influences $(380) \ldots \ldots \ldots \ldots . . \ldots 93$

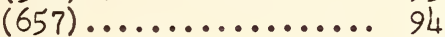

Iperial Valley, Calif. (390).......... 96

a surement $(20)(22) \ldots \ldots \ldots \ldots \ldots . . \ldots . . . \ldots 6$

(26)

$(261) \ldots \ldots \ldots \ldots \ldots \ldots \ldots \ldots$

vement $(20) \ldots \ldots \ldots \ldots \ldots \ldots \ldots . . . \ldots \ldots$

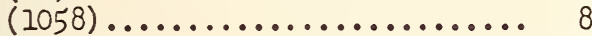

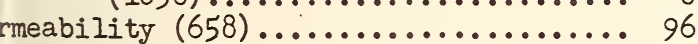

lation to plants $(19) \ldots \ldots \ldots \ldots \ldots . \ldots \ldots$

$(1427)(1428) \ldots \ldots . . . .88$

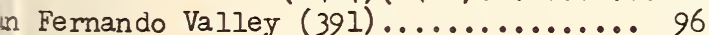

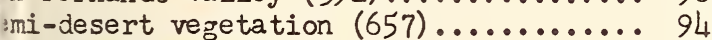

1211 watersheds $(777) \ldots \ldots \ldots \ldots \ldots . . \ldots \ldots$

suthern California (261)............ 87

ermodynamics $(22) \ldots \ldots \ldots \ldots \ldots \ldots . \ldots \ldots$

permeability $(1178) \ldots \ldots \ldots \ldots \ldots$

" $\quad(1179) \ldots \ldots \ldots \ldots \ldots \ldots \ldots . \ldots . \ldots 8$

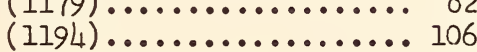

ific gravity, oils $(904) \ldots . . . . . . .60$

ere, accelerated motion $(1104) \ldots . . . .39$

llways

eration, Pine Flat, Calif. (992)....... 124
Spillways

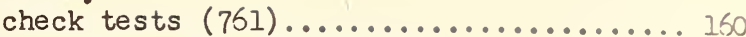

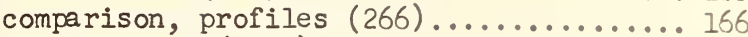

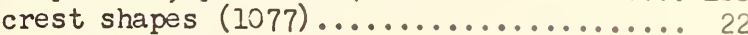
dams

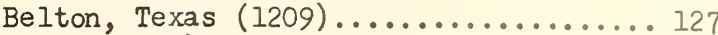

Boone $(1274) \ldots . . \ldots \ldots \ldots . . . . . . . . .161$

C. J. Strike Power Dev. Co. (1184)..... 86

Cabinet Gorge (1422)............... 86

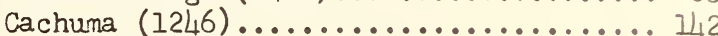

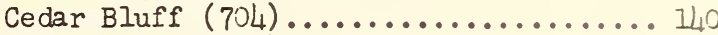

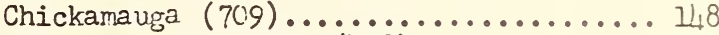

Chief Joseph, Wash. (408)............ 110

(409)

Clarion River, $\mathrm{Pa} .(426) \ldots \ldots \ldots . . . . . .120$

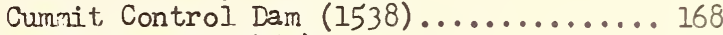

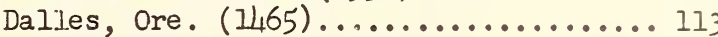

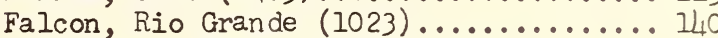

Fall River, Kansas $(1114)(1350) \ldots . . . .43$

Folsom Dam, Calif. (1473)........... 130

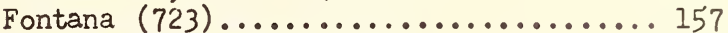

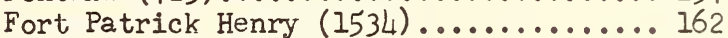

Ft. Randa 11, S. D. (674) ............. 121

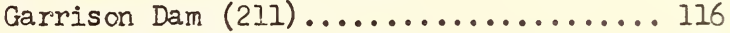

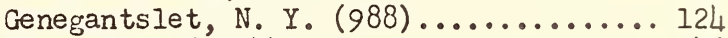

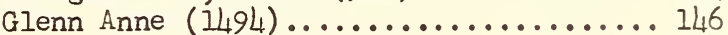

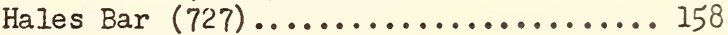

" (1038) ........................ 161

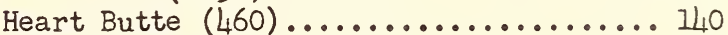

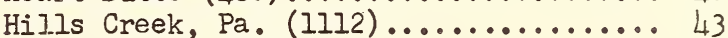

Hungry Horse $(705) \ldots \ldots . . . . . . . . .140$

Jim Woodruff, Fla. (676) ............ 122

Kentucky $(761) \ldots \ldots \ldots \ldots \ldots \ldots . . \ldots \ldots$

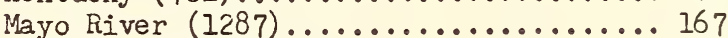

McNary, Ore. (189).................. 110

Morganza Floodway, Ia. (213)......... 117

Orwel], Minn. (982) ................ 116

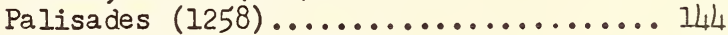

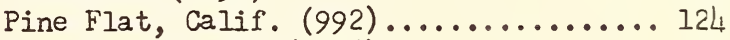

Rio Grande Canal (1316).............. 21

Rio Hondo, Calif. (980)............. 114

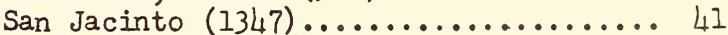

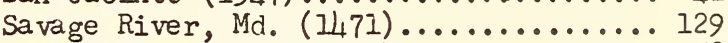

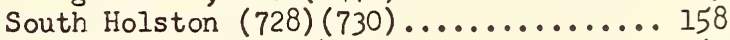

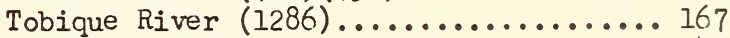

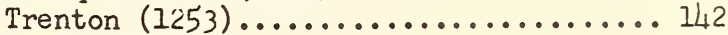

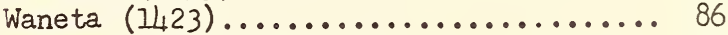

Watauga $(728)(732) \ldots \ldots \ldots \ldots \ldots \ldots \ldots$

Waynesboro, $\mathrm{Pa} .(1351) \ldots \ldots \ldots \ldots . . . . . . .43$

Willow Creek $(1244) \ldots \ldots . . . . . . . . .141$

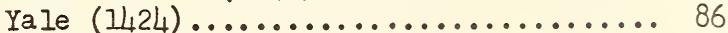

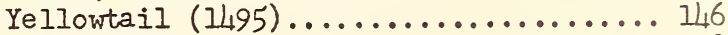

design $(538) \ldots \ldots \ldots \ldots \ldots \ldots \ldots . \ldots \ldots . . \ldots \ldots$

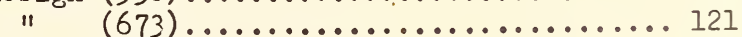

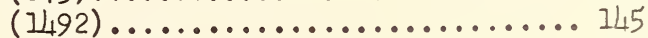

" , drop $(112) \ldots \ldots \ldots \ldots \ldots \ldots . . \ldots \ldots$

Discharge ratings, dams

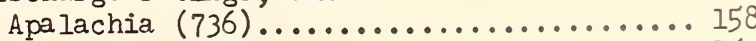

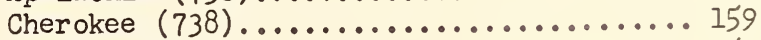

Douglas $(741) \ldots \ldots \ldots \ldots \ldots \ldots \ldots . . \ldots \ldots \ldots$

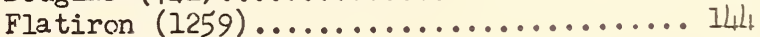

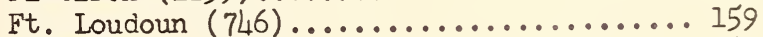

Ocoee No. $3(753) \ldots \ldots \ldots \ldots \ldots . \ldots \ldots$ 


\section{Spillways}

discharge ratings, dams

Watt's $\operatorname{Bar}(755) \ldots \ldots \ldots \ldots \ldots . . . . . .160$

discharge, weir-type (1289) ............ 168

drop, design (112) ................ 73

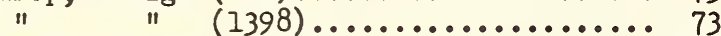

effect tailrace $(732) \ldots \ldots \ldots \ldots \ldots \ldots . \ldots 158$

" tailwater (62)................ 23

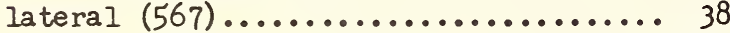

$" \quad(426) \ldots \ldots \ldots \ldots \ldots \ldots \ldots \ldots \ldots . \ldots 120$

morning-glory, dams

Heart Butte $(460) \ldots \ldots \ldots \ldots \ldots . . .140$

Hungry Horse $(705) \ldots \ldots \ldots \ldots . . . . .140$

South Holston $(728) \ldots \ldots \ldots \ldots \ldots \ldots 158$

Watauga $(728) \ldots \ldots \ldots \ldots \ldots \ldots \ldots \ldots \ldots . \ldots \ldots$

ogee, flow patterns (541)............ 24

profiles (266) ................... 166

reservoirs, Clarion River, $\mathrm{Pa}$. (426).... 120

roller-type bucket (673) .............. 121

scale effects (1001)............... 126

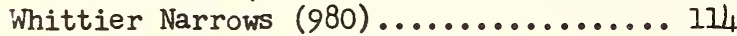

Sprinkling systems

irrigation (842)

" (1076).................. 20

jets, distribution (2l)............. 6

Stability

model studies (5)................... submarines, automatic control (909).....

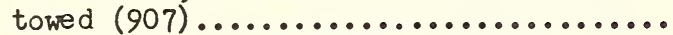
water circulating systems (1135)........ wave tests $(1136)(1137) \ldots \ldots \ldots \ldots \ldots . .$.

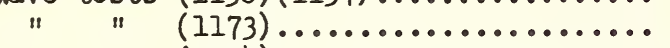

Stilling basins

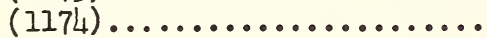

canals (1497)

dams

Cedar Bluff (704)................ 140

Chickamauga (709) ................ 148

Chief Joseph, Wash. (409) ............ 111

Clarion River, $\mathrm{Pa}$. (426)........... 120

Folsom Dam, Calif. (1473).......... 130

Ft. Randali, S. D. $(674) \ldots \ldots \ldots \ldots . . .121$

Garrison, N. D. (2li) ............. 116

Hungry Horse $(705) \ldots \ldots \ldots \ldots \ldots . . . .140$

Island Falls $(1540) \ldots \ldots \ldots \ldots \ldots \ldots 168$

Morganza Floodway, Ia. (213)........ 117

Narrows, Ark. (420) ............... 120

San Jacinto $(1347) \ldots \ldots \ldots \ldots \ldots \ldots . . . . .41$

South Holston (730)............. 158

Texarkana (991)................. 124

Trenton $(1253) \ldots \ldots \ldots \ldots \ldots \ldots \ldots . . \ldots 142$

design $(1074) \ldots \ldots \ldots \ldots \ldots \ldots \ldots \ldots . . . . .20$

scour $(823) \ldots \ldots \ldots \ldots \ldots \ldots \ldots \ldots \ldots . \ldots \ldots$

Stilling wells

meter gates $(539) \ldots \ldots \ldots \ldots \ldots \ldots \ldots . . . \ldots 18$

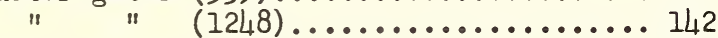

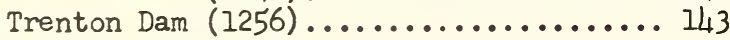

Streamflow forecasts

Colorado (55) (57)................... 16

snow surveys $(55)(57) \ldots \ldots \ldots \ldots \ldots . . . \ldots 16$

Stream gaging

(387)................. 95

backwater $(437) \ldots \ldots \ldots \ldots \ldots \ldots . . . \ldots 135$
Stream gaging

bridges (690)
dam leakage $(773)$

gage (1013)

radio gages (1536)

Tennessee Valley

Streams

distribution, Calif. (1061)

effect logging (969)

erosion control (226) research (69)

forest effects (439)

meandering (226).

peak discharge (691)

roughness coefficient

stage-discharge

Iowa (67)

Texas (386)

water quality (786)

Strut wake (1389)

Submerged bodies

pressure distribution

basic research (16)

" " (579)

electric analogy (72)

theoretical analysis (81)

Surges

irrigation systems (1257)

pipes (1180)

sewers (683)

Surge tanks

electric analog (869)

mechanical-pneumatic (127)

South Holston dam (73I)

Suspended particles

oscillating motion (1358)

Tailraces

McNary Dam, Ore. (189)

Watauga Dam (732)

Tidal flow

channels

Charleston Harbor, S. C. (678)

Delaware River, $\mathrm{Pa}$. (425)

Fraser River (1044) .......

Lynnhaven Bay, Va. (672)
Raritan River, N. J. (679)

effect of causeway (10L8)

Strait of Canso (1048)

Towing tank research

David Taylor Model Basin

Michigan University (585)

Newport News S. and D. D. Co.

Northwestern University.

Society of Naval Architects.

Stevens Institute of Technology

Transitions

open channels (114)

(1321)

pipes (318)
$1488)$ 


\section{itions}

inels (1206)

Is

ck tests (760)

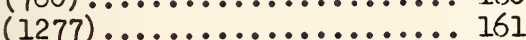

3lakely Mountain, Ark. (675)

iontana (726)

(760)

ucky Peak, Idaho (979) ............. Ill

isuring system $(1245) \ldots . . . . . . . . .141$

ines

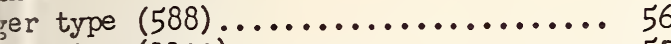

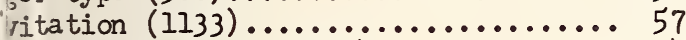

ischarge channels $(1305) \ldots \ldots \ldots \ldots \ldots 1_{4}$ ratings $(735) \ldots \ldots \ldots \ldots . \ldots 158$

incis type

avitation

erformance

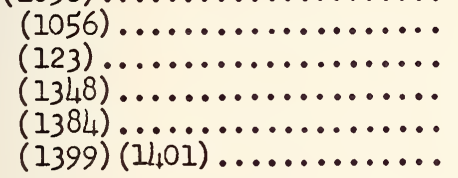

pulse

head effect, tests $\left(11_{4} 6\right) \ldots \ldots \ldots \ldots \ldots$ instruction laboratory (1057) ......... del tests $(123) \ldots \ldots \ldots \ldots \ldots \ldots \ldots . . . \ldots$

opeller

cavitation ( 271 )

performance

(271) ....................... $(1054)(1055)(1296) \ldots \ldots \ldots$ (588) (1385) (1402)

search (806) (1349)

ne moments (896)

ulence

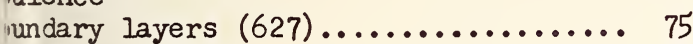

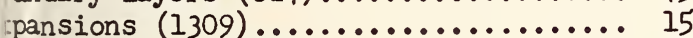

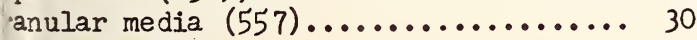

sasurement

apparatus (73)

(1307)

"

agnetic $(46)$

electro-magnetic (46)

hot-wire, air $(851) \ldots \ldots \ldots \ldots \ldots \ldots \ldots \ldots . \ldots \ldots \ldots$ , water (467) techniques (6I). (578)

ipes $(627)$.

artificially rough (1)

basic research (46).

(467)

timulation $\left(\mathrm{H}_{4} 06\right)$

$$
\text { (1506) }
$$

ubmerged jets

heory (1312)

(1323)

(1344)

46
Valves

automatic $(1526)(1527) \ldots \ldots \ldots \ldots \ldots . . \ldots \ldots$ balanced flapper (1369) (1370)(1371)..... 51 " $"$ " $(1372) \ldots \ldots \ldots \ldots \ldots \ldots . . . . . .52$

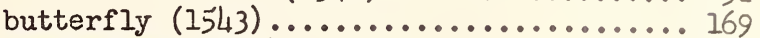

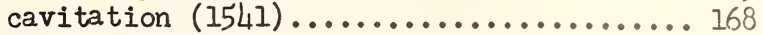

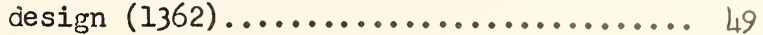
forces on pistons $(1364)(1365)(1366) \ldots . .50$

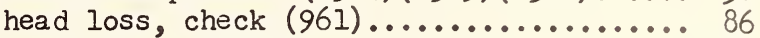

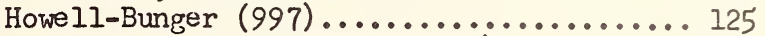
discharge coefficient (1282)............161

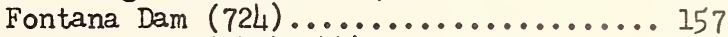

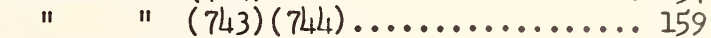

Lucky Peak, Idaho (979) .............. 111

Narrows Dam, Ark. (420)............. 120 jet flow

Spring Creek Dam (698) ..............140 outlet works

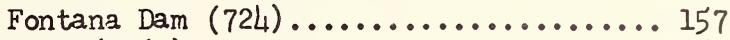

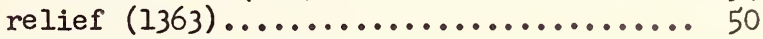
Velocity distribution

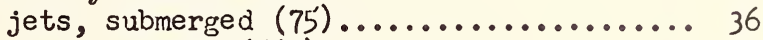

open channels $(562) \ldots \ldots \ldots \ldots \ldots . \ldots . \ldots 33$

Velocity measurement

electro-magnetic (46)................. 10 15

\section{0}

\section{6}

\section{6}

$\frac{10}{10}$

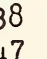

$\begin{array}{ll}\text { "1 } & \text { " } \\ \text { " } & \text { " }\end{array}$

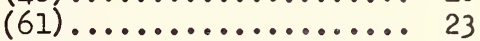

$(467) \ldots \ldots \ldots \ldots \ldots \ldots \ldots, 147$

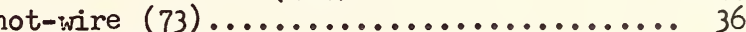

" $"$ (467) ........................ 147

ultrasonics $(1154) \ldots \ldots \ldots \ldots \ldots \ldots \ldots \ldots, 67$

Venturi

calibration (910)..................... 62

" (1326)....................... 25

entrance effects $(1130) \ldots \ldots \ldots \ldots \ldots \ldots \ldots . .656$

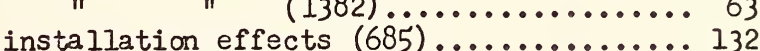

irrigation (1028) ....................... $]_{0} 0$

Venturi flume $(949) \ldots \ldots \ldots \ldots \ldots \ldots . . . .61$

Viscosity

effect on Pitot tubes (881) ............ 48

oils $(904) \ldots \ldots \ldots \ldots \ldots \ldots \ldots \ldots \ldots \ldots . . .60$

oils, water $(957) \ldots \ldots . . . . . . . . . . . . . .684$

Vortex, pumps $(1064) \ldots \ldots \ldots \ldots \ldots \ldots \ldots \ldots . . . .13$

Vortex-source flow, supersonic (1117)....... 48

Vortex tubes, design (537)............... 17

" " " (1264)................ 144

Water channel rotating $(279) \ldots . . . \ldots \ldots \ldots \ldots . .3$

Nater, consumptive use $\left(\mathbb{1}_{121}\right) \ldots \ldots \ldots \ldots \ldots . . .65$

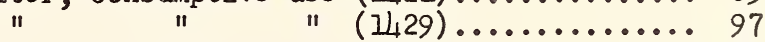

" $"$ " $\quad(1435) \ldots . . . . . . . . .99$

" " " $\left(144_{4}\right)(1446) \ldots . . . . .101$

" " " $" 1448) \ldots \ldots \ldots \ldots . . .102$

Water entry $(1299)(1300) \ldots \ldots \ldots \ldots \ldots \ldots \ldots . . .5$

" " , airplanes (1405)............. 77 " $\quad$ reference book (1530)......... 155

Water hammer

pipes (791).......................... 166

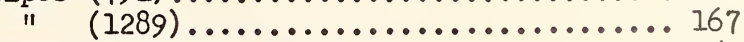

surge suppressors $(127) \ldots \ldots \ldots \ldots \ldots \ldots \ldots . .659$

Water measurement

24
40
$\quad$ irrigation $(23)(24) \ldots \ldots \ldots \ldots \ldots \ldots \ldots \ldots \ldots \ldots \ldots$ 
Water measurement

stream flow (67)

Watershed management

Continental Divide (377)..............

fundamental relations $(1427)(1 / 428) \ldots . .$.

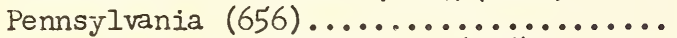

Rocky Mountain Front Range (376).......

Sierra Ancha, Ariz. (657).............

southeastern United States (380)........

southern California (261)............. 87

Wayne County, Pa. (966).............. 90

Watershed studies

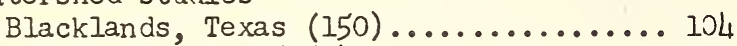

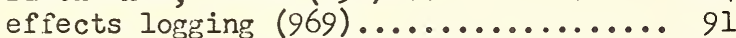

forest influences $(656)(966) \ldots . . . . .990$

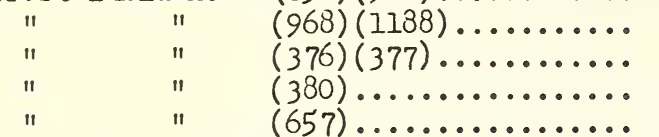

frost studies (1187)

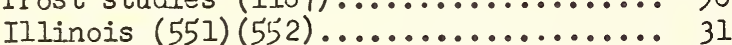

Imperial Valley, Calif. (390) ......... 96

Lafayette, Ind. (394) .............. 104

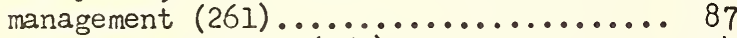

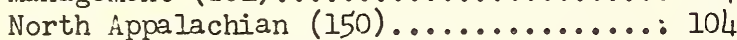

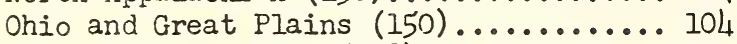

Priest River, Idaho (968)............ 91

Ralston Creek, Iowa (66)............ 35

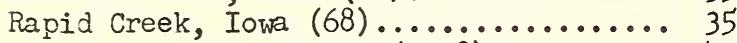

relation to hydrograph $(1108) \ldots \ldots . . . .40$

soil moisture (967)................ 90

Tennessee River Valley $(772) \ldots \ldots \ldots \ldots . . .163$

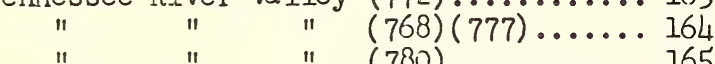

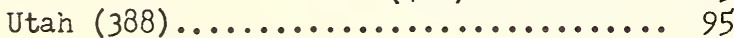

Water tunnel

design

Calif. Inst. of Tech. (15) (16)...... 3

Penn. State College (1151).......... 66

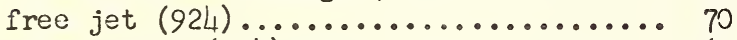

vaned turns $(104) \ldots \ldots \ldots \ldots . . . \ldots . . . . .69$

Water utilization $(769) \ldots \ldots \ldots \ldots \ldots \ldots . \ldots \ldots$ Wave action

beaches $(47) \ldots \ldots \ldots \ldots \ldots . . . \ldots . . . . .11$

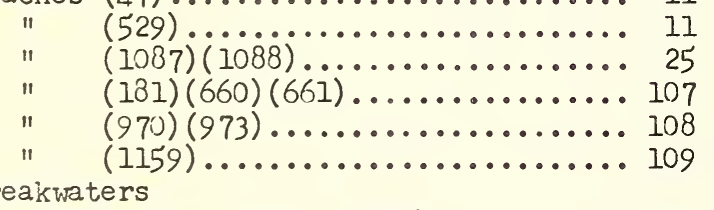

pervious, impervious (998) ......... 125

rubble-mound (257) ............... 119

" $"$ " (999)............... 126

harbors

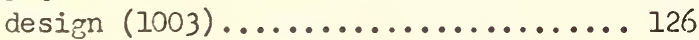

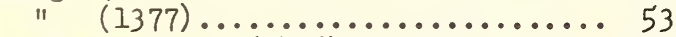

East Beaver Bay $\left(1_{4} 76\right) \ldots \ldots \ldots . . . \ldots 130$

Indiana Harbor, Ind. $(1472) \ldots . . . . .130$

research $(808) \ldots \ldots \ldots \ldots \ldots . . \ldots \ldots$

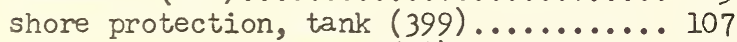

" $"$ works $(38) \ldots \ldots \ldots \ldots . . . . .9$

" $"$ " (529)............. 11

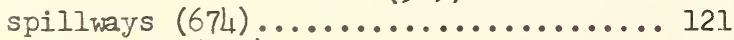

structures $(972) \ldots \ldots \ldots \ldots \ldots . \ldots \ldots . . \ldots 108$
Waves

ripples, sediment (1165)

theory (1335).

Waves, surface

breaking (1381)

characteristics, observed (660)

contours (340)

diffraction (47).

(1376)

energy losses (1461)

" positive, dry channels (1480)

gages (977)

general research $(47)$

generation (35)

(4)

(1478)

heights $(770)$

forecasting (47)

measurement (1460)

model laws (184).

Waves, surface

oscillatory

(309)

"1

theory (47)

resistance ( 709 ).

shallow water (35)

shock (811).

" (1062)

solitary ( 577 )

" (159)

standing (1162)

wind-generated

Wave tank, design

( 1457 )

Weirs

critical depth (1396).

ogee-flow patterns (541)

sharp-crested (567)

circular (1113).

parabolic (268)

rectangular (319)

silting basin (733)

spillway (1289)...

submergence (541)

Wells

casings (1195)

drilling $(24)$.

testing instruments (1337)

Well screens

design (287) .

head loss (1195)

turbulence (557)

wind

building forms (299)

design (1152)

lake levels $(160)$
" $(1457)$

(1079)

set up (1457), Tennessee Valley (770)

velocity (1042) 
answering a number of questions regarding the adequacy of stack venting of plumbing fixtures for one- and two-story dwellings. Diagrams, tables, and graphs show the various components of a stack-vented system and provide pressure and trap-seal data.

Order NBS Building Materials and Structures Report 118, Stack Venting of Plumbing Fixtures, 21 pages. Price: 15 cents.

\section{Hydraulic Research in the United States, 1951}

A guide to projects conducted by various hydraulic and hydrologic laboratories in the United States and Canada during 1951. Project reports cover work done at 66 private or State laboratories in the United States, 34 Federal laboratories, and five Canadian laboratories. The publication outlines individual projects on nearly 200 subjects in the field and includes lists of committees working in the field and of foreign publications and translations available on loan.

Order NBS Miscellaneous Publication 201, Hydraulic Research in the United States, 190 pages. Price: $\$ 1.25$.

\section{Correcting for Density and Viscosity of Incompressible Fluids in Float-Type Flowmeters}

Information on the theory of the flow of incompressible fluids through floattype flowmeters developed by the methods of dimensional analysis and experimental verification of the relations thus derived. Procedures are described whereby, after calibration of a metering tube with a few fluids of known physical properties, accurate corrections may be calculated for any fluid whose properties lie within the range embraced by the calibration fluids.

Order NBS Research Paper 2247, Correcting for Density and Viscosity of Incompressible Fluids in Float-Type Flowmeters, 12 pages. Price: 10 cents.

\section{Wind Tides in Small Closed Channels}

A theoretical and experimental consideration of wind tide or set-up, involving the wind effects of surface traction on the water and form resistance of the waves. Inhibition of the formation of waves in an experimental channel permitted a separate study of the surface traction effect, including both laminar and turbulent motion of the drift and gravity currents produced by the wind.

Order NBS Research Paper 2207, Wind Tides in Small Closed Channels, 24 pages. Price: 15 cents. 
